\title{
Influence of marijuana and ecstasy (MDMA) on cognitive function and driving performance
}

Citation for published version (APA):

Lamers, C. T. J. (2004). Influence of marijuana and ecstasy (MDMA) on cognitive function and driving performance. [Doctoral Thesis, Maastricht University]. NeuroPsych Publishers.

https://doi.org/10.26481/dis.20040514cl

Document status and date:

Published: 01/01/2004

DOI:

$10.26481 /$ dis.20040514cl

Document Version:

Publisher's PDF, also known as Version of record

\section{Please check the document version of this publication:}

- A submitted manuscript is the version of the article upon submission and before peer-review. There can be important differences between the submitted version and the official published version of record.

People interested in the research are advised to contact the author for the final version of the publication, or visit the DOI to the publisher's website.

- The final author version and the galley proof are versions of the publication after peer review.

- The final published version features the final layout of the paper including the volume, issue and page numbers.

Link to publication

\footnotetext{
General rights rights.

- You may freely distribute the URL identifying the publication in the public portal. please follow below link for the End User Agreement:

www.umlib.nl/taverne-license

Take down policy

If you believe that this document breaches copyright please contact us at:

repository@maastrichtuniversity.nl

providing details and we will investigate your claim.
}

Copyright and moral rights for the publications made accessible in the public portal are retained by the authors and/or other copyright owners and it is a condition of accessing publications that users recognise and abide by the legal requirements associated with these

- Users may download and print one copy of any publication from the public portal for the purpose of private study or research.

- You may not further distribute the material or use it for any profit-making activity or commercial gain

If the publication is distributed under the terms of Article $25 \mathrm{fa}$ of the Dutch Copyright Act, indicated by the "Taverne" license above, 


\section{INFLUENCE OF MARIJUANA AND ECSTASY (MDMA) ON COGNITIVE FUNCTION AND DRIVING PERFORMANCE}


(C) C.T.J. Lamers, Maastricht 2004

(C) Cover design en uitvoering: Theo Buiting

Productie: Ponsen \& Looijen b.v.

ISBN: $90-75579-18-7$

Neuropsych Publishers is a non-profit organization which aims at promoting the science of Brain \& Behavior and improving the application of products of this science in health care and education. Neuropsych Publishers accomplishes these aims by publishing books, dissertations and other products of scientific activity, dissemination of educational materials and publication of tests, assessment scales and other psychometric instruments in the field of Neuropsychology, Neuropsychiatry and other areas within the domain of Brain and Behavior.

Postal address: Neuropsych publishers, Department of Psychiatry and Neuropsychology, Lniversity of Maastricht, NL 6200 MD Maastricht, The Netherlands 


\title{
INFLUENCE OF MARIJUANA AND ECSTASY (MDMA) ON COGNITIVE FUNCTION AND DRIVING PERFORMANCE
}

\begin{abstract}
PROEFSCHRIFT
ter verkriiging van de graad van doctor aan de Universiteit Maastricht, op gezag van de Rector Magnificus, Prof. mr. G.P.M.F. Mols, volgens het besluit ran het College van Decanen, in het openbaar te verdedigen op rrijdag 14 mei 2004 om 14:00 uur
\end{abstract}

door

Carolina Theodora Johanna Lamers

Gcboren op 22 december 1969 te Tegelen 


\section{Promotor}

Prof. dr. J. Jolles

\section{Co-promotor}

Dr. J.G. Ramaekers

\section{Beoordelingscommissie}

Prof. dr. H.L.G.J. Merckelbach (voorzitter)

Prof. dr. G. Berghaus (Universität Köln)

Dr. A. Honig

Prof. dr. J. van Os

Prof. dr. H.G.M Rigter (Erasmus Universiteit Rotterdam)

The research described in this thesis was conducted at the Brain \& Beharior Institute, the department of Neurocognition, University of Maastricht and the University of Iowa Hospital. The studies described in this thesis were funded by the US National Highway Traffic Safety Administration (ch 3), The Dutch ministry of Transport (ch. 4, 5) and financially supported by the National Institute of Drug Abuse (ch 6, 7), the National Institute of Aging (ch 7) and Foundation De Drie Lichten (ch 6, 7).

Financial support for the publication of this dissertation from the Dutch Ministry of Transport and Lundbeck Nederland is greatly appreciated. 
Paranimlen

Lef Theunissen

Bclinda $\operatorname{ran}$ Wijlick.

Voor Theo 



\section{CONTENTS}

Page

Chapter 1 General Introduction

Chapter 2 Performance and behavioral effects of illicit drugs

Chapter 3 Visual search and urban city driving under the influence of marijuana and alcohol

Chapter 4 Dissociable effects of a single dose of ecstasy (MDMA) on psychomotor skills and attentional performance

Chapter 5 MDMA levels in four different human body fluids after a placebo-controlled single dose of MDMA predict changes in in psychomotor performance, physiological activation and mood

Chapter 6 Cognitive function and mood in MDMA/THC users, THC users and non-drug using controls

Chapter 7 Simulated driving and attention in repeated users of MDMA and THC as compared to THC users and non-drug using controls

Chapter 8 Concluding remarks

Summary

Samenvatting

Dankwoord

Curriculum vitae

Publications 



\section{CHAPTER 1}

GENERAL INTRODUCTION 
Psychoactive substances have been used for their therapcutic and mind-altcriner propertics for centuries. As early as $7000 \mathrm{BC}$, the Sumerian civilization used opium for religious ceremonies and the first written account of the therapeutic use of marijuana can be fround in Chinese literature from about 2700 BC (Grob et al. 1996; Smith 1970). Many psychoactive substances are still used therapeutically, mostly for the treatment of mental disorders. In today's Western societies, a group of psychoactive substances known as recreational drugs, including $\Delta^{9}$-tetrahydrocannabinol (THC, marijuana), alcohol and amphetamines, are used for pleasure. While recreational drugs were originally prepared from plants, and were considered "natural", a new group of psychoactive drugs were developed in the 2 t) $^{\text {th }}$ century. These so-called "designer drugs", such as amphetamine and the amphetamine derivate \pm 3,4-methylenedioxymethampatamine (MDMA, ecstasy), are synthetic drugs and are often manufactured illegally (Ziporyn 1986).

The three most commonly used recreational drugs in the Western world are alcohol, marijuana and MDMA (Frank and Galea 1996; Winstock et al. 2001). Alcohol and marijuana are considered sedatives whereas MDMA is a psychostimulant. The unique mechanism of action of marijuana induces relaxation, distorted visual and auditory perception and altered time perception (Ameri 1999; Mathew et al. 1998). Since the mid1980s, MDMA has become commonplace in the dance and music scene (Cohen 1998; Ropero Miller and Goldberger 1998). Like other psychostimulants, MDMA induces physiological activation. What distinguishes MDMA from other psychostimulants such as cocaine and amphetamine is its property to induce feelings of sociability, euphoria, insight and empathy (Cami et al. 2000). These drugs are very popular: incidence is $1-53 \%$ among high-school students aged 13-17 years for cannabis and 0-12\% for MDMA (Smart and Ogborne 2000). MDMA is used by $10-39 \%$ of undergraduate students and by $81-96 \%$ of visitors to dance parties. By comparison, the lifetime use of marijuana by undergraduate students and visitors to dance parties is estimated $46 \%$ and $91 \%$, respectirely. (Peroutha 1987; Pope et al. 2001; Spruit 1997; Winstock et al. 2001).

The use of mind-altering recreational drugs is likely to affect the user's abilities and behaviour while in an intoxicated state. But even in abstinent drug users (current users who were not intoxicated during testing), complex behaviour may be impaired if their drug of choice is neurotoxic and causes neural degeneration. Driving a motorized vehicle is a part of daily life for most people living in the Western world and people depend on cars for getting to work, school and recreational activities. Driving requires the coordinated use of sereral complex abilities such as attention, reaction speed, anticipation of other traffic, time to contact estimation, risk assessment, tracking, car handling, etc. If any one of these abilities is compromised in any way, driving performance may become impaired. Survers show that $2 \%$ of adult drivers and $22 \%$ of regular marijuana users drive while under the influence of marijuana (Spruit 1997; Walsh and Mann 1999). According to a Dutch survey, as many as $60 \%$ of people planning to drive home from big dance parties had used MDNA during the evening (Spruit 1997; Walsh and Mann 1999). 
Many studies have investigated the impairing influence of aleohes on driving alsility and wo can now predict the dose-related detrimental effect of alcohol on driving performance (Moskowitz 1973; De Gier 1979; Kearney and Guppy 1988; Koclega 1995). Yet, litte is known about the influence of marijuana and MDMA on driving performance. Civers the frequency of marijuana and MDMA use, it is crucial to evaluate the risk of marijuana and MDMA use on cognitive functions and complex behaviours, such as these required for driving performance. The current dissertation addresses these issues. Some background information is presented briefly below, followed by a description of the aims and outline of this dissertation.

\section{NEUROPHARMACOLOGY OF MARIJUANA AND MDMA}

The psychoactive properties of marijuana depend on its binding to cannabinoid receptors in the brain (i.e. CB1). The density of CB1 receptors is high in brain regions involved in the consolidation of new information, time estimation and movement (Ameri 1999; Mathew et al. 1998). Although for many years the use of marijuana was considered harmless, recent findings indicate that the impairments of memory, executive functioning, attention and psychomotor speed seen in heavy marijuana users increase in severity with prolonged use of marijuana (Bolla et al. 2002; Solowij et al. 2002). Moreover, the brain function of abstinent marijuana users is also changed, and especially in the prefrontal cortex, cerebellum and hippocampus (Block et al. 2002).

MDMA mainly induces elevated levels of extracellular dopamine and serotonin (Battaglia et al. 1988; Daws et al. 2000). Serotonin is involved in a variety of behariours that involve a high cognitive demand, including memory, learning and information processing (Buhot et al. 2000; Vitiello et al. 1997). Dopamine activates the central nerrous system, increasing arousal, attention and reaction speed (Rihet et al. 2002; Robbins 1997; Servan-Schreiber et al. 1998). There are strong indications that MDMA may change brain activity and induce structural changes in specific types of neurons, especially in serotonin neurons, i.e. reducing serotonin transporter binding and density (Croft et al. 2001; Dafters et al. 1999; Semple et al. 1999). Abstinent MDMA users show impairments in learning, memory, complex attention, control inhibition and higher cognitive processing (Gouzoulis-Marfrank et al. 2000; Morgan 1998; Reneman et al. 2001). Furthermore, psychiatric disorders, e.g. depression, anxiety, psychotic disorders and impulse control disorders, have been associated with heavy MDMA use (Schifano et al. 1998).

$A s$ it is beyond the scope of this thesis to provide a description of the mechanisms and sites of action of marijuana and MDMA, the interested reader is referred to reviews by Ameri (1999) and Parrott (2001), respectively. 


\section{MARIJUANA, MDMA AND DRIVING PERFORMANCE}

After alcohol, marijuana was the second most detected drug in drivers whe werc suspected of being intoxicated and in drivers who sustained injury of death in car crashes (Budd et al. 1989; Cimbura et al. 1982; Seymour and ()liver 1999; Williams ct al. 1985). Fixperimental studies have shown that the effects of marijuana on driving ability are dose related and increase with increasing dose (Ramaekers et al. 2000); Robbe 1998). The impairmcnt of driving ability was greater after a dose of up to THC $300 \mu \mathrm{g} / \mathrm{kg}$ than after alcohos] consumption to achieve a blood alcohol concentration of $0.05 \mathrm{mg} / \mathrm{ml}$, the legal limit in most European countries (Ramackers et al. 2000); Robbe 1998).

Similar conclusions were drawn in a review of available information on the influence of marijuana on driving performance (Ramaekers et al 2003). These authors concluded that recent use of 'THC increases the risk of being responsible for a motor vehicle accident two to six times compared to that of drug-free drivers, depending on the THC concentration detected in blood (Ramaekers et al. 2003). Concurrent use of marijuana and alcohol can seriously compromise driving ability since the effects of the two drugs appear to be additive (Ramaekers et al. 2003; Robbe 1998).

There is less information on the impact of MDMA on driving performance or car crash risk, but a series of case reports describe unsafe driving in intoxicated MDMA users (Henry et al. 1992; Mocller and Hartung 1997; Schifano 1995). Logan and Couper (1996) reviewed the influence of MDMA on driving and psychomotor performance based on findings from laboratory studies and case reports. They concluded that MDMA intoxication was associated with unsafe driving and car crashes.

Even in abstinent users, marijuana and MDMA may affect driving performance if they have neurotoxic properties. By destroying neurons, these drugs may produce long-lasting neural damage. Neural damage may seriously compromise driving safety if the stills and abilities essential to safe driving, such as reaction speed, information processing, attention or control inhibition, are impaired (Rizzo et al. 2001). It is therefore important to evaluate not only the impact of recent drug intake on driving performance, but also the impact of previous drug use on the driving skill of abstinent users of marijuana and MDMA.

\section{AIM OF THE DISSERTATION}

The use of marijuana and MDMA is widespread in the Western world. Yet, little is known about the degree to which MDMA or concurrent use of marijuana and alcohol influences cognitive function and driving performance. Do marijuana/alcohol and MDNA impait cognitive abilities and is driving performance compromised in intoxicated users? Is there reason for concern about a long-lasting impairment of cognitive function and driving ability in MDMA and/or marijuana users? On the basis of their mechanism of action, it can be 
hypothesized that both acute and long-term effects may impair crognitive function and driving ability, but not many experimental studies have addressed this issuc (Ricdel et al. 1998). The main emphasis of the studics presented in this disscrtation is on the effects of marijuana and MDM $\triangle$ on cognition and driving performance. lixperimental studics address both the acute effects and longer lasting effects of marijuana and MDMA.

\section{RESEARCH DOMAINS AND METHODOLOGY}

The studies described in this dissertation focused on the cognitive functioning and driving performance of intoxicated and abstinent users of marijuana and MDMA, although some aspects of mood were also investigated. The most important tests and techniques used in these studies are described briefly below.

\section{COGNITION}

To investigate the effects of marijuana and MDMA on cognitive performance, tests were used that rely on aspects of cognition that were expected to be sensitive to the effects of marijuana and MDMA. These aspects included memory, executive functions, decisionmaking and attention. Memory was assessed using the Rey Auditory Verbal I earning Task (learning and delayed recall) and the Rey Complex Figure Test (visual memory) (Bohbot et al. 1998). Aspects of executive function were assessed using the Wisconsin Card Sorting Test (shifting), the Stroop Color Test (selective attention and cognitive flexibility) and the Trail Making Test (mental flexibility) (Ratti et al. 2002). Decision-making was assessed using the Gambling Task, a test investigating judgement (Bechara et al. 1999).

\section{DRIVING PERFORMANCE}

Assessment of driving performance was based on different methods and included three major approaches. Simulated driving and driving-related psychomotor performance were assessed in a laboratory. Actual driving performance was investigated during a drixing session within the city limits of Maastricht. The latter two approaches were mainly based on studies conducted by Robbe (1998).

\section{Psychomotor tasks}

Tracking performance can be considered to reflect steadiness in driving and was assessed using the Critical Tracking Task (CTT) and the Divided Attention Task (DAT) (Tex et al. 1966; Moskowitz 1973). "Time-to-contact estimation" was measured with the Object Movement Estimation under Divided Attention Task (OMEDA) (Read et al. 2000). 
Performance on this task can be considered to reflect the capacity of a driver to cstimate time to contact with another vehicle approaching an interscction.

\section{Actual driving}

When crossing an intersection, it is essential for drivers to scan other strects for approaching traffic in order to avoid a crash. Visual search during actual driving was studied in a city driving test based on a study of Robbe (1998); however, in the present study, a new test procedure was introduced. Visual search was now studied using a head-mounted eje tracking system. The system consisted of a camera system for registering the subjects' line of gaze. The information obtained was used to determine whether subjects looked for vehicles that had the right of way.

\section{Driving simulator}

In general, actual driving performance offers the best method of assessing driving impairment. However, in order to study increased risk taking and poor judgement in demanding traffic situations in which participants were expected to exhibit dangerous driving behaviour, a driving simulator was used instead (Rizzo et al. 2001). The simulated drive was divided into uneventful driving performance and driving behaviour during controlled events. Data collected during the simulated drive included steering, speed and crash avoidance in potentially dangerous traffic situations.

\section{MOOD}

Changes in mood after MDMA administration were assessed by means of the Profile of Mood Questionnaire (POMS). This questionnaire categorized mood changes into several mood clusters. To study more resistant changes in mood, the Beck Depression Index (BDI) and the Beck Anxiety Index (BAI) were used (Beck et al. 1988; Beck et al. 1996).

\section{STUDY DESIGN}

Within subject designs were used to examine the acute effects of a single dose of marijuana or MDMA. These studies were conducted according to a double-blind, placebo-controlled, cross-over design to compare the participant's performance of a task under placebo and intoxicated conditions. The long-term effects of drug use were studied according to a between-subject design. Here, task performance etc. was compared between three different study groups: recreational users of MDMA and marijuana (MDMA/marijuana), recreational users of marijuana and non drug users. These groups were matched for age and education. If the performance of drug users differed from that of non drug users, then drug use could be associated with an impaired task performance. If the performance of users of 
MDMA/marijuana was worse than that of users of marijuana, then onc crould speculate that MDMA was responsible for the observed impairment.

\section{OUTLINE OF THE DISSERTATION}

Chapter 2 provides a review of the mechanisms and acute behavioural effects of the most common recreational drugs belonging to different categories, such as stimulants, marijuana, hallucinogens, inhalants and opiates. Furthermore, implications for cognitive performance, psychomotor function and driving performance are discussed.

Chapter 3 describes a study of the influence of marijuana alone or in combination with alcohol on city driving performance. Eight male and eight female users of marijuana entered a study with a randomized, double-blind, placebo-controlled, 4-way cross-over design. On four different occasions, recreational marijuana users were administered placebo, marijuana, alcohol and marijuana, and alcohol. After drug administration, participants took part in a city driving test. Visual search at intersections and general driving proficiency after drug administration were examined.

Chapters 4 and 5 describe studies of the acute effects of a single dose of MDMA in twelve recreational users, eight male and four female, in a placebo-controlled 3-way cross-over design. Chapter 4 describes the acute effects of MDMA on driving-related task performance and chapter 5 presents the association between MDMA concentrations and physiological activation and mood. The ability to predict driving performance on the basis of MDMA levels in body fluids is discussed.

Chapters 6 and 7 describe studies of the behavioural effects of repeated use of MDMA and marijuana, alone and combined, in abstinent users. Chapter 6 presents the effects of MDMA and MDMA/marijuana on reported feelings of depression and anxiety, cognitive function and decision making in eleven users of MDMA/marijuana as compared to fifteen marijuana users and fifteen non drug users. The study described in chapter 7 compared attention and simulated driving in twelve MDMA/marijuana users, fifteen marijuana users and fifteen non drug users.

Chapter 8 presents concluding remarks concerning ethical issues and problems with study designs related to the validity of MDMA research. It is concluded that the findings of the studies described in this dissertation provide relevant information about the implications on driving performance of acute or recent use of MDMA and/or marijuana. 


\section{REFERENCES}

Ameri $\Lambda$ (1999) The effects of cannabinoids on the brain. Progress in Neurobioblogy 58: 31.5-48

Battaglia G, Brooks BP, Kulsakdinun C, De Souza EB (1988) Pharmacologic profile of MD).MA (3,4methylenedioxymethamphetamine) at various brain recognition sites. Europcan Journal of Pharmacology 149: 159-63.

Bechara A, Damasio H, Damasio AR, Lee GP (1999) Different contributions of the human amygdala and ventromedial prefrontal cortex to decision-making. Journal of Neuroscience 19: 5473-81

Beck AT, Epstein N, Brown G, Steer RA (1988) An inventory for measuring clinical anxiety: psychometric properties. Journal of Consulting and Clinical Psychology 56: 893-7

Beck AT, Steer RA, Ball R, Ranieri W (1996) Comparison of Beck Depression Inventories - IA and -II in psychiatric outpatients. Journal of Personality Assessment 67: 588-97

Block RI, O'Leary DS, Hichwa RD, Augustinack JC, Boles Ponto IL., Ghoneim MiV, Arndt S, Hurtigr RR, Watkins GL, Hall JA, Nathan PE, Andreasen NC (2002) Eiffects of frequent marijuana use on memory-related regional cerebral blood flow. Pharmacology, Biochemistry and Behavior 72: 237-50

Bohbot VD, Kalina M, Stepankova K, Spackova N, Petrides M, Nadel L (1998) Spatial memory deficits in patients with lesions to the right hippocampus and to the right parahippocampal cortex. Neuropsychologia 36: 1217-38

Bolla Kl, Brown K, Eldreth D, Tate K, Cadet JL (2002) Dose-related neurocognitive effects of marijuana use. Neurology 59: 1337-43

Budd RD, Muto JJ, Wong JK (1989) Drugs of abuse found in fatally injured drivers in Los Angeles County. Drug and Alcohol Dependence 23:153-8

Buhot MC, Martin S, Segu L. (2000) Role of serotonin in memory impairment. Annals of Medicine 32: $210-21$

Cami J, Farre M, Mas M, Roset PN, Poudevida S, Mas A, San L, de la Torre R (2000) Human pharmacology of 3,4-methylenedioxymethamphetamine ("ecstasy"): psychomotor performance and subjective effects. Journal of Clinical Psychopharmacology 20: 455-66.

Cimbura G, Lucas DM, Bennett RC, Warren RA, Simpson HM (1982) Incidence and toxicological aspects of drugs detected in 484 fatally injured drivers and pedestrians in Ontario. Journal of Forensic Sciences 27: 855-67

Cohen RS (1998) The love drug: marching to the beat of ecstasy. The Haworth Medical Press, The Haworth Medical Press

Croft RJ, Klugman A, Baldeweg T, Gruzelier JH (2001) Electrophysiological evidence of serotonergic impairment in long-term MDMA ("ecstasy") users. American Journal of Psychiatry 158: 1687-92.

Dafters RI, Duffy F, O'Donnell PJ, Bouquet C (1999) Level of use of 3,4methylenedioxymethamphetamine (MDMA or Ecstasy) in humans correlates with EEG power and coherence. Psychopharmacology 145: 82-90.

Daws EC, Irvine RJ, Callaghan PD, Toop NP, White JM, Bochner F (2000) Differential behavioural and neurochemical effects of para-methoxyamphetamine and 3,4-methylenedioxy-methamphetamine in the rat. Prog Neuropsychopharmacol Biol Psychiatry 24: 955-77

De Gier JJ (1979) A subjective measurment of the influence of ethyl/alcohol in moderate doses on real driving performances. Blutalkohol 16:363-370

Frank B, Galea J (1996) Cocaine trends and other drug trends in New York City, 1986-1994. Journal of Addictive Diseases 15: 1-12

Gouzoulis-Mayfrank E, Daumann J, Tuchtenhagen F, Pelz S, Becker S, Kunert HJ, Fimm B, Sass H (2000) Impaired cognitive performance in drug free users of recreational ecstasy (NIDMA). Journal of Neurology, Neurosurgery and Psychiatry 68: 719-25

Grob CS, McKenna DJ, Callaway JC, Brito GS, Neves ES, Oberlaender G, Saide OL, Labigalini E, Tacla C, Miranda CT, Strassman RJ, Boone KB (1996) Human psychopharmacology of hoasca, a plant hallucinogen used in ritual context in Brazil. Journal of Nervous and Mental Disease 184: 86-94 
Henry JA, Jeffreys $\mathrm{KJ}$, Dawling $\mathrm{S}(1992)$ Toxicity and deaths from 3,4-methylencdirsy. methamphetamine ("ecstasy"). Lancet 340: 384-7

Jex HR, McDonnel JD, Phatak AV (1966) A "critical" tracking task for manual contrel rescarch. Institute of Electrical and Electronic EngineersTransactions on Human Factors In Electronics HF:7: $138-145$

Kearney SA, Guppy A (1988) The effects of alcohol on speed perccption in a closed-coursc drivingt situation. Journal of Studies on Alcohol 49: 340-5.

Koelega HS (1995) Alcohol and vigilance performance: a review. Psychopharmacology 118: 233-49

I.ogan BK (1996) Methamphetamine and driving impairment. Journal of Forensic Sciences 41: 457-64

Mathew RJ, Wilson WH, Turkington TG, Coleman RE (1998) Cerebellar activity and disturbed time sense after THC. Brain Research 797: 183-9

Moeller MR, Hartung M (1997) Ecstasy and related substances-serum levels in impaired drivers. Journal of Analytical Toxicology 21: 591

Morgan MJ (1998) Recreational use of "ecstasy" (MDMA) is associated with elevated impulsivity. Neuropsychopharmacology 19: 252-64

Moskowitz H (1973) Laboratory studies of the effects of alcohol on some variables related to driving. Journal of Safety Research 5: 185-199

Parrott $\Lambda C$ (2001) Human psychopharmacology of Ecstasy (MDMA): a review of 15 years of empirical research. Human Psychopharmacology Clinical and Experimental 16: 557-577

Peroutka SJ (1987) Incidence of recreational use of 3,4-methylenedimethoxymethamphetamine (MDMA, "ecstasy") on an undergraduate campus. New England Journal of Medicine 317: 1542-3

Pope HG, Jr., lonescu-Pioggia M, Pope KW (2001) Drug use and life style among college undergraduates: a 30-year longitudinal study. American Journal of Psychiatry 158: 1519-21.

Ramaekers JG, Berghaus G, van Laar M, Drummer OH (2003) Dose related risk of motor vehicle crashes after cannabis use. Drug and $\mathrm{Alcohol}$ Dependence In Press

Ramackers JG, Robbe HW, O'Hanlon JF (2000) Marijuana, alcohol and actual driving performance. Human Psychopharmacology Clinical and Experimental 15: 551-558

Ratti MT, Bo P, Giardini A, Soragna D (2002) Chronic alcoholism and the frontal lobe: which executive functions are imparied? Acta Neurologica Scandinavica 105: 276-81

Read NI, Ward NJ, Parkes AM (2000) The role of dynamic tests in assessing the fitness to drive of healthy and cognitively impaired elderly. Journal of Traffic Medicine 28: 34-35S

Reneman L., Lavalaye J, Schmand B, de Wolff FA, van den Brink W, den Heeten GJ, Booij J (2001) Cortical serotonin transporter density and verbal memory in individuals who stopped using 3,4methylenedioxymethamphetamine (MDMA or "ecstasy"): preliminary findings. Archives of General Psychiatry 58: 901-6

Riedel WJ, Vermeeren A, van Boxtel MP, Vuurman EFPM, Verhey FRJ, Jolles J, Ramaekers JG (1998) Mechanisms of drug-induced driving impaiment: a dimensional approach. Human Psychopharmacology 13: S49-S63

Rihet P, Possamai CA, Micallef-Roll J, Blin O, Hasbroucq T (2002) Dopamine and human information processing: a reaction-time analysis of the effect of levodopa in healthy subjects. Psychopharmacology 163: 62-7

Rizzo M, McGehee DV, Dawson JD, Anderson SN (2001) Simulated car crashes at intersections in drivers with Alzheimer disease. Alzheimer Disease and Associated Disorders 15: 10-20

Robbe H (1998) Marijuana's impairing effects on driving are moderate when taken alone but severe when combined with alcohol. Human Psychopharmacology Clinical and Experimental 13: S70-S78

Robbins TW (1997) Arousal systems and attentional processes. Biological Psychology 45: 57-71

Ropero Miller JD, Goldberger BA (1998) Recreational drugs. Current trends in the 90s. Clinics in Laboratory Medicine 18: 727-46, x

Schifano F (1995) Dangerous driving and MDMA ('Ecstacy') abuse. Journal of Serotonin Research 1: 53-57 
Schifano F, Di Furia I., Forza G, Minicuci N, Bricolo R (1998) MDMA (ecstasy') consumption in the context of polydrug abuse: a report on 150 patients. Drug and Alcohol Dependence 52: $85-9)$

Semple DM, Ebmeier KP, Glabus MF, O'Carroll RE, Johnstone EC (1999) Reduced in vivo binding to the serotonin transporter in the cerebral cortex of MDMA (ecstasy") users. British journal of Psychiatry 175: 63-69

Servan-Schreiber D, Carter CS, Bruno RM, Cohen JD (1998) Dopamine and the mechanisms of cognition: Part II. D-amphetamine effects in human subjects performing a selective attention task. Biological Psychiatry 43: 723-9.

Seymour A, Oliver JS (1999) Role of drugs and alcohol in impaired drivers and fatally injured drivers in the Strathclyde police region of Scotland, 1995-1998. Forensic Science International 103: 89-100)

Smart RG, Ogborne AC (2000) Drug use and drinking among students in 36 countries. Addictive Behaviors 25: 455-60.

Smith DE (1970) The new social drug; cultural, medical, and legal perspectives on marijuana. PrenticeHall, Inc., Englewood Cliffs, New Jersey, pp 186 p

Solowij N, Stephens RS, Roffman RA, Babor T, Kadden R, Miller M, Christiansen K, McRee B, Vendetti J (2002) Cognitive functioning of long-term heavy cannabis users seeking treatment. Jama 287: 1123-31

Spruit IP (1997) XTC in Nederland. Trimbos-Instituut in opdracht van ministerie van Volksgezondheid, Welzijn en Sport, Den Haag, pp 49

Vitiello B, Martin A, Hill J, Mack C, Molchan S, Martinez R, Murphy DL, Sunderland T (1997) Cognitive and behavioral effects of cholinergic, dopaminergic, and serotonergic blockade in humans. Neuropsychopharmacology 16: 15-24

Walsh GW, Mann RE (1999) On the high road: driving under the influence of cannabis in Ontario. Canadian Journal of Public Health 90: 260-3

Williams AF, Peat MA, Crouch DJ, Wells JK, Finkle BS (1985) Drugs in fatally injured young male drivers. Public Health Reports 100: 19-25

Winstock AR, Griffiths P, Stewart D (2001) Drugs and the dance music scene: a survey of current drug use patterns among a sample of dance music enthusiasts in the LK. Drug and Alcohol Dependence 64: $9-17$

Ziporyn T (1986) A growing industry and menace: makeshift laboratory's designer drugs. Jama 256: 3061-3 


\section{CHAPTER 2}

\section{PERFORMANCE AND BEHAVIORAL EFFECTS OF ILLICIT DRUGS*}

* Published as:

Schmitt JA, Lamers CTJ, Ramaekers JG, Riedel WJ (2003) Performance and Beharioral Effects of Illicit Drugs. In: Burns $M$ (ed) Medical-Legal Aspects of Drugs. Lawyers and Judges Publishing Company Inc, pp 450 


\section{INTRODUCTION}

It is estimated that in the year 2000 fourteen million Americans used illicit drugs, which constitutes 6.3 percent of the population above twelve years of age (Substance Abuse and Mental Health Services Administration (SAMHSA), 2001). Necdless to say, abuse of illicit drugs is a serious and widespread problem in our society. The term illicit drugs refers tos a variety of compounds such as marijuana, cocaine, amphetamines, heroin, and various hallucinogens, including PCP and ISD, which are generally obtained through illegal channels. In addition, drug abuse also includes the nonmedical use of prescription drugs, such as tranquillizers and sedatives, medicinal stimulants and analgesics, as well as the abuse of psychoactive compounds found in common household or industrial products (e.g., inhalants). Alcohol and nicotine, although illegal for youths, are not considered illicit drugs.

Illicit drugs can impair behavior and mental performance in various ways. They may cause sedation or orer-activation. They can blur or distort perception, compromise a clear judgment of situations, impair decision-making and responding. The behavioral toxicity of a drug can be ascertained through a variety of methods, ranging from subjectively reported experiences to various kinds of epidemiological surveys and controlled experimental studies. Adverse behavioral effects may even be predicted solely on the basis of a drug's pharmacological propertics (Riedel et al. 1998; Schmitt et al. 2001). Each method has its advantages and limitations. For example, the assessment of drug-induced changes with laboratory tests of specific cognitive and psychomotor functions in a controlled and supervised setting may have limited predictive value for real-life complex behaviors, such as driving (Moran 1999). Conversely, with a methodologically sound experimental design, any observed effects can be attributed to a clear factor, notably the administered drug, thus establishing a causal link between performance and use of a drug at a certain dose. Causality is particularly difficult to ascertain in cross-sectional epidemiological studies comparing groups of drug abusers to normal controls, since the influence of factors other than drug use is unknown. For example, pre-existing differences in characteristics and life-style cannot be excluded as potential discriminating factors.

The combined picture emerging from various viewpoints and research lines can provide insight into a drug's potential behavioral toxicity. Unfortunately, for many drugs, and particularly for illicit drugs, the data on effects on mental performance and potential risk are incomplete. Existing data are limited to narrow dose ranges, selected research subjects (often young healthy volunteers) and specific behavioral outcome parameters. Although effects in other circumstances may be inferred based on existing information, the actual demonstration of such behavioral effects, for example on driving capacity, remains essential.

This chapter provides an overview of the known behavioral and performance effects of the most commonly abused illicit drugs. It will focus on the effects of acute drug intoxication, occurring at the time when the psychoactive substance is present in the body and exerting 
its pharmacological effects in the central ncrvous systcm (CNS). 'The long-term scyuclac of drug abuse as behavioral changes that are the result of structural and irreversible brain damage from long-term exposure to neurotoxic compounds do not fall within the scepe ref this chapter. The cognitive, emotional and social effects of prolonged drug abuse are addressed in reviews, articles and book sections on various illicit drugs, e.g. cocaine (Brown et al. 1992), ecstacy (Morgan 2000), stimulants (Ornstein et al. 2000); Simon et al. 20(0)(j) marijuana (Adams and Martin 1996; Ameri 1999), inhalants (Marelich 1997; Sharp and Rosenberg 1997), hallucinogens (Halpern and Pope 1999) and heroin (Darke et al. 200)(1).

\section{PSYCHOSTIMULANTS}

Psychostimulants boost the users' confidence and temporally enhance feelings of well being and euphoria. The fatigue-counteracting capability of these drugs also make them rery popular among truck drivers and other who perform demanding jobs (Crouch et al. 1993). The three most used psychostimulants are cocaine, amphetamines (including methamphetamine) and ecstasy. Cocaine was the first widely used psychostimulant. Amphetamines soon followed, and different amphetamine analogues became available, including methamphetamine and dextro-amphetamine. Amphetamines are often used as a substitute for cocaine. The effects are similar, but amphetamines are cheaper and more available, and their effects are longer lasting. Ecstasy is popular among people in the dance and club scene. Ecstasy can rely for its effect on several derivatives, including MDA and MDE, but the original psychoactive substance of the drug, MDMA, is still the most popular.

\section{Cocaine}

Cocaine raises levels of dopamine and norepinephrine by inhibiting their reuptake into presynaptic terminals and to a lesser degree by acting as direct agonists. The influence of cocaine on the dopamine system seems to play a prominent role in the drugs' psychostimulant properties (Feldman et al. 1997; Gawin 1991; Izenwasser 1998).

Cocaine increases pulse rate, body temperature, glucose availability, pupil size, vasoconstriction, alertness, motor activity and restlessness and it counteracts sleep (Rush et al. 1999; Stillman et al. 1993). The drug heightens energy levels and enhances consciousness, talkativeness, feelings of euphoria and self-confidence (Higgins and Katz 1998). The cocaine "high" often is followed by a fatigue rebound with a period of anxiety, depression and paranoia (Higgins and Katz 1998). After higher doses, tremors, convulsions and a severe loss of coordination can occur (Feldman et al. 1997). High doses also can produce sleeplessness, anxiety, paranoia, psychosis, hypervigilance, hyperreactivity, increased impulsivity, compulsive behaviour and increased aggression (Higgins and Katz 1998; Licata et al. 1993). 
Cocaine administration under experimental conditions has produced contrasting findings. Some investigators reported improved reaction time, performance spece, enhanced attention and information processing (Farre et al. 1993; Higgins et al. 199(); Higgins et al. 1993; Johnson et al. 1998; Stillman et al. 1993). Others found no effect of a single dosse rof cocaine on information processing, learning, recognition memory, simple and chrice reaction time, concentration, and central nervous system processing capacity (Farre et al. 1993; Foltin et al. 1993; Higgins et al. 1990; Johnson et al. 1998; Rush et al. 1999).

Combined use of cocaine and alcohol is very common among cocaine abusers (Grant and Harford 1990). When cocaine and alcohol have been administered together under experimental conditions, cocaine compensated for impaired task performance that was observed with alcohol alone, including reaction speed and information processing (Farre et al. 1993; Higgins et al. 1993).

The influence of cocaine on driving performance has not been studied. In traffic situations, however, increased self-confidence, impulsivity and aggression could result in overestimation of one's driving performance and higher risk acceptance. Another expected problem for adequate driving performance is the rebound of sleep during withdrawal. In this stage, cocaine abusers can experience extreme fatigue, lack of concentration and anxiety. This impairs focus of attention, and therefore would impair driving performance. A combination of cocaine and ethanol use has been frequently identified in fatally injured drivers (Marzuk et al. 1990). This finding suggests that the reduction of alcohol-induced sedation does not lead to safer driving performance.

\section{AMPHETAMINE}

Amphetamine acts to release newly synthesized dopamine and norepinephrine and inhibit their reuptake (Feldman et al. 1997; King and Ellinwood 1997). Under experimental conditions, small doses of amphetamines $(5-20 \mathrm{mg}$ ) have been shown to increase arousal and improve task performance in fatigued, as well as non-fatigued, subjects. The effects include increases in reaction speed, vigilance, accuracy in a spatial delay response task, verbal reasoning, coordination and cognitive processing speed (Fleming et al. 1995; Koelega 1993; Newhouse et al. 1989). Enhanced memory was observed after $10 \mathrm{mg} d$-amphetamine due to improved consolidation of new material (Soetens et al. 1995). Data from other studies, however, show that amphetamines did not affect task performance, including information processing and mental set shifting (Pickworth et al. 1997). The amounts administered in experiments resemble therapeutic dosages (2.5-60 mg), but amphetamine abusers often take much higher doses (50-300 mg) and multiple doses (Logan 1996; Newhouse et al. 1989; Pickworth et al. 1997).

In one study, methamphetamine abusers had used their regular dose of the drug during the seventy-two hours prior to assessment (Simon et al. 2000). The exact time between drug consumption and assessment was not given, but only 55 percent of subjects reported using methamphetamine on the day of assessment. Therefore, many subjects possibly were in 
withdrawal while being tested. They had problems manipulating information and were less able to combine information in new ways. They also had difficulty focusing on the task at hand, because they lacked the capacity to ignore irrelevant information. These observed impairing effects may indicate either reduced processing resources or reduced processing rate (Simon et al. 2000).

Methamphetamine abusers admitted to trauma centres were most likely to have been injured in traffic accidents, whereas cocaine abusers' primary causes for admission were injuries caused by violence, such as gunshot or stab wounds and assaults (Schermer and Wisner 1999). This does not necessarily indicate safer driving after cocaine, in comparison to methamphetamine. Instead, it may reflect a relatively higher rate of traffic participation after the use of methamphetamine as seems to be confirmed by field studies. Although only two percent of voluntarily tested truck drivers tested positive for methamphetamine, twelve percent refused participation. The actual number of questioned truck drivers who had used methamphetamine, therefore, may be higher (Lund et al. 1988). In another study, methamphetamine was found in seven percent of fatally injured truck drivers (Crouch et al. 1993). Complex behavioral tasks, such as driving, require rapid processing of incoming information and correct decision making in regard to other traffic and traffic signaling. Thus, incorrect or slowed information processing can be expected to reduce traffic safety. Other impairing effects of amphetamines during withdrawal include extreme exhaustion (amphetamine abusers can go without sleep for up to a week), loss of concentration, paranoia and anxiety (Logan 1996). Typical amphetamine-related driving behaviors, which lead to arrest, accidents, or fatal car crash, include drifting in and out of lane of travel, weaving, drifting of the road, speeding, high speed collisions and erratic driving (Logan 1996).

In conclusion, a therapeutic dose of amphetamine will generally not severely reduce task performance and traffic safety. High doses, however, can impair driving performance during the acute phase by inducing hallucinations, panicky behavior and increased risk taking. During withdrawal the reduced capacity to ignore irrelevant information, manipulate and combine information, together with extreme exhaustion and confusion, mediate misinterpretation of information, wrong decision making, reduced attention, risk taking and dangerous driving.

\section{ECSTASY}

$\pm 3,4-$ Methylenedioxymethamphetamine (MDMA, ecstasy) is a phenethylamine, structurally related to amphetamine and mescaline (De Man 1994; Morgan 2000). MDMA is a monoaminergic agonist that releases and inhibits reuptake of serotonin (Rudnick and Wall 1992; White et al. 1996) and to a lesser extent of dopamine (Battaglia et al. 1988; Shankaran and Gudelsky 1998).

In some studies, single doses of MDMA (range $0.9-1.9 \mathrm{mg} / \mathrm{kg}$ ) were not found to impair task performance, including selective attention, visual search, planning or retrieval from 
semantic memory (Downing 1986; Vollenweider et al. 1998a). In a study with MDMA doses of 75 and $125 \mathrm{mg}$, esophoria (squinting) was observed after the higher dese but there was no effect on simple reaction time (Cami et al. 2000). After $75 \mathrm{mg}$, however, dissrociative effects were observed on perceptual performance under divided attention conditions; i.e., improved compensatory tracking and movement speed, and object movement estimation was impaired. This latter task measured the subjects' ability to correctly estimate the timeto-collision of a moving dot with a central target under various conditions of occlusion. The reduction in timing ability, as indicated in this task, may become of crucial importance in certain traffic situations (Lamers et al. accepted).

Little is known about participation in complex operations such as driving while under the influence of ecstasy or MDMA. Although some aspects of vehicle control, such as tracking capacity, appear to improve after a single dose of MDMA, traffic safety may be seriously compromised nonetheless as a result of the users' inability to perceive and adapt to the behaviour of other traffic participants (Lamers et al. accepted). In addition impaired coordination, concentration difficulties and hallucinations have been observed in people while under the influence of MDMA (Downing 1986; Schifano 1995; Vollenweider et al. 1998a).

Any cognitive or psychomotor impairment can compromise driving performance. Therefore, any combination of the observed impairing effects of MDMA is likely to seriously impair driving performance. The drug's use has already been linked to sometimes fatal car crashes (Henry et al. 1992; Moeller and Hartung 1997; Morland 2000; Schifano 1995). Furthermore, in real life, MDMA doses may be higher than those administered under experimental conditions, and it may be combined with sedative psychoactive substances such as marijuana and alcohol. In a recent review of studies of MDMA effects on motor skills and of the relationship between dose and blood concentrations, and studies and case reports of the specific effects on driving, it was concluded that MDMA use is not consistent with safe driving, and that impairment of various types persist for a considerable time after last use (Logan and Couper 2001). In conclusion, the driving skills of persons under the influence of MDMA may be seriously impaired as indicated by its effects on object movement estimation, coordination, concentration and esophoria.

\section{CANNABIS}

Cannabis sativa contains more than 400 chemical compounds, of which about sixty are cannabinoids. The cannabinoid primarily responsible for the drugs' physiological and psychological effects is $\Delta^{9}$ - tetrahydrocannabinol (THC). When entering the systemic circulation, THC is rapidly distributed in fatty tissues, including the brain, and full elimination from the body can take several days to weeks. Consequently, THC metabolites can be present in urine for an extended period after the last drug intake. To date, two 
cannabinoid receptors, $C B_{1}$ and $C_{2}$, have been identified. Cannabinoid receptors are involved in analgesia, cognition, memory, motor activity, control of appetite and vomiting. THC is generally used for recreational purposes because of its psychotropic properties, but it is also indicated in the medical treatment of pain, inflammation, glaucoma and the nausea associated with cancer therapy (Voth and Schwartz 1997).

THC is rapidly absorbed during cannabis smoking and its peak effects appear after thirty to sixty minutes. Acute subjective effects are dose dependent, and their duration is two to four hours. Subjectively, the principal psychological effect of THC is euphoria or a "high". This state is sometimes accompanied by a mild state of anxiety, tension and confusion. Acute consumption of cannabis is associated with impairment of a variety of cognitive and psychomotor tasks, including memory, sense of time, motor coordination, and reaction speed. Memory impairment is the most consistently reported cognitive deficit. The acquisition or consolidation of newly learned information and work seems particularly impaired after an acute dose of THC (Ameri 1999; Robbe 1994).

Numerous experimental studies have investigated the effects of THC on isolated psychological functions and skills related to driving performance. These have generally shown that THC amounts between 40 and $300 \mu \mathrm{g} / \mathrm{kg}$ cause a dose dependent reduction in performance on laboratory tasks of attention, reaction time, tracking, or motor control (Robbe 1994). Results from driving simulator and closed-course studies of THC doses up to $250 \mu \mathrm{g} / \mathrm{kg}$ have generally failed to demonstrate severe effects (Attwood et al. 1981; Casswell 1977 ; Peck et al. 1986; Smiley et al. 1981; Stein et al. 1983). Results of these studies have shown differences between the effects of alcohol and the effects of THC. Alcohol leads to an increase in driving speed whereas THC leads to a decrease in speed. THC subjects drive in a more conservative manner, i.e., in the studies, they maintained a longer headway and refused more opportunities to pass, whereas the opposite was the case following alcohol. THC did, however, increase reaction time and the standard deviation of lateral position (SDLP), although the magnitude of impairment was generally small. There were also no significant interactions between alcohol and marijuana effects on performance, indicating that the combined effects of the drugs are additive.

A series of driving studies in actual traffic was conducted by a group of researchers at Maastricht University, The Netherlands. Robbe (1998) investigated the effects of THC 0 , 100,200 and $300 \mu \mathrm{g} / \mathrm{kg}$ on performance in a one-hour road-tracking test and a thirtyminutes car-following test on a primary highway, and the effect alcohol and THC 100 $\mu \mathrm{g} / \mathrm{kg}$ on a city driving test.

The combined effects of THC and alcohol were further investigated in two subsequent studies with subjects who were recreational users of marijuana. The first assessed the effects of THC 0,100 and $200 \mu \mathrm{g} / \mathrm{kg}$ with and without a low dose of alcohol on road tracking and car-following performance (Robbe, 1998; Ramackers et al. 2000). In the second study, during a city driving test a licensed driving instructor used a standardized questionnaire to rate the effects of $\mathrm{THC} 0$ and $100 \mu \mathrm{g} / \mathrm{kg}$ with and without a low alcohol dose $(\mathrm{BAC}<0.05$ 
$\mathrm{g} / \mathrm{dl}$ ) on general driving proficiency (Lamers and Ramaekers 2001). In addition, the subjects' visual search for traffic at intersections was recorded by means of head-mounted cameras that registered the subject's eye and direction of gaze.

In these studies, THC produced a dose related increment in SDLP, which is a measure of "weaving", during the road-tracking test. Reaction time to the speed accelerations/ decelerations of a lead vehicle in the car-following test and general driving proficiency in the city driving test were not affected by THC. Blood concentrations of THC and THC$\mathrm{COOH}$ were not related to the degree of impairment. The effects of THC on SDLP were comparable to those of alcohol at a $\mathrm{BAC}$ of $0.05 \mathrm{~g} / \mathrm{dl}$, the legal limit for driving in most European countries. THC in combination with a low dose of alcohol, however, produced severe performance impairment in the road-tracking test, and to lesser extents also in the car-following and city driving test. There were no significant interactions between alcohol and THC, indicating that the effects were additive. When compared to a previously established alcohol calibration curve (Louwerens et al. 1987), the combination of THC 100 and $200 \mu \mathrm{g} / \mathrm{kg}$ with alcohol produced a rise in mean SDLP equal to that associated with BACs of $0.09 \mathrm{~g} / \mathrm{dl}$ and $0.14 \mathrm{~g} / \mathrm{dl}$, respectively.

In summary, experimental studies indicate that THC impairs cognition, psychomotor performance and driving performance in a dose-related manner. The degrees of impairment observed in simulated or actual driving tests after THC doses up to $300 \mu \mathrm{g} / \mathrm{kg}$ are mild to moderate and comparable to the effects of an alcohol dose producing 0.05-0.08 g/dl BAC. It has been argued, however, that most THC doses in experimental research have been less than those used for recreational purposes. In this regard, in a dose-finding study by Robbe (1994) twenty-three recreational users of THC indicated that they had achieved their desired effects after smoking a mean dose of $300 \mu \mathrm{g} / \mathrm{kg}$ THC. The range of this preferred dose varied, however, between $194-524 \mu \mathrm{g} / \mathrm{kg}$ THC indicating considerable inter-individual variation. It is thus likely that drivers in the general population will at times use doses that are higher than the ones that have been studied. It can be predicted from currently available data that the use of higher doses of THC $(>300 \mu \mathrm{g} / \mathrm{kg})$ will be associated with severe driving impairment. It is absolutely clear also that THC in combination with alcohol always produces severe driving impairment, even at low doses.

\section{HALLUCINOGENS}

A wide variety of pharmacological substances produce so-called hallucinogenic effects. Briefly, a psychiatric definition of a hallucination is 'sensory perception without external stimulus of the relevant sensory organ' (DSM III-R 1987, American Psychiatric Association). There are no systematic epidemiological studies of hallucinogen use by drivers or laboratory studies of the effects of hallucinogens on skills related to driving. Visual disturbances while driving, even more than ten hours after drug use, have been reported in 
individual cases (Woody 1970). Delayed visual hallucinations appearing days to months after the use of LSD potentially could impair driving capacity (Seppälä et al. 1979).

Many substances that are discussed in other sections of this chapter, such as cannabis, amphetamines and MDMA, are said to possess hallucinogenic properties. This, however, appears not to be their primary characteristic. Therefore, this section focuses on substances, which are used primarily for their hallucinogenic effects. They are categorized according to their primary pharmacological mechanisms of action.

\section{GLUTAMATERGIC HALLUCINOGENS (NMDA RECEPTOR ANTAGONISTS)}

Phencyclidine (PCP) and ketamine are noncompetitive NMDA glutamate receptor antagonists. PCP can induce a broad range of psychological symptoms in nonschizophrenic subjects that resemble the symptoms observed in schizophrenia (Ellison 1995; Krystal et al. 1994; Oranje et al. 2000), including hallucinations, delusions, idiosyncratic and illogical thinking, poverty of speech and thought, agitation, disturbances of emotion, withdrawal, decreased motivation, and dissociation (Newcomer et al. 1999). Ketamine, a PCP analog still used in human anesthesia, has been reported to cause reactions similar to but not as severe as those caused by PCP, including brief, reversible "positive" and "negative" schizophrenia-like symptoms (Krystal et al. 1994; Newcomer et al. 1999). Both PCP and ketamine can exacerbate the psychosis in schizophrenia (Newcomer et al. 1999).

\section{KETAMINE}

The most important adverse effects of the anaesthetic ketamine are hallucinations and excessive increases in blood pressure and heart rate (Moran 1999). These reactions can be attenuated or avoided by combining ketamine with sedative or hypnotic drugs (Adams and Werner 1997). A standard recreational dose of ketamine is typically $1 / 8 \mathrm{~g}$, usually taken intranasally, with effects lasting for approximately one hour. It is one of the drugs consumed regularly amongst members of the new dance culture. At present, the long-term consequences of ketamine use, including addictive potential, are not known (Moran 1999). Subanaesthetic doses of ketamine can produce psychedelic effects in healthy volunteers. Several investigators have studied the effects of ketamine in volunteers to model cognitive deficits in schizophrenia, memory impairment and dementia. These studies have shown that NMDA antagonists produce a broad range of symptoms, behaviours, and cognitive deficits that resemble aspects of endogenous psychoses and thought disorder, particularly schizophrenia and dissociative states (Adler et al. 1998; Adler et al. 1999; Bowdle et al. 1998; Breier et al. 1997; Duncan et al. 2001; Hetem et al. 2000; Lahti et al. 2001; Newcomer et al. 1999; Van Berckel et al. 1998; Vollenweider et al. 1997a; Vollenweider et al. 1997b), 


\section{PHENCYCLIDINE}

Phencyclidine (PCP) or "angel dust" is a dissociative anaesthetic with notoriety as an abuse substance. A derivative of the anaesthetic ketamine, PCP is the predominant member of the arylhexylamine class of designer drugs (Buchanan and Brown 1988). States of florid psychosis lasting for days can follow a brief encounter with PCP (Isaacs et al. 1986). Observations of many investigators have shown that the acute effects of PCP following several toutes of administration are dose-related (Pradhan 1984). High doses produce acute intoxication with disturbing manifestations including psychosis, numbness, lightheadedness, vertigo, ataxia, and nystagmus. Furthermore, some subjects in these studies became irritable, argumentative or negative under conditions of social stress and demanding tasks. In addition to a variety of central actions, PCP has also been shown to affect cardiovascular function, heat storage, and exercise performance. It can also induce, although rarely, psychotic episodes in psychotic and pre-psychotic personalities. Tolerance, but not physical dependence, develops to the effects of PCP. Psychological dependence as indicated by craving for the drug has, however, been reported. The elicitation of violent of psychotic behaviour by phencyclidine is well documented (Moran 1999).

\section{SEROTONERGIC HALLUCINOGENS}

The classical hallucinogens, such as LSD, DMT, mescaline or psilocibin, are all characterised by a serotonergic pharmacology; all display agonist activity at $5-\mathrm{HT}_{2}$ receptors, and there is evidence that some may interact with other 5-HT receptor subtypes as well, such as $5-\mathrm{HT}_{1 \Lambda}$ receptors (McKenna 1996). Chemically they tend to fall into one of three categories: phenylethylamine derivatives (mescaline and synthetic analogues), lysergamides (LSD, morning glory seeds) and tryptamine derivatives (psilocybin, psilocin, DMT) (McKenna 1996).

\section{LYSERGIDE}

Lysergide (LSD) familiarly called "acid", is the synthetic version of ergotamine, produced by ergot, which is a parasite of rice or rye (Maes et al. 1999). It is the diethylamide of lysergic acid. After its discovery, LSD was misused very quickly for its hallucinogenic effects, because the active dose of this hallucinogenic is so small that the drug can be delivered in many forms, including microtablets, window pane, or stamps) (Maes et al. 1999).

The most likely mechanism to account for LSD-induced hallucinations is the increase of neocortical glutamatergic neurotransmission through an initial partial agonistic action at 5$\mathrm{HT}_{2}$ receptors, predominantly $5-\mathrm{HT}_{2 \mathrm{~A}}$ receptors (Aghajanian and Marek 1999). The effects appear fifteen minutes to one hour after ingestion, and can last six to eight hours. Tolerance develops after only a few days of use. Cardiac frequency, blood pressure and temperature increase, and spatiotemporal distortion and depersonalization are frequently reported. Reaction time is significantly increased. Users can become so fearful that they will make suicide attempts. LSD induces a solid psychic dependence (Maes et al. 1999). 


\section{MAGIC MUSHROOMS: PSILOCYBIN AND PSILOCIN}

Magic mushrooms belong essentially to three groups: psilocybe, panaeolus and conocybe. The psychoactive hallucinogenic substances are psilocybin and psilocin, chemically similar to LSD. Effects can be obtained with 10 to $60 \mathrm{mg}$, and can last five to six hours. First, the user will be affected by nausea, and then sensations affecting eyes, hearing and consciousness occur. These products seem to induce less panic than LSD (Maes et al. 1999), but their effects are similar. With psilocibin, $5-\mathrm{HT}_{2 \mathrm{~A}}$ agonism has been demonstrated as the mechanism to induce symptoms (Vollenweider et al. 1998b).

\section{AYAHUASCA (DMT)}

Ayahuasca is a South American psychoactive beverage that contains the naturally occurring psychedelic agent N,N- dimethyltryptamine (DMT) (Riba et al. 2001). This "tea" has been used for centuries in religious and medicinal contexts in the rain forest areas of South America, and is presently gaining the attention of psychedelic users in North America and Europe. Tea brewed of encapsulated freeze-dried ayahuasca in a dose range of $0.5,0.75$, and $1.0 \mathrm{mg} \mathrm{DMT} / \mathrm{kg}$ body weight, produces psychological effects including hallucinatory sensations. The effects begin within thirty to sixty minutes, peak between sixty and 120 minutes, and last until about 240 minutes. Ayahuasca effects are of longer duration and milder intensity than those previously reported for intravenously administered DMT. DMT and hence ayahuasca, like LSD, has affinity for $5-\mathrm{HT}_{2 \mathrm{~A}}$ receptors (Riba et al. 2001).

\section{MESCALINE (PEYOTECACTUS LOPHOPHORA WILLIAMSII)}

Mescaline is the active compound extracted from the peyote, a cactus from Central America. The chemical structure is 3,4,5-trimethoxy-phenethylamine. After oral ingestion, 66 percent can be absorbed (Maes et al. 1999). The effects are very similar to LSD, with reinforcement of color visions. Users call mescaline the "mellow LSD", but real hallucinations are more frequent than with LSD. Tachycardia, hypertension, hyperthermia, hypersalivation and tremor are the most frequent side effects. Mescaline induces tolerance and psychic dependence, and may sometimes produce physical dependence (Maes et al. 1999). Synthetic derivatives of phenethylamine are substances like DOM (2,5-dimethoxy-4methylamphetamine), and MDA (3,4-methylenedioxyamphetamine) that are structurally similar to the amphetamines (Christophersen 2000; De Bruin et al. 1998).

\section{HALLUCINOGEN EFFECTS ON DRIVING PERFORMANCE}

The incidence of the use of hallucinogens is not well documented. Taken from a database containing 44,000 records of persons registered in an addiction care unit in The Netherlands, it appeared that there were twenty-nine cases reporting frequent LSD use. For comparison: 328 reported frequent use of MDMA (De Bruin et al. 1998).

There are no data from studies of hallucinogens effects on driving behaviour, but the many observations from experimental studies with healthy volunteers provide evidence that 
hallucinogen use and traffic participation do not mix in a safe manner. The reason for this is the primary motive for the use of hallucinogenic substances, which is to alter or distort the perception of reality.

\section{INHALANTS}

The term inhalants refers to a broad range of gases and vapors that can be inhaled to induce a psychoactive or mind-altering effect. Inhalants are inexpensive, readily available, and often abused by children, adolescents and young adults (Kurtzman et al. 2001; SAMHSA, 2001). Based on their pharmacological and behavioral effects, they can be categorized in three main groups: (1) volatile solvents and fuels, (2) nitrous oxide and (3) alkyl nitrites (Balster 1998).

\section{VOLATILE SOLVENTS AND FUELS}

Volatile solvents are liquids that vaporize at room temperature. They are abundantly found in household and industrial products, including thinners, paint, nail polish remover, and correction fluids (acetone, toluene, methylene chloride, methanol), dry-cleaning fluids and degreasers (tetrachloroethylene, trichloroethane), gasoline and glues (toluene, hexane, ethyl acetate, trichloroethylene), and felt-tip marker fluids (toluene). Aerosols, including hairspray, deodorants and air fresheners, contain propellants (propane, butane, fluorocarbons ["freons"]), whereas paint and shoeshine sprays may contain solvents (toluene).

The majority of solvents have behavioral effects that are similar to that of the classic CNS depressants, i.e. alcohol, barbiturates and benzodiazepines (Balster 1998; Bowen et al. 1996a; Evans and Balster 1991). The neuronal mechanisms underlying the CNS effects have not yet been identified, but they may include enhancement of GABA and inhibition of NMDA neurotransmission (Balster 1998). Inhalation of solvents produces a very rapid intoxicated state that resembles alcohol intoxication in many respects (Bowen et al. 1996a; Bowen et al. 1996b; Sharp and Rosenberg 1997) including the psychomotor and cognitive effects (Echeverria et al. 1991). The symptoms include initial excitation turning to drowsiness, euphoria, disinhibition, lightheadedness and agitation. Increasing intoxication can lead to ataxia, slurred speech, delusions, dizziness and disorientation, and further intoxication may induce signs of sleeplessness, general muscle weakness, nystagmus and occasionally hallucinations (Dinwiddie 1994; Kurtzman et al. 2001; Sharp and Rosenberg 1997). In extreme cases, stupor typically develops and may progress to seizures, coma, cardiopulmonary arrest or, not uncommonly, death. Abusers may feel invulnerable and engage in high-risk, impulsive behaviors (Sharp and Rosenberg 1997)

Although intoxication is characterized by a rapid onset and equally rapid recorery, a "high" can be maintained for several hours by repeated sniffing (Meredith et al. 1989). As a result, 
performance may be impaired for extended periods of time may thus present a safety hazard. To illustrate the potential risk, almost a quarter of related fatalities studied recently in Virginia were associated with sniffing while driving, riding or sitting in a motor vehicle (Bowen et al. 1999). Also, the use of the propellant difluorethane while driving was related to a fatal car accident (Broussard et al. 1997). Therefore, although no experimental data are available on solvent intoxication and driving capacity, impairment of performance that is qualitatively and quantitatively comparable to that of alcohol may be expected.

\section{NITROUS OXIDE}

Nitrous oxide or "laughing gas" is the most abused of the gases. Because nitrous oxide is commonly used as an analgesic in medicine and dentistry, medical personnel sometimes abuse it. It is also used as a propellant in whipped cream dispensers.

There is a wealth of information documenting that extended nitrous oxide inhalation (minutes to more than an hour) impairs psychomotor and cognitive functioning (Armstrong et al. 1995; Cheam et al. 1995; Fagan et al. 1994; File et al. 1992; Janiszewski et al. 1999; Walker and Zacny 2001; Zacny et al. 1994a; Zacny et al. 1999). However, nitrous oxide is most commonly abused via inhalation of higher concentrations for a very brief period of time (i.e., one or several breaths). The behavioral effects, including those on psychomotor performance, peak approximately thirty seconds after bolus inhalation and gradually subside over the time course of about five minutes. Nonetheless, even brief inhalation (four breaths) of 80 percent nitrous oxide has been shown to produce memory deficits as well as psychomotor impairment. Higher concentrations of nitrous oxide (100 percent) produce hypoxia, which may also add to the behavioral sequelae (Zacny et al. 1994b).

\section{ALKYL NITRITES}

Alkyl nitrites act primarily to dilate blood vessels and relax smooth muscle tissue through the release of endogenous nitric oxide. Most abused compounds are amyl nitrite (used medically for the treatment of angina), butyl nitrite and cyclohexyl nitrite. The latter is present in room odorizers, whereas amyl nitrite and butyl nitrite are sold in ampules or bottles and are called "poppers", "snappers" or "rush". Alkyl nitrites are used as a euphoriant and as a sexual enhancer (Chalmers 1991). The use of nitric inhalants can acutely produce dizziness and headache from orthostatic hypotension. Nitrites increase global cerebral blood flow, and have been noted to decrease anger, fatigue and depression (Mathew et al. 1989). As with solvents and alcohol, biphasic effects on activity (activation followed by inactivation at higher dosages) are seen with amyl nitrite in animal studies (Bowen and Balster 1998). Users report a variety of short-term effects that are consistent with CNS depression, including lack of coordination and balance, blurred vision, short-term memory loss, and lethargy (French and Power 1997). 


\section{OPIODS}

The opioids are a group of compounds that includes natural opium derivates (morphine and codeine), semisynthetic substances, the most notorious being heroin (diacetylmorphine), and synthetic drugs. The characteristics common to all opioids is that they exert their action by binding to specific opioid receptors, which are widely distributed throughout the brain and peripheral nervous system. Three main receptor subtypes have been identified; mu, delta and kappa receptors (Reisine and Pasternak 1996). Based on their affinity and actions on these receptors, opioids can be categorized into prototypical mu-agonists (morphine, heroin, methadone), partial mu-agonists (codeine) and mixed agonists-antagonists (buprenorphine) (Jaffe and Martin 1990; Zacny 1995).

Opioids are potent analgesics and opioid drugs are extensively used for the management of moderate to severe pain, and chronic pain in cancer patients (Joranson et al. 2000). They produce altered mood (often euphoria), decreased anxiety, tespiratory depression, inhibition of gastrointestinal motility, inhibition of certain spinal reflexes, suppression of cough and a reduction of pupil size (miosis). They can also produce pruritus (itching), nausea and vomiting (Jaffe et al. 1997). The development of tolerance and physical dependence is a classic feature of all opioid drugs (Reisine and Pasternak 1996)

The primary opioid drug of abuse is heroin. However, among medical professionals who have readily access to them, other morphine-like agonists such as fentanyl and meperidine may also be abused. Methadone, a morphine-like agonist, is used to treat heroin abuse. Its longer action, availability as an oral preparation, and ability to blunt the craving for other opioids make methadone the most effective treatment for opioid abuse currently used.

The current general consensus with regard to the cognitive and psychomotor effects of opioids is that, while some impairment of performance may occur following a single administration, the debilitating effects soon wear off with continued administration of a fixed dose. Tolerance usually develops within days. As a result, people who are on stable doses of opioids for an extended period of time, show little if any treatment-related cognitive impairment (Zacny 1995; Zacny 1996). Patients who are on chronic opioid therapy, including methadone treatment for heroin abuse, are considered fit to drive and work (Chapman 2001; Galski et al. 2000; Hanks 1995; Smith 1996; Vainio et al. 1995; Zacny 1996). However, sudden dose increments may result in the temporary reappearance of impaired performance. For example, Bruera et al. (Bruera et al. 1989) demonstrated that after receiving their opioid medication (usually morphine or hydromorphone) cancer patients on stable opioid therapy experience no performance decrements, whereas patients who had a dose increment of at least 30 percent in the last three days showed impaired psychomotor, memory and arithmetic performance compared to pre-drug assessments. 


\section{MORPHINE}

Identification of the cognitive and psychomotor effects of opioid drugs is largely based on studies with morphine. A comprehensive review of these studies, dating back to the 1940)s 1950s and 1960s, was published by Zacny (1995). In opioid-naive healthy volunteers, morphine in acute dosages up to $30 \mathrm{mg}$ has been shown to impair a variety of functions, including reaction time, tracking, information processing, attention, and memory (Zacny, 1995; Cleeland et al. 1996; Hanks et al. 1995; Walker and Zacny 1999; Zacny et al. 1998). This broad pattern of impairment is consistent with a mild dearousing effect (sedation), which is also apparent from subjective teports of mental clouding, confusion, grogginess and light-headedness. Generally, speed rather than accuracy is reduced (Zacny 1996). It must be noted that the observed detrimental effects are generally very mild when compared, for example, to those of low dosages of benzodiazepines (Hanks et al. 1995), and most often performance is found to be unchanged (Zacny, 1995; Hill and Zacny 2000; Walker and Zacny 1998, 1999; Zacny et al. 1998; Zacny et al. 1994c) or may even be improved $\left(\mathrm{O}^{\prime} \mathrm{Neill}\right.$ et al. 2000). As mentioned above, in opioid-dependent users the cognitive effects are even less pronounced as a result of tolerance (Zacny 1995)

\section{HEROIN}

Given the highly addictive profile of heroin, major ethical objections prevent studies of it in an experimental setting. Hence, scant experimental data are available on the performance effects of heroin. Nevertheless, two remarkable studies conducted in the early $1960 \mathrm{~s}$ describe the effect of both acute and sub-chronic administration of heroin in nondependent opioid abusers (Fraser et al. 1963; 1964). The subjects were incarcerated men with a history of opioid abuse, but they were not dependent at the start of the experiment. In the two double-blind experiments, the subjects initially received placebo (saline) injections for thirty days (phase 1), with an exception of day seventeen, at which time saline was replaced by $8 \mathrm{mg}$ heroin. Psychomotor (eye-hand coordination) performance was somewhat lower compared to the previous day, but performance on a twelve minute number cancellation task was not affected by the acute heroin administration. In the next phase, which lasted sixty days, the subjects received heroin four times a day in a incremental dosing regimen (10 to $95 \mathrm{mg}$ ) and became they physically dependent. During this time, psychomotor performance showed a small but significant decline in the first twelve days but returned to normal (phase 1) levels for the remainder of the study. These results clearly demonstrate that, similar to other opioids, i.e. morphine, tolerance develops for the performance degrading effects of heroin.

The scantiness of experimental heroin studies allows no specific statement as to its performance effects. However, there is marked similarity between heroin and morphine in terms of their efficacy and at the mu-receptor, their ability to produce physical dependence. There also is similarity in their subjective, reinforcing and discriminative stimulus effects. 
Thus, one may predict minimal, if any, impairing effects of heroin in opioid-dependent users (Zacny 1995).

\section{METHADONE}

In a recent study by Curran et al (Curran et al. 2001), opioid dependent abusers who underwent a methadone treatment programme received their normal dose (10-50 mg) or a doubled dose according to a crossover design. Diminished long-term memory functioning was seen following the double dose but not the normal dose. Information processing, attention, and psychomotor speed remained unchanged. Reviewing the experimental data, Zacny (1995) concludes that orally administered doses used for methadone maintenance would not impair cognitive or psychomotor performance. Again, in nonusers (Rothenberg et al. 1977) and in users following a sharp dose increase, there is a greater risk of mild impairment.

In conclusion, impairment of cognitive ability by opioid drugs is not necessarily or specifically linked to absolute dosage levels. Although there appears to be a rather straightforward dose-response relation in drug-naive users (Walker and Zacny 1999; Zacny et al. 1994c), prolonged opioid users become insensitive to the adverse cognitive effects of even quite high fixed doses (Zacny 1995). In the practical setting of drug abuse, however, opioid doses for an individual are likely show considerable variation. Heroin content may vary greatly from dose to dose and the prevalence of nonlethal heroin overdose is extremely high (McGregor et al. 1998). This incidental exposure to higher than normal dosages is likely to produce diminished psychomotor and cognitive abilities. Also, in certain specific situations impairment by occur despite apparent habituation. For example under conditions of low light, the miotic effect to which no tolerance develops (Reisine and Pasternak 1996), may impair performance that is dependent on visual acuity, such as night driving. Furthermore, opiods are known to alter mood, attitude and most likely risk assessment, changes which may ultimately result in careless, indifferent and risky behaviour and increase the likelihood of traffic accidents. Epidemiological data, however, do not indicate that opioid use is associated with increased accident risk (Zacny 1995). This supports the notion that stable doses are safe and may indicate that those who abuse opioid are not likely to engage in traffic.

\section{GAMMA HYDROXYBUTYRIC ACID}

Gamma hydroxybutyric acid (GHB) is a substance akin to Gamma-Amino-Butyric-Acid (GABA) that is naturally present in mammal species. It is used as an anaesthetic agent, but other indications have been suggested, such as the treatment of insomnia, alcohol and opiates withdrawal, and many cerebrovascular disorders. After oral absorption, the GHB peak is reached in serum after twenty to forty-five minutes, and the half-life is proportional 
to the amount ingested (more or less twenty minutes). Metabolism occurs in the liver with oxidation in $\mathrm{CO}_{2}$. Urinary elimination is very limited (1 to 5 percent of the absorbed quantity) (Maes et al. 1999).

GHB is abused for its euphoric, sedative and anabolic (bodybuilding) effects. An "amphetamine like" sensation is obtained after 20 to $30 \mathrm{mg} / \mathrm{kg}$, and with $10 \mathrm{mg} / \mathrm{kg}$, amnesia and muscular relaxation can be observed. These properties have led to its use as a rape drug. Physical dependence occurs. Side effects are nausea, vomiting, vertigo, sleepiness, bradycardia, and respiratory depression. Coma and seizures have been reported following GHB abuse. Patients regain consciousness spontaneously within a few hours after ingestion. Indigestion in combination with alcohol or other psychoactive drugs is very dangerous. In one study, the effects of GHB on human psychomotor performance and subjective feelings important for the safety of skilled performance, such as driving, were investigated (Ferrara et al. 1999). After single doses of 12.5 and $25 \mathrm{mg} / \mathrm{kg}$ (therapeutic doses in alcohol addiction treatments), GHB did not induce changes in psychomotor performance and, therefore, the drug did not seem to influence the ability to drive or work (Ferrara et al. 1999). However, repeated reports of the abuse potential of GHB and its use in treating ethyl alcohol addiction indicate that it may play an "agonist-like" role, which means that it should only used under close medical supervision (Ferrara et al. 1999).

\section{CONCLUSIONS}

Without exception, all illicit drugs have the potential to impair the cognitive and behavioural skills that allow a person to engage in normal daily activities, such as driving and working. A person's ability to interact optimally with the environment may be compromised by a distorted perception of the world due to the effects of hallucinogens, marijuana or psychostimulant drugs. Miotic or mydriatic effects of opioids and psychostimulants, respectively, prevent optimal adaption to changing environmental light intensities. On a more global level, drugs such as opioids and inhalants produce CNS depressant effects and may cause sedation, leading to reduced accuracy and responsivity as well as overall dysfunction over a wide range of cognitive domains. In contrast, psychostimulants can induce a state of over-activation in which premature and inaccurate responding may occur. In addition, most drugs produce mood and attitude changes, diminish a person's judgment, quality of decision-making and risk assessment, and produces disinhibition. Most notable are the feelings of overconfidence and increased aggression following stimulant abuse and consequent exposure to risky and dangerous situations. Thus, despite their apparent performance-enhancing effects in certain controlled laboratory task, stimulants are likely to reduce performance in real life.

If, and to what extent, impairment will actually occur with adrug is dependent of certain additional factors besides its potential behavioural effects. Drug dosage, of course, is an 
important determinant as many behavioural effects are dose-dependent. However, the development of tolerance or sensitisation, or metabolic differences leading to unusually high or low blood drug levels, can modify an individual's response to a particular dose. Environmental cues may also play an important role.

It must also be noted that the dosage and purity of a street drug is often unclear, and illicit drug formulations may contain numerous, potentially toxic constituents, the combined effects of which are largely unknown. Furthermore, poly-drug use is a common, rather than exceptional, practice among drug abusers. Interaction effects between various illicit drugs, as well as co-use of alcohol, can produce additive and potentiated behavioural effects, which are often not investigated and thus are unknown.

\section{REFERENCES}

Adams HA, Werner C (1997) From the racemate to the eutomer: (S)-ketamine. Renaissance of a substance? Anaesthesist 46: 1026-42.

Adams IB, Martin BR (1996) Cannabis: pharmacology and toxicology in animals and humans. Addiction 91: 1585-614

Adler CM, Goldberg TE, Malhotra AK, Pickar D, Breier A (1998) Effects of ketamine on thought disorder, working memory, and semantic memory in healthy volunteers. Biol Psychiatry 43: 811-6

Adler CM, Malhotra AK, Elman I, Goldberg T, Egan M, Pickar D, Breier A (1999) Comparison of ketamine-induced thought disorder in healthy volunteers and thought disorder in schizophrenia. Am J Psychiatry 156: 1646-9

Aghajanian GK, Marek GJ (1999) Serotonin and hallucinogens. Neuropsychopharmacology 21: 16S23S

Ameri A (1999) The effects of cannabinoids on the brain. Prog Neurobiol 58: 315-48

American Psychiatric Association (1987) Diagnostic and statistical manual of mental disorders, DSM III-R. American Psychiatric Association, Washington DC.

Armstrong PJ, Morton C, Sinclair W, Tiplady B (1995) Effects of nitrous oxide on psychological performance. A dose-response study using inhalation of concentrations up to $15 \%$. Psychopharmacology 117: 486-90

Attwood DA, Williams RD, McBurney LJ, Frecker RC (1981) Cannabis alcohol and driving: effect on selected closed-course tasks Alcohol Drugs and Traffic Safety. Almqvist and Witsell International, Stockholm

Balster RL (1998) Neural basis of inhalant abuse. Drug Alcohol Depend 51: 207-14

Battaglia G, Brooks BP, Kulsakdinun C, De Souza EB (1988) Pharmacologic profile of MDMA (3,4methylenedioxymethamphetamine) at various brain recognition sites. Eur J Pharmacol 149: 159-63.

Bowdle TA, Radant AD, Cowley DS, Kharasch ED, Strassman RJ, Roy-Byrne PP (1998) Psychedelic effects of ketamine in healthy volunteers: relationship to steady-state plasma concentrations. Anesthesiology 88: 82-8.

Bowen SE, Balster RL (1998) A direct comparison of inhalant effects on locomotor activity and schedule-controlled behavior in mice. Experimental and Clinical Psychopharmacology 6: 235-247

Bowen SE, Daniel J, Balster RL (1999) Deaths associated with inhalant abuse in Virginia from 1987 to 1996. Drug Alcohol Depend 53: 239-45

Bowen SE, Wiley JL, Balster RL (1996a) The effects of abused inhalants on mouse behavior in an elevated plus-maze. Eur J Pharmacol 312: 131-6 
Bowen SE, Wiley JL, Evans EB, Tokarz ME, Balster RL (1996b) Functional observational battery comparing effects of ethanol, 1,1,1-trichlorocthane, ether, and flurothyl. Neurotoxicol Teratol 18 : 577-85

Breier A, Malhotra AK, Pinals DA, Weisenfeld NI, Pickar D (1997) Association of ketamine-induced psychosis with focal activation of the prefrontal cortex in healthy volunteers. Am J Psychiatry 154: 805-11

Broussard LA, Brustowicz T, Pittman T, Atkins KD, Presley L (1997) Two traffic fatalities related to the use of difluoroethane. Journal of Forensic Sciences 42: 1186-1187

Brown E, Prager J, Lee HY, Ramsey RG (1992) CNS complications of cocaine abuse: prevalence, pathophysiology, and neuroradiology. AJR Am J Roentgenol 159: 137-47.

Bruera E, Macmillan K, Hanson J, MacDonald RN (1989) The cognitive effects of the administration of narcotic analgetics in patients with cancer pain. Pain 39: 13-16

Buchanan JF, Brown CR (1988) 'Designer drugs'. A problem in clinical toxicology. Med Toxicol Adverse Drug Exp 3: 1-17

Cami J, Farre M, Mas M, Roset PN, Poudevida S, Mas A, San L, de la Torre R (2000) Human pharmacology of 3,4-methylenedioxymethamphetamine ("ecstasy"): psychomotor performance and subjective effects. J Clin Psychopharmacol 20: 455-66.

Casswell S (1977) Cannabis and alcohol: effects on closed course driving behaviour. In: Johnson I (ed) Seventh International Conference on Alcohol Drugs and Traffic Safety, Melbourne Australia

Chalmers EM (1991) Volatile substance abuse. Med J Aust 154: 269-74

Chapman S (2001) The effects of opioids on driving ability in patients with chronic pain. APS bulletin 11

Cheam EW, Dob DP, Skelly AM, Lockwood GG (1995) The effect of nitrous oxide on the performance of psychomotor tests. A dose-response study. Anaesthesia 50: 764-8

Christophersen AS (2000) Amphetamine designer drugs - an overview and epidemiology. Toxicol Lett 112-113: 127-31

Cleeland CS, Nakamura Y, Howland EW, Morgan NR, Edwards KR, Backonja M (1996) Effects of oral morphine on cold pressor tolerance time and neuropsychological performance. Neuropsychopharmacology 15: 252-62

Crouch DJ, Birky MM, Gust SW, Rollins DE, Walsh JM, Moulden JV, Quinlan KE, Beckel RW (1993) The prevalence of drugs and alcohol in fatally injured truck drivers. J Forensic Sci 38: 1342-53

Curran HV, Kleckham J, Bearn J, Strang J, Wanigaratne S (2001) Effects of methadone on cognition, mood and craving in detoxifying opiate addicts: a dose-response study. Psychopharmacology (Berl) 154: $153-60$

Darke S, Sims J, McDonald S, Wickes W (2000) Cognitive impairment among methadone maintenance patients. Addiction 95: 687-95

De Bruin A, Vuurman EFPM, Riedel WJ (1998) Gedragseffecten van geneesmiddelen en (1)legale genotmiddelen als risicofactor bij verkeersdeelname: een literatuuroverzicht. Instituut Hersenen \& Gedrag, Universiteit Maastricht

De Man RA (1994) Morbiditeit en sterfte als gevolg van ecstacygebruik. Ned Tijdschr Geneeskd 138: 1850-5

Dinwiddie SH (1994) Abuse of inhalants: a review. Addiction 89: 925-39

Downing J (1986) The psychological and physiological effects of MDMA on normal volunteers. J Psychoactive Drugs 18: 335-40

Duncan EJ, Madonick SH, Parwani A, Angrist B, Rajan R, Chakravorty S, Efferen TR, Szilagyi S, Stephanides M, Chappell PB, Gonzenbach S, Ko GN, Rotrosen JP (2001) Clinical and sensorimotor gating effects of ketamine in normals. Neuropsychopharmacology 25: 72-83.

Echeverria D, Fine L, Langolf G, Schork T, Sampaio C (1991) Acute behavioural comparisons of toluene and ethanol in human subjects. Br J Ind Med 48: 750-61 
Ellison G (1995) The N-methyl-D-aspartate antagonists phencyclidine, ketamine and dizrcilpine as both behavioral and anatomical models of the dementias. Brain Res Rev 2(): 250-267

Evans EB, Balster RL (1991) CNS depressant effects of volatile organic solvents. Neurosci Biobehav Rev 15: 233-41

Fagan D, Paul DL, Tiplady B, Scott DB (1994) A dose-response study of the effects of inhaled nitrous oxide on psychological performance and mood. Psychopharmacology 116: 333-338

Farre M, de la Torre R, Llorente M, Lamas X, Ugena B, Segura J, Cami J (1993) Alcohol and cocaine interactions in humans. J Pharmacol Exp Ther 266: 1364-73.

Feldman RS, Meyer JS, Quenzer LF (1997) Principles of Neuropyschopharmacology. Sinauer Associates, Inc., Sinauer Associates, Inc.

Ferrara SD, Giorgetti R, Zancaner S, Orlando R, Tagliabracci A, Cavarzeran F, Palatini P (1999) Effects of single dose of gamma-hydroxybutyric acid and lorazepam on psychomotor performance and subjective feelings in healthy volunteers. European Journal of Clinical Pharmacology 54: 821 827

File SE, Balakrishnan J, Murray A, Harris A, Skelly AM (1992) Effects of nitrous oxide on memory for instructions in dental patients. Hum Psychopharmacol 7: 37-44

Fleming K, Bigelow LB, Weinberger DR, Goldberg TE (1995) Neuropsychological effects of amphetamine may correlate with personality characteristics. Psychopharmacol Bull 31: 357-62

Foltin RW, Fischman MW, Pippen PA, Kelly TH (1993) Behavioral effects of cocaine alone and in combination with ethanol or marijuana in humans. Drug Alcohol Depend 32: 93-106.

Fraser HF, Jones BE, Rosenberg DE, Thompson AK (1963) Effects of addiction to intravenous heroin on patterns of physical activity in man. Clinical Pharmacology and Therapeutics: 188-196

Fraser HF, Jones BE, Rosenberg DE, Thompson AK (1964) Effect of a cycle of addiction to intravenous heroin on certain physiological measurements. Bulletin of Narcotics 16: 17-23

French RS, Power R (1997) Self-reported effects of alkyl nitrite use: A qualitative study amongst targeted groups. Addiction Research 5: 519-548

Galski T, Williams JB, Ehle HT (2000) Effects of opioids on driving ability. Journal of Pain and Symptom Management 19: 200-208

Gawin FH (1991) Cocaine addiction: psychology and neurophysiology. Science 251: 1580-6.

Grant BF, Harford TC (1990) Concurrent and simultaneous use of alcohol with cocaine: results of national survey. Drug Alcohol Depend 25: 97-104.

Halpern JH, Pope HG (1999) Do hallucinogens cause residual neuropsychological toxicity? Drug Alcohol Depend 53: 247-56

Hanks GW (1995) Morphine sans morpheus. Lancet 346: 652-3

Hanks GW, O'Neill WM, Simpson P, Wesnes K (1995) The cognitive and psychomotor effects of opioid analgesics. II. A randomized controlled trial of single doses of morphine, lorazepam and placebo in healthy subjects. Eur J Clin Pharmacol 48: 455-60

Henry JA, Jeffreys KJ, Dawling $S$ (1992) Toxicity and deaths from 3,4methylenedioxymethamphetamine ("ecstasy"). Lancet 340: 384-7

Hetem LAB, Danion JM, Diemunsch P, Brandt C (2000) Effect of a subanesthetic dose of ketamine on memory and conscious awareness in healthy volunteers. Psychopharmacology 152: 283-288

Higgins ST, Bickel WK, Hughes JR, Lynn M, Capeless MA, Fenwick JW (1990) Effects of intranasal cocaine on human learning, performance and physiology. Psychopharmacology 102: 451-8

Higgins ST, Katz JL (1998) Cocaine abuse: Behavior, pharmacology and clinical applications. Academic Press, Academic Press

Higgins ST, Rush CR, Bickel WK, Hughes JR, Lynn M, Capeless MA (1993) Acute behavioral and cardiac effects of cocaine and alcohol combinations in humans. Psychopharmacology 111: 285-94

Hill JL, Zacny JP (2000) Comparing the subjective, psychomotor, and physiological effects of intravenous hydromorphone and morphine in healthy volunteers. Psychopharmacology (Berl) 152: $31-9$ 
Isaacs SO, Martin P, Washington JA, Jr. (1986) Phencyclidine (PCP) abuse. A close-up look at a growing problem. Oral Surg Oral Med Oral Pathol 61: 126-9.

Izenwasser S (1998) Basic Pharmacological mechanisms of cocaine. In: Higgins ST, Katz JL (eds) Cocaine abuse: Behavior, Pharmacology and CLinical Applications. Academic Press, San Diego, pp $1-20$

Jaffe JH, Knapp CM, Ciraulo DA (1997) Opiates: clinical aspects. In: Lowinson JH, Ruiz P, Millman RB, Langrod JG (eds) Substance Abuse: A Comprehensive Textbook. Williams \& Wilkins, Baltimore, pp 158-166

Jaffe JH, Martin WR (1990) Opioid analgesic and antagonists. In: Gilman AG, Rall TW, Nies AS, Taylor P (eds) Goodman and Gilman's: The pharmacological basis of therapeutics. Pergamon Press, New York, pp 485-521

Janiszewski DJ, Galinkin JL, Klock PA, Coalson DW, Pardo H, Zacny JP (1999) The effects of subanesthetic concentrations of sevoflurane and nitrous oxide, alone and in combination, on analgesia, mood, and psychomotor performance in healthy volunteers. Anesth Analg 88: 1149-54

Johnson B, Overton D, Wells L, Kenny P, Abramson D, Dhother S, Chen YR, Bordnick P (1998) Effects of acute intravenous cocaine on cardiovascular function, human learning, and performance in cocaine addicts. Psychiatry Res 77: 35-42.

Joranson DE, Ryan KM, Gilson AM, Dahl JL (2000) Trends in medical use and abuse of opioid analgesics. JAMA 283: 1710-4

King CR, Ellinwood EH (1997) Amphetamines and other stimulants. In: Lowinson JH, Ruiz P, Millman RB, Langrod JG (eds) Substance abuse: a comprehensive textbook. Williams and Wilkons, Baltimore, pp 207-223

Koelega HS (1993) Stimulant drugs and vigilance performance: a review. Psychopharmacology 111: 116

Krystal JH, Karper LP, Seibyl JP, Freeman GK, Delaney R, Bremner JD, Heninger GR, Bowers MB, Jr., Charney DS (1994) Subanesthetic effects of the noncompetitive NMDA antagonist, ketamine, in humans. Psychotomimetic, perceptual, cognitive, and neuroendocrine responses. Arch Gen Psychiatry 51: 199-214

Kurtzman TI, Otsuka KN, Wahl RA (2001) Inhalant abuse by adolescents. J Adolesc Health 28: 17080

Lahti AC, Weiler MA, Michaelidis T, Parwani A, Tamminga CA (2001) Effects of Ketamine in Normal and Schizophrenic Volunteers. Neuropsychopharmacology 25: 455-467

Lamers CTJ, Ramaekers JG (2001) Visual search and urban city driving under the influence of marijuana and alcohol. Human Psychopharmacology 16: 393-401

Lamers CTJ, Ramaekers JG, Muntjewerff ND, Sikkema K, Samijn N, Read NL, Brookhuis KA, Riedel WJ (accepted) Dissociable effects of a single dose of MDMA on psychomotor skills and attentional performance. Journal of Psychopharmacology.

Licata A, Taylor S, Berman M, Cranston J (1993) Effects of cocaine on human aggression. Pharmacology of Biochemical Behaviour 45: 549-52.

Logan BK (1996) Methamphetamine and driving impairment. J Forensic Sci 41: 457-64

Logan BK, Couper FJ (2001) 3,4-Methylenedioxymethamphetamine (MDMA, ecstasy) and driving impairment. J Forensic Sci 46: 1426-33.

Louwerens JW, Gloerich ABM, Vries Gd, Brookhuis KA, O'Hanlon JF (1987) The relationship between drivers' blood alcohol concentration (BAC) and actual driving performance during high speed travel. In: Noordzij PC, Roszbach R (eds) Alcohol, drugs and traffic safety-T86. Elsevier, Amsterdam, pp 183-186

Lund AK, Preusser DF, Blomberg RD, Williams AF (1988) Drug use by tractor-trailer drivers. J Forensic Sci 33: 648-61 
Maes V, Charlier C, Grenez O, Verstraete A (1999) Drugs and medicines that are suspected to have a detrimental impact on road user performance. The Toxicological Socicty of Belgium and Luxembourg (BLT) as subcontractor of University of Gent (RUG), Gent

Marelich GP (1997) Volatile substance abuse. Clinical Reviews in Allergy and Immunology 15: 271-289

Marzuk PM, Tardiff K, Leon AC, Stajic M, Morgan EB, Mann JJ (1990) Prevalence of recent cocaine use among motor vehicle fatalities in New York City. Jama 263: 250-6.

Mathew RJ, Wilson WH, Tant SR (1989) Regional cerebral blood flow changes associated with amyl nitrite inhalation. Br J Addict 84: 293-99

McGregor C, Darke S, Ali R, Christie P (1998) Experience of non-fatal overdose among heroin users in Adelaide, Australia: circumstances and risk perceptions. Addiction 93: 701-11

McKenna DJ (1996) Plant hallucinogens: springboards for psychotherapeutic drug discovery. Behavioural Brain Research 73: 109-16

Meredith T], Ruprah M, Liddle A, Flanagan RJ (1989) Diagnosis and treatment of acute poisoning with volatile substances. Human Toxicology 8: 277-286

Moeller MR, Hartung M (1997) Ecstasy and related substances-serum levels in impaired drivers. Journal of Analytical Toxicology 21:591

Moran R (1999) Literature Review on the Relation between Drug Use, Impaired Driving and Traffic Accidents. EMCDDA/HRB, Health Research Board, Drugs Misuse Research Division, Tel. 00353 16761176 , email rmoran@hrb.ie, Dublin

Morgan MJ (2000) Ecstasy (MDMA): a review of its possible persistent psychological effects. Psychopharmacology (Berl) 152: 230-48.

Morland J (2000) Toxicity of drug abuse--amphetamine designer drugs (ecstasy): mental effects and consequences of single dose use. Toxicol Lett 112-113: 147-52

Newcomer JW, Farber NB, Jevtovic-Todorovic V, Selke G, Melson AK, Hershey T, Craft S, Olney JW (1999) Ketamine-induced NMDA receptor hypofunction as a model of memory impairment and psychosis. Neuropsychopharmacology 20: 106-118

Newhouse PA, Belenky G, Thomas M, Thorne D, Sing HC, Fertig J (1989) The effects of damphetamine on arousal, cognition, and mood after prolonged total sleep deprivation. Neuropsychopharmacology 2: 153-64

O'Neill WM, Hanks GW, Simpson P, Fallon MT, Jenkins E, Wesnes K (2000) The cognitive and psychomotor effects of morphine in healthy subjects: a randomized controlled trial of repeated (four) oral doses of dextropropoxyphene, morphine, lorazepam and placebo. Pain 85: 209-15

Oranje B, van Berckel BN, Kemner C, van Ree JM, Kahn RS, Verbaten MN (2000) The effects of a sub-anaesthetic dose of ketamine on human selective attention. Neuropsychopharmacology 22: 293302.

Ornstein TJ, Iddon JL, Baldacchino AM, Sahakian BJ, London M, Everitt BJ, Robbins TW (2000) Profiles of Cognitive Dysfunction in Chronic Amphetamine and Heroin Abusers. Neuropsychopharmacology 23: 113-126

Peck RC, Biasotti A, Boland PN, malloy C (1986) The effects of marijuana and alochol on actual driving performance. Alcohol, Drugs and Driving 2: 135-154

Pickworth WB, Rohrer MS, Fant RV (1997) Effects of abused drugs on psychomotor performance. Exp Clin Psychopharmacol 5: 235-41

Pradhan SN (1984) Phencyclidine (PCP): some human studies. Neurosci Biobehav Rev 8: 493-501.

Ramaekers JG, Robbe HWJ, O'Hanlon JF (2000) Marijuana, alcohol and actual driving performance. Hum Psychopharmacol 15: 551-8

Reisine T, Pasternak G (1996) Opioid analgesic and antagonists. In: Gilman Goodman A, Goodman LS, Gilman A, Hardman JG, Molinoff PB, Ruddon RW, Limbird LE (eds) Goodman and Gilman's: The Pharmacological Basis of Therapeutics. McGraw-Hill, New York, pp 521-555 
Riba J, Rodrigue\%-Fornells A, Urbano $G$, Morte $A$, Antonijoan R, Montero M, Callaway JC, Barban $)$ j MJ (2001) Subjective effects and tolerability of the South American psychoactive beverage Ayahuasca in healthy volunteers. Psychopharmacology (Berl) 154: 85-95.

Riedel WJ, Vermeeren A, Van Boxtel MPJ, Vuurman EFPM, Verhey FRJ, Jolles J, Ramaekers JG (1998) Mechanisms of Drug-Induced Driving Impairment: A Dimensional Approach. Human Psychopharmacology 13: \$49-63

Robbe HWJ (1994) Influence of marijuana on driving. Datawyse, Datawyse.

Robbe HWJ (1998) Marijuana's impairing effects on driving are moderate when taken alone but severe when combined with alcohol. Human Psychopharmacology Clinical and Experimental, 13 (Suppl 2): 70-78.

Rothenberg S, Schottenfeld S, Gross K, Selkoe D (1977) Performance differences between addicts and non-addicts. Psychopharmacology 52: 299-306

Rudnick G, Wall SC (1992) The molecular mechanism of "ecstasy" [3.4methylenedioxymethamphetamine (MDMA)]: Serotonin transporters are targets for MDMAinduced serotonin release. Proceedings of the National Academy of Sciences of the United States of America 89: 1817-21

Rush CR, Baker RW, Wright K (1999) Acute physiological and behavioral effects of oral cocaine in humans: a dose-response analysis. Drug Alcohol Depend 55: 1-12.

Schermer CR, Wisner DH (1999) Methamphetamine use in trauma patients: a population-based study. $J$ Am Coll Surg 189: 442-9

Schifano F (1995) Dangerous driving and MDMA (Ecstacy') abuse. Journal of Serotonin Research 1: 53-57

Schmitt JAJ, Kruizinga M, Riedel WJ (2001) Non-serotonergic pharmacological profiles and associated cognitive effects of Serotonin Reuptake Inhibitors. Journal of Psychopharmacology 15: 173-179

Selby MJ, Azrin RL (1998) Neuropsychological functioning in drug abusers. Drug Alcohol Depend 50: $39-45$

Seppälä T, Linnoila M, Mattila MJ (1979) Drugs, alcohol and driving. Drugs 17: 389-408

Shankaran M, Gudelsky GA (1998) Effect of 3,4-methylenedioxymethamphetamine (MDMA) on hippocampal dopamine and serotonin. Pharmacol Biochem Behav 61: 361-6

Sharp CW, Rosenberg NL (1997) Inhalants. In: Lowinson JH, Ruiz P, Millman RB, Langrod JG (eds) Substance Abuse; a Comprehensive Textbook. Williams \& Wilkins, Baltimore, pp 246-258

Simon SL, Domier C, Carnell J, Brethen P, Rawson R, Ling W (2000) Cognitive impairment in individuals currently using methamphetamine. Am J Addict 9: 222-31.

Smiley AM, Moskowitz H, Ziedman K (1981) Driving simulator studies of marijuana alone and in combination with alcohol 25th Conference of the American Association of Automotive Medicine, pp 107-116

Smith AM (1996) Patients taking stable doses of morphine may drive. BMJ 312: 56-7

Soetens E, Casaer S, D'Hooge R, Hueting JE (1995) Effect of amphetamine on long-term retention of verbal material. Psychopharmacology 119: 155-62

Stein AC, Allen RW, Cook ML, Karl RL (1983) A simulator study of the combined effects of alcohol and marihuana on driving behaviour. National Highway Safety Traffic Administration Systems Technology Inc Hawthorne California

Stillman R, Jones RT, Moore D, Walker J, Welm S (1993) Improved performance 4 hours after cocaine. Psychopharmacology 110: 415-20

Substance-Abuse-and-Mental-Health-Services-Administration (2001) Summary of findings from the 2000 National Household Survey on Drug Abuse. SAMSHA

Vainio A, Ollila J, Matikainen E, Rosenberg P, Kalso E (1995) Driving ability in cancer patients receiving long-term morphine analgesia. Lancet 346: 667-70 
Van Berckel BNM, Oranje B, van Ree JM, Verbaten MN, Kahn RS (1998) The effects of low dose ketamine on sensory gating, neuroendocrine secretion and behavior in healthy human subjects. Psychopharmacology 137: 271-281

Vollenweider FX, Gamma A, Liechti M, Huber T (1998a) Psychological and cardiovascular effects and short-term sequelae of MDMA ("Ecstasy") in MDMA-naieve healthy volunteers. Neuropsychopharmacology 19: 241-251

Vollenweider FX, Leenders KL, Oye I, Hell D, Angst J (1997a) Differential psychopathology and patterns of cerebral glucose utilisation produced by $(\mathrm{S})$ - and $(\mathrm{R})$-ketamine in healthy volunteers using positron emission tomography (PET). Eur Neuropsychopharmacol 7: 25-38

Vollenweider FX, Leenders KL, Scharfetter C, Antonini A, Maguire P, Missimer J, Angst J (1997b) Metabolic hyperfrontality and psychopathology in the ketamine model of psychosis using positron emission tomography (PET) and [18F]fluorodeoxyglucose (FDG). Eur Neuropsychopharmacol 7: 9-24

Vollenweider FX, Vollenweider-Scherpenhuyzen MF, Babler A, Vogel H, Hell D (1998b) Psilocybin induces schizophrenia-like psychosis in humans via a serotonin-2 agonist action. Neuroreport 9: 3897-902

Voth EA, Schwartz RH (1997) Medicinal applications of delta-9-tetrahydrocannabinol and marijuana. Ann Intern Med 126: 791-8

Walker DJ, Zacny JP (1998) Subjective, psychomotor, and analgesic effects of oral codeine and morphine in healthy volunteers. Psychopharmacology (Berl) 140: 191-201

Walker DJ, Zacny JP (1999) Subjective, psychomotor, and physiological effects of cumulative doses of opioid mu agonists in healthy volunteers. J Pharmacol Exp Ther 289: 1454-64

Walker DJ, Zacny JP (2001) Within- and between-subject variability in the reinforcing and subjective effects of nitrous oxide in healthy volunteers. Drug Alcohol Depend 64: 85-96

White SR, Obradovic T, Imel KM, Wheaton MJ (1996) The effects of methylenedioxymethamphetamine (MDMA, "Ecstasy") on monoaminergic neurotransmission in the central nervous system. Prog Neurobiol 49: 455-79

Woody GE (1970) Visual disturbances experienced by hallucinogenic drug abusers while driving. Am J Psychiatry 127: 683-6.

Zacny JP (1995) A review of the effects of opioids on psychomotor and cognitive functioning in humans. Experimental and Clinical Psychopharmacology 3: 432-466

Zacny JP (1996) Should people taking opioids for medical reasons be allowed to work and drive? [editorial]. Addiction 91: 1581-4

Zacny JP, Coalson DW, Lichtor JL, Yajnik S, Thapar P (1994a) Effects of naloxone on the subjective and psychomotor effects of nitrous oxide in humans. Pharmacol Biochem Behav 49: 573-8

Zacny JP, Hill JL, Black ML, Sadeghi P (1998) Comparing the subjective, psychomotor and physiological effects of intravenous pentazocine and morphine in normal volunteers. J Pharmacol Exp Ther 286: 1197-207

Zacny JP, Janiszewski D, Sadeghi P, Black ML (1999) Reinforcing, subjective, and psychomotor effects of sevoflurane and nitrous oxide in moderate-drinking healthy volunteers. Addiction 94: 1817-28

Zacny JP, Lichtor JL, Coalson DW, Apfelbaum JL, Flemming D, Foster V (1994b) Time course of effects of brief inhalations of nitrous oxide in normal volunteers. Addiction 89: 831-9

Zacny JP, Lichtor JL, Flemming D, Coalson DW, Thompson WK (1994c) A dose-response analysis of the subjective, psychomotor and physiological effects of intravenous morphine in healthy volunteers. J Pharmacol Exp Ther 268: 1-9 


\section{CHAPTER 3}

\section{VISUAL SEARCH AND URBAN CITY DRIVING UNDER THE INFLUENCE OF MARIJUANA AND ALCOHOL*}

\section{* Published as:}

Lamers CTJ, Ramaekers JG (2001) Visual search and urban city driving under the influence of marijuana and alcohol. Human Psychopharmacology Clinical and Experimental 16: 393401 


\section{SUMMARY}

The purpose of present study was to assess the effects of low doses of marijuana and alcohol, and their combination, on visual search at intersections and on general driving proficiency in a City Driving Test. Sixteen recreational users of alcohol and marijuana (eight males and eight females) were treated with these substances or placebo according to a balanced, 4-way, cross-over, observer- and subject-blind design. On separate evenings, subjects received weight-calibrated doses of THC, alcohol or placebo in each of the following treatment conditions: alcohol placebo + THC placebo, alcohol + THC placebo, THC $100 \mu \mathrm{g} / \mathrm{kg}+$ alcohol placebo, THC $100 \mu \mathrm{g} / \mathrm{kg}+$ alcohol. Alcohol doses administered were sufficient for achieving blood alcohol concentrations of about $0.05 \mathrm{~g} / \mathrm{dl}$. Initial drinking preceded smoking by one hour. The City Driving Test commenced 15 min after smoking and lasted 45 minutes. The test was conducted over a fixed route within the city limits of Maastricht. An eye movement recording system was mounted on the subjects' head for providing relative frequency measures of appropriate visual search at intersections. General driving quality was rated by a licensed driving instructor on a shortened version of the Royal Dutch Tourist Association's Driving Proficiency Test. After placebo treatment subjects searched for traffic approaching from side streets on the right in $84 \%$ of all cases. Visual search frequency in these subjects did not change when they were treated with alcohol or marijuana alone. However when treated with the combination of alcohol and marijuana, the frequency of visual search dropped by $3 \%$. Performance as rated on the Driving Proficiency Scale did not differ between treatments. It was concluded that the effects of low doses of THC $(100 \mu \mathrm{g} / \mathrm{kg})$ and alcohol $(\mathrm{BAC}<0.05 \mathrm{~g} / \mathrm{dl})$ on higher level driving skills as measured in the present study are minimal.

\section{INTRODUCTION}

Findings from the 1996 National Household Survey of Drug Abuse (NHSDA) suggest that more than a quarter of the 166 million drivers aged 16 and older in the United States occasionally drive under the influence of alcohol and/or marijuana (Townsend et al. 1998). Of the 11847 respondents, $23 \%$ (representing 38 million drivers) reported that they had driven within two hours of consuming alcohol in the past year. Five percent of the respondents, representing approximately 8.9 million people, reported having driven after the use of marijuana. In addition, more than $80 \%$ of the latter reported the combined use of marijuana and moderate doses of alcohol (blood alcohol concentration $(B A C)<0.08 \mathrm{~g} / \mathrm{dl}$ ). These drivers subjectively felt that marijuana with or without alcohol did not affect their ability to drive safely or their likelihood of being stopped by the police.

Subjective impressions should never be taken as conclusive evidence for determining the effect of $\Delta^{9}$-tetrahydrocannabinol (THC) on driving ability, especially as most 
epidemiological surveys have revealed the presence of marijuana in roughly $4-12 \%$ of drivers injured or killed in traffic accidents (Budd et al. 1989; Chesher and Starmer 1983; Cimbura et al. 1982; Cimbura et al. 1980; Daldrup et al. 1987; Donelson et al. 1985; Garriott et al. 1986; McLean et al. 1987; Soderstrom et al. 1988; Terhune 1982; Williams et al. 1985) (Terhune et al. 1992). If the population at risk is indeed about $4 \%$ as indicated by the NHSDA survey, this injury/fatality rate must be taken to indicate that the users of drugs are overrepresented among crash victims. It is doubtful, however, that THC was the only factor responsible for the crashes, because alcohol was also present in the majority of survey victims showing any plasma concentration of THC. This may indicate that THC in combination with alcohol possesses a greater risk potential than either of these substances alone.

Several experimental studies have been conducted to assess the separate and combined effects of THC and alcohol in driving simulators (Liguori et al. 1998; Smiley et al. 1981; Stein et al. 1983), closed-course driving test (Attwood et al. 1981; Casswell 1979; Peck et al. 1986; Smiley 1987) and driving tests in normal traffic (Ramaekers et al. 2000; Robbe 1998). To a large extend, the results from experimental studies are in line with epidemiological findings. They indicate that THC in single doses up to $250 \mu \mathrm{g} / \mathrm{kg}$ has relatively minor effects on driving performance, certainly less than BACs in the range of 0.08 to $0.1 \mathrm{~g} / \mathrm{dl}$. The combined effects of THC doses and social doses of alcohol were essentially additive. They were no greater than the sum of effects that each drug produced separately. Still, the magnitude of impairment observed after combinations of THC and alcohol were sometimes large. Our research group (Ramaekers et al. 2000; Robbe 1998) showed that lowto-moderate THC doses combined with low alcohol doses are as, or more, impairing than BACs around the legal limit $(0.08 \mathrm{~g} / \mathrm{dl}$ in most American states). Doses of $100 \mu \mathrm{g} / \mathrm{kg}$ and $200 \mu \mathrm{g} / \mathrm{kg}$ THC, in combination with small amounts of alcohol (BAC $<0.04 \mathrm{~g} / \mathrm{dl}$ ), impaired highway driving performance in a road tracking test and to a level previously observed in social drinkers conducting the same tests with $\mathrm{BAC}$ of $0.09 \mathrm{~g} / \mathrm{dl}$ and $0.14 \mathrm{~g} / \mathrm{dl}$ respectively. The objective of the present study was to determine whether a low dose of THC in combination with a low dose of alcohol would also have a significant effect on driving performance in a more complex urban environment. Because the combination of 200 $\mu \mathrm{g} / \mathrm{kg}$ THC and alcohol produced serious driving impairment in our previous study (Ramaekers et al. 2000), the maximal dose was reduced to $100 \mu \mathrm{g} / \mathrm{kg}$ in the present study for safety reasons. The research approach combined retrospective expert rating for assessing drug effects on driving performance and measurement of visual search at intersections through eye movement recordings. The method of using a retrospective expert rating has previously been applied to show the impairing effects of alcohol and diazepam (De Gier 1979; de Gier et al. 1981; Robbe 1994) and the lack of impairing effects of low THC doses (70-120 $\mu \mathrm{g} / \mathrm{kg}$ ) on driving performance (Klonoff 1974; Robbe 1994). Klonoff did find some reduction in the subjects scores on judgement and concentration 
under the influence of $120 \mu \mathrm{g} / \mathrm{kg}$ THC, but behaviours that were more directly related to driving performance were unaffected by THC in both studies.

The rationale for measuring visual search at intersections is that many researchers have demonstrated that THC causes attentional deficits in dual-task situations (Azorlosa et al. 1992; Barnett et al. 1985; Heishman et al. 1989; Marks and MacAvoy 1989; Moskowitz 1985; Perez-Reyes et al. 1988). Dual-tasks or divided attention tasks involve the detection of peripheral signals by subjects who simultaneously perform a task presented on a central display, such as pursuit tracking or counting light flashes. Under the influence of THC subjects were less able to conduct central and peripheral tasks simultaneously. This adverse effect was most notable in the peripheral visual search tasks. It might indicate that drivers under the influence of THC apply their attention more to the main road, partially neglecting traffic coming from side roads. Such narrowing of the attentional field might become particularly dangerous when the driver crosses intersections without right of way, as in many urban or suburban areas.

\section{METHODS}

\section{SUBJECTS}

Sixteen subjects (eight males and eight females) between 21 and 40 yrs of age participated in the study. Initial screening was accomplished on the basis of a questionnaire on medical history and driving experience. Subjects who were accepted were examined by the medical supervisor, who also checked vital signs and took blood and urine samples. Standard blood chemistry, haematological and drug screen tests were conducted on these samples. Inclusion criteria were the possession of a valid driving licence for at least three years, driving experience of at least $5000 \mathrm{~km}$ per year, experience of driving at least once while under the influence of marijuana in the preceding year, Dutch nationality, normal binocular vision (corrected or uncorrected), body weight within 15\% percent of the average for individual's height and weight, use of marijuana and alcohol more than once a month but less than daily and informed consent in writing. Exclusion criteria were a history of treatment for drug or alcohol abuse or current addiction, record of arrest or conviction for drunken driving or drug trafficking, history of psychiatric, neurological, cardiovascular, respiratory, metabolic, hepatic or renal disorders, current use of psychoactive medication, and pregnancy. Subjects were paid an hourly rate for their participation. The characteristics of the 16 subjects who entered the study are displayed in Table 1.

The study's protocol was reviewed and approved by the Medical Ethics Committee of the University of Maastricht and the District Attorney of Maastricht. The subjects were treated according to the code of ethics on human experimentation stated in the Declaration of Helsinki (1964) and its subsequent amendments. 
Table 1. Mean \pm SD (range) of the subject's characteristics

\begin{tabular}{lcccccc}
\hline & \multicolumn{2}{c}{ males } & \multicolumn{2}{c}{ females } & \multicolumn{2}{c}{ Total } \\
\hline & mean $\pm \mathrm{SD}$ & range & mean $\pm \mathrm{SD}$ & range & mean $\pm \mathrm{SD}$ & range \\
\hline Age $(\mathrm{yrs})$ & $22.9 \pm 2.0$ & $21-26$ & $24.3 \pm 3.6$ & $21-32$ & $23.6 \pm 2.9$ & $21-32$ \\
weight $(\mathrm{kg})$ & $74.4 \pm 9.6$ & $62-87$ & $61.7 \pm 2.6$ & $59-68$ & $68.0 \pm 9.4$ & $59-87$ \\
driving experience $(\mathrm{yrs})$ & $4.3 \pm 1.8$ & $3-7$ & $5.3 \pm 2.7$ & $3-11$ & $4.8 \pm 2.2$ & $3-11$ \\
driving experience & $48 \pm 39.7$ & $15-140$ & $42.4 \pm 30.0$ & $15-100$ & $45.2 \pm 34.1$ & $15-140$ \\
$\begin{array}{l}\text { ( 1000km) } \\
\text { \# joints/month }\end{array}$ & $10.4 \pm 9.1$ & $2-24$ & $2.8 \pm 2.1$ & $2-8$ & $6.6 \pm 7.5$ & $2-24$ \\
\# alcohol/week & $13.1 \pm 7.2$ & $2-25$ & $9.3 \pm 5.1$ & $2-15$ & $11.2 \pm 6.4$ & $2-25$ \\
\hline
\end{tabular}

\section{DESIGN, DOSES AND ADMINISTRATION}

The study followed a four-way, double-blind, cross-over design. Treatment orders were balanced and randomly assigned from those residing in four $4 \times 4$, William Squares (Winer 1971). A minimum wash-out period of 7 days transpired between treatments.

Subjects began treatment by drinking alcohol or alcohol-placebo. Then, they smoked the marijuana placebo or marijuana, which delivered THC in a dose of $100 \mu \mathrm{g} / \mathrm{kg}$. All four combinations of alcohol and THC treatment were consumed by each subject on separate occasions: alcohol placebo + marijuana placebo (PLA), alcohol placebo $+100 \mu \mathrm{g} / \mathrm{kg}$ THC (THC), alcohol + marijuana placebo (ALC), and alcohol $+100 \mu \mathrm{g} / \mathrm{kg}$ THC (ALC/THC).

Alcohol was administered as $99.8 \%$ ethanol mixed with orange juice to a volume of $300 \mathrm{ml}$, and consumed within 15 minutes of the consumption a standard meal that consisted of two sandwiches. The alcohol doses were $0.5 \mathrm{~g} / \mathrm{kg}$ body weight for males and $0.43 \mathrm{~g} / \mathrm{kg}$ for females. These were chosen to yield a BAC of $0.04-0.05 \mathrm{~g} / \mathrm{dl}$ at the beginning of the driving test. Subjects' BACs were monitored at 15 minutes intervals for 1 hour after drinking using a Lion SD-4 Breath-Alcohol Analyzer. Those failing to reach the expected peak were given a booster dose of $0.05-0.02 \mathrm{~g} / \mathrm{kg}$ in the same proportion to mixer at 45 minutes after the first dose, whereas others were given the mixer alone.

Smoking followed drinking by 45 minutes and lasted for about 5 minutes. The cigarettes were prepared beforehand for each individual from stock provided by the National Institute of Drug Abuse of the United States. Marijuana cigarettes were prepared from batches containing $2.2 \%$ THC. They were cut to a length appropriate for each subjects' body weight. Placebo cigarettes were similarly shortened. Subjects smoked them as completely as possible trough a plastic holder in their customary fashion. 


\section{TESTING PROCEDURE}

Two subjects were tested per day, one at 7.00 p.m. and one at 8.00 p.m. After their arrival at the laboratory subjects were tested for the presence of alcohol and drugs (methadone, cocaine, amphetamines, opiates, cannabinoids, benzodiazepines and tricyclic antidepressants) in breath and urine respectively. Drinking and smoking commenced at 70 and $25 \mathrm{~min}$, respectively, prior to onset of the driving test. Drinking of the booster dose directly followed the smoking. Subjects' BACs were determined at the start and conclusion of the City Driving Test (duration 40 minutes) while they completing a number of questionnaires.

Successive test sessions for particular subjects were ordinarily scheduled at weekly intervals. They were forbidden from smoking marijuana or hashish outside the study, or from taking any other illicit drug, from 7 days before their first session until the conclusion of the last. They were told that detection of any drug in urine samples provided at the beginning of each session would cause their immediate dismissal. They were similarly forbidden from drinking alcohol $24 \mathrm{~h}$ before sessions. They were instructed to keep normal sleeping times. Consumption of beverages containing caffeine was prohibited during sessions.

\section{The City Driving TEST}

The City Driving Test in the current study largely followed standard procedures from a previous version (Robbe 1994). Driving tests were conducted in the evening over a constant route $( \pm 15 \mathrm{~km})$ within the city of Maastricht. The route went through business and residential areas on mostly 2-lane undivided streets and included a $5 \mathrm{~km}$ 4-lane divided segment on a major cross-city thoroughfare. Manoeuvres included left and right turns at some intersections and driving through others, left and right lane changes, responding to traffic control devices, and a turn on a residential street.

A shortened version of the Royal Dutch Tourist Association (ANWB) Driving Proficiency Test was used for rating the drivers' performance after each test. In total, 90 items were scored dichotomously as either 'pass' or 'fail'. The total test performance was the percentage of items scored as 'pass'. Sub-scores were calculated for vehicle checks, vehicle handling, traffic manoeuvres, observation and understanding traffic, and turning.

Eye movements were recorded during all tests using a head mounted eye tracking system (4000SU Eye Tracker, Applied Science Laboratories, Bedford, MA, USA). The eye-tracker is designed to accurately measure a freely moving subject's eye line of gaze with respect to the head. The eye is illuminated by a beam from an infra-red light source, and an optical system focuses an image of the pupil onto a solid-state eye camera. Both the illumination beam and the image of the eye are reflected from a helmet visor which is coated so as to be reflective in the near infrared region and transitive to visible light. Pupil and comeal reflections outlines and centroids (i.e. centres of reflection marked by ctoss hairs) are displayed on a pupil monitor over the video image of the eye. A second miniature camera is focussed on the subject's forward scene of vision. The line of gaze is represented on a 
monitor as a set of cross hairs superimposed on the image from this scene camera. The illuminator, optical system and both cameras are all helmet mounted (see Figure 1). Video recordings of the subject's line of gaze during the driving tests are used to determine their visual search for vehicles proceeding with right of way on the right at 58 intersections along the route. The number of times a subject checked for traffic at intersections was taken as the dependent variable.

Fig. 1. The right panel shows the subject wearing the head-mounted eye tracking system consisting of an infrared and optical camera system for registering the subjects' eye line of gaze (striped lines) and the forward visual scene (solid line). The left panel shows the eye line of gaze on a scene monitor as a set of cross hairs superimposed on the image from the scene camera.

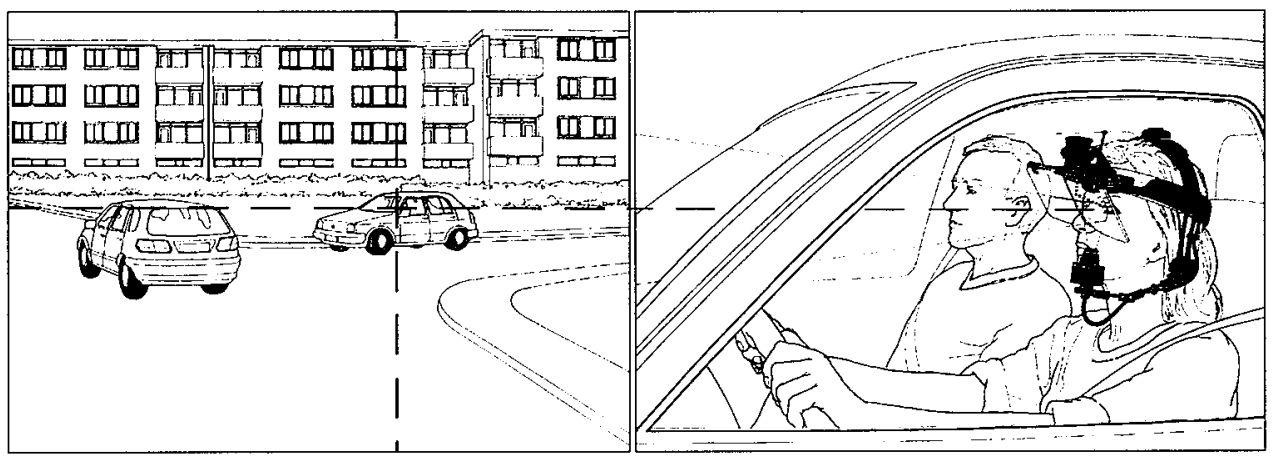

Driving tests were conducted in a dual-control, Volkswagen Golf estate car. Two persons accompanied the subject: a licensed driving instructor sitting in the front passenget seat and an assistant sitting in the centre of the rear seat. The former had access to redundant controls and his primary responsibilities were controlling safety and retrospectively rating the driver's performance. The observer in the rear seat operated and monitored the eye tracking system. All subjects received a full dress-rehearsal of the driving test.

\section{QUESTIONNAIRES}

Prior to the driving test, subjects were asked about their willingness to drive in three different situations: a) unimportant though gratifying, such as transporting a friend to a party, b) important but avoidable, such as transporting a mildly sick friend home when he would otherwise have to call a taxi, c) urgent, such as transporting a severely sick child to the hospital. Visual-analogue scales for measuring subjective feelings of intoxication ('high' and 'drunkenness') and mental effort while performing the test (Zijlstra and L. 1985) were administered at the onset and after the conclusion of the driving test. In addition, subjects were asked to retrospectively rate their perceived driving quality on a $10 \mathrm{~cm}$ visual analogue scale. Mood was assessed using Bond and Lader's (1974) (Bond and Lader 1974) series of 
16 visual-analogue mood scales; the authors' procedures were followed for deriving three statistically independent scores for alertness, calmness and contentment.

\section{STATISTICAL ANALYSIS}

Because most data did not pass the requirements for conducting parametric statistics, as indicated by Mauchly sphericity tests, all variables measured on interval or ratio level were analysed by means of non-parametric tests. Friedman tests were used for detecting an overall difference between treatments. These were followed by Wilcoxon's signed-rank tests to analyze each drug-placebo comparison separately. Willingness-to-drive data were analyzed to assess differences between the three drug conditions (THC and ALC/THC) and placebo condition (PLA) using Cochran's Q-test.

\section{RESULTS}

\section{MISSING DATA}

One subject did not complete questionnaires on mood, perceived driving quality and effort questionnaires during treatment with alcohol.

\section{INTOXICATION}

Mean BACs at the onset of the driving test were practically identical after both ALC and the ALC/THC treatments: 0.042 and $0.041 \mathrm{~g} / \mathrm{dl}$ respectively. Amount of decline in BAC over the course of the driving tests were also comparable: 0.007 and $0.006 \mathrm{~g} / \mathrm{dl}$ respectively. Perceived levels of drunkenness and highs differed between treatments $\left(\chi^{2}>10.9 ; p<.012\right)$. Few subjects reported intoxication after PLA, and their average levels were about $5 \%$ of maximum perceived level. After receiving THC or ALC, mean intoxication levels rose to about $26 \%$ at the beginning of the driving test. At the conclusion, intoxication levels declined to $10 \%$ in ALC but were virtually unchanged in THC condition. Combined treatment (PLA/THC) produced similar levels of perceived high as in the THC condition, whereas mean levels of drunkenness were about $37 \%$ and thus slightly higher than with ALC. The declines in intoxication levels after ALC/THC were similar to those observed in the separate treatments. Wilcoxon's signed-rank tests showed that ratings of intoxication after all drug treatments were significantly different from PLA both before $(Z>-2.9 ; \mathrm{p}<$ $.006)$ and after driving $(\mathrm{Z}>2.5 ; \mathrm{p}<.001)$. 


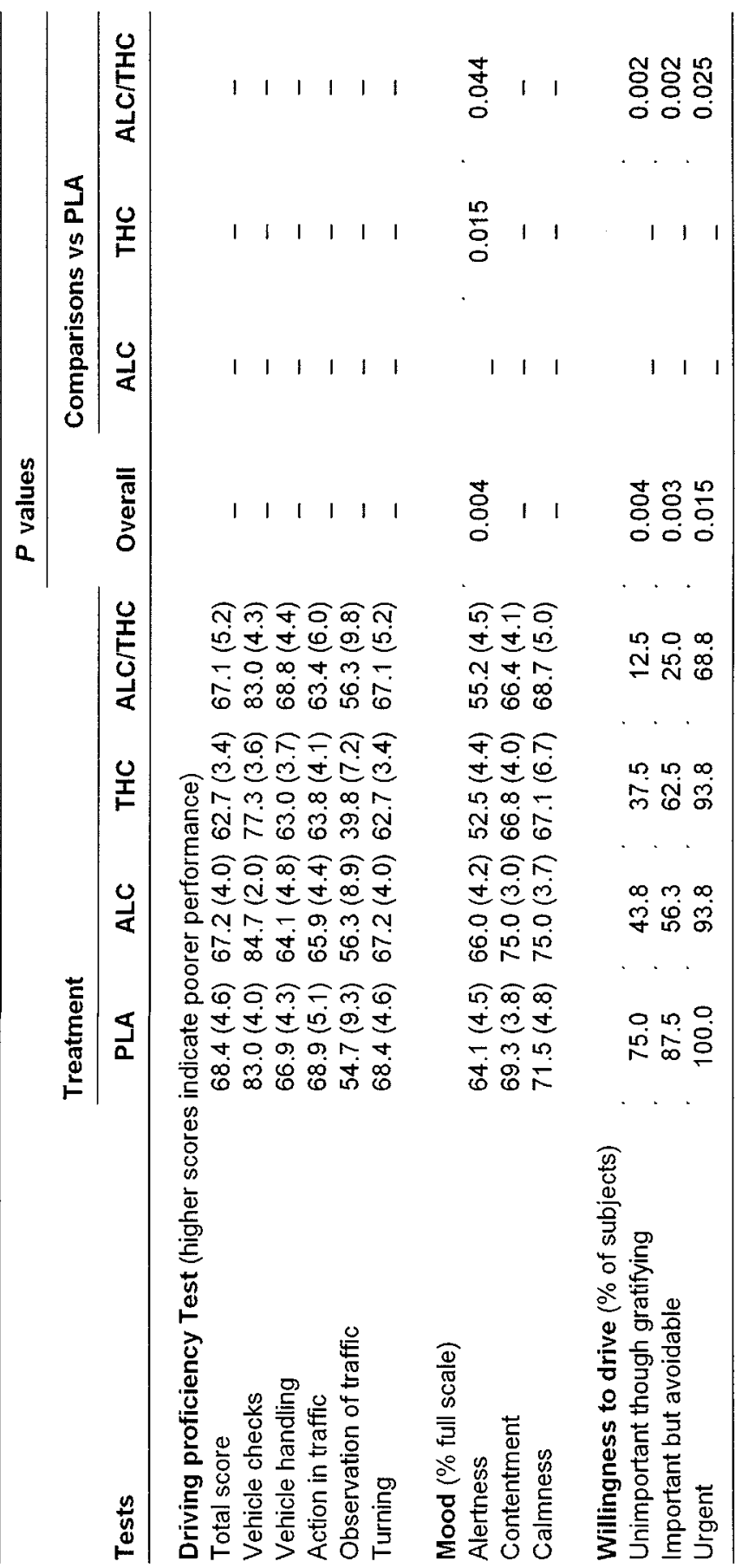




\section{DRIVING PERFORMANCE}

Means of all performance variables of the Driving Proficiency Test and the results from statistical analyses are given in Table 2. Treatment (THC, ALC or ALC/THC) did not significantly affect the total score or any of the component scores. An apparent change in the performance on the sub-score 'observation of traffic' after 'THC was only of marginal significance $(\mathrm{p}=0.088)$.

The mean frequency of intersections at which traffic was searched for was about $84 \%$ during placebo treatment. Treatment with ALC or THC did not significantly affect the subjects' visual search frequency compared with placebo. However, ALC/THC reduced visual search frequency, by about $3 \%(Z>-2.05 ; p<.041)$. Decline in search frequency was most pronounced in female subjects $(-7 \%)$ than in males $(0.3 \%)$, but the effect of gender was only marginally significant $(\mathrm{p}=0.09)$. According to the Wilcoxon's signed ranks test 12 subjects (75\% 7 females and 5 males) performed less well after ALC/THC compared with PLA. Decline in visual search frequency was thus not limited to females, but the occurrence and amount of impairment were less consistent in males. Mean (SE) search frequencies for each treatment condition are shown in Figure 2.

Figure 2. Mean (SE) frequencies of visual search for traffic at intersections

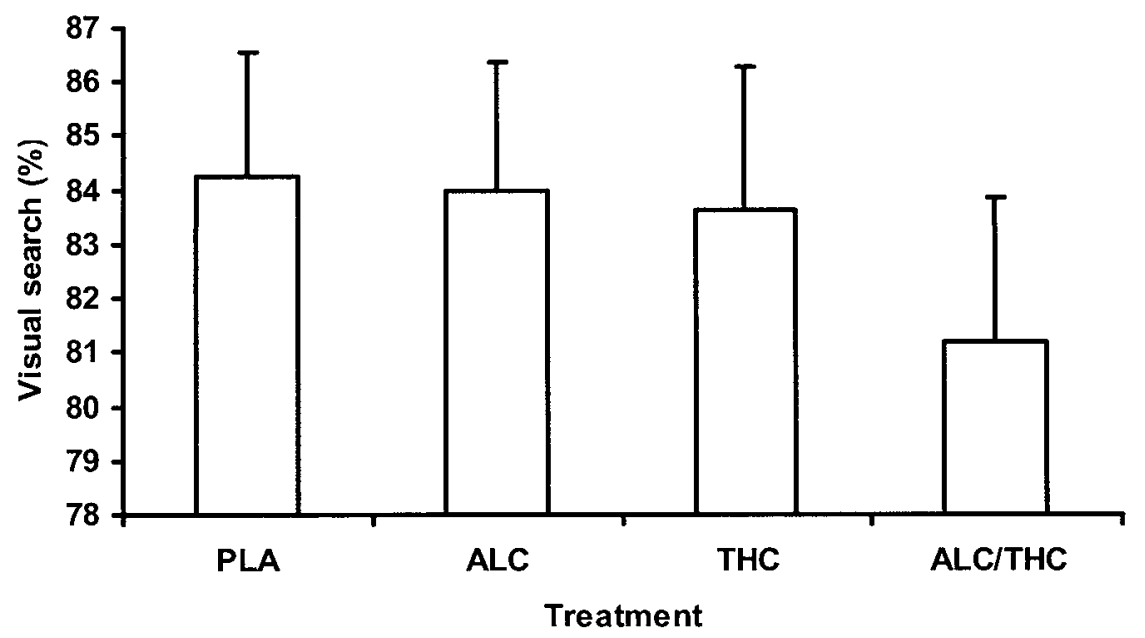

\section{Questionnaires}

Mean (SE) ratings of perceived driving performance and perceived effort are shown in figures 3 and 4 respectively. The subjects' rating of their driving performance was 
significantly lower in the THC condition compared with PLA $(Z=-2.51 ; p=0.012)$. Subjects also perceived that higher levels of effort were needed to perform the driving test in the THC condition, compared with PLA ( $Z=-2.327 ; p=0.20)$. ALC and ALC/THC did not significantly alter the subjects' ratings of driving performance and effort.

Figure 3. Mean (SE) perceived driving performance in the City Driving Test

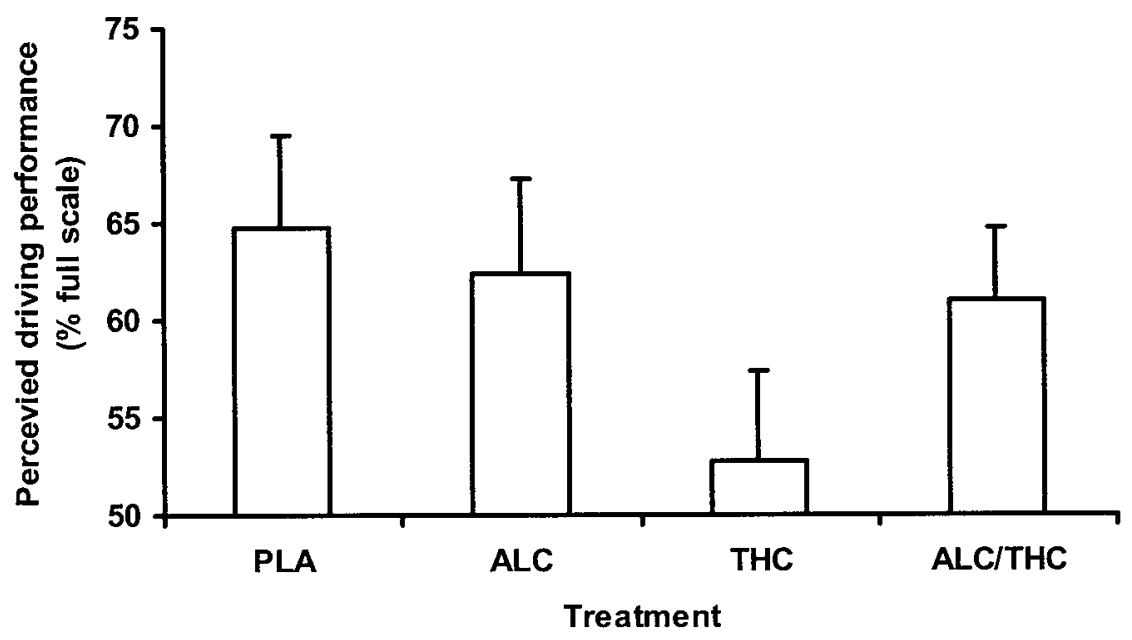

Figure 4. Mean (SE) perceived effort in performing the City Driving Test

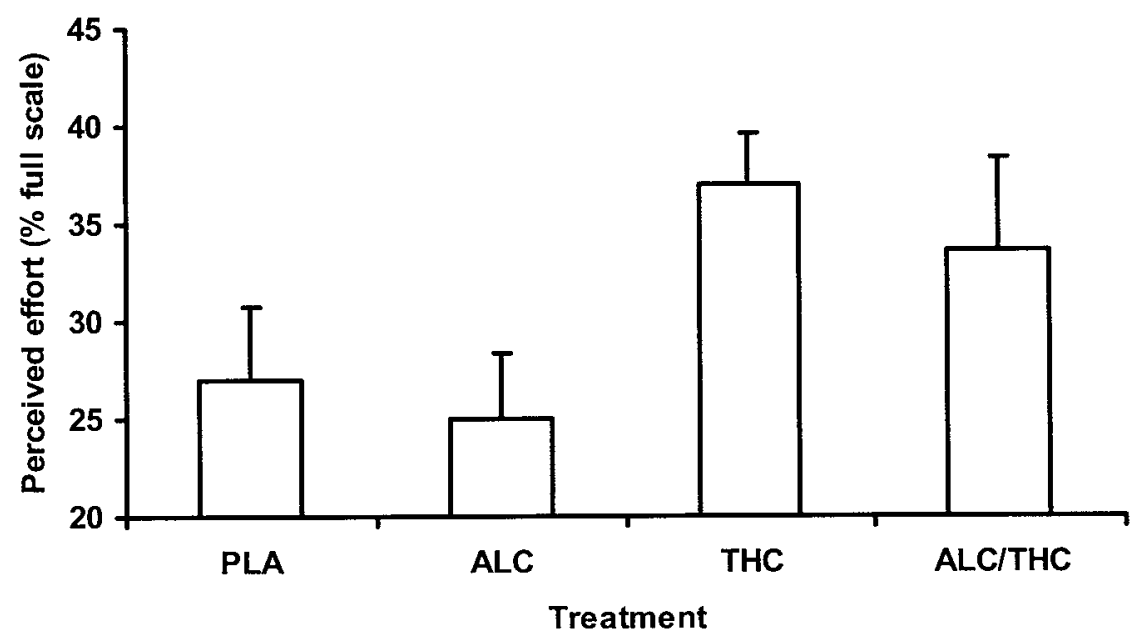


54 | CHAPTER 3

The percentages of the subjects declaring they were willing to driving under different circumstances of lesser or greater urgency are presented in Table 2 . The more urgent the reason for driving, the greater the number of subjects that declared they would be willing to drive. Treatment with THC or ALC did not affect willingness to drive, although there were indications that both THC and ALC reduced the number of subjects willing to drive in unimportant conditions $(\mathrm{Q}=3.6 ; \mathrm{p}=0.058)$ and in important conditions $(\mathrm{Q}=3.57 ; \mathrm{p}=0.059)$ respectively. ALC/THC significantly decreased the subjects' willingness to drive in any circumstance $(\mathrm{Q}>5.0 ; \mathrm{p}<.025)$.

Subjective ratings of alertness, contentment and calmness are shown in Table 2. Feelings of alertness were significantly diminished after treatment with THC $(Z=-2.43 ; p=0.02)$ and after ALC/THC ( $\mathrm{Z}=-2.02 ; \mathrm{p}=0.04)$. Relative to placebo, alertness declined by $18 \%$ in the THC condition and by $14 \%$ in ALC/THC. Statistical tests revealed no significant treatment effects on contentment and calmness.

\section{DISCUSSION}

The main objective of the present study was to measure the effects of a low dose of THC with and without a low dose of alcohol on driving proficiency of recreational users of marijuana and alcohol. The selected doses of THC and alcohol were comparable to those that produced practically no impairment in previous driving studies (Klonoff 1974; Robbe 1994). It was hypothesized that relatively low doses of THC and alcohol may still become hazardous to driving proficiency when taken together.

The results of the present study went in the expected directions. According to the instructor's rating neither THC nor alcohol alone affected the subjects' driving performance. The subjects' visual search for traffic at intersections also remained unaffected in the presence of each drug given alone. The combination of THC and alcohol slightly impaired the subjects' performance in the driving test. Alcohol plus THC reduced the mean search frequency for traffic at intersections by about 3\%. The central driving task as measured by the instructor's rating of driving proficiency was not affected by alcohol plus THC. Apparently, subjects were less able to detect peripheral traffic while trying to effectively perform the central driving task when under the influence of alcohol and THC together. They were not able or chose not to divide their attention equally over both subtasks, but focussed on the central driving task instead. This corroborates results from previous simulator and laboratory studies that show adverse effects of THC and alcohol on subsidiary task performance (Moskowitz 1973; Ramaekers et al. 1996; Smiley 1986). In these studies, where peripheral search or recognition tasks were combined with a visual central tracking task, the greater error always occurred in the peripheral task. This is due not to a direct drug effect on the peripheral task itself but to a focusing on the central task. In the actual driving situation of the present study, for example, the constant demands of the 
ongoing central driving task may overshadow the intermittent demands of the peripheral search task, particularly in the presence of drugs.

In females, search frequency at intersections dropped with a remarkable $7 \%$ after alcohol plus THC. However, this apparent interaction between gender and treatment failed to reach statistical significance $(\mathrm{p}=0.09)$. It is possible that females in the current sample may have been more sensitive to the drugs' effects. Inspection of demographic data of the present study shows that females were less experienced THC smokers than the males: On average, the females smoked about three THC cigarettes (range 2-8) per month, whereas the latter group consumed about 10 (range 2-24). The possibility, therefore, exists that males had driven more often under the influence of THC and developed more behavioural tolerance or task specific learning to compensate for the drugs' impairing influence on performance (Young and Góudie 1994).

There were other differences between the subjects' reactions to the drugs compared with placebo. Subjects felt less alert and invested more effort in the test while driving under the influence of THC. They also rated their driving performance as being significantly worse after THC than placebo. In contrast, alcohol did not affect their subjective ratings of alertness, effort and driving proficiency. These results indicate that subjects were aware of the impairing properties of THC but not of alcohol. Consequently, they were more cautious during the driving test following THC. Previous studies of driving on the road have also demonstrated that subjects are generally aware of the impairing properties of THC and try to compensate by driving more carefully (Casswell 1979; Hansteen et al. 1976; Peck et al. 1986; Robbe 1994). However, subjects were no longer aware of the impairing properties of THC when they also took alcohol. Their ratings of perceived driving proficiency and effort after combined use were similar to their ratings after placebo. It is of interest that feelings of drunkenness were stronger than feelings of high during the combined treatment. Levels of drunkenness rose by $12 \%$, but levels of high did not change compared with when the drugs were given alone. These findings support earlier notions that drivers become overconfident during drunkenness and more cautious and self-critical while in a state of high (Bates and Blakely 1999; Robbe 1994). If so, the differences in driving performance observed during treatment with THC and THC in combination with alcohol might follow from the subjects' desire to compensate for detrimental effects in one condition but not in the other.

These impressions were somewhat contradicted by the subjects' responses indicating their willingness to drive after drugs and placebo. Between $12 \%$ and $25 \%$ of the subjects said they would have been willing to drive for less than urgent reasons after the combined use of THC and alcohol. The validity of willingness-to- drive ratings has been questioned because of subjects' desire to give socially desirable answers (Robbe 1994). Indeed, all subjects in the present study admittedly to having driven under the influence of marijuana, alcohol or both toghether on previous occasions. At these times, impairment may also have been more severe, since perceived levels of intoxication in the current study were far below the maximum. 
It is clear from the present results that the effects of low doses of marijuana and alcohol on urban driving proficiency and visual search were mild. Yet it is well to remember that the dose of neither drug was particularly high. The marijuana dose was only a third of the dose preferred by cannabis smokers (Robbe 1998), whereas the alcohol dose produced BACs that were well below the legal limit in most countries. One can safely assume that drivers in the real world occasionally drive after consuming more of either or both in combination. If they do, our results suggest that their frequency of visual search for traffic would be considerably less than observed in the present study.

However, the low dose of THC is not the only explanation for the absence of a strong drug effect in the present study. As mentioned in the introduction, the performance-impairing properties of $100 \mu \mathrm{g} / \mathrm{kg}$ THC with and without a small amount of alcohol have already been demonstrated in an previous driving study conducted by our group (Ramaekers et al. 2000). There is no reason to believe that THC and alcohol produced less impairment in the subjects of the present study. The subjects' BACs were identical in both studies, i.e between 0.05 and $0.035 \mathrm{mg} / \mathrm{dl}$, as were mean subjective intoxication ratings after $100 \mu \mathrm{g} / \mathrm{kg}$ THC, i.e. $29 \%$ and $26 \%$.

The main difference between our studies lies in the separate cognitive demands of the three actual driving tests that we employed for measuring the effects of THC and alcohol. The Road Tracking Test and the Car-Following Test in the previous study specifically measure aspects of driving at the operational level, i.e. tracking and speed adjustment, and the manoevring level, i.e. distance keeping and breaking, respectively. The City Driving Test measures aspect of driving at the manoevring level as well as the strategic level. The latter includes observation and understanding of traffic, risk assessment and planning. It is assumed that the strategic and manoevring levels are particularly demanding of resources in that they require effortfull processing and attention. Thus processing is comparatively slow and inherently flexible. In contrast, the operational level is considered to be an automatic, routine process which is fast and relatively inflexible (Sanders 1986).

An evaluation of the results of both studies shows that THC alone produced significant impairment in the Road Tracking Test only and left performance in the Car Following and the City Driving Test relatively unaffected. Likewise, impairment of road tracking performance increased to unacceptable levels when alcohol was added, but performance impairment after the combination of drugs was minimal to moderate in both the other driving tests. Together these results may indicate that THC, or its combination with a low alcohol dose specifically impair driving skills that are operated at a lower, automatic level. This is not to say that THC or alcohol can never affect any higher level driving skills under any circumstance. With increasing doses all driving skills at any hierarchical level will eventually deteriorate, starting from the lower levels. Consequently, the results of the present study should not be interpreted in isolation as showing that THC or alcohol produces minimal driving impairment. Rather, our results may be taken to indicate at which dose THC and alcohol begin to impair higher-level driving skills. These effects are 
independent from and additional to driving impairment that can be observed at the operational level after the same doses of THC and alcohol. We therefore conclude that low doses of THC and alcohol produce minimal effects on higher level driving skills. Yet these may still become potentially dangerous in traffic situations when superimposed on coexisting impairment of operational driving skills.

\section{ACKNOWLEDGEMENT}

The research was sponsored by the US National Highway Traffic Safety Administration (NHTSA).

\section{REFERENCES}

Attwood DA, Williams RD, Bowser JS, McBurney LJ, Frecker RC (1981) The effects of moderate levels of alcohol and marijuana, alone and in combination on closed-course driving performance. Defence and Civil Institute of Environmental Medicine, Downsview, Ontario

Azorlosa JL, Heishman SJ, Stitzer ML, Mahaffey JM (1992) Marijuana smoking: effect of varying delta 9-tetrahydrocannabinol content and number of puffs. J Pharmacol Exp Ther 261: 114-22

Barnett G, Licko V, Thompson $T$ (1985) Behavioral pharmacokinetics of marijuana. Psychopharmacology (Berl) 85: 51-6

Bates MN, Blakely TA (1999) Role of cannabis in motor vehicle crashes. Epidemiol Rev 21: 222-32

Bond A, Lader M (1974) The use of analogue scales in rating subjective feelings. British Journal of Medical Psychology 23: 211-218

Budd RD, Muto JJ, Wong JK (1989) Drugs of abuse found in fatally injured drivers in Los Angeles County. Drug Alcohol Depend 23: 153-8

Casswell S (1979) Cannabis and alcohol: Effects on closed course driving behaviour. In: Johnston I (ed) Seventh International Conference on Alcohol, Drugs and Traffic Safety. Proceedings. Australian Government Publishing Service, Canberra., Melbourne 23-28 January 1977.

Chesher GB, Starmer GA (1983) Cannabis and human performance skills. Drug and Alcohol Authority Research, Sydney, Australia, NSW

Cimbura G, Lucas DM, Bennett RC, Warren RA, Simpson HM (1982) Incidence and toxicological aspects of drugs detected in 484 fatally injured drivers and pedestrians in Ontario. J Forensic Sci 27 : 855-67

Cimbura G, Warren RA, R.C. B, Lucas DM, Simpson HM (1980) Drugs detected in fatally injured drivers and pedestrians in the province of Ontario. Traffic Injury Research Foundation of Canada, Ottawa

Daldrup T, Reudenbach G, Kimm K (1987) Cannabis und Alkohol im Strassenverkehr. Blutalkohol 24: 144-56

De Gier JJ (1979) A subjective measurment of the influence of ethyl/alcohol in moderate doses on real driving performances. Blutalkohol 16: 363-370

de Gier JJ, t Hart BJ, Nelemans FA, Bergman H (1981) Psychomotor performance and real driving performance of outpatients receiving diazepam. Psychopharmacology (Berl) 73: 340-4

Donelson AC, Cimbura G, Bennett RC, Lucas DM (1985) The Ontario monitoring project: Cannabis and alcohol use among drivers and pedestrians fatally injured in motor vehicle accidents from March 1982 through July 1984. Traffic Injury Research Foundation of Canada, Ottawa, Canada

Gatriott JC, Di Maio VJ, Rodriguez RG (1986) Detection of cannabinoids in homicide victims and motor vehicle fatalities. J Forensic Sci 31: 1274-82 
Hansteen RW, Miller RD, Lonero L, Reid LD, Jones B (1976) Effects of cannabis and alcohol on automobile driving and psychomotor tracking. Ann N Y Acad Sci 282: 240-56

Heishman SJ, Stitzer ML, Yingling JE (1989) Effects of tetrahydrocannabinol content on marijuana smoking behavior, subjective reports, and performance. Pharmacol Biochem Behav 34: 173-9

Klonoff H (1974) Marijuana and driving in real-life situations. Science 186: 317-24

Liguori A, Gatto CP, Robinson JH (1998) Effects of marijuana on equilibrium, psychomotor performance, and simulated driving. Behav Pharmacol 9: 599-609

Marks DF, MacAvoy MG (1989) Divided attention performance in cannabis users and non-users following alcohol and cannabis separately and in combination. Psychopharmacology (Berl) 99: 397401

McLean S, Parsons RS, Chesterman RB, Dineen R, Johnson MG, Davies NW (1987) Drugs, alcohol and road accidents in Tasmania. Med J Aust 147: 6-11

Moskowitz H (1973) Laboratory studies of the effects of alcohol on some variables related to driving. Journal of Safety Research 5: 185-199

Moskowitz H (1985) Marihuana and driving. Accid Anal Prev 17: 323-45.

Peck RC, Biasotti A, Boland PN, Mallory C, et al. (1986) The effects of marijuana and alcohol on actual driving performance. Alcohol, Drugs and Driving 2: 135-154

Perez-Reyes M, Hicks RE, Bumberry J, Jeffcoat AR, Cook CE (1988) Interaction between marihuana and ethanol: effects on psychomotor performance. Alcohol Clin Exp Res 12: 268-76

Ramaekers JG, Muntjewerff ND, Uiterwijk MMC, van Veggel LMA, et al. (1996) A study of the pharmacodynamic interaction between befloxatone and ethanol on performance and mood in healthy volunteers. Journal of Psychopharmacology 10: 288-294

Ramaekers JG, Robbe HW, O'Hanlon JF (2000) Marijuana, alcohol and actual driving performance. Hum Psychopharmacol 15: 551-558

Robbe H (1998) Marijuana's impairing effects on driving are moderate when taken alone but severe when combined with alcohol. Human Psychopharmacology Clinical and Experimental 13: S70-S78

Robbe HWJ (1994) Influence of Marijuana on Driving. University of Maastricht, University of Maastricht

Sanders AF (1986) Drugs, driving and the measurement of human performance. In: O'Hanlon JF, De Gier JJ (eds) Drugs and Driving. Taylor and Francis, London, pp 3-16

Smiley A (1986) Marijuana: On-road and driving simulator studies. Alcohol, Drugs and Driving 2: 121 134

Smiley AM (1987) The effects of marijuana alone and in combinationa with alcohol on driving performance. In: Noordzij PCaR, R. (ed) Proceedings of the 10th International Conference on Alcohol, Drugs and Traffic Safety, September 9-12, 1986. Excerpta Medica, Amsterdam, Amsterdam, The Netherlands, pp 203-206

Smiley AM, Moskowitz H, Ziedman K (1981) Driving simulator studies of marijuana alone and in combination with alcohol Proceedings of the 25th Conference of the American Association for Automotive Medicine., ?, pp 107-116

Soderstrom CA, Trifillis AL, Shankar BS, Clark WE, Cowley RA (1988) Marijuana and alcohol use among 1023 trauma patients. A prospective study. Arch Surg 123: 733-7

Stein AC, Allen RW, Cook ML, Karl RL (1983) A Simulator Study of the Combined Effects of Alcohol and Marijuana on Driving Behavior. System Technology Inc., Hawthorne, CA

Terhune KW (1982) The role of alcohol, marijuana and other drugs in the accidents of injured drivers. Calspan Field Services Inc., Buffalo, New York

Terhune KW, Ippolito CA, Hendriks DL, Michalovic JG (1992) The incidence and role of drugs in fatally injured drivers. National Highway Traffic Safety Administration, Washington DC

Townsend TN, Lane J, Dewa S, Brittingham AM (1998) Driving after drug or alcohol use: findings from the 1996 National Household Survey on Drug Abuse. National opinion Research Center, Chicago, Illinois, pp 119 
Williams AF, Peat MA, Crouch DJ, Wells JK, Finkle BS (1985) Drugs in fatally injured young male drivers. Public Health Rep 100: 19-25

Winer BJ (1971) Statistical principles in experimental design. McGraw-Hill, McGraw-Hill

Young AM, Goudie AJ (1994) Adaptive processes regulating tolerance to behavioral effects of drugs. In: Bloom FE, Kupfer DJ (eds) Psychopharmacology: The fourth Generation of Progress. Raven Press, New York

Zijlstra FRH, L. VD (1985) The construction of a Scale to Measure Perceived Effort. University of Delft, The Netherlands, Delft 



\section{CHAPTER 4}

\section{DISSOCIABLE EFFECTS OF A SINGLE DOSE OF ECSTASY (MDMA) ON PSYCHOMOTOR SKILLS AND ATTENTIONAL PERFORMANCE*}

* Published as:

Lamers CTJ, Ramaekers JG, Muntjewerff ND, Sikkema K, Samyn N, Read NL, Brookhuis KA, Riedel WJ (2003) Dissociable effects of a single dose of MDMA on psychomotor skills and attentional performance. Journal of Psychopharmacology 17: 369-377 


\begin{abstract}
土3,4-methylenedioxymethamphetamine (MDMA; ecstasy), a psychoactive recreational drug widely used by young people visiting dance parties and has been associated with poor cognitive function. The current study assessed the influence of a single dose of MDMA 75 $\mathrm{mg}$ and alcohol $0.5 \mathrm{~g} / \mathrm{kg}$ on cognition, psychomotor performance and driving-related task performance. Twelve healthy recreational ecstasy users participated in an experimental study conducted according to a double-blind, double-dummy, placebo-controlled three-way crossover design. MDMA improved psychomotor performance, such as movement speed and tracking performance in a single task, as well as in a divided attention task. MDMA impaired the ability to predict object movement under divided attention. However, the inability to accurately predict object movement after MDMA may indicate impairment of particular performance skills relevant to driving. There was no effect of MDMA on visual search, planning or retrieval from semantic memory.
\end{abstract}

\title{
INTRODUCTION
}

The party drug $\pm 3,4$-Methylenedioxymethamphetamine (MDMA; ecstasy) is structurally related to mescaline and stimulant drugs such as amphetamines (de Man 1994; Morgan $2000)$. The widespread use of ecstasy ( $\pm 3,4$-methylene-dioxymethamphetamine; MDMA) by young people causes concern, especially due to its associated risk of traffic accidents (Henry et al. 1992). Epidemiological research and case studies have shown that impaired judgement and higher risk taking are the most likely contributors to methamphetamine-related traffic accidents (Schifano 1995; Logan and Couper 2001). However, no experimental studies addressing the relation between MDMA and driving performance have been reported to date. Previous psychopharmacological publications about MDMA largely focused on the brain and behaviour (Krystal et al. 1992; McCann et al. 1999; Morgan 1999; Gouzoulis Mayfrank et al. 2000; Verkes et al. 2001), while publications about its acute effects largely focused on its acute medical adverse effects and associated emergency medical affairs (Henry 1992; de Man 1994; Vollenweider Scherpenhuyzen and Vollenweider 1998;). Previous studies that have been conducted under controlled conditions showed that single doses of MDMA (range $0.9-1.9 \mathrm{mg} / \mathrm{kg}$ ) did not affect performance on tasks of immediate recall, digit repetition and selective attention (Downing 1986; Vollenweider et al. 1998). Cami et al (2000) observed slight impairment of performance on the digit-symbol substitution test and esophoria (squinting) in subjects after MDMA $125 \mathrm{mg}$, but not after 75 mg MDMA as compared to placebo. They did not observe a significant effect of a single dose of MDMA (75 or $125 \mathrm{mg}$ ) on simple reaction time as compared to placebo (Cami et al. 2000). 
The present study was designed to further investigate the acute effects of a normal single recreational dose of MDMA (75mg) on psychomotor and cognitive performance in recreational ecstasy users under experimentally controlled conditions. Placebo treatment was used as a passive control. Performance effects were assessed in tests previously shown to be sensitive to a variety of psychoactive drugs covering a wide range of cognitive and psychomotor constructs. In addition, well validated tasks were added to specifically measure the effects of MDMA and alcohol on skills related to driving (Riedel et al. 1995; Ramaekers et al. 1998; Vermeeren and O'Hanlon 1998). Alcohol was chosen as a reference because of its ability to impair driving related skills, even at low doses.

\section{METHODS AND MATERIALS}

\section{SUBJECTS}

Fourteen Dutch recreational users of MDMA were recruited by an advertisement posted in the University of Maastricht and in bars and discotheques in the Maastricht region. Inclusion criteria were experience with ecstasy ( $>4$ times/year) and alcohol consumption (>3 units/week) and a good physical and psychological health. Volunteers were excluded if they had a history of medical or psychiatric illness, alcohol or drug addiction, hypertension and history of severe adverse side effects of MDMA. Subjects underwent a standard medical screening and a shortened version of the Structured Clinical Interview for DSM-IV (Ventura et al. 1998) to confirm absence of any physical illness or Axis I and II diagnoses. Subjects were screened for previous convictions for drug possession or drug trafficking by the public prosecutor. Female volunteers were screened for pregnancy before entering the study and at the beginning of test days. Written informed consent was obtained from all subjects. The subjects were paid for their participation.

The study was conducted according to the declaration of Helsinki (1969) and its subsequent amendments and approval was obtained from the Medical Ethics Committee of the University Hospital of Maastricht.

\section{EXPERIMENTAL DESIGN AND TREATMENT}

The study was conducted according to a double-blind, double-dummy, placebo-controlled, 3-way cross-over design. MDMA, alcohol and placebo were administered on separate occasions spaced at least two weeks apart. On all test days subjects received a solution of 25 $\mathrm{ml}$ of bitter orange syrup in a small cup with or without MDMA $75 \mathrm{mg}$ in a powder form, which had to be consumed at once. They also received a beverage of $500 \mathrm{ml}$ orange juice with or without alcohol, to be consume within 15 minutes. In the alcohol condition, the beverage consisted of $0.5 \mathrm{~g} / \mathrm{kg}$ pure ethanol adjusted to $500 \mathrm{ml}$ with orange juice. That dose was chosen to achieve an estimated Blood Alcohol Concentration (BAC) of approximately $0.4-0.5 \mathrm{mg} / \mathrm{ml}$ (Lamers and Ramaekers 2001). This BAC level was previously shown to 
produce significant performance impairment in tests identical to those in the present studies (Ramaekers et al. 1996). The alcohol-placebo condition was administered as $500 \mathrm{ml}$ of orange juice with a few drops of ethanol on top.

The double-dummy procedure was employed to ensure that subjects were unaware of whether an active drug was delivered via syrup or orange juice.

\section{Performance assessments}

The battery consisted of tests measuring psychomotor skills (critical tracking test, motor choice reaction time), attentional functions (divided attention task, object movement estimation under divided attention, visual search) and executive functions (word fluency, tower of London). Apart from the Word Fluency test, all test administration was computerized and presented on a 17 -inch monitor with subjects sitting approximately 50 $\mathrm{cm}$ from the monitor. In order to minimize learning effects, subjects conducted a practice session of each test several days before entering the experiment.

The Critical Tracking Test (CTT) measures the ability to control an inherently unstable error signal in a 1 st-order compensatory tracking task (jex et al. 1966). Subjects attempt to keep a cursor centred in a target area in the middle of a display using a joystick. The cursor appears at the centre of the screen and tends to move away from the centre. The operator's input introduces error, which is magnified by the system, making it increasingly necessary to respond to the velocity of the cursor as well as its position. Compensatory movements increase in frequency until these lag the cursor's last movement by $180^{\circ}$, whereupon control is lost. The point where this occurs is defined as the 'critical frequency' or lambda-c $\left(\lambda_{c}\right)$ expressed in radians per second $(\mathrm{rad} / \mathrm{sec})$. A single test involves five repetitions of this task, each lasting about 45 seconds. The median value of these trials is taken as the test score. Theoretically, $\lambda_{\mathrm{c}}$ is the reciprocal of the operating delay lag in human closed-loop control. The Divided Attention Task (DAT) assesses the subjects' ability to divide attention between tracking and monitoring tasks performed simultaneously (Moskowitz 1973). The tracking subtask is similar to the CTT described above, except that the error signal velocity is fixed at a constant level: i.e. $50 \%$ of individual's optimal performance during the training sessions $\left(\lambda_{c} / 2\right)$. Tracking error is measured as the average absolute distance $(\mathrm{mm})$ between the cursor's position and display centre over the entire $12 \mathrm{~min}$ tests. The other subtask is of a more cognitive nature and consists of monitoring 24 peripheral LED displays fixed to the four corner sides of the main display. These displays each present numerals, $0-9$, which change asynchronously every 5 seconds. The subject removes his foot from a pedal-switch as quickly as possible after detecting the target numeral, "2". Median correct reaction time (msec) to targets is the second response measure.

The Motor Choice Reaction Time (MCRT) is a test in which reaction time (RT) is studied as a function of task complexity (Houx and Jolles 1993). The subject is presented with a 
computerized panel with one central red and five white buttons. The subject is asked to hold down the central red button until one of the white buttons light up. The response set consisted of pressing the only one button lit up (simple RT), pressing one of three buttons which lit up (choice RT), or pressing the button located to the right of the lit button (incompatible RT). Reaction time was dissected into an initiation phase, (i.e. time from stimulus onset until release of the red button), and a movement phase (i.e. time between release of the red button and pressing the response button). Initiation time represents the time needed for perception, decision and motor planning whereas movement time represents the time needed for actual movement execution. Dependent measures are median initiation time for simple, choice and incompatible RT and median movement time for the three RT tasks together.

The Object Movement Estimation under Divided Attention (OMEDA) consists of a task to estimate time to contact (TTC) of a moving object to a fixed point (Read et al. 2000). The subject is seated in front of a computer screen in which the corners are covered by green triangles and a yellow circle occludes the centre of the screen. The occlusion circle varies in size per trial $(2,100$ or 200 pixels). From one of the corners, a red dot (target) travels towards the centre of the screen. Once it encounters the edge of the occlusion circle, it travels underneath and is no longer visible. For the primary task, the subjects have to indicate at what point in time the target reaches the centre of the computer screen, by pressing a foot pedal. During movement of the target, five geometrical shapes appear; one on top of the occlusion circle and one on top of each of the triangles in the corners. For the secondary task, the subject is required to press a button in case the geometric shape at the occlusion circle matches one of the others. Absolute TTC error (defined as the absolute mean difference between estimated and actual TTC) and the number of correct responses to the geometric targets (divided attention) are the primary and secondary measures. The test was designed to assess effects of diseases and drugs on higher level cognitive functions, including working memory, time-to-contact estimates, collision judgment and divided attention in particular in traffic situations (i.e. intersection approach). Preliminary findings showed a clear detrimental effect of age on OMEDA performance, especially the estimation of time-to-contact (Read et al. 2000). Similar impairments were found when comparing a group of cannabis users with age-matched normal controls (Ward et al. 2000). The Duration of the test is approximately 20-25 minutes.

The original version of the Tower of London (TOL) consists of three coloured balls, which must be arranged on three sticks to match the target configuration on a picture while only one ball can be moved at a time (Shallice 1982). The present version consists of computergenerated images of begin- and end-arrangements of the balls. Every time a ball is moved counts as one step. The subject decides as quickly as possible, whether the end-arrangement can be accomplished in 2, 3, 4 or 5 steps from the begin arrangement by pushing the corresponding number coded button (Owen et al. 1995). Six different versions of this test were assessed balanced over test days and time of assessment per six subjects. Reaction 
times and errors are the main performance measures. A new analytical procedure was applied to reduce the set of RT data across levels of difficulty. Transformation and regression functions of RT on the number of steps have been determined to obtain slope and intercept coefficients, based on previous data obtained in groups of 20 young- and 20 elderly volunteers (Riedel 2000). Briefly, each RT value is transformed according to the equation: $y=\operatorname{sqrt}[10 \log (\mathrm{x})]$, so that transformed $\mathrm{RT}$ 's are a linear function of the number of steps. Regression analyses are then carried out on transformed RTs to yield individual slopes and intercepts of the RT on steps function. Slope is considered the primary outcome variable measuring problem solving ability. Intercept is a variable measuring response speed unrelated to problem solving ability. Because no consistent association has been established between number of etrors and the number of steps, the total number of errors is the other outcome variable.

In the Word Fluency Task subjects are asked to name as many four-letter words as possible beginning with a particular letter $(\mathrm{B}, \mathrm{H}, \mathrm{R}, \mathrm{L}, \mathrm{P}$ or $\mathrm{M})$ within one minute. The fluency test measures strategy-driven retrieval of information from semantic memory (Luteijn and van der Ploeg 1983). Order of the six versions over test days and time of assessments were balanced per 6 subjects. The dependent variable is the number of correctly produced words. The Signal Detection Task. (SDT) is a visual search task. Small white squares $(3 \times 3 \mathrm{~mm})$ are presented in a pseudo-random fashion on a computer screen. Twenty squares are randomly assigned to a $10 \times 6$ grid, all squares being $2.5 \mathrm{~cm}$ apart. Targets are defined as a set of four stimuli forming a square of $2.5 \times 2.5 \mathrm{~cm}$. Every 3 seconds three squares move to a different location within the matrix. Subjects are required to respond to the target stimuli with their dominant hand by pressing a button as fast as possible. Total number of squares presented is 400 , and the total number of target stimuli is 56 , yielding a signal probability of 0.14 . The task lasts $6.40 \mathrm{~min}$. Sensitivity (A') defined as the non-parametric proportion of correctly identified targets corrected for false positives is the dependent measure according to the signal detection theory (Pollack and Norman 1964).

Repetitions of the psychomotor and cognitive tests were scheduled at 1 and 3 hrs post drug with the exception of the CTT and the OMEDA. The former test, which is easy to administer and only takes a few minutes to complete, was conducted before, and at 1, 2, 3 and 5 hrs post drug. The OMEDA was conducted 4-5 hrs after drug intake.

\section{TOXICOLOGICAL ASSESSMENTS}

Blood samples were taken every 60 minutes starting just before, and up to 5 hours after drug intake using glass venotubes with sodium fluoride and potassium oxalate as anticoagulant. MDMA concentrations were determined in the corresponding plasma samples using solid phase extraction and gas chromatography with mass spectrometric detection with a limit of quantitation of $10 \mathrm{ng} / \mathrm{ml}$. 
Blood alcohol levels were estimated every 30 minutes, starting just before and until $5.5 \mathrm{~h}$ after drug intake using Lion SD-4 Breath Alcohol Analyser®.

\section{STUDY PROCEDURES}

On test days subjects arrived at the research facility between $11.45 \mathrm{~h}$ and $12.00 \mathrm{~h}$. The use of drugs other than the study drugs was prohibited throughout the study. Subjects were prohibited to consume alcohol for $24 \mathrm{hrs}$ and caffeine for $16 \mathrm{hrs}$ before treatments. Smoking was not allowed during experimental sessions. Upon arrival, subjects were questioned about possible use of alcohol, drugs or medication in preceding weeks. The presence of alcohol was explored using a Lion SD-400 Breath Alcohol Analyser ${ }^{\circledR}$ (Lion Laboratories, Barry UK). Urine, collected upon arrival, was tested for recent use of THC, amphetamine, methamphetamine, cocaine and opiates by means of the qualitative Syva Rapid Test $(\circledR)$ (Dade Behring, Liederbach Germany). Female subjects were also tested for pregnancy with a QuickVue One-step HcG Urine Pregnancy test ${ }^{\circledR}$ (Quidel, San Diego USA). When inclusion or exclusion criteria were violated the test day was postponed.

At $12.30 \mathrm{~h}$ subjects consumed a light lunch consisting of 2 slices of bread and unlimited fruit juice or mineral water. At $13.15 \mathrm{~h}$ MDMA, alcohol or placebo was administered. During the day subjects had free access to mineral and tap water, fruit juice, an isotonic drink and sugar-free chewing gum.

A physician was on call during all experimental sessions, which took place at the Maastricht University Hospital. Additional clinical blood chemistry, with particular reference to liver and renal functions was conducted at 7 and 11 days after each treatment. Subjects were asked to contact the medical supervisor or one of the researchers when experiencing any sign of nausea, vomiting, intolerance of fatty food, yellowish colour of skin, or tiredness during the 2 weeks after test days.

\section{STATISTICAL ANALYSES}

All variables were tested in repeated-measures multivariate analysis of variance (MANOVA) for the main effects of Treatment (three levels) and Treatment by Time (two or five levels). In case of the TOL, MCRT and OMEDA the factorial models were expanded with one additional factor (i.e. Task complexity or Occlusion diameter). Following a significant overall effect of Treatment or its interaction with Time, Task complexity or Occlusion diameter, univariate $F$-tests for establishing differences between drugs and placebo were conducted. All univariate F-tests were conducted across all times of testing.

A special proceeding was followed in case of the OMEDA. The alcohol treatment was dropped from the analysis, because at the time of testing, $\mathrm{BAC}$ had dropped to $0.0 \mathrm{mg} / \mathrm{ml}$ and was no longer active. A univariate $F$-test was conducted to assess performance differences between placebo and MDMA. The $\alpha$-probability criterion for determining the significance of mean differences was set at $\mathrm{p}=0.05$. 


\section{RESULTS}

Twelve subjects (eight males and four females) completed the study. Their demographic characteristics are summarised in table 1. Data of the MCRT of one subject is missing due to computer failure. An overview of all statistical comparisons of main effects of Treatment and interactions including Treatment of the subjects' performance tests is given in table 2 . No serious adverse events were observed and none of the subjects needed special care during or after the experimental sessions.

Table 1 Overview of the subjects' characteristics and their alcohol and recreational drug use, where Total use = lifetime use (number of occasions).

\begin{tabular}{llcclc}
\hline Variable & N & Mean & SD & Min & Max \\
\hline Age (years) & 12 & 23.5 & 3 & 21 & 30 \\
Weight (kg) & 12 & 65.9 & 4.0 & 60.0 & 73.0 \\
Years of education & 12 & 16 & 2.5 & 13 & 22 \\
& & & & & \\
Ecstasy use per year (times) & 12 & 9 & 6 & 5 & 25 \\
Total ecstasy use (times) & 12 & 39 & 34 & 5 & 125 \\
Marijuana use per year (times) & 12 & 91 & 114 & 0.5 & 318 \\
Total marijuana use (times) & 12 & 760 & 1076 & 3 & 3500 \\
Alcohol per week (units) & 12 & 17 & 17 & 4 & 50 \\
Total amphetamine use (times) & 8 & 7 & 10 & 1 & 30 \\
Total cocaine use (times) & 7 & 13 & 17 & 2 & 50 \\
Total psilocybine use (times) & 3 & 14 & 11 & 3 & 25 \\
Total LSD use (times) & 3 & 1 & 0 & 1 & 1 \\
\hline
\end{tabular}

\section{Performance ASSESSMENTS}

Critical tracking did not differ between treatments at baseline $F[2.10]=0.339, \mathrm{p}=\mathrm{ns}$; Fig. 1). MANOVA showed a main effect of Treatment on tracking performance. There was no interaction with Time. Separate drug-placebo comparisons revealed a significant effect of MDMA indicating improved tracking performance relative to placebo.

MANOVA revealed an overall effect of Treatment on sub-critical tracking performance in the Divided Attention Task (Fig. 2). There was no overall interaction between Treatment and Time. Separate drug-placebo comparison showed that MDMA significantly improved tracking performance by lowering tracking error as compared to placebo. Alcohol had no effect on tracking error.

MANOVA showed a significant overall effect of Treatment on movement time in the MCRT. There was no overall interaction between Treatment and Time. Separate comparison between MDMA and placebo indicated that movement time significantly improved after MDMA administration (100 and $108 \mathrm{msec}$, respectively), while alcohol did not affect movement time $(110 \mathrm{msec})$. 
Table 2 Overview of effects of the statistical comparisons of the subjects' cognitive and psychomotor performance. All p-values exceeding .10 are shown as ns. The arrows indicate improvement $(\uparrow)$ and impairment ( $)$ relative to placebo.

\begin{tabular}{|c|c|c|c|c|c|c|c|c|c|}
\hline \multirow[t]{2}{*}{ test } & \multirow[t]{2}{*}{ Construct } & \multirow[t]{2}{*}{ factor } & \multirow[t]{2}{*}{$d f$} & \multicolumn{2}{|c|}{ overall-effect } & \multicolumn{2}{|c|}{ placebo-alcohol } & \multicolumn{2}{|c|}{ placebo-MDMA } \\
\hline & & & & $\mathrm{F}$ & $\mathrm{p}$ & $\mathrm{F}$ & $p$ & $\mathrm{~F}$ & $p$ \\
\hline \multirow[t]{2}{*}{ CTT } & Lambda C & Treatment & 2.10 & 4.52 & .04 & 0.01 & ns & 5.92 & $.03 \uparrow$ \\
\hline & & Treatment*Time & 6.6 & 2.01 & ns & & & & \\
\hline \multirow[t]{2}{*}{ DAT } & Tracking & Treatment & 2.10 & 6.19 & .02 & 2.53 & ns & 6.83 & $.02 \uparrow$ \\
\hline & Error & Treatment*Time & 2.10 & 1.62 & ns & & & & \\
\hline \multirow[t]{2}{*}{ DAT } & Reaction & Treatment & 2.10 & 0.13 & ns & & & & \\
\hline & Time & Treatment*Time & 2.10 & 0.17 & ns & & & & \\
\hline \multirow[t]{5}{*}{ MCRT } & Initiation & Treatment & 2.9 & 0.08 & ns & & & & \\
\hline & Time & Treatment ${ }^{\star}$ Time & 2.9 & 0.74 & ns & & & & \\
\hline & & Treatment* Complexity & 4.7 & 1.16 & ns & & & & \\
\hline & & Treatment*Time ${ }^{\star}$ & & & & & & & \\
\hline & & Complexity & 4.7 & 0.91 & ns & & & & \\
\hline \multirow[t]{2}{*}{ MCRT } & Movement & Treatment & 2.9 & 5.26 & .03 & 0.25 & ns & 9.63 & $.01 \uparrow$ \\
\hline & Time & Treatment ${ }^{*}$ Time & 2.9 & 0.74 & ns & & & & \\
\hline \multirow[t]{2}{*}{ Omeda } & TTC error & $\begin{array}{l}\text { Treatment } \\
\text { Treatment* }\end{array}$ & & & & & & 4.59 & $.06 \downarrow$ \\
\hline & & Occlusion & & & & & & 4.18 & $.07 \downarrow$ \\
\hline \multirow[t]{2}{*}{ Omeda } & Divided & Treatment & & & & & & 0.44 & ns \\
\hline & $\begin{array}{l}\text { attention } \\
\text { error }\end{array}$ & $\begin{array}{l}\text { Treatment }^{\star} \\
\text { Occlusion }\end{array}$ & & & & & & 0.00 & ns \\
\hline \multirow[t]{2}{*}{ TOL } & Slope/ & Treatment & 4.7 & 0.76 & ns & & & & \\
\hline & Intercept & Treatment*Time & 4.7 & 1.09 & ns & & & & \\
\hline \multirow[t]{2}{*}{ TOL } & Number of & Treatment & 2.9 & 7.39 & .01 & 10.50 & $.01 \uparrow$ & 0.52 & ns \\
\hline & errors & Treatment*Time & 2.9 & 0.03 & ns & & & & \\
\hline Word & Number of & Treatment & 2.10 & 0.59 & ns & & & & \\
\hline Fluency & words & Treatment*Time & 2.10 & 1.75 & ns & & & & \\
\hline \multirow[t]{2}{*}{ SDT } & Sensitivity & Treatment & 2.10 & 1.09 & ns & & & & \\
\hline & $\left(A^{\prime}\right)$ & Treatment ${ }^{\star}$ Time & 2.10 & 0.16 & ns & & & & \\
\hline
\end{tabular}

Fig. 1 Mean ( $+\mathrm{se}$ ) critical tracking error $(\mathrm{rad} / \mathrm{sec})$ in the Critical Tracking Test at baseline and 1, 2, 3 and 5 hours after placebo $(\downarrow)$, alcohol $(\mathbf{-})$ and $\operatorname{MDMA}(\boldsymbol{\Delta})$ administration.

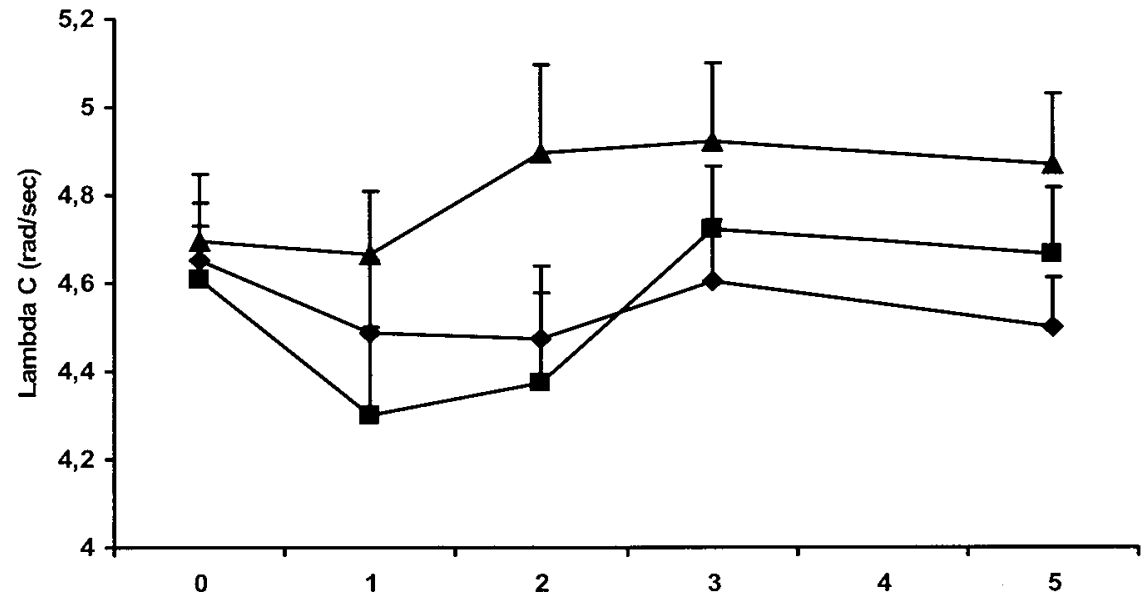

Time after drug/alcohol (hrs) 
Fig. 2 Mean (+ se) Tracking Error in the Divided Attention Task 1 and 3 hours after placebo, alcohol and MDMA.

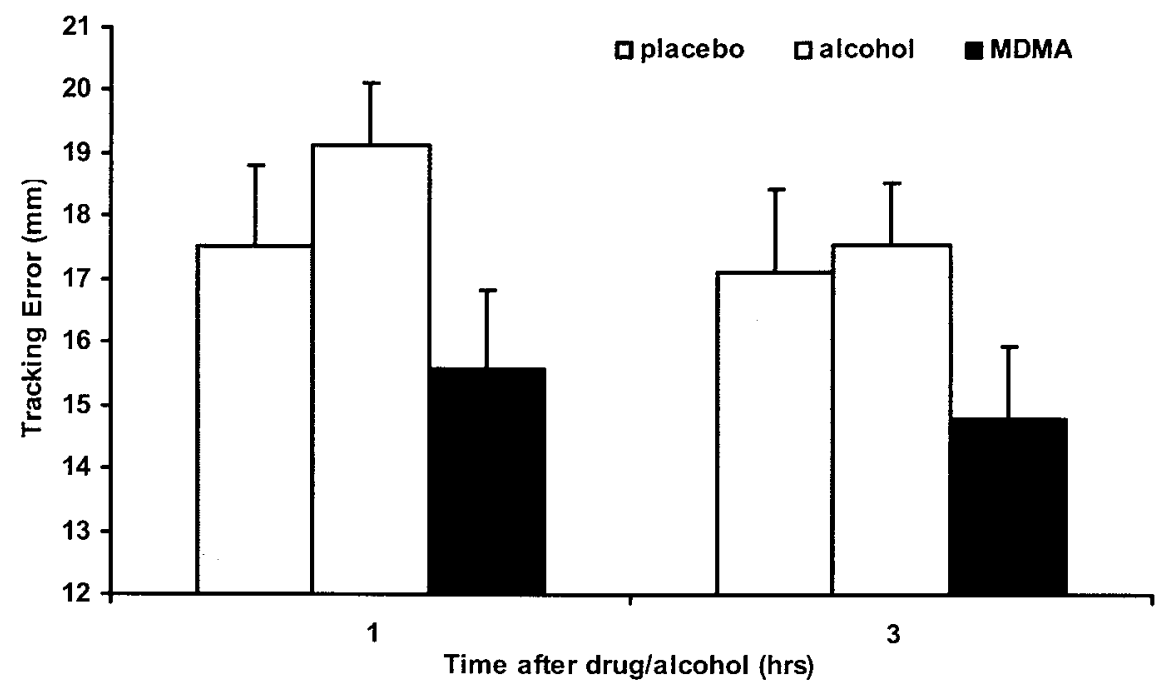

The results of the primary and secondary task of the OMEDA are presented in Table 2 and Figure 3. Univariate F-comparison strongly suggested that MDMA elevated TTC error and that this effect increased as a function of occlusion. Increments in estimated absolute TTC resulted from increments in overestimation, as well as increments in underestimation of the actual TTC. Performance on the secondary task of the OMEDA (DA) was not affected by Treatment or the interaction between Treatment and Occlusion.

MANOVA analysis of slope and intercept of TOL-RT as a function of steps showed no overall effect of Treatment. The intercept of the transformed RT [ ${ }^{2}[10 \log (\mathrm{RT})]$ was 1.89 at 3 hrs after MDMA and 1.91 in all other conditions. Overall mean slope was 0.04 , and MANOVA revealed no overall effect of Treatment or interaction between Treatment and Time. MANOVA showed an overall effect of Treatment on number of errors. Drugplacebo comparison between alcohol and placebo showed that fewer errors were made after alcohol relative to placebo ( $6.8 \%$ versus $11.4 \%$ errors, respectively). Comparison between MDMA and placebo showed no effect of MDMA on number of errors (mean $12.7 \%$ ) in the TOL.

In the Word Fluency Test, an average of 12 words were retrieved within 1 minute across treatments and time of assessments with the exception of an average of 11 words $1 \mathrm{hr}$ after MDMA intake. MANOVA showed no effect of Treatment or interaction of Treatment with Time.

In the SDT, subjects detected $87.4 \%$ of the signals after placebo, $84.9 \%$ after alcohol and $84.7 \%$ after MDMA administration. MANOVA showed no effect of Treatment or interaction with Time. 
Fig. 3 Mean ( + se) Z-scores of Time to Contact Error and Divided Attention Error in the OMEDA task as a function of occlusion diameter 4-5 hrs after placebo ( $\downarrow)$, alcohol $(\mathbf{-})$ and MDMA $(\boldsymbol{\Delta})$ administration. Both TTC error and divided attention error scores in all conditions were first separately subjected to Z-transformation and subsequently averaged to obtain compound scores, reflecting "whole-task" performance.

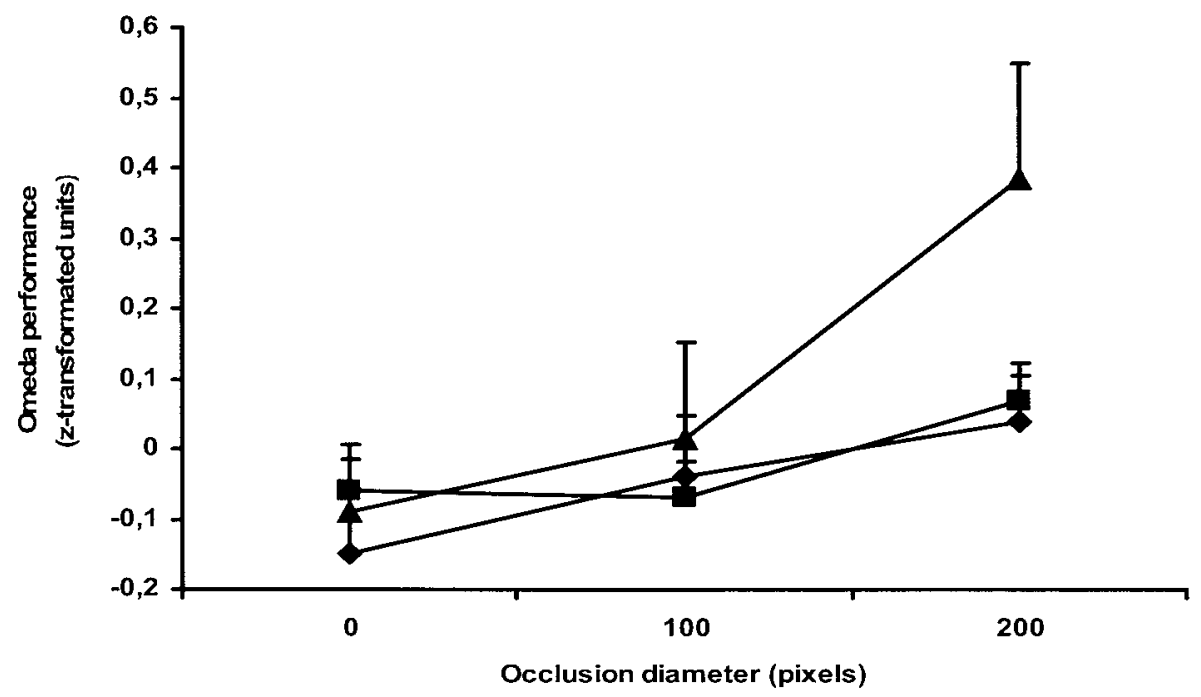

Fig. 4 Mean (tse) blood plasma concentrations of MDMA $(\Delta)$ and mean ( + se) blood alcohol concentration (ש) as a function of time after drug/alcohol intake.

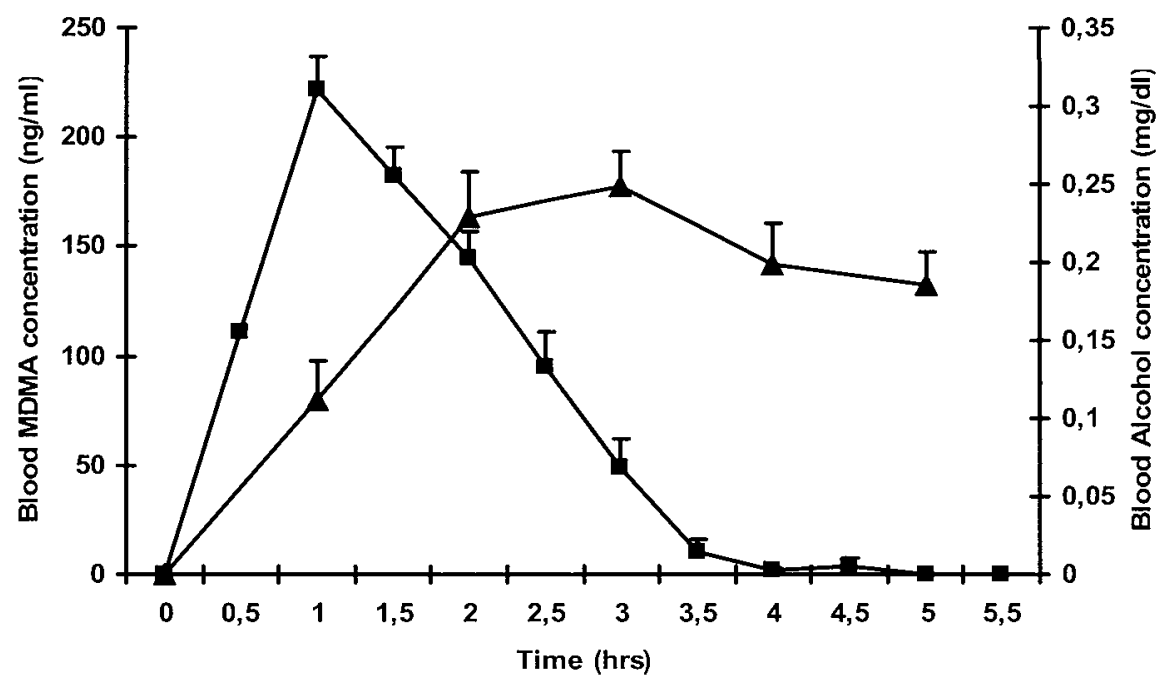




\section{ToXicological ASSESSMENTS}

Figure 4 shows mean ( \pm se) MDMA Blood plasma concentration and BAC as a function of time after consuming MDMA $75 \mathrm{mg}$ or drinking ethanol $0.5 \mathrm{~g} / \mathrm{kg}$. Mean $\mathrm{C}_{\max }$ of MDMA was $178 \mathrm{ng} / \mathrm{ml}$ (range $85-295 \mathrm{ng} / \mathrm{ml}$ ) at 3 hours after drug intake. Mean BAC peak concentration $(0.3 \mathrm{mg} / \mathrm{ml})$ was reached 60 minutes after alcohol intake. During the second repetition of the test battery BAC dropped to $0.1 \mathrm{mg} / \mathrm{ml}$ and BACs had dropped to 0.0 $\mathrm{mg} / \mathrm{ml}$ during last assessments in all subjects.

\section{EFFECT OF TREATMENT ORDER}

The order of treatment was not completely balanced, as a result of the exclusion of subjects after violation of excluding criteria. Four subjects received MDMA on their first, three on their second and five on their third test day. Alcohol was administered to three subjects on their first, five on their second and four on their third test day. To control for Treatment order effect, performance as a function of order of MDMA was analysed by means of ANOVA for the dependent variables affected by MDMA, e.g. Lambda-C (CTT), Tracking error (DAT), movement time (MCRT) and TTC error (OMEDA). None of the dependent variables analysed differed as a function of MDMA order except DAT tracking error in the placebo condition ( $\mathrm{F}=807, \mathrm{p}=.022$ ) indicating that subjects receiving MDMA on their first test day performed better when they received placebo on one of their next test days compared to subjects after placebo who received MDMA on their second or third test day. It could be suggested that MDMA improved the learning process of this test, because none of the other dependent variables showed an effect of MDMA treatment order, this conclusion is unlikely.

\section{DISCUSSION}

Briefly summarised, the results showed that a single recreational dose of MDMA improved tracking performance either under single task conditions as well as under divided attention or double task conditions. Movement time in the choice reaction time paradigm improved after MDMA, whereas object movement estimation under divided attention was impaired after MDMA. Number of errors in the TOL test was slightly reduced after alcohol administration. Before any conclusions can be drawn, several limitations of the study need to be addressed.

\section{DURATION OF EFFECTS}

MDMA improved tracking performance by $5.6 \%$ to $13.7 \%$ and movement time decreased by an average of $7.6 \%$ relative to placebo. MDMA blood plasma concentrations peaked at approximately $2 \mathrm{hrs}$ post administration and remained virtually unchanged until the last 
measurement at 5 hrs post administration. MDMA induced changes in performance also, remained constant during the assessment period. It is likely these performance effects lasted during the rest of the day given that MDMA has an elimination half-life of approximately 8 hrs (Mas et al. 1999). Future studies need to assess performance effects for a longer time period to establish the exact duration of MDMA effects.

\section{MAGNITUDE OF EFFECTS}

In the current study, a single dose of MDMA did not affect visual search and executive functions, including divided attention while performing a tracking task, planning or retrieval from semantic memory. These findings appear in line with those of previous studies. Vollenweider et al. (1998) reported no effect of a single dose of MDMA on Stroop performance while Downing (1986) reported difficulties with multiplication and decision making after MDMA administration in only a minority of the subjects. These findings appear to indicate that a single dose of MDMA may cause relatively minor disturbances of cognitive performance, although these can be considered typical for acute effects of psychostimulants. An alternative explanation for the observed minor cognitive impairment could be that the sample size in this study was relatively small. However, even though only 12 subjects completed the study, the number of subjects provided sufficient statistical power to detect changes in many tests (e.g. CTT, DAT, MCRT OMEDA). Yet, it cannot be excluded that other tests were not sensitive enough to detect MDMA effects.

In contrast to our data, Parrott and Lasky (1998) found an impairing effect of MDMA on visual scanning in an uncontrolled study. In the present study MDMA was administered under controlled circumstances in otherwise drug free subjects. However, the subjects in Parrott and Laskys' study were tested at a party under less than perfect circumstances while taking different amounts of MDMA. Furthermore, polydrug use was reported among the subjects while tested at the party (alcohol, cannabis, cocaine and amphetamine). Therefore, factors other than acute MDMA use may have contributed to the effects found by Parrott and Lasky (1998). Alternatively, the number of subjects in our study might have been too low to detect effects on these cognitive functions.

\section{DIFFERENT EFFECTS IN DIFFERENT DIVIDED ATTENTION TASKS}

Two divided attention tasks were conducted in this experiment, the DAT and the OMEDA task. The influence of MDMA on these two divided attention tasks in this study, was opposite. MDMA improved performance of the primary task in the DAT (continuous tracking), while MDMA impaired performance in the primary OMEDA task (object movement estimation) compared to placebo in both tasks. The nature of both tasks differs considerably. Whereas the former test depends more on psychomotor capacity, the latter is more of a cognitive nature (i.e. time estimation). The motor components of both primary tasks also differ; in the DAT, motor execution is central, whereas in the OMEDA task, 
inhibition and delay of the response are more important. Although the improved performance on the DAT likely reflects improved psychomotor performance, impairment of TTC error in the OMEDA most likely results from impaired time estimation whereas impaired working memory may also play a role.

\section{IMPLICATIONS FOR MDMA EFFECTS ON DRIVING SAFETY}

Tracking performance and object movement under divided attention were assessed in this experiment to study the influence of psychoactive substances on task performance, related to driving. The tests used in the current study all have a strong validity with respect to traffic safety. The results show a clear dissociation of effects on different aspects of performance. Whilst MDMA enhanced speed of manual movement and capacity to steer or track fast moving objects, it impaired the ability to perceive and predict motion. The prediction of Time to Contact in actual traffic would mean the ability to judge whether another car will collide with one's own car. This ability depends on adequate perception of actual motion and the capacity to predict if, when and where a collision will occur. Estimating other vehicles' speeds is required of any traffic participant for safe manoeuving in traffic, such as crossing an intersection. Any drug-induced impairment of these abilities is unacceptable due to its compromising effect on traffic safety and may lead to increased risk taking. Although increments in TTC include both overestimation and underestimation of the actual TTC, it can be inferred that this observation may be in line with an independent other observation that the use of MDMA will lead to shorter gap acceptance in carfollowing behaviour. This realistic driving-simulator study showed that MDMA users indeed accepted shorter gaps, especially when MDMA was combined with other drugs (Waard et al. 2000). Furthermore, the observed MDMA blood levels in this experiment (85$295 \mathrm{ng} / \mathrm{ml}$ ), were within the range of methamphetamine concentrations reported after toxicological analyses of methamphetamine-related traffic deaths which ranged from 50$2600 \mathrm{ng} / \mathrm{ml}$ (median $350 \mathrm{ng} / \mathrm{ml}$ ) (Logan 1996). Therefore, it is likely that the observed impairment of movement estimation reflects an impairment due to actual MDMA intoxication rather than to impairments associated with the so-called 'crash phase', which refers to a period during and shortly after elimination of the substance in which feelings of depression may emerge. Dangerous driving and accidents after MDMA use have already been reported in the past (Henty et al. 1992; Logan and Couper 2001; Schifano 1995). Impairment in coordination, difficulty concentrating and hallucinations have all been observed in people while under the influence of MDMA (Downing 1986; Schifano 1995; Vollenweider et al. 1998). These factors, possibly combined with exhaustion after a night of dancing, have already led to involvement in sometimes fatal car accidents of MDMA users in the past (Henry et al. 1992; Moeller and Hartung 1997; Morland 2000). Furthermore, in real life, MDMA dosages taken may be higher than in the present study and may be taken in combination with sedative psychoactive substances such as marijuana and alcohol. 


\section{EFFECTS OF ALCOHOL}

Alcohol was used as a comparator drug: to compare the effects of MDMA with the effects of alcohol at BACs close to the legally permitted BAC for participating in traffic in most European countries $(0.5 \mathrm{mg} / \mathrm{ml})$. The alcohol dose used in the current study has been shown to produce BACs ranging from $0.6 \mathrm{mg} / \mathrm{ml}$ when given alone (Ramaekers et al. 1996) to $0.4 \mathrm{mg} / \mathrm{ml}$ when combined with a small lunch (Lamers and Ramaekers 2001).

In the present study, consumption of a standard lunch may also explain why mean BAC did not rise above $0.3 \mathrm{mg} / \mathrm{ml}$. Performance changes were also rather minimal. Alcohol reduced the number of errors in the TOL. Alcohol is known to impair task performance (Franks et al. 1976; Heishman 1997) and because stimulating effects of alcohol on cognitive functioning are not supported by other studies, this may present a spurious finding. Critical tracking performance declined 1 and 2 hrs after drinking. However, the latter effect did not reach statistically significance, possibly as a result of the limited study sample.

\section{MDMA BLOOD PLASMA LEVELS}

Blood plasma concentrations of MDMA were as expected. Our subjects received MDMA $75 \mathrm{mg}(1.03 \mathrm{mg} / \mathrm{kg}$ to $1.25 \mathrm{mg} / \mathrm{kg})$. Maximal blood concentrations of MDMA were slightly higher than those found in prevrious studies using the same dosage: $170 \mathrm{ng} / \mathrm{ml}$ versus 131 $\mathrm{ng} / \mathrm{ml}$ (Mas et al. 1999) and $126 \mathrm{ng} / \mathrm{ml}$ (de la Torre et al. 1999). $T_{\max }$ for the current study differed somewhat from previous studies: while Mas (1999) and de la Torre (1999) found a $\mathrm{T}_{\max }$ of approximately 2 hours, mean highest concentrations in the present study were measured at 3 hrs post MDMA.

\section{AWARENESS OF DRUG TREATMENT}

Prior knowledge about treatment effects, obtained through informed consent and prior experience of subjects, as well as conscious and unconscious drug discrimination during the experiment, can contribute or counteract to the observed effects of that treatment. To prevent this from happening active control conditions are often used in experimental drug studies. We chose an active control, alcohol, on the basis of its recognized imparing effects on psychomotor and driving performance. From the point of view of preventing drug discrimination of MDMA and placebo, it would have been more logical to choose amphetamine as an active control condition. However, the effects of amphetamine on psychomotor and driving performance are hypothesized to be similar to MDMA, but more importantly, just as unprecedented in controlled experimental studies. The question arises if subjects could have manipulated their performance once they were aware of the drug they received. It is unlikely that subjects could have manipulated their results. One could argue that, by performing badly under placebo, subjects could have manipulated results in a way to indicate that MDMA improved performance. The CTT showed MDMA-induced improvement and was assessed before and after drug treatment. If subjects performed 
worse after placebo on purpose, their performance would have been low in comparison to findings in other studies using the CTT but subjects' placebo performance on this test, is comparable to findings of other studies after placebo (Ramaekers et al. 1992; Ramaekers et al. 1996; Vermeeren and O'Hanlon 1998). This finding not only indicates that it is unlikely that the MDMA-induced effects observed in this study are a result of awareness of the kind of drug subjects received, but also that the lack of alcohol-induced impairment is not resulting from bad performance after placebo, and instead is a result of the low alcohol concentration.

\section{IMPLICATIONS OF POSSIBLE NEURAL DAMAGE DUE TO PREVIOUS DRUG USE OR TOLERANCE IN TERMS OF LABORATORY COGNITIVE PERFORMANCE}

It is possible that performance of subjects during placebo treatment was impaired relative to non-drug users. Impaired cognitive performance has been reported in previous studies in abstinent (poly-drug) MDMA users and is often regarded as a result of serotonergic neurotoxicity (Parrott et al. 1998; McCann et al. 1999; Gouzoulis Mayfrank et al. 2000; Verkes et al. 2001). As described earlier, performance after placebo on at least some of the tests was not affected in MDMA users as compared to non-drug users. Yet, if, subjects in the current study were cognitively impaired, the impairment might have been counteracted somewhat by the acute effects of increased cellular serotonin and dopamine levels after MDMA. Tolerance might also have influenced the results observed in this study; it can not be excluded that tolerance to the drug might have diminished MDMA-induced effects relative to the effect the drug might have to naive MDMA users. The sample of the current study is too small to analyze a possible influence of tolerance to MDMA by relating subjects' prior exposure to ecstasy with performance changes after MDMA.

\section{IMPLICATIONS FOR PREDICTING REAL LIFE EFFECTS}

Performance effects after MDMA administration observed in the present study may not always be present at the same level in the real life setting at dance parties. In the latter situation other factors have to be taken into consideration to predict the effect of MDMA on cognitive and psychomotor performance. Dehydration, exhaustion, lack of sleep and hyperthermia are only some of those factors that may affect performance. They may produce detrimental effects in performance that were not observed in the present study. Additionally, it is known that MDMA users at times take higher doses than the one used in our study. Often MDMA users take a second, or third dose when they feel the effect of the first dose is subsiding or they combine MDMA with other drugs. The subjects in our study all stated they were poly drug users. When in a recreational setting, 10 subjects in this study often combined MDMA with other psychoactive substances such as marijuana, alcohol or amphetamine. A higher, or multiple dose of MDMA or combined use of MDMA with other drugs may be associated with more adverse events. 
In conclusion, the primary findings of our study constitute dissociative effects of a single acute dose of MDMA (75 mg) on psychomotor and perceptual performance under divided attention. MDMA impaired object movement estimation under divided attention, which can lead to increased risk taking and impaired traffic safety. MDMA improved psychomotor performance, such as compensatory tracking and manual movement speed. Visual search, planning or retrieval from semantic memory were not affected by MDMA. The dissociative effects of MDMA on different divided attention tasks need further investigation.

\section{ACKNOWLEGDEMENTS}

Financial support for this study was provided by the Dutch Ministry of Transport. We would like to thank Gert De Boeck, John Deckers, Linda Booij and Ferry van Nie for their contribution to this study. The authors would also like to thank Profs. T.W. Robbins and B.J. Sahakian, University of Cambridge UK, for their collaborative efforts enabling the use of the one-touch-Tower of London.

\section{REFERENCES}

Cami J, Farre M, Mas M, Roset PN, Poudevida S, Mas A, San L, de la Torre R (2000) Human pharmacology of 3,4-methylenedioxymethamphetamine ("ecstasy"): psychomotor performance and subjective effects. Journal of Clinical Psychopharmacology 20: 455-66.

De la Torre R, Ortuno J, Mas M, Farre M, Segura J (1999) Fatal MDMA intoxication [letter]. Lancet 353: 593

De Man RA (1994) Morbiditeit en sterfte als gevolg van ecstacygebruik. Nederlands Tijdschrift der Geneeskunde 138: 1850-5

Downing J (1986) The psychological and physiological effects of MDMA on normal volunteers. Journal of Psychoactive Drugs 18: 335-40

Franks HM, Hensley VR, Hensley WJ, Starmer GA, Teo RK (1976) The relationship between alcohol dosage and performance decrement in humans. Journal of Studies on Alcohol 37: 284-97.

Gouzoulis-Mayfrank E, Daumann J, Tuchtenhagen F, Pelz S, Becker S, Kunert HJ, Fimm B, Sass H (2000) Impaired cognitive performance in drug free users of recreational ecstasy (MDMA). Journal of Neurology, Neurosurgery and Psychiatry 68: 719-25

Heishman SJ, Arasteh, K. and Stitzer, M.L. (1997) Comparative effects of alcohol and marijuana on mood, memory, and performance. Pharmacology, Biochemistry and Behavior 58: 93-101

Henry JA (1992) Ecstasy and the dance of death [editorial; comment]. British Medical Journal 305: 5-6

Henry JA, Jeffreys KJ, Dawling S (1992) Toxicity and deaths from 3,4methylenedioxymethamphetamine ("ecstasy"). Lancet 340: 384-7

Houx PJ, Jolles J (1993) Age-related decline of psychomotor speed: effects of age, brain health, sex, and education. Perceptual and Motor Skills 76: 195-211.

Jex HR, McDonnel JD, Phatak AV (1966) A "critical" tracking task for manual control research. Institute of Electrical and Electronic EngineersTransactions on Human Factors In Electronics HFE7: $138-145$

Krystal JH, Price L.H, Opsahl C, Ricaurte GA, Heninger GR (1992) Chronic 3,4methylenedioxymethamphetamine (MDMA) use: effects on mood and neuropsychological function? American Journal of Drug and Alcohol Abuse 18: 331-41 
Lamers CT], Ramaekers JG (2001) Visual search and urban city driving under the influence of marijuana and alcohol. Human Psychopharmacology Clinical and Experimental 16: 393-401

Logan BK (1996) Methamphetamine and driving impairment. Journal of Forensic Sciences 41: 457-64

Logan BK, Couper FJ (2001) 3,4-Methylenedioxymethamphetamine (MDMA, ecstasy) and driving impairment. Journal of Forensic Sciences 46: 1426-33.

Luteijn F, van der Ploeg FAE (1983) Manual Groningen Intelligencetest (GIT). Swets and Zeitlinger, Swets and Zeitlinger

Mas M, Farre M, de la Torre R, Roset PN, Ortuno J, Segura J, Cami J (1999) Cardiovascular and neuroendocrine effects and pharmacokinetics of 3, 4-methylenedioxymethamphetamine in humans. Journal of Pharmacology and Experimental Therapeutics 290: 136-45

McCann UD, Mertl M, Eligulashvili V, Ricaurte GA (1999) Cognitive performance in (+-) 3,4methylenedioxymethampetamine (MDMA, 'ecstacy') users: a controlled study. Psychopharmacology 143: 417-425

Moeller MR, Hartung M (1997) Ecstasy and related substances-serum levels in impaired drivers. Journal of Analytical Toxicology 21: 591

Morgan MJ (1999) Memory deficits associated with recreational use of "ecstasy" (MDMA). Psychopharmacology 141: 30-6

Morgan MJ (2000) Ecstasy (MDMA): a review of its possible persistent psychological effects. Psychopharmacology 152: 230-48.

Morland J (2000) Toxicity of drug abuse--amphetamine designer drugs (ecstasy): mental effects and consequences of single dose use. Toxicology Letters 112-113: 147-52

Moskowitz H (1973) Laboratory studies of the effects of alcohol on some variables related to driving. Journal of Safety Research 5: 185-199

Owen AM, Sahakian BJ, Hodges JR, Polkey CE, Summers BA, Robbins TW (1995) Dopaminedependent fronto-striatal planning deficits in early Parkinson's Disease. Neuropsychology 9: 126-140

Parrott AC, Lees A, Garnham NJ, Jones M, Wesnes K (1998) Cognitive performance in recreational users of MDMA of 'ecstasy': evidence for memory deficits. Journal of Psychopharmacology 12: 79-83

Pollack I, Norman D (1964) A non-parametric analysis of recognition experiments. Psychonomic Sciences 1: 125-126

Ramaekers JG, Muntjewerff ND, Uiterwijk MMC, van Veggel LMA, Patat A, Durrieu G, O'Hanlon JF (1996) A study of the pharmacodynamic interaction between befloxatone and ethanol on performance and mood in healthy volunteers. Journal of Psychopharmacology 10: 288-294

Ramaekers JG, Muntjewerff ND, Van Veggel LMA, Uiterwijk MMC, O'Hanlon JF (1998) Effects of nocturnal doses of mirtazapine and mianserin on sleep and on daytime psychomotor and driving performance in young, healthy volunteers. Human Psychopharmacology Clinical and Experimental 13: S87-S97

Ramaekers JG, Swijgman HF, O'Hanlon JF (1992) Effects of moclobemide and mianserin on highway driving, psychometric performance and subjective parameters, relative to placebo. Psychopharmacology 106 Suppl: S62-7

Read NL, Ward NJ, Parkes AM (2000) The role of dynamic tests in assessing the fitness to drive of healthy and cognitively impaired elderly. Journal of Traffic Medicine 28: 34-35S

Riedel W, Hogervorst E, Leboux R, Verhey F, van Praag H, Jolles J (1995) Caffeine attenuates scopolamine-induced memory impairment in humans. Psychopharmacology 122: 158-68.

Riedel WJ (2000) Farmacologische determinanten van het geheugen In proceedings of: Medisch Wetenschappelijke dag over nieuwe inzichten in Dementie. Federatie van Medisch Wetenschappelijke Verenigingen, Amsterdam, RAI

Schifano F (1995) Dangerous driving and MDMA ('Ecstacy') abuse. Journal of Serotonin Research 1: 53-57

Shallice T (1982) Specific impairments of planning. Philosophical Transactions of the Royal Society of London. Series B: Biological Sciences 298: 199-209. 
Ventura J, Liberman RP, Green MF, Shaner A, Mintz J (1998) Training and quality assurance with the Structured Clinical Interview for DSM-IV (SCID-I/P). Psychiatry Research 79: 163-73.

Verkes RJ, Gijsman HJ, Pieters MS, Schoemaker RC, de Visser S, Kuijpers M, Pennings EJ, de Bruin D, Van de Wijngaart G, Van Gerven JM, Cohen AF (2001) Cognitive performance and serotonergic function in users of ecstasy. Psychopharmacology 153: 196-202.

Vermeeren A, O'Hanlon JF (1998) Fexofenadine's effects, alone and with alcohol, on actual driving and psychomotor performance. Journal of Allergy and Clinical Immunology 101: 306-11

Vollenweider FX, Gamma A, Liechti M, Huber T (1998) Psychological and cardiovascular effects and short-term sequelae of MDMA ("Ecstasy") in MDMA-naive healthy volunteers. Neuropsychopharmacology 19: 241-251

Vollenweider Scherpenhuyzen MF, Vollenweider FX (1998) Der Drogennotfall. Anaesthesist 47: $946-$ 55

Waard Dd, Brookhuis KA, Pernot LMC, Lamers CTJ, Booij L, Sikkema KL, Muntjewerff ND, Vuurman EFPM, Riedel WJ (2000) Een onderzoek naar de effecten van MDMA (ecstasy) op cognitieve- en psychomotorische functies, rijgedrag in de simulator, en consequenties voor de verkeersveiligheid. Rijksuniversiteit Groningen, Groningen, pp 87

Ward N, Dye L, Dobson P, Read NL (2000) The effect of chronic cannabis consumption on time estimation and reproduction: implications for driving performance. In: Seidel H (ed) Proceedings of the ICADTS 2000, Stockholm 



\section{CHAPTER 5}

\section{MDMA LEVELS IN FOUR DIFFERENT HUMAN BODY FLUIDS AFTER A PLACEBO- CONTROLLED SINGLE DOSE OF MDMA PREDICT CHANGES IN PSYCHOMOTOR PERFORMANCE, PHYSIOLOGICAL ACTIVATION AND MOOD*}

* Submitted for publication as:

Lamers CTJ, Ramaekers JG, Samyn N, Schmitt JAJ, Riedel WJ (submitted) MDMA levels in four different human body fluids after a placebo-controlled single dose of MDMA predict changes in psychomotor performance, physiological activation and mood. 


\section{ABSTRACT}

Former findings indicate that MDMA (3,4-methylenedioxymethampetamine; ecstasy) may impair driving ability and increase the risk of becoming involved in traffic accidents. It is hypothesised that MDMA levels in body fluids (blood, urine, saliva and sweat) may be used for predicting driver impairment if a close association between driving performance and MDMA levels in these markers can be established under well controlled, experimental conditions. In addition, it was hypothesised that physiological activation and estimates of mood might be used for recognizing the use of MDMA in drivers. Performance on laboratory tasks associated with driving, along with biological and physiological markers of MDMA use were collected in 12 recreational MDMA users who were treated with a single dose of MDMA $75 \mathrm{mg}$ and placebo according to a double-blind, cross-over study design. MDMA increased heart rate, blood pressure, body temperature and cortisol secretion and dilated pupil size as compared to placebo. Task performance (i.e. visuomotor tracking performance and movement time) and MDMA concentrations assessed in blood, urine, saliva and sweat were moderately but significantly associated. Physiological activation after MDMA use as well as feelings of vigor, friendliness and reduced feelings of fatigue as measured by the Profile of Moods States were also significantly associated with changes in MDMA concentrations in most of the four body fluids. It is concluded that the detection of MDMA in blood, saliva, sweat and urine can predict changes in mental task performance, physiological variables and mood in MDMA users under the influence of MDMA.

\section{INTRODUCTION}

The use of MDMA (3,4-methylenedioxymethamphetamine; ecstasy) as a recreational drug is widespread among visitors of raves and dance parties. MDMA is known to induce physiological effects like hyperthermia, tachycardia and elevated blood pressure (Dinse 1997; Mueller and Korey 1998; Vollenweider Scherpenhuyzen and Vollenweider 1998) but also a range of psychological effects such as thought disturbances and impulsivity (Morgan 1998; Liechti, et al. 2001; Morgan, et al. 2002). The latter may be of particular relevance to MDMA users who drive while under the influence of MDMA. Several reports of MDMA use among drivers involved in car accidents have recently appeared in the scientific literature (Henry, et al. 1992; Schifano 1995; Moeller and Hartung 1997; Wijngaart, et al. 1997; Logan and Couper 2001, 2003), suggesting that the drug may increase the risk of becoming involved in traffic crashes. In $54 \%$ of driving under the influence of drugs cases in Belgium from the period 2000-2001, amphetamine and/or MDMA were detected in plasma in concentrations above the legal limit (Willekens, et al. 2002). MDMA's potential to impair driving has also been shown in two experimental studies measuring psychomotor function and simulated driving performance of recreational users (chapter 4; Waard, et al. 
2000). Both studies demonstrated that single doses of MDMA impaired the subjects' ability to accurately estimate time to collision with moving objects or cars as created in experimental conditions.

It is presently unknown whether MDMA levels in body fluids, such as blood, urine, sweat and saliva can be taken as reliable indicators of driving impairment. Blood is generally considered the most useful sample for identifying drugs for quantitative analyses but alternative, non-invasive matrices such as urine, saliva and sweat are currently being explored for their functionality and validity in road side drug testing as well. Reliable, easy to use screening devices are crucial to establish cases of driving under the influence as a prerequisite for subsequent legal measures. Implementation of these devices however largely depends on whether predictive validity can be established in well-controlled experimental studies.

The current study was designed to investigate the associations between MDMA levels in body fluids after a single dose of MDMA $75 \mathrm{mg}$ and MDMA-induced effects on task performance associated with driving, mood and physiological activation, i.e. heart rate, blood pressure, body temperature and cortisol secretion. Associations were determined by calculating intra-subject correlations of MDMA levels with behavioural and physiological markers of MDMA use. It is hypothesised that MDMA levels in body fluids (blood, urine, saliva and sweat) may be used for predicting changes in driver performance if a close association between driving performance and MDMA levels can be established, and that physiological activation and mood might serve as indicators of acute MDMA use.

\section{METHODS}

\section{SUBJECTS}

Fourteen recreational users of MDMA were recruited in the Maastricht area. Subjects were included when they met the following criteria: experience with ecstasy ( $\geq 5$ times/year) and alcohol ( $\geq 3$ units/week), aged 21-40 years and a good physical and mental health. Subjects underwent a standard medical screening and a shortened version of the Structured Clinical Interview for DSM-IV (Ventura, et al. 1998). Exclusion criteria were current, or a history of, medical or psychiatric illness, diagnosed alcohol or drug addiction, pregnancy or lactation, hypertension and history of severe adverse side effects of MDMA. Female subjects were screened for pregnancy before entering the study and at the beginning of test days by a urine pregnancy test. All subjects were screened for previous convictions for drug possession or drug trafficking prior to participation

Subjects gave their written informed consent and received a small payment for their participation. The study was conducted according to the standards of the 1969 Declaration of Helsinki and its amendments and was approved by the Medical Ethics Committee of the University Hospital of Maastricht. 


\section{DESIGN AND TREATMENT}

The original study was conducted according to a placebo controlled, three-way crossover, randomized, double blind, and double dummy design (chapter 4). On three separate test days, spaced at least two weeks apart, subjects received a bottle containing $400 \mathrm{ml}$ orange juice and a small cup containing $25 \mathrm{ml}$ bitter orange syrup. On one occasion $0.5 \mathrm{mg} / \mathrm{kg}$ pure alcohol was complemented with orange juice to a total of $400 \mathrm{ml}$. On another test day the cup contained bitter orange syrup mixed with MDMA $75 \mathrm{mg}$ (powder). Subjects were requested to consume the content of the cup at once and the content of the $400 \mathrm{ml}$ bottle within 15 minutes. The MDMA dose used in the current study is within range of regular recreational doses (Burgess, et al. 2000, Konijn 1997). Alcohol was used in the original design as a comparator drug: to compare the effects of MDMA with the effects of alcohol at BAC's close to the legally permitted BAC for participating in traffic in most European countries $(0.5 \mathrm{mg} / \mathrm{ml})$. Since the effects of alcohol are not essential for any of the hypotheses in this study, data of the alcohol treatment condition were excluded from analysis.

\section{STUDY PROCEDURE}

Throughout the study the use of drugs other then the study drugs was prohibited. Alcohol and caffeine were prohibited 24 and 16 hrs prior to test days, respectively and smoking was prohibited during experimental sessions. At the beginning of test days recent alcohol use was screened by assessing the subjects' breath alcohol concentration (BAC) by means of a Lion SD-4 Breath Alcohol Analyzer. Recent use of cannabinoids (THC), amphetamine, methamphetamine, cocaine and opiates was tested by means of the qualitative urine Syva Rapid Test ${ }^{\circledR}$ (Dade Behring). Subjects received a standard lunch of 2 small sandwiches and fruit juice 30 minutes before drug administration. Throughout the test day subjects had free access to water, fruit juice, an isotonic drink and sugar-free chewing gum. Room temperature was constant at 20 degrees Celsius.

MDMA and placebo were administered at $13.15 \mathrm{~h}$ and assessment took place until $18.45 \mathrm{~h}$. After completion of the test session subjects were driven home by one of the researchers. A physician was on call at all times and subjects were asked to contact the medical superrisor or one of the researchers immediately when experiencing any sign of nausea, vomiting, intolerance of fatty food, yellowish colour of skin, or tiredness during the 2 weeks after test days. With reference to liver and renal functions, additional clinical blood chemistry analysis was done at 7 and 11 days after each treatment.

\section{ASSESSMENTS}

An overview of all dependent variables and their time of assessment is presented in Table 1. 


\section{Body fluids}

MDMA was determined in 4 body fluids: blood plasma, urine, sweat and saliva. Blood samples were drawn after collection of all other body fluids, including saliva samples used for analyses of cortisol secretion, and were collected using glass venotubes containing sodium fluoride and potassium oxalate as anticoagulant. Blood samples were placed on ice immediately, later centrifuged for 10 minutes and subsequently frozen at $-20^{\circ} \mathrm{C}$ until analyzed. Sweat samples were collected from the subject's forehead using a small cotton cloth that was moisturized with an isopropanol mixture ( 7 parts isopropanol and 3 parts purified water) just before sample collection. Saliva samples used for MDMA detection were collected by spitting in a small plastic tube and preceded saliva samples used for cortisol secretion. Urine, saliva and sweat samples were frozen immediately at $-20^{\circ} \mathrm{C}$. Detailed information about sample collection and analyses is reported elsewhere (Samyn, et al. 2002).

\section{Physiological variables and pupil diameter}

Heart rate, diastolic blood pressure (DBP), systolic blood pressure (SBP) and body temperature were assessed using an automated vital signs monitor (Dinamap 1800 BP; Critikon Inc. Tampa FL) and an in-ear thermometer (Braun Thermo scan). During assessments subjects were seated in a relaxed sitting position.

Cortisol was assessed from saliva. Saliva was obtained with a citric-acid containing cotton roll (Salivette $(B)$. Cortisol samples were stored at $-20^{\circ} \mathrm{C}$ until analysis (no more than 7 months later). Saliva cortisol was determined in duplex by direct radioimmunoassay, using 125I-cortisol and antiserum made against the 3-CMO-BSA conjugate (Ansseau, et al. 1984). Pupil diameter was measured using a small infrared camera. The camera and an infrared light source that was directed at the eye were mounted at the end of a translucent tube. The opposite side of the tube was placed on the left eye and the eye was recorded on videotape for a period of at least 10 continuous seconds between eye blinks. The measurements took place with dimmed ambient lighting and after an adaptation period of 10 minutes. Pupil diameter was measured four times with $2-3$ seconds intervals on a television monitor. A conversion formulae derived from the recording of a range of 10 circles with 1 to 10 millimetre diameters was used to calculate pupil diameter in millimetres. The average of the four pupil measurements was taken as outcome variable.

\section{Subjective effects}

The 65-item version of the Profile of Mood States was used to evaluate mood changes (McNair, et al. 1992). Subjects scored each item using a 5-point scale ranging from absolutely not $(0)$ to very strong (4). The version used in the current study consists of 7 mood clusters: tension-anxiety (range 0-36), depression-dejection (range 0-60), anger- 
hostility (range 0-48), vigor-activity (range 0-36), fatigue-inertia (range 0-28), confusionbewilderment (range 0-28) and friendliness (range 0-28).

An additional questionnaire was used to assess subjective physical and psychological effects of MDMA, e.g. dry mouth, light-headedness, and control loss. The presence of feelings and discomforts was scored by means of a 3-point scale $(0=$ not at all, $1=$ in some degree, $2=$ yes). Subjective reports of effects after treatment are presented in table but not statistically analysed.

Table 1: Overview of dependent variables and their time of assessment (in minutes).

\begin{tabular}{|c|c|c|c|c|c|c|c|c|c|c|c|c|}
\hline Dependent variable/test & -30 & 0 & 30 & 60 & 90 & 120 & 150 & 180 & 210 & 240 & 270 & 300 \\
\hline Drug administration & & $\bar{x}$ & & & & & & & & & & \\
\hline \multicolumn{13}{|l|}{ Body fluids } \\
\hline Blood plasma & $\mathrm{x}$ & & & $x$ & & $x$ & & $x$ & & $x$ & & $x$ \\
\hline Urine & $x$ & & & $x$ & & $x$ & & $x$ & & $x$ & & $x$ \\
\hline Saliva & $x$ & & & $x$ & & $x$ & & $x$ & & $x$ & & $x$ \\
\hline Sweat wipes & $x$ & & & $x$ & & $x$ & & $x$ & & $x$ & & $x$ \\
\hline
\end{tabular}

\section{Physiological variables}

Heart rate

Diastolic blood pressure

Systolic blood pressure

Body temperature

Cortisol secretion in saliva

$\begin{array}{llllllllllll}x & x & x & x & x & x & x & x & x & x & x & x \\ x & x & x & x & x & x & x & x & x & x & x & x \\ x & x & x & x & x & x & x & x & x & x & x & x \\ x & x & x & x & x & x & x & x & x & x & x & x \\ x & x & x & x & x & x & x & x & x & x & x & x\end{array}$

\section{Pupil size}

$x$

\section{Subjective variables}

Profile of Mood States $X$

Physical and psychological $X$

effects

\section{Performance variables}

Critical tracking frequency $X$

Tracking error

Movement time

Time to contact error

$\begin{array}{lll}x & x & x \\ x & x & x\end{array}$

\section{Performance}

Cognitive and psychomotor tests were conducted at baseline and between 1 and 5 hrs post drug. For a detailed description see chapter 4. Performance variables significantly affected by MDMA were included for correlational analyses: i.e. tracking performance in the critical tracking test, movement time in the choice reaction time task and time to collision estimation in the object movement estimation under divided attention (OMEDA) task. 


\section{STATISTICAL ANALYSES}

Physiological variables were analysed using multivariate analysis of variance (MANOVA) for the overall effect of Treatment (placebo and MDMA) and if measured more than once, interaction of Treatment by Time. Subjective mood data were analysed by means of nonparametric Wilcoxon Signed Ranks tests.

The hypothesised associations of MDMA levels with behavioural and physiological variables were tested on the basis of the calculation of intra-subject correlations. This approach has previously been used to predict drug effects on changes in performance by using raw treatment scores of each variable (Ramaekers 2003). The procedure entailed the following: Pearson-R coefficients of correlation were calculated for every subject between each pair of variables using the raw data collected during MDMA and placebo treatment. The raw data were corrected for baseline performance, assessed before drug intake, when available. Thus, individual intra-subject correlations were based on the total number of test repetitions across MDMA and placebo conditions (an overview of times of assessments is presented in table 1). Individual intra-subject correlations were then averaged across subjects and tested for a significant deviation from 0 by means of independent one-sample t-tests. In addition, intra-subject correlations between the four body fluids were calculated using the same methods as described above but now only raw data collected during MDMA treatment were included for analysis.

All analyses were two-tailed and $\alpha$-probability criterion for determining the significance of mean differences was defined as $\mathrm{p}<0.05$.

\section{RESULTS}

Two subjects were excluded after violating exclusion criteria (drug use during the study). None of their data is included for further analyses. Twelve subjects, eight male and four female, completed the study (mean age 23.5, range 21-30; mean weight $65.9 \mathrm{~kg}$, range 60-73 $\mathrm{kg}$ ). All subjects had previously used ecstasy (mean total lifetime use: 39, range 5-125), marijuana (mean total lifetime use: 760, range 3-3500) and alcohol (mean units/week: 17, range 4-50).

All subjects included for the study produced negative urine drug screens before entering a test day. Quantitative analyses after the study however, showed that one subject was positive for MDMA at baseline in the MDMA treatment condition. The MDMA levels in urine were not high enough to detect recent MDMA use by Syva Rapid urine drugs screen. MDMA levels in this subject were very low at baseline in urine $(0.16 \mathrm{mg} /$ creatine $)$, saliva ( $3 \mathrm{ng} / \mathrm{ml}$ ) and sweat ( $3 \mathrm{ng} /$ wipe) and below the detection limit in the blood sample. Therefore test results from this subject were not excluded for analyses. 


\section{MISSING DATA}

Three cortisol samples (out of a total of 288) were missing. One sample was missing for 1 subject in the placebo condition and two for another subject in the MDMA condition due to insufficient saliva volume, 2 and 3 hours after drug administration, respectively. Missing cortisol samples were replaced by the average value of the assessments one hour before and one hour after the time of the invalid sample. Furthermore, not all subjects could produce urine samples for all 6 assessments and some blood samples were not obtained due to difficult venapunction in some subjects (Table 2). Also, the questionnaire for physiological and psychological effects was not filled out correctly by one subject after MDMA administration resulting in missing data of half of the items of the questionnaire in this case.

\section{INTOXICATION}

Mean MDMA concentrations in blood plasma, urine, saliva and sweat as a function of time are reported in table 2.

Table 2: Median and interquartile range $\left[25^{\text {th }}-75^{\text {th }}\right.$ percentile] for MDMA concentrations in plasma, urine, saliva and sweat at different times after administration of drug. $\mathrm{N}$ is the number of valid samples for each matrix.

\begin{tabular}{lllllllll}
\hline $\begin{array}{l}\text { Time } \\
\text { after }\end{array}$ & Plasma & \multicolumn{2}{c}{ Urine } & Saliva & Sweat wipes \\
\cline { 2 - 9 } $\begin{array}{l}\text { drug } \\
\text { (min) }\end{array}$ & $\mathbf{N}$ & $\begin{array}{l}\text { Concentration } \\
\text { (ng/mL) }\end{array}$ & $\mathbf{N}$ & $\begin{array}{l}\text { Concentration } \\
\text { (mg/creatinine) }\end{array}$ & $\mathbf{N}$ & $\begin{array}{l}\text { Concentration } \\
\text { (ng/mL) }\end{array}$ & $\mathbf{N}$ & $\begin{array}{l}\text { Concentration } \\
\text { (mg/creatinine) }\end{array}$ \\
\hline 60 & 12 & $65[29-119]$ & 11 & $0.9[0.4-4.1]$ & 12 & $65[29-119]$ & 11 & $0.9[0.4-4.1]$ \\
120 & 12 & $152[127-189]$ & 9 & $5.0[3.2-22.3]$ & 12 & $152[127-189]$ & 9 & $5.0[3.2-22.3]$ \\
180 & 11 & $185[145-206]$ & 9 & $12.6[7.4-18.5]$ & 11 & $185[145-206]$ & 9 & $12.6[7.4-18.5]$ \\
240 & 9 & $126[113-149]$ & 10 & $12.5[8.1-20.7]$ & 9 & $126[113-149]$ & 10 & $12.5[8.1-20.7]$ \\
300 & 9 & $122[96-169]$ & 11 & $14.4[6.4-16.2]$ & 9 & $122[96-169]$ & 11 & $14.4[6.4-16.2]$ \\
\hline
\end{tabular}

\section{PHYSIOLOGICAL VARIABLES AND PUPIL SIZE}

Mean heart rate, body temperature, blood pressure and cortisol levels as a function of treatment and time of assessment are presented in Figure 1. Multivariate analyses showed that body temperature, heart rate, DBP, SBP and cortisol did not differ between treatments at baseline $(F[1.11] \leq 3.984, p=n s)$. Therefore baseline assessments were not included for further group comparisons of physiological variables.

Multivariate analyses showed increased heart rate, DBP, SBP and body temperature $(\mathrm{F}[1.11] \geq 6.17, \mathrm{p} \leq .03)$ after MDMA as compared to placebo. Quadratic interactions between Time and Treatment reached significance for heart rate, DBP and SBP $(\mathrm{F}[1.11] \geq 5.33, \mathrm{p} \leq .04)$ and there was a trend toward significance for body temperature 
$(\mathrm{F}[1.11]=4.34, \mathrm{p}=.06)$. The interactions between Time and Treatment reflect the primary MDMA-induced initial increase of levels, followed by a return to baseline.

Cortisol baseline levels before placebo and MDMA administration were $437( \pm 37)$ and 399 $( \pm 50) \mathrm{nmol} / \mathrm{L}$ (mean $\pm \mathrm{se}$ ) respectively. Cortisol further increased after MDMA by 668 ( \pm 178) nmol/L to a peak value of $1067 \mathrm{nmol} / \mathrm{L}$. Peak values were observed after 1 hour in 4 subjects after 2 hours in 4 subjects, after 3 hours in 3 subjects and after 4 hours in 1 subject. Cortisol after placebo further increased by $75( \pm 78) \mathrm{nmol} / \mathrm{L}$ to a peak value of 512 $\mathrm{nmol} / \mathrm{L}$. Cortisol peak was significantly higher after MDMA as compared with placebo $(\mathrm{F}[1.11]=7.081, \mathrm{p}=.022)$.

Average pupil size after placebo was $5.00( \pm 0.28)$ mm (mean \pm se). MDMA significantly increased pupil size with an average of $1.77( \pm 0.31) \mathrm{mm}$ as compared to placebo $(\mathrm{F}[1.11]=31.97, \mathrm{p}<.001)$.

Figure 1: Mean ( + se) heart rate, blood pressure ( $\boldsymbol{\Delta}$ systolic and $\Delta$ diastolic), body temperature and cortisol concentrations as a function of Treatment ( $\mathbf{\Lambda}$ placebo and + MDMA $)$ and Time.
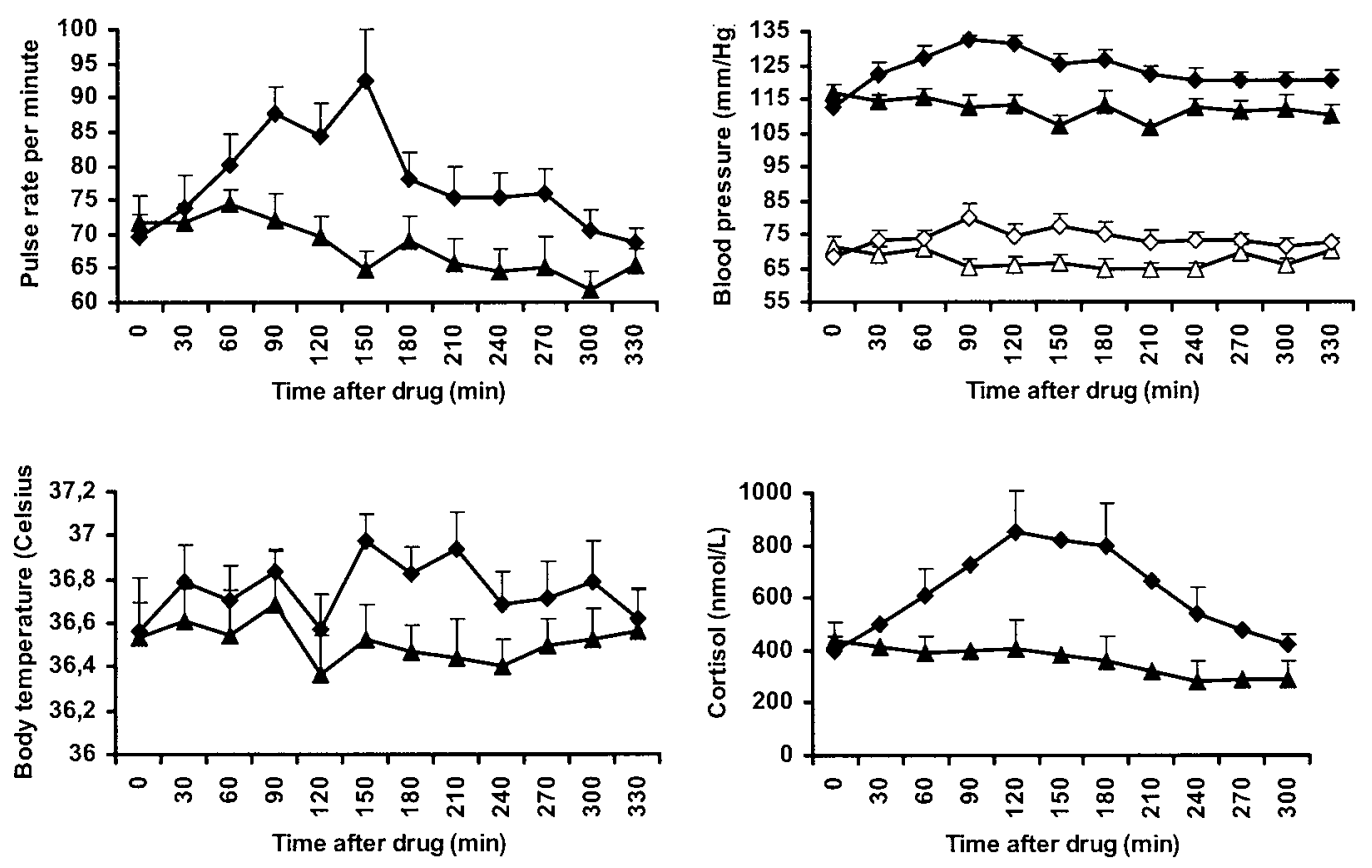
Table 3: Mean scores ( \pm se) of the individual mood clusters of the Profile of Mood States as a function of treatment and time and their statistic comparisons as a function of treatment. None reported p-values are nost significant.

\begin{tabular}{|c|c|c|c|c|c|}
\hline \multirow[t]{2}{*}{ Mood cluster } & \multirow{2}{*}{$\begin{array}{l}\text { Time after } \\
\text { drug (hrs) }\end{array}$} & \multicolumn{2}{|c|}{ Mean } & \multicolumn{2}{|c|}{$\begin{array}{l}\text { Wilcoxon Signed Rank } \\
\text { Placebo - MDMA }\end{array}$} \\
\hline & & Placebo & MDMA & $Z$ & $p$ \\
\hline \multirow[t]{4}{*}{ Tension } & 0 & $2.33( \pm 0.6)$ & $3.83( \pm 0.8)$ & -1.373 & \\
\hline & 2 & $1.83( \pm 0.4)$ & $4.83( \pm 0.9)$ & -2.572 & .01 \\
\hline & 4 & $1.67( \pm 0.4)$ & $4.42( \pm 1.1)$ & -2.533 & 01 \\
\hline & 5 & $1.75( \pm 0.3)$ & $2.83( \pm 0.5)$ & $-2,214$ & .03 \\
\hline \multirow[t]{4}{*}{ Depression } & 0 & $0.67( \pm 0.5)$ & $0.33( \pm 0.3)$ & 0.535 & \\
\hline & 2 & $1.33( \pm 1.2)$ & $0.58( \pm 0.3)$ & 0.000 & \\
\hline & 4 & $0.25( \pm 0.1)$ & $0.50( \pm 0.3)$ & -1.134 & \\
\hline & 5 & $0.08( \pm 0.1)$ & $0.08( \pm 0.1)$ & 0.000 & \\
\hline \multirow[t]{4}{*}{ Anger } & 0 & $0.50( \pm 0.2)$ & $0.50( \pm 0.2)$ & 0.000 & \\
\hline & 2 & $0.33( \pm 0.2)$ & $0.42( \pm 0.2)$ & -0.447 & \\
\hline & 4 & $0.42( \pm 0.2)$ & $1.00( \pm 0.6)$ & -1.134 & \\
\hline & 5 & $0.33( \pm 0.2)$ & $0.50( \pm 0.3)$ & -0.447 & \\
\hline \multirow[t]{4}{*}{ Vigor } & 0 & $11.00( \pm 2.2)$ & $9.50( \pm 2.4)$ & -1.286 & \\
\hline & 2 & $9.92( \pm 2.3)$ & $11.17( \pm 2.2)$ & -1.078 & \\
\hline & 4 & $7.33( \pm 2.0)$ & $9.25( \pm 2.1)$ & -1.129 & \\
\hline & 5 & $7.92( \pm 1.8)$ & $7.17( \pm 1.8)$ & 0.655 & \\
\hline \multirow[t]{4}{*}{ Fatigue } & 0 & $0.67( \pm 0.2)$ & $0.67( \pm 0.2)$ & 0.000 & \\
\hline & 2 & $2.08( \pm 0.6)$ & $0.67( \pm 0.3)$ & -1.798 & \\
\hline & 4 & $2.00( \pm 0.5)$ & $1.00( \pm 0.3)$ & -1.498 & \\
\hline & 5 & $2.58( \pm 1.0)$ & $1.58( \pm 0.7)$ & -1.388 & \\
\hline \multirow[t]{4}{*}{ Confusion } & 0 & $2.83( \pm 0.3)$ & $2.75( \pm 0.3)$ & -0.108 & \\
\hline & 2 & $3.25( \pm 0.5)$ & $6.33( \pm 1.3)$ & -2.199 & .03 \\
\hline & 4 & $3.42( \pm 0.5)$ & $5.33( \pm 0.7)$ & -2.099 & .04 \\
\hline & 5 & $3.58( \pm 0.3)$ & $4.33( \pm 0.7)$ & -1.075 & \\
\hline \multirow[t]{4}{*}{ Friendliness } & 0 & $13.67( \pm 1.8)$ & $12.00( \pm 1.9)$ & -2.059 & .04 \\
\hline & 2 & $12.08( \pm 2.1)$ & $13.17( \pm 2.0)$ & -1.418 & \\
\hline & 4 & $12.33( \pm 1.9\}$ & $10.83( \pm 2.1)$ & -1.843 & \\
\hline & 5 & $11.58( \pm 1.9)$ & $9.92( \pm 2.0)$ & -1.663 & \\
\hline
\end{tabular}

\section{MOOD}

Mean scores for the mood clusters and their statistics are presented in Table 3. Wilcoxon Signed Ranks test showed that MDMA increased feelings of tension at 2, 4 and $5 \mathrm{~h}$ after intake and subjects were more confused at 2 and $4 \mathrm{~h}$ after MDMA intake relative to placebo. Because Wilcoxon Signed Ranks test for baseline assessment of the $7 \mathrm{mood}$ clusters showed that subjects felt less friendly before MDMA intake as compared to placebo at baseline an extra Wilcoxon Signed Ranks test comparison was executed with the relative changes to baseline between MDMA and placebo. Relative changes to baseline showed that MDMA increased feelings of friendliness at $2 \mathrm{~h}$, but not at 4 or $5 \mathrm{~h}$ post drug as compared to placebo $(Z=-2.075, p=.038$ and $Z \leq-.367, p=$ ns respectively). 


\section{SUBJECTIVE PHYSIOLOGICAL AND PSYCHOLOGICAL EFFECTS}

The subjective effects reported by subjects after placebo and MDMA treatment are presented in Table 4. Reported effects after MDMA include light-headedness, restlessness, difficulties concentrating, confusion and the feeling of lost control and/or lost sense of time. Furthermore, subjects reported distorted vision and experienced light, colours and sounds more intensely after MDMA. Only 1 subject reported mild hallucinations.

Table 4: Presented are subjective effects reported by subjects after placebo and MDMA treatment and thcir incidence. Total number of subjects was 12 or 11 (marked by *).

\begin{tabular}{|c|c|c|}
\hline \multirow{2}{*}{ Subjective effects } & \multicolumn{2}{|c|}{ Number of subjects (\%) } \\
\hline & Placebo & MDMA \\
\hline Warm body & $1(8 \%)$ & $8(67 \%)$ \\
\hline Headache & $2(17 \%)$ & $3(25 \%)$ \\
\hline Shaky & $1(8 \%)$ & $8(67 \%)$ \\
\hline Increased light/color perception & $2(17 \%)$ & $6(50 \%)$ \\
\hline Distorted vision (blurred/double) & $2(17 \%)$ & $8(67 \%)$ \\
\hline Tiredness/fatigue & $11(92 \%)$ & $10(83 \%)$ \\
\hline Dehydration (thirst, dry mouth) & $5(42 \%)$ & $11(92 \%)$ \\
\hline Difficulty concentrating & $8(67 \%)$ & $10(83 \%)$ \\
\hline Increased transpiration & $1(8 \%)$ & $9(75 \%)$ \\
\hline Palpitations & 0 & $5(42 \%)$ \\
\hline Increased sound perception & 0 & $6(50 \%)$ \\
\hline Cold & $8(67 \%)$ & $10(83 \%)$ \\
\hline Aching jaw & 0 & $7(58 \%)$ \\
\hline Hunger & $8 \quad(67 \%)$ & $7(58 \%)$ \\
\hline Energetic & $10(83 \%)$ & $10(83 \%)$ \\
\hline Increased sex drive & 0 & $3(25 \%)$ \\
\hline Decreased sex drive & 0 & $2(17 \%)$ \\
\hline Tingling skin & $1(8 \%)$ & $7(58 \%)$ \\
\hline Restless & $2(17 \%)$ & $9(75 \%)$ \\
\hline Dilated pupils (subjective) & $1(8 \%)$ & $11(92 \%)$ \\
\hline Grinding & 0 & $6(50 \%)$ \\
\hline Lost sense of time & $1(8 \%)$ & $7^{*}(64 \%)$ \\
\hline Urge for physical contact & $1(8 \%)$ & $4^{*}(36 \%)$ \\
\hline Tense & 0 & $3^{*}(27 \%)$ \\
\hline Control loss & 0 & $4^{*}(36 \%)$ \\
\hline Confused & 0 & $5^{\star}(45 \%)$ \\
\hline Light headed & $2(17 \%)$ & $8^{*}(73 \%)$ \\
\hline Mild hallucinations & $1(8 \%)$ & $1 *(9 \%)$ \\
\hline Observant & $9(75 \%)$ & $10^{\star}(91 \%)$ \\
\hline Friendly & $11(92 \%)$ & $9^{*}(82 \%)$ \\
\hline Talkative & $7(58 \%)$ & $8^{*}(73 \%)$ \\
\hline
\end{tabular}

\section{PERFormanCE}

Critical tracking frequency and tracking error as well as movement time improved as a function of MDMA use. Estimation of object movement under divided attention was impaired after MDMA as indicated by the increased Time to Contact error after MDMA, relative to placebo. Results are described in more detail in chapter 4 of this dissertation. 
Table 5: Mean intra-subject associations between MDMA concentrations in body fluids and physiosesgical measures, mood and task performance.

\begin{tabular}{|c|c|c|c|c|}
\hline Variable & blood MDMA & Urine MDMA & Saliva MDMA & Sweat MDMA \\
\hline \multicolumn{5}{|l|}{ Physiological function } \\
\hline Body temperature & .32 & $.33^{\star}$ & .23 & .26 \\
\hline Heart rate & $.43^{*}$ & $.38^{*}$ & $.30^{*}$ & $.51^{\star \star \star}$ \\
\hline Diastolic blood pressure & $.46^{\star \star}$ & $.43^{\star \star}$ & $.34^{* *}$ & $.44^{\star \star}$ \\
\hline Systolic blood pressure & $.65^{\star \star}$ & $.53^{\star \star}$ & $.50^{\star \star}$ & $.63^{\star \star}$ \\
\hline Cortisol levels & .34 & .23 & .15 & $.37^{\star}$ \\
\hline \multicolumn{5}{|l|}{ Profile of Mood States } \\
\hline Tension & .28 & .10 & .35 & .30 \\
\hline Depression & .14 & .14 & .17 & .06 \\
\hline Anxiety & .06 & .14 & .21 & .18 \\
\hline Vigor & $.42^{\star}$ & .18 & $.45^{\star}$ & .33 \\
\hline Fatigue & $-.46^{*}$ & -.28 & $-.48^{\star *}$ & -.31 \\
\hline Confusion & .33 & .33 & .36 & .29 \\
\hline Friendliness & $.35^{\star}$ & .03 & $.35^{*}$ & .15 \\
\hline \multicolumn{5}{|l|}{ Performance } \\
\hline Critical tracking frequency & $.50^{\star \star}$ & $.47^{\star \star}$ & $.40^{\star \star}$ & $.46^{\star *}$ \\
\hline Tracking error & $-.37^{*}$ & $-.35^{*}$ & $-.48^{\star \star}$ & $-.37^{\star}$ \\
\hline Movement time & $-.57^{\star \star}$ & -.31 & $-.63^{\star \star}$ & $-.66^{\star \star}$ \\
\hline Time to contact error & .25 & .28 & .28 & .25 \\
\hline \multicolumn{5}{|l|}{ MDMA levels } \\
\hline Blood plasma & & $.59^{\star \star}$ & .24 & .24 \\
\hline Urine & & & .13 & .27 \\
\hline Saliva & & & & -.12 \\
\hline
\end{tabular}

$* \leq .05$

$* * \leq .01$

\section{CORRELATIONS}

Intra-subject correlations between MDMA levels in blood plasma, urine, saliva and sweat as well as intra-subject correlations between MDMA levels and physiological variables, cortisol levels, mental task performance and mood are presented in Table 5. Besides a positive association between MDMA levels in urine and blood plasma, none of the MDMA levels in body fluids were significantly associated. All body fluids were positively associated with absolute changes in heart rate, DBP and SBP relative to baseline. Only MDMA levels in urine was positively associated with MDMA induced changes in body temperature relative to baseline. MDMA levels in sweat, but not in blood, urine and saliva were positively associated with changes in cortisol secretion after MDMA administration relative to baseline.

Significant positive associations were observed between MDMA levels in blood and saliva with feelings of friendliness and vigor relative to baseline. Negative associations between MDMA levels in blood and saliva with feelings of fatigue relative to baseline were significant. No significant other associations between MDMA levels in body fluids and mood clusters were observed. 
Significant associations were observed between MDMA levels in all 4 body fluids and psychomotor performance, with the exception of the association between MDMA levels in urine and movement time, which was not significant. No significant association was observed between MDMA levels in body fluids and Time to Contact Error.

\section{DISCUSSION}

In the current study the use of MDMA levels in body fluids to predict changes in driving performance, as well as the role of physiological activation and mood as indicators of MDMA use were investigated in a placebo controlled study with a single dose of MDMA 75 mg. Before discussing the primary hypothesis, the latter objective will be addressed first.

MDMA increased all physiological indicators of central nervous system activation and these findings are in line with other studies (Vollenweider, et al. 1998; Mas, et al. 1999; Lester, et al. 2000; Liechti, et al. 2000). MDMA-induced elevation in body temperature in the current study (mean $+0.4^{\circ} \mathrm{C}-+0.5^{\circ} \mathrm{C}$ at peak) may not seem alarmingly high, but testing took place under an ambient temperature of $20^{\circ} \mathrm{C}$, in contrast to the warm and crowded environments MDMA is mostly consumed in. Animal studies show that MDMA-induced changes in body temperature are sensitive to external factors such as ambient temperature (Dafters and Lynch 1998; Malberg and Seiden 1998). Furthermore, physiological activation varied between subjects and the maximum individual increases observed were: heart rate +86 beats $/ \mathrm{min}, \mathrm{DBP}+43 \mathrm{~mm} / \mathrm{Hg}, \mathrm{SBP}+50 \mathrm{~mm} / \mathrm{Hg}$ and body temperature $+1.9^{\circ} \mathrm{C}$ after MDMA administration. Observed changes in physiological variables resemble those reported by subjects, i.e. feeling hot, increased transpiration and palpitations.

MDMA administration was associated with a significant mydriatic response (dilation of the pupil). While the mydriatic effects of other stimulant drugs such as cocaine and amphetamines can be explained by a direct increase of noradrenergic activity, the mydriatic effect of MDMA may occur as a result of its potent pro-serotonergic actions. In humans, administration of serotonin reuptake inhibitors (Deijen, et al. 1989; Saletu and Grünberger 1988; Ramaekers, et al. 1995; Schmitt, et al. 2002); and m-chlorophenylpiperazine (Benjamin, et al. 1997, Broocks, et al. 1998) produces a significant increase in the resting pupil diameter. The 5-HT-induced mydriatic response is probably mediated by central $5 \mathrm{HT}_{\mathrm{I}} \mathrm{A}$ receptors evoking the release of noradrenalin on alpha2-adrenoreceptors (Prow, et al. 1996).

The current study shows robust MDMA-induced increases in cortisol secretion. This observation is in line with prior findings in a placebo-controlled MDMA study (Mas, et al. 1999). In human studies it is suggested that physiological changes are closely associated with increases in serotonergic availability in the brain shortly after MDMA is consumed (Liechti, et al. 2000, Liechti, et al. 2000, Liechti and Vollenweider 2000). Although cortisol increases 
are consistent with activation of serotonergic neurotransmission, dopaminergic and noradrenergic mechanisms may also be involved.

Subjective reports of acute effects of MDMA or ecstasy often focus on feelings of insight, sociability, talkativeness and friendliness while results from the Profile of Mood States in the current study only indicate increased feelings of tension and confusion. Difference in setting between the controlled study and circumstances under which MDMA is usually consumed may have contributed to this contrast in subjective reports. All efforts were made to make subjects feel comfortable and at ease during the experiment. Yet, it is still possible subjects might have been more aware of the fact that they were the object of research while feeling intoxicated by MDMA as compared to their experiences in real life settings.

In the current study it was hypothesised that MDMA levels in blood, urine, saliva and sweat can predict MDMA-induced effects on physiological variables, mental task performance and mood. Before discussing the predictive validity of MDMA levels in body fluids one should note that sampling of the body fluids took place every hour after MDMA intake. Therefore all samples, including sweat and urine should be regarded as representing acute levels of MDMA rather than cumulative. Observed intra-subjects associations between MDMA levels in body fluids and physiological variables indicate that fluctuations in those variables depend at least partly on MDMA levels observed in body fluids. In the current study increased MDMA levels in blood and saliva were significantly associated with increased feelings of friendliness and vigor and decreased feelings of fatigue. While some changes in feelings of friendliness were detected after MDMA, feelings of fatigue and vigor were not affected by drug. The associations between the latter two and MDMA levels in body fluids should therefore be interpreted with some caution. MDMA levels in body fluids were also associated with improved psychomotor performance, defined as movement time and tracking performance. MDMA levels in body fluids were not significantly associated with impaired time to contact error (T'TC error). The somewhat smaller magnitude of the latter effect relative to the observed improving effect on task performance may have contributed to the lack significant association between TTC error and MDMA lerels in body fluids. It can be suggested that MDMA levels in body fluids can predict at least some elements of -driving associated-task performance.

It should be noted that intra-subject associations provide a first and general indication of a positive association between MDMA levels and performance or physiological variables. Basically, the method aimed to establish whether changes in performance or physiological variables could be predicted from changes in MDMA levels as measures in the four different body fluids. As such, it does not take into account certain factors that might affect the strength of association as well: i.e. time after drug intake and absolute drug levels. Time after drug intake obviously is a very relevant parameter as it may determine the nature of the relation between pharmacokinetic and pharmacodynamic variables. Nature of association (positive/negative) between MDMA levels and performance as observed in the present study during the first hours after drug use may develop into an opposite direction in a later 
stage of the drug elimination phase. The time window for measuring drug effects however was too limited in the present study to state any conclusion regarding the association between MDMA levels and performance throughout the full elimination phase (i.e. about $48 \mathrm{hrs}$ ). Likewise, intra-subject associations do not provide evidence for performance impairment at particular "threshold" levels of MDMA in any of the four body fluids. MDMA levels varied substantially between individuals in the present study even though drug effects were present in most of them. Furthermore, possible predictions in regard to cumulative MDMA levels after multiple doses need to be investigated. Yet within the limitations of these results the conclusion must be that MDMA levels in body fluids are positively associated with behavioural or physiological signs of MDMA use, at least between 1-5 hrs after drug intake.

In sum, MDMA $75 \mathrm{mg}$ increased heart rate, both systolic and diastolic blood pressure and body temperature, as well as cortisol levels and feelings of confusion and tension as compared to placebo. MDMA levels in body fluids were positively associated with physiological variables, feelings of vigor, friendliness and decreased feelings of fatigue and psychomotor performance but not with time to contact estimation. MDMA levels in biological markers may prove to be useful in predicting impaired traffic safety although the limitations of the current study will need to be addressed in future studies.

\section{ACKNOWLEGDEMENTS}

Financial support for this study was provided by the Dutch Ministry of Transport. We would like to thank Gert De Boeck, John Deckers, Linda Booij, Ferry van Nie and Karen Sikkema for their contribution to this study.

\section{REFERENCES}

Ansseau, M, Sulon, J, Doumont, A, Cerfontaine, JL, Legros, JJ, Sodoyez, JC and Demey-Ponsart, E (1984) Use of saliva cortisol in the dexamethasone suppression test. Psychiatry Research 13: 203-11

Benjamin, J, Nemetz, H, Fux, M, Bleichman, I and Agam, G (1997) Acute inositol does not attenuate $\mathrm{m}$-CPP-induced anxiety, mydriasis and endocrine effects in panic disorder. Journal of Psychiatric Research 31: 489-495

Broocks, A, Little, JT, Martin, A, Minichiello, MD, Dubbert, B, Mack, C, Tune, L, Murphy, DL and Sunderland, $\mathrm{T}$ (1998) The influence of ondansetron and m-chlorophenylpiperazine on scopolamineinduced cognitive, behavioral, and physiological responses in young healthy controls. Biological Psychiatry 43: 408-416

Burgess, C, O'Donohoe, A and Gill, M (2000) Agony and ecstasy: a review of MDMA effects and toxicity. Eur Psychiatry 15: 287-94.

Dafters, RI and Lynch, E (1998) Persistent loss of thermoregulation in the rat induced by 3,4methylenedioxymethamphetamine (MDMA or "Ecstasy") but not by fenfluramine. Psychopharmacology Berl 138: 207-12 
Deijen, JB, Loriaux, SM, Orlebeke, JF and De Vries, J (1989) Eiffects of paroxetinc and maprotiline on mood, perceptual-motor skills and eye movements in healthy volunteers. Journal of Psychopharmacology 3: 148-155

Dinse, H (1997) Ecstasy (MDMA)-Intoxikation. Ein Uberblick. Anaesthesist 46: 697-703

Henry, JA, Jeffreys, KJ and Dawling, S (1992) Toxicity and deaths from 3,4methylenedioxymethamphetamine ("ecstasy"). Lancet 340: 384-7

Konijn, KZ, Pennings, F.A. \& de Wolff, F.A. (1997) XTC, klinische en toxicologische aspecten. Leids Universitair Medisch Centrum: Klinische Chemie, Farmacie en Toxicologie \& Universiteit van Amsterdam, Humane Toxicologie Academisch Medisch Centrum., Leiden, pp 75

Lester, SJ, Baggott, M, Welm, S, Schiller, NB, Jones, RT, Foster, E and Mendelson, J (2000) Cardiovascular effects of 3,4-methylenedioxymethamphetamine. A double-blind, placebo-controlled trial. Annals of Internal Medicin 133: 969-73

Liechti, ME, Baumann, C, Gamma, A and Vollenweider, FX (2000) Acute psychological effects of 3,4methylenedioxymethamphetamine (MDMA, "Ecstasy") are attenuated by the serotonin uptake inhibitor citalopram. Neuropsychopharmacology 22: 513-21

Liechti, ME, Gamma, A and Vollenweider, FX (2001) Gender differences in the subjective effects of MDMA. Psychopharmacology (Berl) 154: 161-8.

Liechti, ME, Saur, MR, Gamma, A, Hell, D and Vollenweider, FX (2000) Psychological and physiological effects of MDMA ("Ecstasy") after pretreatment with the 5-HT(2) antagonist ketanserin in healthy humans. Neuropsychopharmacology 23: 396-404.

Liecht, ME and Vollenweider, FX (2000) Acute psychological and physiological effects of MDMA ("Ecstasy") after haloperidol pretreatment in healthy humans. European Neuropsychopharmacology 10: 289-95.

Logan, BK and Couper, FJ (2003) 3,4-Methylenedioxymethamphetamine - Effects on Human Performance and Behavior. Forensic Science Review 15: 11-28

Logan, BK and Couper, FJ (2001) 3,4-Methylenedioxymethamphetamine (MDMA, ecstasy) and driving impairment. Journal of Forensic Sciences 46: 1426-33.

Malberg, JE and Seiden, LS (1998) Small changes in ambient temperature cause large changes in 3,4methylenedioxymethamphetamine (MDMA)-induced serotonin neurotoxicity and core body temperature in the rat. Journal of Neuroscience 18: 5086-94

Mas, M, Farre, M, de la Torre, R, Roset, PN, Ortuno, J, Segura, J and Cami, J (1999) Cardiovascular and neuroendocrine effects and pharmacokinetics of 3,4-methylenedioxymethamphetamine in humans. Journal of Pharmacology and Experimental Therapeutics 290: 136-45

McNair, DM, Lorr, M and Droppleman, LF (1992) Manual for the Profile of Mood States (Revised). Educational and Industrial Testing Service, San Diego, CA

Moeller, MR and Hartung, M (1997) Ecstasy and related substances-serum levels in impaired drivers. Journal of Analytical Toxicology 21: 591

Morgan, MJ (1998) Recreational use of "ecstasy" (MDMA) is associated with elevated impulsivity. Neuropsychopharmacology 19: 252-64

Morgan, MJ, McFie, L, Fleetwood, $\mathrm{H}$ and Robinson, JA (2002) Ecstasy (MDMA): are the psychological problems associated with its use reversed by prolonged abstinence? Psychopharmacology (Berl) 159: 294-303

Mueller, PD and Korey, WS (1998) Death by "ecstasy": the serotonin syndrome? Annals of Emergency Medicine 32: 377-80

Prow, MR, Martin, KF and Heal, DJ (1996) 8-OH-DPAT-induced mydriasis in mice: a pharmacological characterisation. European Journal of Pharmacology 317: 21-8

Ramaekers, JG (2003) Antidepressants and Driver Impairment: Empirical Evidence From a Standard On-the-Road Test. Journal of Clinical Psychiatry 64: 20-9 
Ramaekers, JG, Muntjewerff, ND and O'Hanlon, JF (1995) A comparative study of acute and subchronic effects of dothicpin, fluoxetine and placebo on psychomotor and actual driving performance. British Journal of Clinical Pharmacology 39: 397-404

Saletu, B and Grünberger, J (1988) Drug Profiling by computed electroencephalography and brain maps, with special consideration of sertraline and its psychometric effects. Journal of Clinical Psychiatry 49: 59-71

Samyn, N, De Boeck, G, Wood, M, Lamers, CTJ, De Waard, D, Brookhuis, KA, Verstraete, AG and Riedel, WJ (2002) Plasma, oral fluid and sweat wipe ecstasy concentrations in controlled and real life conditions. Forensic Science International 128: 90-7

Schifano, F (1995) Dangerous driving and MDMA (Ecstacy') abuse. Journal of Serotonin Research 1: $53-57$

Schmitt, JAJ, Riedel, WJ, Vuurman, EFPM, Kruizinga, M and Ramaekers, JG (2002) Modulation of the Critical Flicker Fusion effects of serotonin reuptake inhibitors by concomitant pupillary changes. Psychopharmacology 160: 381-6

Ventura, J, Liberman, RP, Green, MF, Shaner, A and Mintz, J (1998) Training and quality assurance with the Structured Clinical Interview for DSM-IV (SCID-I/P). Psychiatry Research 79: 163-73.

Vollenweider, FX, Gamma, A, Liecht, M and Huber, T (1998) Psychological and cardiovascular effects and short-term sequelae of MDMA ("Ecstasy") in MDMA-naive healthy volunteers. Neuropsychopharmacology 19: 241-251

Vollenweider Scherpenhuyzen, MF and Vollenweider, FX (1998) Der Drogennotfall. Anaesthesist 47: 946-55

Waard, Dd, Brookhuis, KA, Pernot, LMC, Lamers, CT\}, Booij, L, Sikkema, KL, Muntjewerff, ND, Vuurman, EFPM and Riedel, WJ (2000) Een onderzoek naar de effecten van MDMA (ecstasy) op cognitieve- en psychomotorische functies, rijgedrag in de simulator, en consequenties voor de verkeersveiligheid. Rijksuniversiteit Groningen, Groningen, pp 87

Wijngaart, vdG, Braam, R, De Bruin, D, Fris, M, Maalste, N and Verbraeck, H (1997) Ecstasy in het uitgaanscircuit: Sociaal-epidemiologisch onderzoek naar de aard, omvang en risico's van het gebruik van XTC en andere uitgaansdrugs op houseparty's. Centrum voor Verslavingsonderzoek Universiteit Utrecht, Centrum voor Verslavingsonderzoek Universiteit Utrecht

Willekens, M, Samyn, N, De Boeck, G, Maes, V and Verstraete, A (2002) First experience with the new law on DUID in Belgium. Field results and plasma levels of illicit drugs. 16th international council on Alcohol, Drugs and Traffic Safety (ICADTS), Montreal 



\section{CHAPTER 6}

\section{COGNITIVE FUNCTION AND MOOD IN MDMA/THC USERS, THC USERS AND NON-DRUG USING CONTROLS*}

* Submitted for publication as:

Lamers, CTJ, Bechara, A. Rizzo, M. and Ramaekers, JG. Cognitive function and mood in MDMA/THC users, THC users and non-drug using controls 


\section{ABSTRACT}

Repeated Ecstasy (MDMA) use is reported to impair cognition and cause increased feelings of depression and anxiety. Yet, many relevant studies have failed to control for use of drugs other than MDMA, especially marijuana (THC). To address these confounding effects we compared behavioral performance of $11 \mathrm{MDMA} / \mathrm{THC}$ users, 15 THC users and 15 nondrug users matched for age and intellect. We tested the hypothesis that reported feelings of depression and anxiety and cognitive impairment, defined as problems with memory, executive function and decision making, are more severe in MDMA/THC users than in THC users. Results showed that the MDMA/THC users reported more intense feelings of depression and anxiety than THC users and non-drug users. Memory function was impaired in both groups of drug users. MDMA/THC users showed slower psychomotor speed and less mental flexibility than non-drug users. THC users exhibited less mental flexibility and performed worse on the decision making task compared to non-drug users but these functions were similar to those in MDMA/THC users.

The results show that MDMA use is associated with increased feelings of depression and anxiety compared to THC users and non-drug users. THC users were impaired in some cognitive abilities at least in the same degree than MDMA/THC, suggesting that some cognitive impairment attributed to MDMA is more likely due to concurrent THC use.

\section{INTRODUCTION}

Ecstasy mostly relies on the methamphetamine derivate 3,4-methylenedioxymethamphetamine (MDMA) for its psychoactive action. A variety of changes in the serotonin (5HT) system, such as reduced $5 \mathrm{H}$ T levels, up-regulation of $5 \mathrm{HT}$ receptors, and decreased 5-HT transporter binding densities have been observed in abstinent MDMA polydrug users. This indicates an association between repeated MDMA use and long lasting 5HT depletion (McCann et al. 2000; McCann et al. 1994; McCann et al. 1998; Reneman et al. 2000; Reneman et al. 2002).

Normal cognitive performance is often influenced by 5HT (Meneses 1999). Behavioral data show that repeated use of MDMA is associated with cognitive deterioration, including impairment of memory, verbal fluency and impulse control (Bhattachary and Powell 2001; Curran and Travill 1997; McCann et al. 1999; Morgan 1998; 1999; Reneman et al. 2000; Schifano et al. 1998). In addition, low levels of 5HT in MDMA users were also associated with signs of clinical depression (Curran and Travill 1997; Gerra et al. 1998; Parrott and Lasky 1998; Shankaran and Gudelsky 1999).

Yet, most MDMA users also use other drugs, mainly $\Delta^{9}$-tetrahydrocannabinol (THC, marijuana) and alcohol (Schifano et al. 1998; Winstock et al. 2001) and cognitive impairments observed in MDMA users also affect polydrug users who do not use MDMA 
(Parrott et al. 2001). Impairments in THC users are often subtle but include also memory, attention, timing, recognition, reproduction of designs, and the processing, organization and integration of complex information (Hall and Solowij 1998; Robbe 1994; Solowij et al. 2002). Furthermore, the severity of THC-induced impairment appears to depend on duration and frequency of THC use (Hall and Solowij 1998; Solowij et al. 2002). Measuring the effects of MDMA on teported feelings of depression and anxiety and on cognition requires controlling for these effects of THC and other concurrently used drugs. Some researchers who controlled for THC use claim that cognitive deficits are more likely to originate from THC use than from repeated use of MDMA (Croft et al. 2001). Others concluded that use of drugs other than MDMA could not explain cognitive decline in MDMA polydrug users (Gouzoulis-Mayfrank et al. 2000; Morgan 1999; Verkes et al. 2001). Because most studies addressing MDMA neurotoxicity have not controlled for THC use more studies are needed to investigate the separate effects of MDMA and THC on psychological changes and cognition. The current study was designed to assess psychological problems, defined as reported feelings of depression and anxiety, and cognitive impairments in MDMA users, controlling for effects of THC and other drugs. We hypothesized that psychological problems and impairments on cognitive tasks of memory, executive function and decision making, are more severe in MDMA/THC users than in THC users.

\section{METHODS}

\section{SubJECTS}

Forty-two subjects between 21 and 42 years old, recruited through advertisement in a local newspaper in the Iowa-City area, entered the study after completing a short telephone checklist about their drug history. Subjects were excluded if they were currently diagnosed with alcohol or drug dependence, had a serious physical or mental illness (e.g. diagnosed schizophrenia, depression, anti-social behavior), were currently using prescribed psychoactive drugs or were pregnant. According to their drug history subjects were enrolled in the marijuana group (THC), the ecstasy and THC (MDMA/THC) group or the control group. THC users ( 5 females, 10 males) had used THC at least 10 times, but with no history of MDMA use. MDMA/THC users (4 females, 7 females) were defined as regular users of MDMA $>10$ times) and THC $>10$ times). Four of the 15 control subjects ( 6 females, 9 males) had remotely tried THC (on 5 occasions of fewer occasions and not within the preceding 12 months). Subjects were excluded from the study if their frequency of illicit drugs other than THC exceeded that of THC or MDMA use. Participants were asked to abstain from drug use on the day of testing. The study was approved by the IRB of the University of lowa Hospital Clinics (UIHC) and was conducted according to the declaration of Helsinki (1964) and its subsequent amendments. Subjects received a financial compensation for their participation. 


\section{Procedure}

Total duration of testing was approximately 2-2.5 hrs. Difference in intelligence between groups was analyzed using the National Adult Reading Test (NART; (Crawford et al. 2001). The NART consisted of a reading test of 50 words of graded difficulty and provided estimated verbal IQ (VIQ). To secure consistency and objectivity pronunciation of the words was recorded on tape and later evaluated by one psychologist who was unaware of the drug history of the participants.

All subjects were tested for recent drug use by means of a subjective questionnaire as well as by urine drug screen (UA-Screen TM "Dirty 5"). The test was FDA approved for medical and forensic use and tested recent use of THC, amphetamines, methamphetamine, cocaine and opiates.

\section{ASSESSMENTS}

\section{Psychological measures}

Symptoms of anxiety and depression were assessed by the Beck. Anxiety Inventory (BAI; (Beck et al. 1988), and the Beck Depression Index (BDI-II; (Beck et al. 1996), respectively. For both questionnaires items were scored from 0 to 3 with higher scores indicating greater severity of the symptom. Total score of each questionnaire was used as dependent variable.

The Addiction Severity Index (ASI) (McLellan et al. 1992) was a psychometrically sound semistructured 30-45 minute interview that assesses problems in medical, employment, alcohol use, drug use, crime, family, social, and psychiatric domains. Composites scores for recent (past 30 days) severity of problems in these domains were used as dependent variable.

\section{Memory functions}

The Rey Auditory Verbal Learning Test (RALLT) assessed verbal memory and intentional learning (Bohbot et al. 1998). Subjects were asked to produce a list of 15 words immediately after 5 individual sequencing trials and after a 30 minute delay. The latter trial assessed delayed recall. Total score of the five trails and delayed recall score were included as dependent variables.

The Rey Complex Figure test (CFT) was a standard test of visual memory. Subjects were asked to copy a figure with no overall semantic meaning and reproduce the figure after a delay of 30 minutes (Bohbot et al. 1998). To secure consistency and objectivity all drawings were scored according to the guidelines by one psychologist who was unaware of the drug history of the participants. Scores for copy and reproduction (max. 36) were used as dependent variables. 


\section{Executive function}

A computerized version of the Wisconsin Card Sorting Test (WCST) was used to assess executive function. The WCST measured abstract reasoning and ability to shift and maintain set (Dehaene and Changeux 1991). For this task a set of cards had to be matched with one of 4 key cards according to matching principles (color, shape etc.) that changed during the task. Dependent variables were total errors and perseverative errors, defined as persisting to respond to a stimulus characteristic that is incorrect.

The Stroop color-word task was a measure of selective attention and cognitive flexibility and a marker for frontal dysfunction (MacLeod 1991). The original test consisted of 3 subtasks each lasting for 45 seconds. In the first task participants read aloud as many color names written in black ink as possible. In the second task color of trigrams, "XXX", printed in colored ink had to be identified. In the third task subjects identified the color of color names printed in ink differing from the names. Based on alterations of the Stroop by Carter et al (2000), a fourth task was added to the test to combine rules from task 1 and 3; subjects were instructed to read aloud words printed in black and identify the color if the ink when words were written in color (Carter et al. 2000). Two interference scores were calculated. The first interference score (I-1) represented the score of the third task relative to the first and second. The second interference score (I-2) represented the score in the fourth subtask relative to the first two subtasks. I-1 and I-2 were used as dependent variables.

The Trail Making Test (TMT) investigated visual-conceptual and visual-motor tracking skills and involved psychomotor speed and mental flexibility (Radford et al. 1978). Subjects had to connect consecutive numbers randomly arranged on a page (TMT-A) or consecutive numbers and letters in alternating order (TMT-B). Time needed to complete the test A and $B$ (speed) were used as dependent variables. To differentiate difference in cognitive processing from impaired psychomotor speed, cognitive processing and shifting ability was defined as time to complete TMT-B minus time to complete TMT-A (TMT-BA) (Ratti et al. 2002).

\section{Decision making}

The Gambling Task (GT) was originally designed to study cognitive function of patients with frontal lesions who performed normally on neuropsychological tests, but often showed poor judgment in decisions and act in a generally irresponsible manner. The test is described in detail elsewhere (Bechara et al. 2001). Subjects repeatedly chose a card from 4 decks ( $A^{\prime}$, $B^{\prime}, C^{\prime}$ and $\left.D^{\prime}\right)$ that are presented on a computer screen. The computer tracks the sequence of the cards selected from the various decks. After a card is chosen, an amount of money is shown on the screen that is won, intermittently followed by a sum of money that is lost. The 4 decks differ in pay-off so that some decks have larger gain as well as larger penalties. The inter-trial interval between two consecutive cards was set on $1000 \mathrm{msec}$ and number of cards per deck and total number of card selections (trials) was set to 60 and 100 respectively. Decks $\mathrm{A}^{\prime}$ and $\mathrm{B}^{\prime}$ are considered the advantageous decks (moderate gain, but 
smaller penalties) while $C^{\prime}$ and $D^{\prime}$ are disadvantageous decks (higher gain, but higher penalties leading to a negative balance). Net score is calculated by subtracting the total number of cards selected from advantageous decks minus disadvantageous decks $\left(C^{\prime}+D^{\prime}\right)$ $\left(A^{\prime}+B^{\prime}\right)$ and was collected for 5 block of 20 successive cards. Number of subjects per group performing advantageously, defined as total net score $\geq 10$; (Bechara and Damasio 20(1) is also included as dependent variable.

\section{STATISTICS}

All statistical analyses were conducted using the software SPSS 11.0 for Windows. Main group differences were tested using one-way ANOVA with group (controls, THC users and MDMA/THC users) as between subject factor. For the GT ANOVA was used with Group as between factor and Block of cards as within subject factor. Planned Tukey's HSD procedure was used for in-depth analyses of differences between specific groups (controlTHC, control-MDMA/THC and THC-MDMA/THC group) in case the overall group effect was significant $(\mathrm{p} \leq .05)$ or approached significance $(\mathrm{p} \leq .06)$. Tukey's HSD test uses the studentized range statistic to make all of the pairwise comparisons between groups and sets the experimentwise error rate at the error rate for the collection for all pairwise comparisons. In case of the GT, post-hoc $\chi^{2}$ was conducted for analyzing number of subjects performing advantageously and to compare gender ratio between groups. All tests were two-tailed and criterion for significance was set on $\mathrm{p}<.05$.

\section{RESULTS}

Table 1 presents demographic characteristics and their statistics (main effect and Tukey's HSD procedure) of the 3 study groups. History of drug use is presented in table 2 . One THC user did not perform the GT correctly and his GT data were not included in the analyses.

Analyses showed that frequency of alcohol use was significantly lower in non drug users than in THC and MDMA/THC users. Furthermore, 19 of the 26 drug users tested positive for THC on the day of testing (see Subjects section). Therefore additional analyses were conducted to investigate a possible influence of these three factors on task performance finding. All analyses were repeated twice: once with all subjects with lifetime alcohol use and THC use as covariates and once with THC and MDMA/THC users with days of THC abstinence as covariate. The results are reported at the end of the result section. 
Table 1. Mean (SD) characteristics of the subjects and their statistics. Overall group effect is analyzed using 'neway ANOV $\Lambda$ (F-value). Group comparisons were analyzed by means of post-hoc Tukey's HSD test.

Mean (SD)

ANOVA [F(2,39)]

\begin{tabular}{lcccc}
\hline Variable & $\begin{array}{l}\text { Controls } \\
\mathbf{N = 1 5}\end{array}$ & $\begin{array}{l}\text { THC users } \\
\mathbf{N = 1 5}\end{array}$ & $\begin{array}{l}\text { MDMA/THC users } \\
\mathbf{N}=11\end{array}$ & Group effect \\
\hline Age (yrs) & $23.9(3.2)$ & $24.3(5.3)$ & $22.9(2.4)$ & 0.422 \\
Education (yrs) & $16.5(1.2)$ & $15.3(1.4)$ & $15.6(0.5)$ & $4.206^{*}$ \\
Verbal IQ (NART) & $109.1(4.5)$ & $108.8(4.7)$ & $104.3(6.8)$ & 3.055 \\
\hline
\end{tabular}

${ }^{*} p<.05$

\section{SUBJECTS}

15 Non-drug using controls, 15 regular THC users and 11 MDMA/THC users completed the study. One subject did not complete cognitive testing due to personal reasons and was excluded from further analyses. Absolute number of females differed between the 3 study groups, but there was no significant difference in gender between the groups $\left(\mathrm{X}^{2}=0.144\right.$, $\mathrm{p}=\mathrm{ns})$. While all controls produced a negative drug screens, 7 MDMA users (64\%) and 12 THC users $(80 \%)$ produced positive urine drug screens for THC (level of detection $\geq 50$ $\mathrm{ng} / \mathrm{ml}$ ). At this level, THC can be detected for 1-30 days, depending on level of use, potency of the drug etc. In the current study no participant tested positive for THC use when reported THC use was more than 7 days ago. Reported mean days of abstinence of THC did not differ between groups of drug users (see table 1). With the exception of 1 male non control and 1 female THC user who were 33 and 42, respectively, all subjects were between 21 and 28 years of age. Groups did not differ in age and mean age of males and females did not differ between groups $F[2.35]=1.058, \mathrm{p}=\mathrm{ns}$. THC users had less years of education relative to controls (Tukey's HSD: $\mathrm{p}=.03$ ). This difference in education was marginal however $(1.2 \mathrm{yrs})$ and since VIQ did not differ significantly between groups, may be considered clinically irrelevant. Years of education, VIQ, frequency of alcohol and illicit drugs use, other than MDMA, did not differ significantly between the 2 groups of drug users (see table 2). In regard to most other studies that have investigated MDMA users, participants in the current study can be regarded as mild to moderate users (Gerra et al. 1998; McCann et al. 1998; Reneman et al. 2000; Reneman et al. 2001; Semple et al. 1999). 


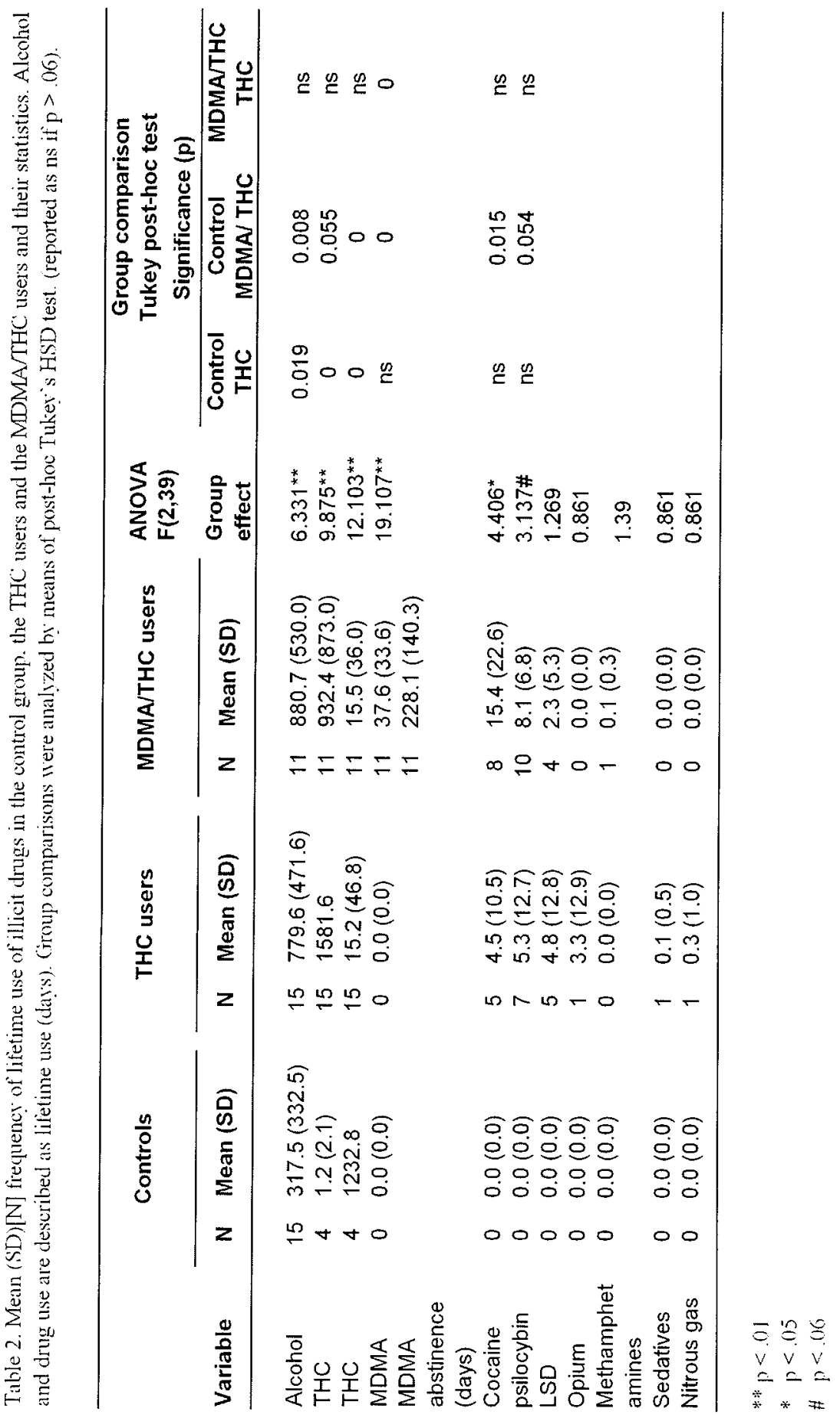


Table 3. Mean (SD) reported depression (BDI-II) and anxicty (BAI), findings on the Addiction Severity Index (ASI) and cognitive task performance and their statistics. Group comparisons are only reported when overall group effect (ANOVA) showed at least trend significance $(p<.06)$. P-values are reported as ns if $p>.06)$.

\begin{tabular}{|c|c|c|c|c|c|c|c|}
\hline \multirow[b]{2}{*}{ Variable } & \multicolumn{3}{|l|}{ Mean (SD) } & \multirow{2}{*}{$\begin{array}{l}\text { ANOVA } \\
\text { F(2,38) } \\
\text { Group } \\
\text { effect }\end{array}$} & \multicolumn{3}{|c|}{$\begin{array}{l}\text { Tukey's Post-hoc test } \\
\text { Significance }(p)\end{array}$} \\
\hline & $\begin{array}{l}\text { Controls } \\
\mathrm{N}=15\end{array}$ & $\begin{array}{l}\text { THC users } \\
\mathrm{N}=15\end{array}$ & $\begin{array}{l}\text { MDMAl } \\
\text { THC users } \\
\mathrm{N}=11 \\
\end{array}$ & & $\begin{array}{l}\text { Control } \\
\text { THC }\end{array}$ & $\begin{array}{l}\text { Control } \\
\text { MDMAV } \\
\text { THC } \\
\end{array}$ & $\begin{array}{l}\text { MDMATTHC } \\
\text { THC }\end{array}$ \\
\hline \multicolumn{8}{|c|}{ Psychological measures } \\
\hline BDI-II & $2.5(2.2)$ & $4.4(3.9)$ & $9.8(12.0)$ & $3.955^{\star}$ & ns & .024 & ns \\
\hline BAI & $4.0(4.3)$ & $2.9(1.9)$ & $10.3(10.4)$ & $5.263^{\star \star}$ & ns & .034 & .010 \\
\hline ASI-alcohol & $0.08(0.05)$ & $0.19(0.13)$ & $0.23(0.09)$ & $8.810^{* *}$ & .008 & .001 & ns \\
\hline ASI-drug & $0.00(0.00)$ & $0.07(0.05)$ & $0.06(0.05)$ & $10.732^{\star \star}$ & .000 & .002 & ns \\
\hline ASI-medical & $0.06(0.17)$ & $0.11(0.17)$ & $0.03(0.08)$ & 0.912 & & & \\
\hline ASI-psychiatric & $0.05(0.07)$ & $0.02(0.07)$ & $0.16(0.20)$ & $4.664^{*}$ & ns & .059 & .015 \\
\hline ASI-employment & $0.31(0.20)$ & $0.32(0.17)$ & $0.28(0.17)$ & 0.125 & & & \\
\hline ASI-social & $0.03(0.07)$ & $0.04(0.05)$ & $0.07(0.09)$ & 1.247 & & & \\
\hline ASI-legal & $0.00(0.00)$ & $0.05(0.10)$ & $0.05(0.10)$ & 2.069 & & & \\
\hline \multicolumn{8}{|l|}{ Memory } \\
\hline $\begin{array}{l}\text { Rey O' figure } \\
\text { Copy (score) }\end{array}$ & $35.1(1.1)$ & $33.4(4.3)$ & $34.4(1.7)$ & 1.340 & & & \\
\hline $\begin{array}{l}\text { Rey O' figure } \\
\text { Recall (score) }\end{array}$ & $23.7(4.2)$ & $22.3(6.8)$ & $20.6(7.6)$ & 0.784 & & & \\
\hline $\begin{array}{l}\text { RAVLT recall } \\
\text { (total words) }\end{array}$ & $60.0(5.3)$ & $52.3(7.1)$ & $51.5(7.6)$ & $7.067^{\star \star}$ & .008 & .007 & $\mathrm{~ns}$ \\
\hline $\begin{array}{l}\text { RAVLT delayed } \\
\text { recall }\end{array}$ & $13.1(1.5)$ & $10.7(3.5)$ & $11.6(2.8)$ & $2.825 \#$ & .060 & ns & ns \\
\hline \multicolumn{8}{|c|}{ Executive functions } \\
\hline Trail A (sec) & $19.0(5.7)$ & $22.3(8.5)$ & $26.8(9.7)$ & $3.051 \#$ & ns & .047 & ns \\
\hline Trail B (sec) & $38.1(9.3)$ & $45.0(13.3)$ & $51.0(17.7)$ & $3.013 \#$ & ns & .051 & ns \\
\hline Trail BA (sec) & $19.1(6.4)$ & $22.7(2.5)$ & $24.2(3.8)$ & 1.005 & & & \\
\hline Stroop CW' 1 & $10.6(5.4)$ & $10.6(9.8)$ & $16.3(17.4)$ & 1.015 & & & \\
\hline Stroop CW 2 & $48.2(9.9)$ & $39.5(9.1)$ & $40.5(9.0)$ & $3.703^{*}$ & .040 & ns & ns \\
\hline WCST total error & $11.3(6.4)$ & $12.9(7.3)$ & $11.5(7.8)$ & 0.235 & & & \\
\hline $\begin{array}{l}\text { WCST } \\
\text { perseverative error }\end{array}$ & $6.7(4.0)$ & $7.6(5.1)$ & $6.0(3.5)$ & 0.417 & & & \\
\hline $\begin{array}{l}* \quad p<.01 \\
\star \quad p<.05 \\
\# \quad p<.06\end{array}$ & & & & & & & \\
\hline
\end{tabular}

\section{PSYCHOLOGICAL MEASURES (BDI-II, BAI AND ASI)}

Relative to non-drug users, MDMA/THC users score on BAI was higher and their BDI-II score was higher than both non-drug users and THC users (see figure 1 and table 3). BDI-II and BAI scores did not differ between non-drug users and THC users.

ASI scores showed similar alcohol and other drug use profiles in the MDMA/THC and THC users, both drug groups reported greater alcohol use than non-drug users (see table 3). MDMA/THC users showed greater psychiatric problems than non-drug users and THC users, although the latter comparison reached only a tendency for significance. There was no difference in psychiatric problems between THC users and non-drug users. Problems in the medical, employment, social or legal field did not differ in severity between groups. 
Figure 1 Mean score ( $+\mathrm{sc}$ ) of the Beck Anxiety Index and the Beck Depression Index-2 as a function of group.

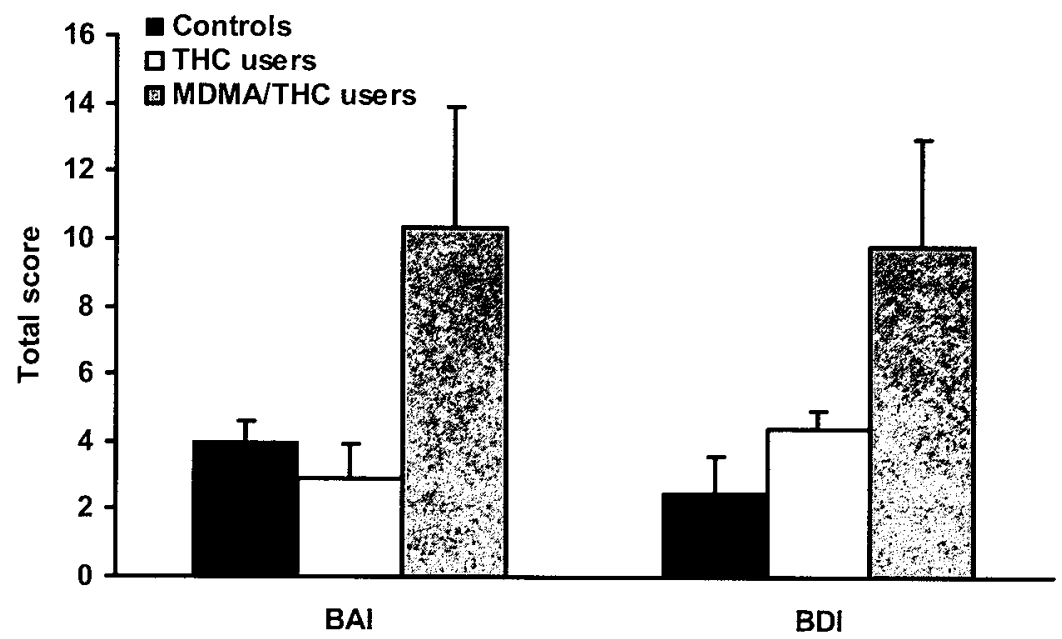

\section{MEMORY FUNCTIONS (RAVLT AND CFT)}

Immediate recall did not differ between MDMA/THC and THC users but was impaired in both these groups as compared to non-drug users (see figure 2). After 30 minutes THC users tended to recall fewer words as compared to non-drug users, but this effect was not significant. Delayed recall in MDMA/THC users did not differ from THC users or nondrug uscrs. Groups did not differ in total score of the copy and reproduction trial of the CFT.

Figure 2 Mean (+ se) word score per trail in the Rey Auditive Verbal Learning Task as a function of group.

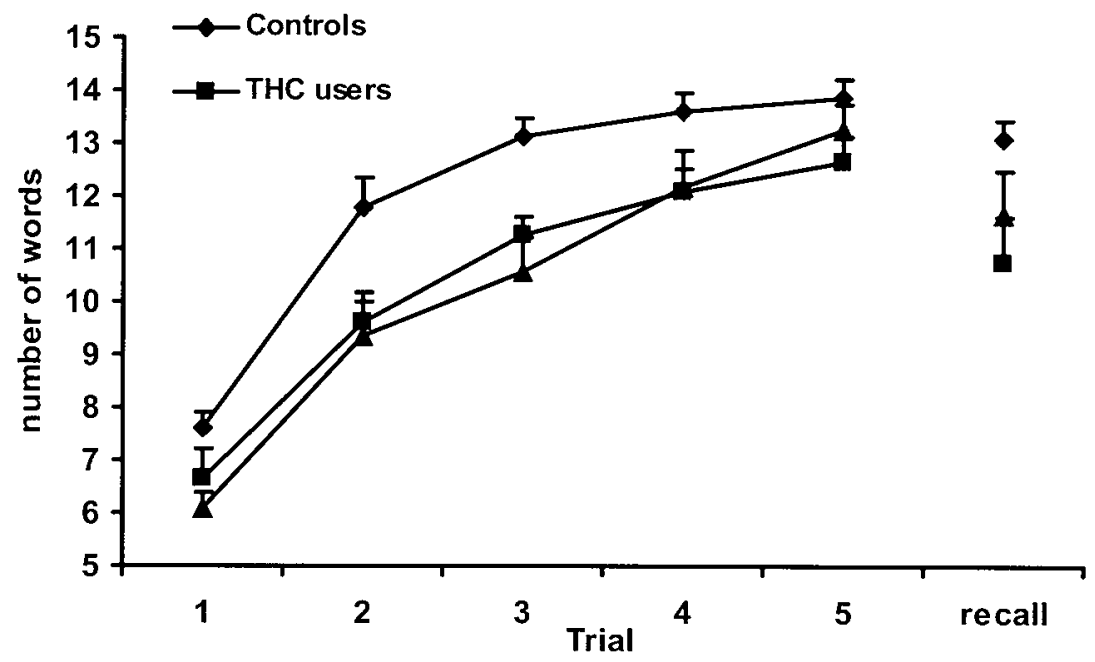




\section{EXECUTIVE FUNCTION (WCST, STROOP AND TMT)}

On the WCST, the groups did not differ in number of total errors and perseverative crrors. On the Stroop test, the groups did not differ on the I-1 score. The I-2 score was significantly lower in THC users than in non-drug users, but MDMA/THC users did not differ significantly from non-drug users or THC users. MDMA/THC users, but not THC users, needed more time to complete TMT-A and TMT-B than non-drug users; the time needed measure did not differ between the drug user groups. Calculated TMT-BA did not differ between groups.

\section{DECISION MAKING (GT)}

Figure 3 presents mean performances of the 3 study groups on the Decision Making Task per block of 20 cards. An overall group effect on the net score of the GT was observed $(\mathrm{F}[2,37]=4.026, \mathrm{p}=.026)$. A main effect was found for within factor Block of cards $(\mathrm{F}[4,34]=14.009, \mathrm{p}<.01)$ but no significant interaction was observed between Block of cards and Group $(\mathrm{F}[8,70]=0.598, \mathrm{p}=\mathrm{ns})$. This indicates that performance of subjects, regardless of group, became more advantageously as the test progressed. Analyses of the effect of Group using Tukey's HSD procedure showed that performance of MDMA/THC users did not differ from that of non-drug users $(p=.124)$ and THC users $(p=.869)$. THC users performed less well than non-drug users $(\mathrm{p}=.026)$. Post hoc analyses showed a trend toward more controls performing advantageously than THC users $\left(\chi^{2}=2.727, \mathrm{p}=.099\right)$. No other group differences in advantageous performance were detected $\left(\chi^{2} \leq 1.896, \mathrm{p}=\mathrm{ns}\right)$.

Figure 3 Mean performance ( + se) on the GT as a function of group and decks of 20 cards.

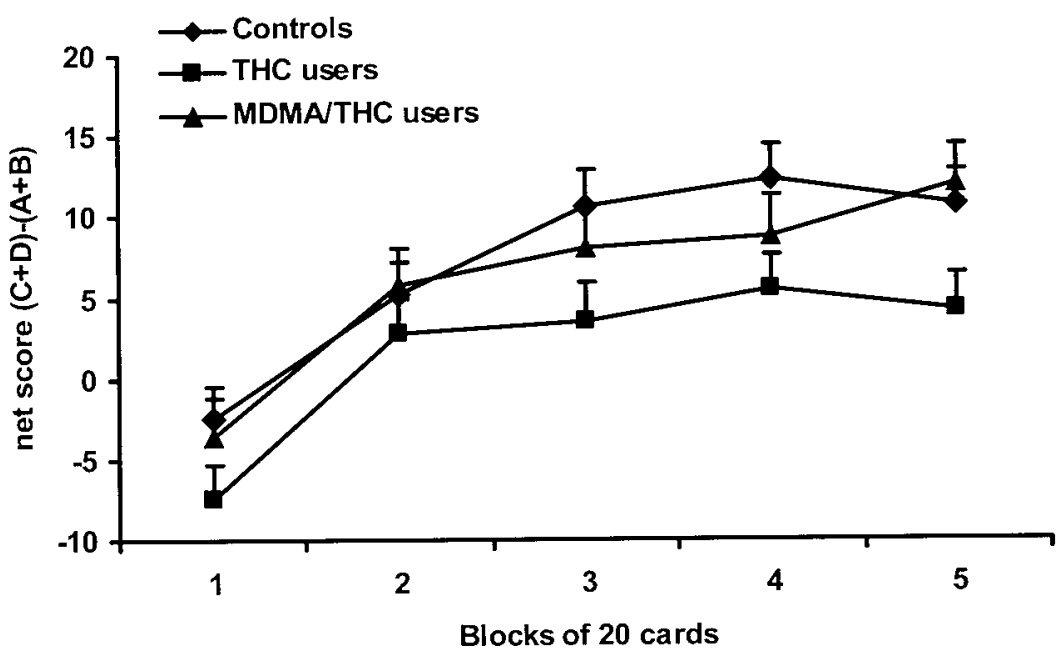




\section{COVARIATES}

Variables are only reported if their significance changed after implementing the covariates lifetime alcohol or THC use and THC abstinence. Changes are discussed per covariate.

\section{LIFETIME ALCOHOL USE}

Feelings of depression did not differ significantly between the 2 drug groups, but when frequency of alcohol use was included as a covariate, significance increased indicating higher level of feelings of depression in MDMA/THC users compared to THC users $(p=.039)$. Also, the trend significance indicating impaired delayed memory (RAVLT) in THC users compared to non drug users became significant after lifetime alcohol use was controlled for $(\mathrm{p}=.017)$.

\section{LIFETIME THC USE}

For difference in feelings of anxiety, significance increased when we controlled for lifetime THC use, indicating increased anxiety in MDMA/THC users as compared to THC users $(\mathrm{p}=.041)$. Impaired performance in the GT was observed between THC users relative to non drug users only but when frequency of THC use was included as a covariate, performance between THC users and MDMA/THC users became significantly different as well $(p=.039)$.

MDMA/THC users needed more time to complete both subtasks of the TMT. After including frequency of THC use as a covariate, MDMA/THC's speed in Trail B no longer differed significantly from that of non drug users, although a trend was still detected $(p=.065)$.

\section{THC ABSTINENCE}

Number of days that THC and MDMA/THC users reported to be abstinent from THC did not affect task performance observed in the current study suggesting that results were not influenced by residual effects of recent THC use.

\section{DISCUSSION}

The current study assessed differences in feelings of depression and anxiety and cognitive functioning between MDMA/THC users, non-drug users and THC users. 


\section{Psychological MEASURES}

We found that MDMA/THC users reported more symptoms of anxiety than non drug users and THC users. A similar finding was observed for feelings of depression when we controlled for frequency of alcohol and THC use suggesting that increased feelings of depression related to use of MDMA, rather than use of alcohol or THC. Increased feelings of depression have been observed previously on days directly following MDMA use (Curran and Travill 1997; Peroutka et al. 1988) and after longer periods of abstinence (Gamma et al. 2001; Gamma et al. 2000; Gerra et al. 1998; Morgan 2000), presumably due to effects on serotoninergic systems. MDMA, but not THC, may cause long term 5HT depletion in abstinent users (Kish et al. 2000; Reneman et al. 2002; Shankaran and Gudelsky 1999; Shankaran et al. 1999). Feelings of anxiety were significantly higher in MDMA/THC users compared to THC users, even after we corrected for frequency of alcohol use and THC use. These findings supports the suggestion that MDMA, rather than THC, may be involved in increased feelings of depression in MDMA/THC users.

\section{MEMORY FUNCTIONS}

In this study MDMA/THC usets and THC users exhibited problems acquiring new verbal information and needed more trials to adequately store the information. Their retrieval of words 30 minutes after presentation was not significantly impaired, although there was a trend for impaired delayed recall in THC users relative to non drug users. When frequency of alcohol use was introduced as a covariate, this impairment in delayed recall in THC users became significant, suggesting that THC use may also affect retrieval from memory. Visual memory assessed by reproduction of a complex figure copied 30 minutes earlier was not affected. Along similar lines, Croft et al (2001) found that memory functions of MDMA/THC users resembled that of THC users as in the current study, indicating that observed deficits in memory function in the former group may be attributed to repeated use of 'THC, rather than MDMA.

Other studies using similar study designs have shown memory impairments in MDMA/THC users as compared to THC users and non users controls (GouzoulisMayfrank et al. 2000; Morgan 1999; Verkes et al. 2001). Possibly, the groups investigated in these studies were better matched for lifetime use of THC and/or consisted of heavy users of MDMA as compared to the MDMA group in the current study. An association between MDMA use and memory impairment was shown by Bolla et al (1998). Although the current findings indicate that THC use may be responsible for memory impairment in MDMA/THC users, these findings do not conclusively rule out an additive role of MDMA in the observed impairment. Since both marijuana and MDMA are known to induce memory impairment, it is likely that both drugs play an additive role in this matter. 


\section{EXECUTIVE FUNCTION}

Several aspects of executive functions were assessed in the current study. Performance on the WCST was not impaired in MDMA/THC users and THC users indicating that abstract reasoning was not affected.

Performance on the original versions of the Stroop test was not affected in MDMA/THC users and THC users. These findings are in line with most research (reviewed by (Parrott 2000) although some researchers report impaired performance on the Stroop test in abstinent MDMA users (Croft et al. 2001). In the current study, a new subtask was added to the Stroop test in which subjects had to read color names printed in black and identify the color of words printed in blue, red or yellow. This subtask adds an extra dimension to the test. Not only are subjects required to suppress irrelevant information, but additionally have to shift between applying rules. It has been suggested that THC users are vulnerable to increasing task complexity creating more sources of interference (Solowij et al. 2002). The present impairment in Stroop performance in THC users may indicate problems with mental shifting and motor inhibition in more complex situations.

Performance on the Trail Making Task requires mental flexibility and explores visualconceptual and visual-motor tracking skills which are based on psychomotor speed, divided attention, mental flexibility and the ability to shift (Ratti et al. 2002; Townsend et al. 2001). Performance on the TMT was not significantly affected in THC users but MDMA/THC users exhibited impaired performance as compared to non-drug users. MDMA/THC users needed more time for TMT-A, reflecting psychomotor speed, and for TMT-B, considered a measure of shifting ability and cognitive processing speed. This effect on TMT-B in MDMA/THC users changed to trend significance when we corrected for lifetime THC use, suggesting that frequency of THC use might have been associated with slower speed on this subtask. Furthermore, once we corrected performance on TMT-B for impaired psychomotor speed on TMT-A, the performance difference between groups was no longer significant. This may indicate that performance on this task by MDMA/THC users may rely on impaired psychomotor speed rather than impaired cognitive processing speed.

In summary, users of MDMA/THC and THC users displayed some specific deficits in executive function. Since performance did not differ between these groups of drug users, impairment can not exclusively attributed to use of MDMA. Drug users in the current study may exhibit problems with psychomotor speed, concept shifting and response inhibition in complex situations while abstract reasoning is not affected.

\section{DECISION MAKING}

The GT assesses the ability to balance immediate rewards against long-term negative consequences. According to Grant et al (2000) the task has strong validity for evaluating a cognitive deficit that may contribute to drug use. Poor decision making has been observed in poly drug users in prior studies (Bechara and Damasio 2002; Grant et al. 2000; Rogers et 
al. 1999). This is in line with findings of the current study where users of THC performed more disadvantageously as compared to non-drug user. There was no significance difference between MDMA/THC users and controls. Once we controlled for frequency of THC use performance of THC users became significantly worse than that of MDMA/THC users, suggesting that frequency of THC use might be associated with poor performance on the GT. Furthermore, the percentage of subjects performing disadvantageously was lower in controls than in THC users and MDMA/THC users although only the difference between controls and THC users reached trend significance (respectively 13\%, 40\% and $36 \%$ of the total subjects per group). The latter suggests that even relative mild drug use may be associated with poor decision making. The ventromedial region may function as a link between certain categories of events stored in memory records and the activation of these events in working memory during decision making processing (Bechara 2002). When memory function is impaired, as in drug users in the current study, decision making may be compromised. At least a subgroup of drug users displayed poor performance on decision making. Poor decision making in drug users make it more likely that they maintain their current drug use and have more problems discontinuing drug use because they tend to choose immediate reward (desired effects of a drug) over future consequences (financial and social problems etc.).

\section{LIMITATIONS}

Some potential limitations of the current study need to be addressed. First, because substance abuse often co-exists with psychopathology and cognitive impairment (Lin et al. 1998), we cannot exclude whether psychopathology antedated drug use in some participants, e.g., attempted self-medication in subjects with cognitive distress. Second, some of the observed cognitive deficits might reflect effects of recent THC use in certain individuals. This is because $8 \mathrm{THC}$ users and $4 \mathrm{MDMA} / \mathrm{THC}$ users reported THC use the day before assessment and 2 THC users and 2 MDMA/THC users used THC 2-3 days before assessment. Results from the drug screen were consistent with subjective reports of recent drug use by participants. Residual effects on cognitive functioning existing a day after THC use often proof to be subtle, inconsistent and of little clinically importance (Chait 1990; Chait and Perry 1994; Fant et al. 1998; Pope et al. 2001). Of note, mean time of THC abstinence (15 days) did not differ between MDMA/THC users and THC users. Furthermore, results did not change when number of days since last THC use was included as a covariate in the statistical analyses. Group differences observed in the present study are therefore most likely not affected by residual effects of recent THC use. Third, mean frequency of MDMA use was relatively low compared to that in other studies of long-term effects of MDMA. Compared to other studies investigating effects of MDMA and THC in abstinent drug users, participants in the current study can be regarded as mild to moderate recreational users. Greater frequency and number of MDMA pills used are associated with greater task performance impairments (Bhattachary and Powell 2001; Bolla et al. 1998). 
Therefore the current study may have underestimated cognitive impairment and feclings of depression and anxiety in drug users who used MDMA more frequently. Fourth, the sample size of the current study was relatively small. It can not be excluded that tests on which performance is apparently unimpaired in THC or MDMA/THC users in the current study, may have been not sensitive enough to pick up subtle impairment due to the relative small sample size. Finally, it is sometimes suggested that an amotivational syndrome might be responsible for impairment in users of THC, rather than cognitive deterioration. The amotivational syndrome is associated with marijuana use and includes apathy, loss of effectiveness and decreased willingness to carry out complex long-term plans (McGlothlin and West 1968). Prior studies have shown that the syndrome is observed only in heavy marijuana users (use more than 4-6 times a week for an average of 6 years) who recently suffered from depression (Musty and Kaback 1995). In comparison, use of marijuana in participants of the present study was mild and none of them was diagnosed with depression in the last year. Furthermore, if drug using subjects in the current study were not motivated to perform well on tests during the experiment, we would have observed impaired performance on all the tests that were assessed. On a personal note, many drug users in the present study expressed that one of the reasons for their participation was to prove that drug use had not impaired their cognitive performance. It is therefore unlikely that current findings result from unmotivated participants, rather than from other variables, such as drug use.

In conclusion, we observed that increments in anxiety and depression may be specific to MDMA users since none of those were observed in the group of THC users or non-drug controls. Cognitive impairments were evident in both the MDMA/THC group and the THC group. Memory disturbances were similar in both groups of drug users and impaired in regard to controls. Some impairments, i.e. poor decision making and mental flexibility, appeared specific to the THC group alone while impaired motor responses was more prevalent in MDMA/THC users.

\section{ACKNOWLEDGEMENTS}

The authors would like to thank Nicole Skaar, Cynthia Cutshal, Jennifer Smothers, Matt Wilson and Carol Devore for their help during the project. This project was supported by NIDA grants DA11779 and DA12487 in the United States and the Foundation De Drie Lichten in The Netherlands. 


\section{REFERENCES}

Bechara A (2002) The neurology of social cognition. Brain 125: 1673-5

Bechara A, Damasio H (2002) Decision-making and addiction (part I): impaired activation of somatic states in substance dependent individuals when pondering decisions with negative future consequences. Neuropsychologia 40: 1675-89

Bechara A, Dolan S, Denburg N, Hindes A, Anderson SW, Nathan PE (20)1) Decision-making deficits, linked to a dysfunctional ventromedial prefrontal cortex, revealed in alcohol and stimulant abusers. Neuropsychologia 39: 376-89

Beck AT, Epstein N, Brown G, Steer RA (1988) An inventory for measuring clinical anxiety: psychometric properties. Journal of Consulting and Clinical Psychology 56: 893-7

Beck AT, Steer RA, Ball R, Ranieri W (1996) Comparison of Beck Depression Inventories -IA and -II in psychiatric outpatients. Journal of Personality Assessment 67: 588-97

Bhattachary S, Powell JH (2001) Recreational use of 3,4-methylenedioxymethamphetamine (MDMA) or 'ecstasy': evidence for cognitive impairment. Psychological Medicine 31: 647-58.

Bohbot VD, Kalina M, Stepankova K, Spackova N, Petrides M, Nadel L (1998) Spatial memory deficits in patients with lesions to the right hippocampus and to the right parahippocampal cortex. Neuropsychologia 36: 1217-38

Bolla KI, McCann UD, Ricaurte GA (1998) Memory impairment in abstinent MDMA ("Ecstasy") users. Neurology 51: 1532-7

Carter CS, Macdonald AM, Botvinick M, Ross LL, Stenger VA, Noll D, Cohen JD (2000) Parsing executive processes: strategic vs. evaluative functions of the anterior cingulate cortex. Proceedings of the National Academy of Sciences of the United States of America 97: 1944-8

Chait LD (1990) Subjective and behavioral effects of marijuana the morning after smoking. Psychopharmacology 100: 328-33

Chait LD, Perry JL (1994) Acute and residual effects of alcohol and marijuana, alone and in combination, on mood and performance. Psychopharmacology 115: 340-9

Croft RJ, Mackay AJ, Mills AT, Gruzelier JG (2001) The relative contributions of ecstasy and cannabis to cognitive impairment. Psychopharmacology 153: 373-9.

Curran HV, Travill RA (1997) Mood and cognitive effects of +-3,4-methylenedioxymethamphetamine (MDMA, "ecstasy"): Week-end "high" followed by mid-week low. Addiction 92: 821-831

Dehaene S, Changeux JP (1991) The Wisconsin Card Sorting Test: theoretical analysis and modeling in a neuronal network. Cerebral Cortex 1: 62-79

Fant RV, Heishman SJ, Bunker EB, Pickworth WB (1998) Acute and residual effects of marijuana in humans. Pharmacology, Biochemistry and Behavior 60: 777-84

Gamma A, Buck A, Berthold T, Vollenweider FX (2001) No difference in brain activation during cognitive performance between ecstasy (3,4-methylenedioxymethamphetamine) users and control subjects: a [H2(15)O]-positron emission tomography study. Journal of Clinical Psychopharmacology 21: 66-71.

Gamma A, Frei E, Lehmann D, Pascual Marqui RD, Hell D, Vollenweider FX (2000) Mood state and brain electric activity in ecstasy users. Neuroreport 11: 157-62

Gerra G, Zaimovic A, Giucastro G, Maestri D, Monica C, Sartori R, Caccavari R, Delsignore R (1998) Serotonergic function after (+/-)3,4-methylene-dioxymethamphetamine ('Ecstasy') in humans. International Clinical Psychopharmacology 13: 1-9

Gouzoulis-Mayfrank E, Daumann J, Tuchtenhagen F, Pelz S, Becker S, Kunert HJ, Fimm B, Sass H (2000) Impaired cognitive performance in drug free users of recreational ecstasy (MDMA). Journal of Neurology, Neurosurgery and Psychiatry 68: 719-25

Grant S, Contoreggi C, London ED (2000) Drug abusers show impaired performance in a laboratory test of decision making. Neuropsychologia 38: 1180-7

Hall W, Solowij N (1998) Adverse effects of cannabis. Lancet 352: 1611-6 
Kish SJ, Furukawa Y, Ang L, Vorce SP, Kalasinsky KS (2000) Striatal scrotonin is depleted in brain of a human MDM $\Lambda$ (Ecstasy) user. Neurology 55: 294-6

Lin CC, Bai YM, Hu PG, Yeh HS (1998) Substance use disorders among inpatients with bipolar disorder and major depressive disorder in a general hospital. General Hospital Psychiatry 20: 98-101

MacLeod CM (1991) Half a century of research on the Stroop effect: an integrative review. Psychological Bulletin 109: 163-203

McCann UD, Eligulashvili V, Ricaurte GA (2000) (+/-)3,4-Methylenedioxymethamphetamine ('Ecstasy')-induced serotonin neurotoxicity: clinical studies. Neuropsychobiology 42: 11-6

McCann UD, Mertl M, Eligulashvili V, Ricaurte GA (1999) Cognitive performance in (+-) 3,4methylenedioxymethampetamine (MDMA, 'ecstacy') users: a controlled study. Psychopharmacology 143: 417-425

McCann UD, Ridenour A, Shaham Y, Ricaurte GA (1994) Serotonin neurotoxicity after (+/-)3,4methylenedioxymethamphetamine (MDMA; "Ecstasy"): a controlled study in humans. Neuropsychopharmacology 10: 129-38

McCann UD, Szabo Z, Scheffel U, Dannals RF, Ricaurte GA (1998) Positron emission tomographic evidence of toxic effect of MDMA ("Ecstasy") on brain serotonin neurons in human beings. Lancet 352: 1433-7

McGlothlin WH, West LJ (1968) The marihuana problem: an overview. American Journal of Psychiatry 125: 126-34

McLellan AT, Kushner H, Metzger D, Peters R, Smith I, Grissom G, Pettinati H, Argeriou M (1992) The Fifth Edition of the Addiction Severity Index. Journal of Substance Abuse Treatment 9: 199-213 Meneses A (1999) 5-HT system and cognition. Neuroscience and Biobehavioral Reviews 23: 1111-25

Morgan MJ (1998) Recreational use of "ecstasy" (MDMA) is associated with elevated impulsivity: Neuropsychopharmacology 19: 252-64

Morgan MJ (1999) Memory deficits associated with recreational use of "ecstasy" (NDMA). Psychopharmacology 141: 30-6

Morgan MJ (2000) Ecstasy (MDMA): a review of its possible persistent psychological effects. Psychopharmacology 152: 230-48.

Musty RE, Kaback L (1995) Relationships between motivation and depression in chronic marijuana users. Life Sciences 56: 2151-8

Parrott AC (2000) Human research on MDMA (3,4-methylene- dioxymethamphetamine) neurotoxicity: cognitive and behavioural indices of change. Neuropsychobiology 42: 17-24

Parrott AC, Lasky J (1998) Ecstasy (MDMA) effects upon mood and cognition: before, during and after a Saterday night dance. Psychopharmacology 139: 261-268

Parrott AC, Milani RM, Parmar R, Turner JD (2001) Recreational ecstasy/MDMA and other drug users from the UK and Italy: psychiatric symptoms and psychobiological problems. Psychopharmacolog: 159: 77-82.

Peroutka SJ, Newman $H$, Harris $H$ (1988) Subjective effects of 3,4-methylenedioxymethamphetamine in recreational users. Neuropsychopharmacology 1: 273-7.

Pope HG, Jr., Gruber AJ, Yurgelun-Todd D (2001) Residual neuropsychologic effects of cannabis. Curr Psychiatry Rep 3: 507-12

Radford LM, Chaney EF, O'Leary MR, O'Leary DE (1978) Screening for cognitive impairment among inpatients. Journal of Clinical Psychiatry 39:712-5

Ratti MT, Bo P, Giardini A, Soragna D (2002) Chronic alcoholism and the frontal lobe: which executive functions are imparied? Acta Neurologica Scandinavica 105: 276-81

Reneman I, Booij J, Schmand B, van den Brink W, Gunning B (2000) Memory disturbances in "Ecstasy" users are correlated with an altered brain serotonin neurotransmission. Psychopharmacology 148: 322-4 
Reneman L, Endert E, de Bruin K, Javalaye J, Feenstra MG, de Wolff FA, Beolij J (2r)2) The acute and chronic effects of MDMA ("ecstasy") on cortical 5-HT2A receptors in rat and human brain. Neuropsychopharmacology 26: 387-96

Reneman L, Lavalaye J, Schmand B, de Wolff FA, van den Brink W, den Hecten GJ, Boroij J (20)1, Cortical serotonin transporter density and verbal memory in individuals who stopped using 3,4methylenedioxymethamphetamine (MDMA or "ecstasy"): preliminary findings. Archives of General Psychiatry 58: 901-6

Robbe HWJ (1994) Influence of Marijuana on Driving. University of Maastricht, University of Maastricht

Rogers RD, Everitt BJ, Baldacchino A, Blackshaw AJ, Swainson R, Wynne K, Baker NB, Hunter J, Carthy T, Booker E, London M, Deakin JF, Sahakian BJ, Robbins TW (1999) Dissociable deficits in the decision-making cognition of chronic amphetamine abusers, opiate abusers, patients with focal damage to prefrontal cortex, and tryptophan-depleted normal volunteers: evidence for monoaminergic mechanisms. Neuropsychopharmacology 20: 322-39

Schifano F, Di Furia L, Forza G, Minicuci N, Bricolo R (1998) MDMA (ecstasy') consumption in the context of polydrug abuse: a report on 150 patients. Drug and Alcohol Dependence 52: 85-90)

Semple DM, Ebmeier KP, Glabus MF, O'Carroll RE, Johnstone EC (1999) Reduced in vivo binding to the serotonin transporter in the cerebral cortex of MDMA (ecstasy') users. British Journal of Psychiatry 175: 63-69

Shankaran M, Gudelsky GA (1999) A neurotoxic regimen of MDMA suppresses behavioral, thermal and neurochemical responses to subsequent MDMA administration. Psychopharmacology 147: 66-72

Shankaran M, Yamamoto BK, Gudelsky GA (1999) Involvement of the serotonin transporter in the formation of hydroxyl radicals induced by 3,4-methylenedioxymethamphetamine. European Journal of Pharmacology 385: 103-10

Solowij N, Stephens RS, Roffman RA, Babor T, Kadden R, Miller M, Christiansen K, McRee B, Vendetti J (2002) Cognitive functioning of long-term heavy cannabis users seeking treatment. Jama 287: 1123-31

Townsend LA, Malla AK, Norman RM (2001) Cognitive functioning in stabilized first-episode psychosis patients. Psychiatry Research 104: 119-31

Verkes RJ, Gijsman HJ, Pieters MS, Schoemaker RC, de Visser S, Kuijpers M, Pennings EJ, de Bruin D, Van de Wijngaart G, Van Gerven JM, Cohen AF (2001) Cognitive performance and serotonergic function in users of ecstasy. Psychopharmacology 153: 196-202.

Winstock AR, Griffiths P, Stewart D (2001) Drugs and the dance music scene: a survey of current drug use patterns among a sample of dance music enthusiasts in the UK. Drug and Alcohol Dependence 64: $9-17$ 

CHAPTER 7

\section{SIMULATED DRIVING AND ATTENTION IN REPEATED USERS OF MDMA AND THC AS COMPARED TO THC USERS AND NON DRUG USING CONTROLS*}

\section{* Submitted as:}

Lamers, CTJ, Rizzo, M, Bechara, A and Ramaekers, JG. Comparison of simulated driving performance and attention of repeated users of MDMA and THC as compared to THC users and non drug using controls 


\section{ABSTRACT}

Repeated use of the popular "party drug" MDMA is associated with neurotoxicity and cognitive impairments, even after periods of abstinence. However it is unclear whether these impairments are due to repeated use of MDMA or concurrent drugs of abuse and how these impairments interfere with key activities of daily life such as automobile driving. The current study assessed the simulated driving performance of $12 \mathrm{MDMA}$ users (MDMA/THC), 15 marijuana (THC) users and 15 non-drug using age-matched controls. Results showed that the THC users' mean speed reduction in response to passing a car parked on the shoulder of the road was $7 \mathrm{mph}$ less than that of controls. Compared to nondrug using controls the MDMA/THC users were less able to mitigate the effects of an illegal intersection incursion by another vehicle and entered the collision with a higher speed (42 versus $26 \mathrm{mph}$ ). In real life this $16 \mathrm{mph}$ difference would have increased the likelihood of injuring parties in both colliding vehicles. Processing speed, divided attention, selective attention, and sustained attention, measured off-road, did not differ between groups, suggesting that driving impairment in the MDMA/THC users was more likely due to changes in executive function (incorrect situation interpretation and awareness). Compared to non-drug users, MDMA/THC users may be at a greater risk for driver performance errors that lead to crashes. As collision speed did not differ between MDMA/THC users and THC users, a specific role of MDMA as opposed to THC toxicity -in driving performance impairment- remains to be established.

\section{INTRODUCTION}

Neurotoxic effects of the "party drug" MDMA may originate from serotonergic mechanisms (Lyles and Cadet 2003; Mechan et al. 2002; Ricaurte et al. 1993; Ricaurte et al. 2002; White et al. 1996). Neurotoxicity in animals has been observed with doses ranging from $15 \mathrm{mg} / \mathrm{kg}$ on a single occasion to $20 \mathrm{mg} / \mathrm{kg}$ twice daily for 4 consecutive days (Aguirre et al. 1997; Colado et al. 1999; Mechan et al. 2002; Ricaurte et al. 1993). Brain degeneration in human MDMA users may be due to depletion of serotonin and lead to impairments in attention, memory, and executive functions even in abstinent MDMA users (Krystal et al. 1992; Lyles and Cadet 2003; McCann et al. 1999; Parrott 2001; Parrott et al. 1998; Wareing et al. 2000). Serotonin may help regulate impulsivity and aggression and increased impulsivity was observed in abstinent MDMA users (McCann et al. 2000; McCann et al. 1994; Morgan 1998; Spreux-Varoquaux et al. 2001).

Some studies suggested that repeated MDMA use underlies impairments of memory and attention in polydrug users (Gouzoulis-Mayfrank et al. 2000; Verkes et al. 2001) while others attribute such effects more to concurrent marijuana use (Croft et al. 2001). To disentangle whether cognitive impairments in MDMA users are due to MDMA use or to 
concurrent drugs of abuse controlled studies are required that take concurrcnt use of other drugs into account. Furthermore, it is unclear how performance of MDMA users on clinical tests map onto behavior impairments in real life tasks.

Driving is a key activity of daily living in many countries around the world. Safe driving requires the coordination of several ongoing cognitive processes including attention, perception, memory and executive functions (decision-making and implementation and impulse control). These processes ate impaired, increasing the risk of driver error and a motor vehicle crash, in different populations of drivers with neurological or psychiatric diagnoses (Rizzo, 2003). Impairment of any of these capacities by MDMA may cause unsafe driving.

We assessed the effects of repeated MDMA and THC use on driving performance and attention. Use of a driving simulator allowed us to directly measure driver performance in simulated collision avoidance situations that could not otherwise be safely tested. We tested the hypothesis that driving performance was more impaired in users of MDMA than in controls who used THC but not MDMA, and non-drug using controls.

\section{METHODS}

\section{SUBJECTS}

In the Iowa-City area, 42 participants between 21 and 42 years were recruited and included in one of the 3 test groups, i.e. MDMA and marijuana users (MDMA/THC), marijuana users (THC), and non-drug using controls. Control subjects ( 6 females, 9 males) had not used illicit drugs except marijuana but not on more than 5 occasions and not within the last 365 days. THC users ( 5 females, 10 males) had never used MDMA and had used THC at least 10 times and the number of occasions other drugs were used did not exceed that of THC use. MDMA/THC polydrug users (7 males, 5 females) had a history of THC use and had used MDMA at least on 10 occasions. Participants were asked to abstain from drug use on the day of testing. Exclusion criteria included (1) alcohol or drug dependence; (2) excessive drug use of drugs other than THC and MDMA (frequency of other drugs should not exceeded the number of occasions of the inclusion criterion drugs); (3) serious physical or psychological illness; and (4) current use of prescripted psychoactive drugs. The study was approved by the IRB of the University of Iowa Hospital Clinics (UIHC) and was conducted according to the declaration of Helsinki (1969) and its subsequent amendments. Subjects received token financial compensation in their effort and any inconvenience associated with participation in the study. 


\section{STUDY PROCEDURE}

Years of education and Verbal IQ subtracted from the National Adult Reading Test (NARTVIO) (Crawford et al. 2001) were used to estimate levels of education and intelligence. The NART was a reading test of 50-irregularly pronounced words of graded difficulty and provided estimated verbal IQ (VIQ). To secure consistency and objectivity, pronunciation of the words was recorded on tape and later evaluated by one psychologist who was unaware of the drug history of the participants. All subjects were tested for recent drug use based on self-report (questionnaire) and urine drug screen. After establishing level of education and drug history, testing proceeded with the laboratory tests and the simulated driving test. Total duration of testing was $2-3$ hrs. The assessment included (1) "off road" tests of vision and attention and (2) a simulated driving performance task that included several scenarios that introduced a set of reproducible and closely controlled cognitive challenges to the drivers that taxed driver attention, perception, motor control and executive functions (e.g., judgment/decision-making and impulse control).

\section{ASSESSMENT}

\section{Visual function}

Static acuity was measured the Snellen Eye chart (Owsley 1994).

Contrast sensitivity was determined by the Pelli-Robson contrast sensitivity chart at a working distance of $1 \mathrm{~m}$. The chart measures the amount of contrast needed to identify letters subtending approximately $2.8^{\circ}$ of visual angle (Mantyjarvi and Laitinen 2001).

Perception of Structure from Motion (Kinetic deptb). Stimulus figures comprised orthographic projections of spatially random dots on a mathematical model of a clockwise or counterclockwise rotating sphere or cube (a diamond shape rotation on its vertex). Subjects were asked to report the shape of the rotating figure presented in each trial. To prevent shape identification from non-motion cues and to index the difficulty of the task, varying amounts of random dot noise were added to a background region surrounding the figure (Rizzo et al. 1995). Threshold of density of dots needed to correctly identify objects was used as dependent variable. Knowledge of structure and depth is critical for successful locomotion around objects and obstacles in our environment (Rizzo and Vecera 2002).

\section{Attention and processing speed}

The Useful Field of Vien test (UFOV) depends on 4 sub-tests (Owsley et al. 1998). Sub-test 1 measured processing speed to identify a single visual target presented in the center of the computer screen. Sub-test 2 assessed divided attention and required identification of a central target and localization of a simultaneously presented peripheral target. Sub-test 3 assessed selective attention abilities and was identical to sub-test 2, except that the peripheral target was embedded amid distracters. Sub-test 4 also assessed selective attention, 
but was more difficult than sub-test 3 because the central task required making a samedifferent discrimination between 2 targets (selective attention-2). Dependent variables were thresholds for processing speed, divided attention, selective attention and selective attention-2. Threshold scores of the 4 subtasks ranged from $16 \mathrm{~ms}$ (no impairment) to 90 ms (maximum impairment).

\section{Driving simulator}

All participants were tested using a driving simulation scenario implemented on SIREN (Simulator for Interdisciplinary Research in Ergonomics and Neuroscience) that was located in UIHC in the University of Iowa College of Medicine's Department of Neurology (Rizzo et al, 2001) SIREN was a four-channel, 150-degree forward view, and 50-degree rear view, high-performance driving simulator. The simulator cab was a four-door 1994 GM Saturn SL2 (see figure 1). Simulation software has been developed with DriveSafety Technologies (Salt Lake City, Utah). Four 1.7GHz Pentium IV PC image generators generate anti-aliased graphics for each of the four visual channels. SIREN maintains a $60 \mathrm{~Hz}$ visual update rate in a fully populated, dynamic driving scenario. Four Epson $710 \mathrm{C}$ polysilicon extended high aperture LCD projectors with $1024 \times 768$ resolution and 1000 ANSI (American National Standards Institute) lumen brightness displayed real-time graphics at $60 \mathrm{~Hz}$. Active entities (e.g., traffic semaphores) in the scene were controllable and their behavior was modifiable. The system could manage independently controlled scenario vehicles with independent dynamics and tire articulation. These vehicles followed the same terrain as the subject vehicle and exhibited naturalistic behaviors and awareness of obstacles and traffic. Collisions with these vehicles and other entities were detected as part of the data collection. Three-dimensional audio output included engine noise, wind, tire squeal, and Doppler effect with passing vehicles and reproduced the low frequency components of the ribration spectrum experienced in a real vehicle.

Driving performance was also recorded onto videotape at 30 frames per second using miniature lipstick-sized cameras to (a) record the scene observed by the driver and provide a backup record of the driver's lane-tracking and (b) evaluate a subject's gaze in regions of interest in the car and on the virtual road. Synchronization of the digital and video data streams facilitated the inspection of artifacts and allows for review of potential driver safety errors including behavior in the moments preceding a crash.

\section{Scenario}

In the current scenario subjects drove on a simulated rural 2-lane highway with interactive traffic, resembling a 15-mile drive on the roads surrounding Iowa City, Iowa, USA. From onboard data recordings we derived performance measures related to vehicle lane position, velocity, steeting, and driver safety errors. The scenario began with several miles of "uneventful" driving on a highway with a speed limit of $55 \mathrm{mph}$. Dependent variables of 
driver performance on these segments were steering wheel position (mean, SD and number of steering deviations $>6^{\circ}$ ) and speed (mean and SD). In Event 1, the driver encountered a lead vehicle stopped at a 4 -way intersection waiting to turn left. The driver had to decide how to slow down or stop to avoid a potential for a collision. The dependent measure was collision avoidance, and avoidance tactics (evaluation based on video review). After the lead vehicle turned left, there was a second segment of uneventful driving until the subject approached the first intersections with traffic lights (Event 2). As the driver approached the intersection, the light changed from green to yellow. In this "dilemma zone" critical Go/No-Go decisions must be made (Mahalel et al. 1985). The decision to accelerate or brake depended on driving speed and the time for which green or yellow were visible (Allsop et al. 1991). Dependent measure was error (running a red light) and driver's tactics. During the drive, participants had to pass a police car parked on the shoulder of the highway (Event 3). Occurrence of a collision and change of driver speed_was the dependent variable of this event. After the last segment of uneventful highway, the driver approached a final intersection (Event 4). Approach by the subject to within 4.0 seconds of the intersection triggered an illegal incursion by another vehicle entering the intersection from the driver's right side. Driver performance at an intersection requires active surveillance of the roadway and other vehicles and placed higher attention and decision-making demands on a driver. The dependent measures of this event were occurrence of a collision and driver speed at the time of the collision.

Figure 1. Simulated driving is assessed using the Simulator for Interdisciplinary Research in Ergonomics and Neuroscience (SIREN). Presented is a side view of the GM Saturn SL.2 while the scenario is running.

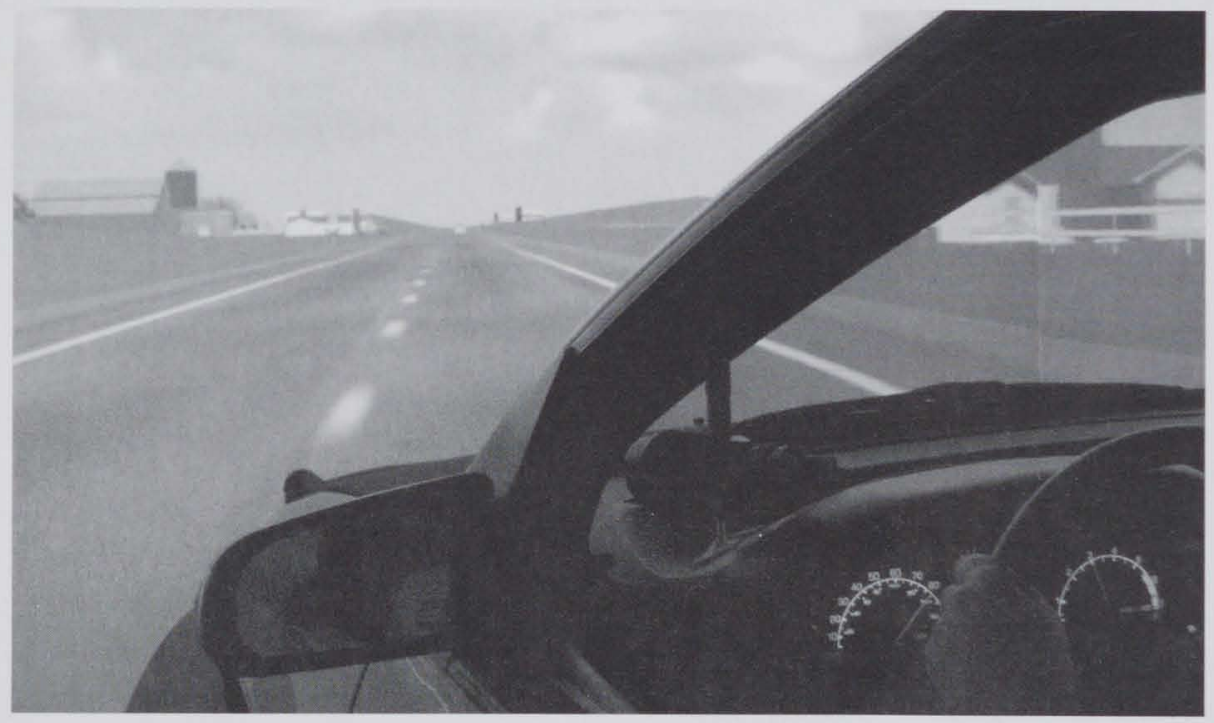




\section{STATISTICS}

All statistical analyses were conducted using the software SPSS 11.0 for Windows. Main group differences were tested using one-way ANOVA with group (controls, THC users and MDMA/THC users) as between subject factor. A priori planned Tukey's HSD procedure was used for in-depth analyses of differences between specific groups (MDMA/THC-non drug users, MDMA/THC-THC users and THC-non drug users) in case of a significant overall Group effect. Ordinal and nominal data was analyzed using the Chi-square $\left(X^{2}\right)$ method. All tests were two-tailed and criteria for significance were set at $\mathrm{p}<.05$.

\section{RESULTS}

Subjects' characteristics are presented in table 1. Findings showed that there were significant group differences in frequency of alcohol use between non drug users and trend significance for frequency of THC use between the groups of drug users. Furthermore, many of the drug users tested positive for THC on the day of testing (see Subjects section). Therefore additional analyses were conducted to study possible influences of these factors on task performance. All ANOVA-analyses were repeated with lifetime alcohol use and THC use included as covariates with the whole dataset. Analyses with number of days of THC abstinence as covariate, included only THC and MDMA/THC users. Results of these additional analyses are reported at the end of the result section.

\section{SUBJECTS}

Table 1 presents demographic characteristics and history of drug use of the 3 study groups. Fifteen non-drug using controls, fifteen regular THC users and twelve MDMA/THC users, enrolled in the study.

Groups did not differ in age. Tukey's HSD procedure revealed that THC users had 1.2 yrs fewer years of education than controls, but NART scores did not differ significantly between groups suggesting the small difference was not clinically relevant. Tukey's HSD procedure showed that THC users and MDMA/THC users had consumed alcohol on more occasions than controls. Alcohol use did not differ significantly between THC and MDMA/THC users. Use of cocaine differed significantly between MDMA/THC users and non drug users and use of MDMA use differed significantly between MDMA/THC users and $\mathrm{THC}$ users as well as non drug users. Additionally, there was a trend significance indicating a higher frequency of THC use in THC users than in MDMA/THC users $(p=.074)$. All controls produced negative drug screens but seren MDMA/THC users $(58 \%)$ and twelve THC users (80\%) produced positive drug screens for THC. Average dars of THC abstinence was 15.7 (range: 1-183 days) days in THC users and 44.6 (range: 1-365 days) days in MDMA/THC users. Tukey's HSD procedure showed that the duration of abstinence of THC in days did not differ between THC and MDMA/THC users. 
Table 1. Mean (SD) characteristics of THC users, MDMA/ $\Gamma H C$ users, non drug uscrs and their statistics. Alcohol and drug use are described as lifetime use. Group comparisons are only reported if the overall effect of Group was $\leq .05$. They are reported as ns if $p>.05$.

\begin{tabular}{|c|c|c|c|c|c|c|c|}
\hline \multicolumn{4}{|c|}{ Mean (SD) [N] } & \multirow{2}{*}{$\begin{array}{l}\text { ANOVA } \\
F(2,39) \\
\begin{array}{l}\text { Group } \\
\text { effect }\end{array}\end{array}$} & \multicolumn{3}{|c|}{$\begin{array}{l}\text { Tukey's HSD post-hoc test } \\
\text { Significance (p) }\end{array}$} \\
\hline Variable & $\begin{array}{l}\text { Controls } \\
\mathrm{N}=15\end{array}$ & $\begin{array}{l}\text { THC users } \\
\mathrm{N}=15\end{array}$ & $\begin{array}{l}\text { MDMA/THC } \\
\text { users } \\
\mathrm{N}=12\end{array}$ & & $\begin{array}{l}\text { Control } \\
\text { THC }\end{array}$ & $\begin{array}{l}\text { Control } \\
\text { MDMA/ } \\
\text { THC } \\
\end{array}$ & $\begin{array}{l}\text { THC } \\
\text { MDMAJ } \\
\text { THC }\end{array}$ \\
\hline Age (yrs) & $24.0(3.2)$ & $24.3(5.3)$ & $22.8(2.3)$ & 0.569 & & & \\
\hline Education (yrs) & $16.5(1.2)$ & $15.3(1.4)$ & $15.5(0.7)$ & $4.092^{*}$ & .028 & ns & ns \\
\hline Verbal IQ (NART) & $109.1(4.5)$ & $108.8(4.7)$ & $104.3(6.8)$ & 3.055 & & & \\
\hline Alcohol (days) & $318(332)$ & $780(472)$ & $824(542)$ & $5.561^{\star \star}$ & .020 & .016 & ns \\
\hline THC (days) & $1.2(2.1)$ & $1582(1433)$ & $855(874)$ & $9.854^{\star *}$ & .000 & ns & ns \\
\hline $\begin{array}{l}\text { Days of THC } \\
\text { abstinence }\end{array}$ & $\begin{array}{l}1232.3 \\
(1377.6)\end{array}$ & $15.7(46.4)$ & $44.6(106.5)$ & $12.115^{\star \star}$ & .000 & .000 & ns \\
\hline $\begin{array}{l}\text { MDMA/Ecstasy } \\
\text { Days of MDMA } \\
\text { abstinence }\end{array}$ & $0.0(0.0)$ & $0.0(0.0)$ & $\begin{array}{l}36.9(32.1) \\
226.9(134.0)\end{array}$ & $20.096^{\star \star}$ & ns & .000 & .000 \\
\hline Cocaine & $0.0(0.0)$ & $4.5(10.5)$ & $14.3(21.8)$ & $4.046^{\star}$ & ns & .021 & ns \\
\hline psylocibine & $0.0(0.0)$ & $11.4(17.2)$ & $8.9(6.6)$ & 2.847 & & & \\
\hline LSD & $0.0(0.0)$ & $14.4(20.1)$ & $6.3(7.8)$ & 1.306 & & & \\
\hline Opium & $0.0(0.0)$ & $3.3(12.9)$ & $0.0(0.0)$ & 0.895 & & & \\
\hline Methamphetamines & $0.0(0.0)$ & $0.0(0.0)$ & $0.1(0.3)$ & 1.266 & & & \\
\hline Sedatives & $0.0(0.0)$ & $0.5(0.1)$ & $0.0(0.0)$ & 0.895 & & & \\
\hline Nitrous gas & $0.0(0.0)$ & $0.3(1.0)$ & $0.0(0.0)$ & 0.895 & & & \\
\hline
\end{tabular}

* $p \leq .05$

** $p \leq .01$

\section{VISUAL FUNCTION}

Subjects had normal vision (median 15/20) and static acuity did not differ between specific groups $\left(\mathrm{F}_{2,39}=0.745, \mathrm{p}=\mathrm{ns}\right)$. Mean contrast sensitivity was 1.90 for all groups and did differ between groups $\left(\mathrm{F}_{2,39}=2.443, \mathrm{p}=\mathrm{ns}\right.$ ). Mean threshold for kinetic depth was 8.9 (sd 2.9) for controls, 8.9 (sd 2.7) for THC users and 8.6 (sd 2.9) in MDMA/THC users and did not differ between groups $\left(\mathrm{F}_{2,39}=0.068, \mathrm{p}=\mathrm{ns}\right)$.

\section{ATTENTION AND PROCESSING SPEED}

Mean performance on the UFOV and its' statistics are presented in table 2. Groups did not differ in performance on the four subtasks of the UFOV. 


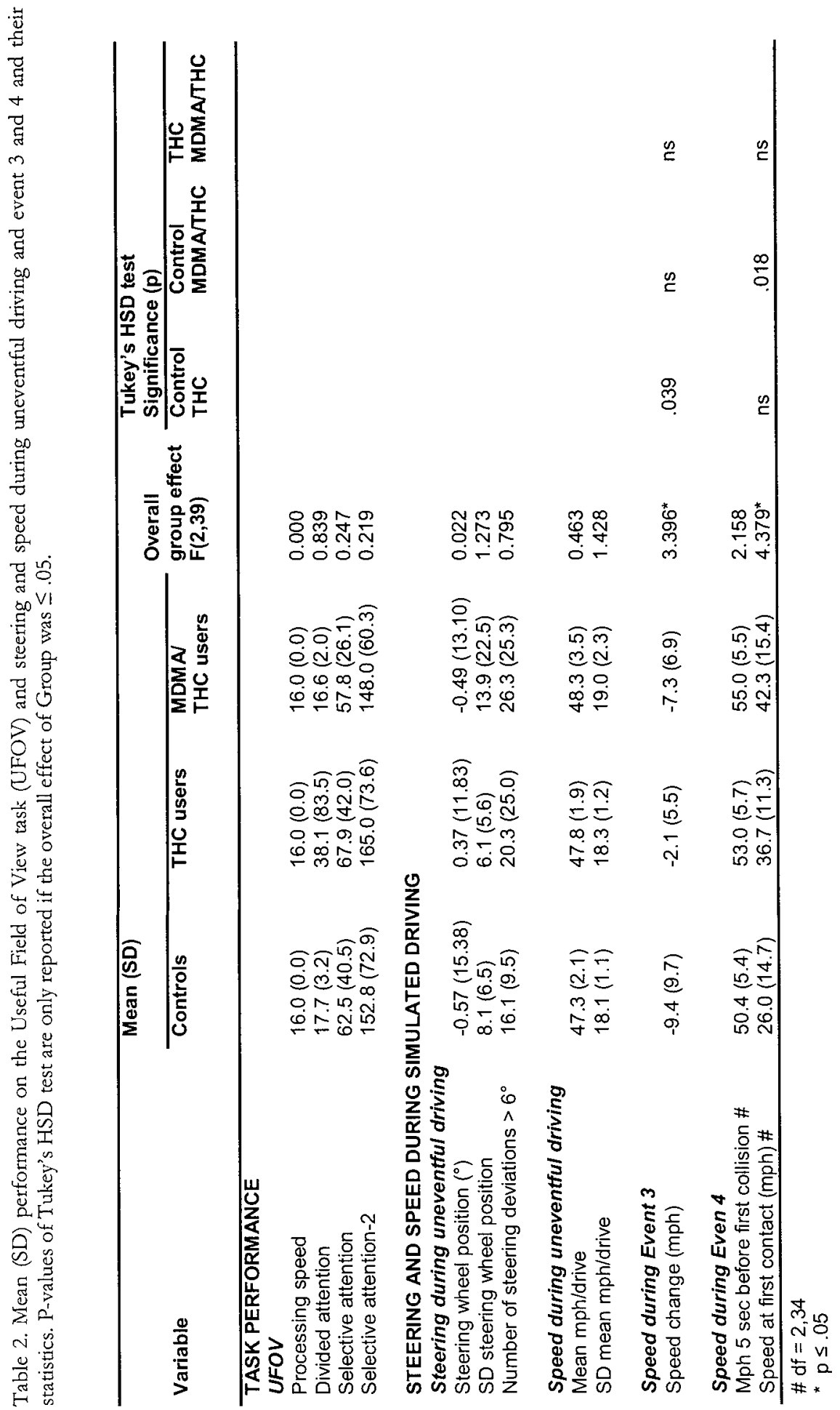




\section{DRIVING SIMULATOR}

All but one of the 41 drivers completed the simulation tasks. One driver (THC user) dropped out of the driving simulation during Event 1 due to discomfort.

\section{Steering and speed during normal driving}

Table 2 shows analyses data during uneventful ("normal') driving. During uneventful driving steering wheel position (mean, sd and number of steering deviations $>6^{\circ}$ ) and speed (mean and sd) did not differ between groups.

Table 3. Tactics of subjects during the Events and their statistics as analyzed by means of Pearson Chisquare.

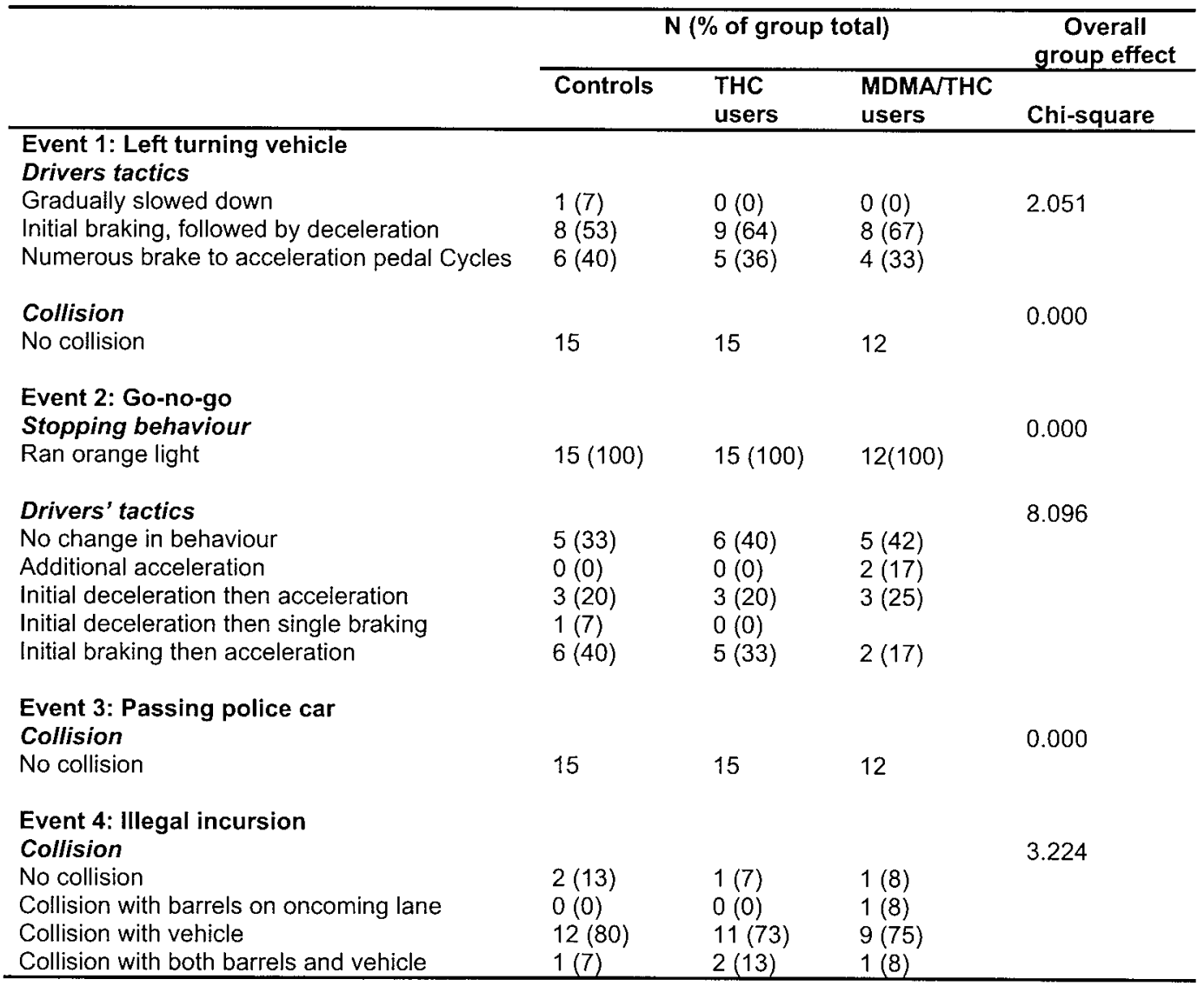




\section{Events}

Strategies of subjects during the events are presented in table 3. Drivers' tactics during Events 1 and 2 did not differ between groups; all participants stopped safely behind the turning car during Event 1 and during Event 2 all subjects tan the yellow light. THC users' driving differed from controls during Event 3; when passing the police car parked on the shoulder of the highway THC users did not slow down as much as controls (table 3 ). There were no differences in speed reduction between other specific groups.

Event 4, the last event in the driving scenario, was a collision avoidance scenario that involved an intersection incursion by another vehicle. This collision was difficult to avoid, but most subjects could react to mitigate the effects of the collision, by releasing the accelerator pedal, braking, and in a few cases by trying to steer around the incurring vehicle. As with Event 3, change of speed differed between groups (table 2 and figure 2). Speed did not differ between groups 5 seconds before the collision, but at the time of the collision MDMA/THC users were travelling at a higher speed as compared to controls. The speed, with which MDMA/THC users entered the collision, was $16.3 \mathrm{mph}$ higher as compared to that of non drug users. Mean speed of THC users were somewhat higher as compared to controls and lower relative to MDMA/THC users, but these differences were not significant.

Figure 2. Mean driving speed ( + se) in very group during an illegal incursion by another vehicle entering an intersection as a function of time to collision.

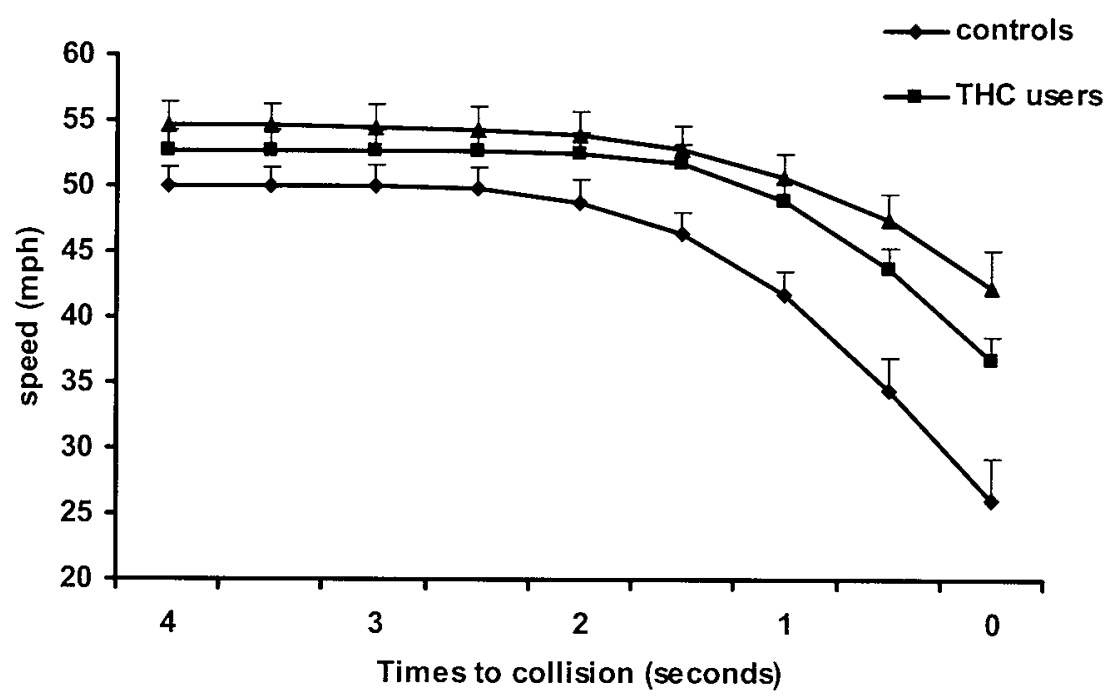

\section{COVARIATES}

Inclusion of duration of abstinence of THC, frequency of THC use or alcohol as a covariate in the analyses did not affect the findings in the current study. 


\section{DISCUSSION}

The current study investigated driving related task performance and simulated driving in repeated MDMA/THC users. To distinguish MDMAs' effects from those of THC, performance of MDMA/THC users was compared to non-drug users and THC users.

\section{VISION, ATTENTION AND PROCESSING SPEED}

Performance on laboratory tests showed that basic visual functions fell within normal limits in all subjects. Compared to non-drug using controls, repeated users of THC and MDMA/THC did not show impairment of processing speed and selective attention (UFOV). The present findings confirm earlier findings by Rodgers (2000). He compared MDMA users with non drug users and polydrug users and did not observe differences in attentional function between groups (Rodgers 2000).

\section{DRIVING SIMULATION}

Steering, speed as well as variances in these factors during uneventful parts of the scenario, were not affected in MDMA/THC users or THC users as compared to non-drug users. No indication of dangerous driving was observed during uneventful driving.

Although uneventful driving performance did not differ between groups, current findings indicate that non drug users slowed down to a safer speed as compared to drug users during some of the events. THC users passed a police car parked on the shoulder of the highway with a higher speed as compared to non drug users. Although a driver is not required to slow down in this situation, a slower speed provides the driver with a greater margin of safety when suddenly required to respond to an unexpected event, e.g. opening of a door of the passed car.

At the end of the scenario an event occurred in which another vehicle, unexpectedly pulled up onto the lane of the participants. Although the incurring vehicle was difficult to aroid for participant in all study groups, the non-drug users were more capable of exerting rapid control over the pedals to mitigate the effects of a crash. Non drug users entered the crash with a speed of about $27 \mathrm{mph}$ but MDMA/THC users were still driving with a speed of approximately $43 \mathrm{mph}$ when hitting the other vehicle; so average speed at the time of the crash was $63 \%$ higher in MDMA/THC users than that in non drug users. Speed at the time of collision also increased in THC users as compared to non-drug users, but not to a level of significance. In real traffic situations, higher speed at the time of impact produces greater trauma, and chances of injury and fatality (Bedard et al. 2002; Dischinger et al. 1998). The results in the current study indicate that the real-life consequences of a collision would be much more severe in MDMA/THC users.

Higher speed of collision in the MDMA/THC was not due to faster overall driving speed because driver speed 5 seconds before the crash did not differ between groups. Similarly, 
the poorer adjustment by the MDMA/THC users was not simply due to reduced speed of processing, selective attention or divided attention, because laboratory results showed preservation of these abilities compared to non-drug using controls. The pattern suggests a problem of situation awareness, or of executive control over response implementation, possible at the level of selecting one of several possible learned alternative evasive motor actions. The results are compatible with recent findings of executive dysfunction in abstinent users of MDMA/THC (Lamers et al. submitted). Of note, MDMA/THC users showed speed reduction when passing the police car comparable to that of non-drug users, but in the latter scenario participants had several seconds more time to make a decision than in the incursion event. The extent to which these differences in time pressure interact with driver impulsivity and risk taking is fertile ground for future research in dynamic simulated environments. Increased impulsivity has been observed in abstinent MDMA users versus non drug users and poly drug users who did not use MDMA (Morgan et al. 2002). Longterm depletion of $5 \mathrm{HT}$, often associated with repeated MDMA user, is believed to play a crucial role in the observed levels of impulsiveness in MDMA users (Morgan 1998).

While driving simulation provides a unique means to closely control the experimental road conditions under which driver decisions are made, drivers may behave differently in the controlled setting of a driving simulator than in real life, where life, limb and licensure are at stake. Participants might have been willing to take greater risks than they normally would have in a real traffic situation, regardless of drug use. Furthermore, there is a predictive relationship between driving simulation and road driving and state records of crashes and moving violations (Rizzo et al. 2001; Rizzo et al. 1997). What makes the driving simulator preferable in regard to real driving is that by using scenarios rather than real driving, one can manipulate the demand on participants. In addition, one can vary with different type of errors that are more likely to occur. Furthermore, in a simulated environment, it is possible to create driving scenarios that are unattainable in the real world. The main reason of concern in MDMA users is that they seem to be willing to take more risks. To investigate this behavior in a real driving situation would be unsafe and unethical. By using simulation, scenarios can be chosen that increase the chance of occurrence of unsafe risk taking and thus investigate this behavior and even infer crash risk that may be difficult to infer from real-life events (Rizzo 2003; Rizzo et al. 2002).

\section{LIMITATIONS OF THE CURRENT STUDY}

The current study has some limitations. Firstly, alcohol use differed between groups and we cannot exclude the possibility that these differences contributed to differences between MDMA/THC users and non-drug using controls, at least with respect to sustained attention and driving speed. Secondly, frequency of THC use differed between the two drug-user groups. However, when frequency of THC use was used as a covariate in analyses, none of the study conclusions changed, indicating that frequency of THC use did 
not significantly affect results in the current study. Thirdly, some effects in drug users might have originated from residual effects of THC use rather than long lasting neural changes. Most drug users in this study showed positive THC drug screens. However, the number of days of abstinence of THC did not differ between drug groups and inclusion of this measure as a covariate in the analyses did not affect results. This supports the notion that current results do not reflect residual effects of recent THC use. Furthermore, several studies indicate that residual effects of THC one day after use are mostly subtle, inconsistent, and clinically unimportant (Chait 1990; Chait and Perry 1994; Fant et al. 1998; Pope et al. 2001). Fourthly, we cannot exclude that apparent increased risk taking in drug users resulted from a pre-morbid factor that lead them to take drugs. Finally, because the results did not show significant differences between THC and MDMA/THC users we cannot conclude that the apparent increase in risk taking behaviour is due to MDMA as opposed to THC use.

In summary, MDMA/THC users and THC users did not exhibit impaired attention as compared to non drug users. During simulated driving THC users were willing to take more risk in a traffic situation that can be evaluated as a slightly dangerous. MDMA/THC users severely increased their chances of serious injury or even death during the driving simulation by entering a collision with a much higher speed as compared to non drug users. This might indicate a willingness to take higher risks as compared to controls. If the current findings resulted from MDMA use, THC use or pre-morbid conditions often apparent in drug users' needs yet to be established.

\section{ACKNOWLEDGEMENTS}

The authors would like to thank Nicole Skaar, Cynthia Cutshal, Jennifer Smothers, Sarah Batchelder and Carol Devore for their help during the project. This project was supported by NIDA grants DA11779 and DA12487 in the United States and Foundation De Drie Lichten in The Netherlands.

\section{REFERENCES}

Aguirre N, Frechilla D, Garcia Osta A, Lasheras B, Del Rio J (1997) Differential regulation by methylenedioxymethamphetamine of 5-hydroxytryptamine1A receptor density and mRNA expression in rat hippocampus, frontal cortex, and brainstem: the role of corticosteroids. Journal of Neurochemistry 68: 1099-105

Allsop R, Brown I, Groeger J, Robertson S (1991) Approaches to modeling driver behavior at actual and simulated traffic light signals. Transport and Road Research Library, Transport and Road Research Library

Bedard M, Guyatt GH, Stones MJ, Hirdes JP (2002) The independent contribution of driver, crash, and vehicle characteristics to driver fatalities. Accident Analysis and Prevention 34: 717-27

Chait LD (1990) Subjective and behavioral effects of marijuana the morning after smoking. Psychopharmacology 100: 328-33 
Chait LD, Perry JL (1994) Acute and residual effects of alcohol and marjuana, alone and in combination, on mood and performance. Psychopharmacology 115: 340-9

Colado MI, Esteban B, O'Shea E, Granados R, Green AR (1999) Studies on the neuroprotective effect of pentobarbitone on MDMA-induced neurodegeneration. Psychopharmacology 142: 421-5

Crawford JR, Deary IJ, Starr J, Whalley LJ (2001) The NART as an index of prior intellectual functioning: a retrospective validity study covering a 66-year interval. Psychological Medicine 31 : $451-8$

Croft RJ, Mackay AJ, Mills AT, Gruzelier JG (2001) The relative contributions of ecstasy and cannabis to cognitive impairment. Psychopharmacology 153: 373-9.

Dischinger PC, Siegel JH, Ho SM, Kufera JA (1998) Effect of change in velocity on the development of medical complications in patients with multisystem trauma sustained in vehicular crashes. Accident Analysis and Prevention 30: 831-7

Fant RV, Heishman SJ, Bunker EB, Pickworth WB (1998) Acute and residual effects of marijuana in humans. Pharmacology, Biochemistry and Behavior 60: 777-84

Gouzoulis-Mayfrank E, Daumann J, Tuchtenhagen F, Pelz S, Becker S, Kunert HJ, Fimm B, Sass H (2000) Impaired cognitive performance in drug free users of recreational ecstasy (MDMA). Journal of Neurology, Neurosurgery and Psychiatry 68: 719-25

Krystal JH, Price LH, Opsahl C, Ricaurte GA, Heninger GR (1992) Chronic 3,4methylenedioxymethamphetamine (MDMA) use: effects on mood and neuropsychological function? American Journal of Drug and Alcohol Abuse 18: 331-41

Lamers CTJ, Bechara A, Rizzo M, Ramaekers JG (submitted) Comparisons of cognitive function and reported mood in MDMA users, THC users and non-drug users.

Lyles J, Cadet JL (2003) Methylenedioxymethamphetamine (MDMA, Ecstasy) neurotoxicity: cellular and molecular mechanisms. Brain Res Brain Res Rev 42: 155-68

Mahalel D, Zaidel D, Klein T (1985) Driver's decision process on termination of the green light. Accident Analysis and Prevention 17: 373-80

Mantyjarvi M, Laitinen T (2001) Normal values for the Pelli-Robson contrast sensitivity test. Journal of Cataract and Refractive Surgery 27: 261-6

McCann UD, Eligulashvili V, Ricaurte GA (2000) (+/-)3,4-Methylenedioxymethamphetamine (Ecstasy')-induced serotonin neurotoxicity: clinical studies. Neuropsychobiology 42: 11-6

McCann UD, Mertl M, Eligulashvili V, Ricaurte GA (1999) Cognitive performance in (+-) 3,4methylenedioxymethampetamine (MDMA, 'ecstacy') users: a controlled study. Psychopharmacology' 143: 417-425

McCann UD, Ridenour A, Shaham Y, Ricaurte GA (1994) Serotonin neurotoxicity after (+/-)3,4methylenedioxymethamphetamine (MDMA; "Ecstasy"): a controlled study in humans. Neuropsychopharmacology 10: 129-38

Mechan AO, Moran PM, Elliott M, Young AJ, Joseph MH, Green R (2002) A study of the effect of a single neurotoxic dose of 3,4-methylenedioxymethamphetamine (MDMLA; "ecstasy") on the subsequent long-term behaviour of rats in the plus maze and open field. Psychopharmacology 159: 167-75

Morgan MJ (1998) Recreational use of "ecstasy" (MDMA) is associated with elevated impulsivity. Neuropsychopharmacology 19: 252-64

Morgan MJ, McFie L, Fleetwood H, Robinson JA (2002) Ecstasy (MDMA): are the psychological problems associated with its use reversed by prolonged abstinence? Psychopharmacology 159: 294303

Owsley C (1994) Vision and driving in the elderly. Optometry and Vision Science 71: 727-35

Owsley C, Ball K, McGwin G, Jr., Sloane ME, Roenker DL, White MF, Overley ET (1998) Visual processing impairment and risk of motor vehicle crash among older adults. Jama 279: 1083-8

Parrott AC (2001) Human psychopharmacology of Ecstasy (MDMA): a review of 15 years of empirical research. Human Psychopharmacology Clinical and Experimental 16: 557-577 
Parrott AC, Lees A, Garnham NJ, Jones M, Wesnes K (1998) Cognitive performance in recreational users of MDMA of 'ecstasy': evidence for memory deficits. Journal of Psychopharmacology 12: 79. 83

Pope HG, Jr., Gruber AJ, Yurgelun-Todd D (2001) Residual neuropsychologic effects of cannabis. Curr Psychiatry Rep 3: 507-12

Ricaurte GA, Markowska AL, Wenk GL, Hatzidimitriou G, Wlos J, Olton DS (1993) 3,4Methylenedioxymethamphetamine, serotonin and memory. Journal of Pharmacology and Experimental Therapeutics 266: 1097-105

Ricaurte GA, Yuan J, Hatzidimitriou G, Cord BJ, McCann UD (2002) Severe dopaminergic neurotoxicity in primates after a common recreational dose regimen of MDMA ("ecstasy"): artikel is teruggeroepen omdat een verkeerd middel (meth) is toegediend. Science 297: 2260-3

Rizzo M (2003) Safe and unsafe driving. In: Rizzo M, Eslinger PJ (eds) Principles and practice of behavioral neutology and neuropsychology. WB Saunders, Philadelphia

Rizzo M, Jermeland J, Severson J (2002) Instrumented vehicles and driving simulators. Gerontechnology 1: 291-296

Rizzo M, McGehee DV, Dawson JD, Anderson SN (2001) Simulated car crashes at intersections in drivers with Alzheimer disease. Alzheimer Disease and Associated Disorders 15: 10-20

Rizzo M, Nawrot M, Zihl J (1995) Motion and shape perception in cerebral akinetopsia. Brain 118 ( $\mathrm{Pt}$ 5): 1105-27

Rizzo M, Reinach S, McGehee D, Dawson J (1997) Simulated car crashes and crash predictors in drivers with Alzheimer disease. Archives of Neurology 54: 545-51

Rizzo M, Vecera SP (2002) Psychoanatomical substrates of Balint's syndrome. Journal of Neurology; Neurosurgery and Psychiatry 72: 162-78

Rodgers J (2000) Cognitive performance amongst recreational users of "ecstasy". Psychopharmacology 151: 19-24.

Spreux-Varoquaux O, Alvarez JC, Berlin I, Batista G, Despierre PG, Gilton A, Cremniter D (2001) Differential abnormalities in plasma 5-HIAA and platelet serotonin concentrations in violent suicide attempters: relationships with impulsivity and depression. Life Sciences 69: 647-57

Verkes RJ, Gijsman HJ, Pieters MS, Schoemaker RC, de Visser S, Kuijpers M, Pennings EJ, de Bruin D, Van de Wijngart G, Van Gerven JM, Cohen AF (2001) Cognitive performance and serotonergic function in users of ecstasy. Psychopharmacology 153: 196-202.

Wareing M, Fisk JE, Murphy PN (2000) Working memory deficits in current and previous users of MDMA ('ecstasy'). British Journal of Psychology 91: 181-8.

White SR, Obradovic T, Imel KM, Wheaton MJ (1996) The effects of methylenedioxymethamphetamine (MDMA, "Ecstasy") on monoaminergic neurotransmission in the central nervous system. Progress in Neurobiology 49: 455-79 


\section{CHAPTER 8}

\section{CONCLUDING REMARKS}


Psychoactive substances, such as alcohol, MDMA and marijuana, are often used in recreational settings for their desired mind-altering and/or energizing effects. The use of the popular recreational drugs marijuana and MDMA has often been associated with altered cognitive function, e.g. memory, and impaired driving ability (Ameri 1999; Parrott 2001). The main aim of the studies described in this dissertation was to investigate the acute and long-term effects of these two drugs on cognition and driving performance. The acute effects were studied using placebo-controlled, within-subject study designs (chapters 3 to 5) while the long-term effects were investigated by means of between-subject study designs (chapters 6 and 7). Both approaches were used to try to avoid certain methodological problems in drug research described later in this chapter.

To summarize our findings, a single dose of MDMA ( $75 \mathrm{mg}$ ) was found to affect aspects of cognition known to be important for driving performance (i.e. increased tracking and movement speed, and reduced object movement prediction). Marijuana (THC $100 \mu \mathrm{g} / \mathrm{kg}$ ) used concurrently with alcohol $( \pm 0.5 \mathrm{mg} / \mathrm{kg})$ reduced visual search at intersections during a city-driving test. Cognitive impairment was also observed in abstinent users of MDMA/marijuana and marijuana users. MDMA use was also associated with increased feelings of depressed mood and anxiety. The results of the individual studies have been presented and discussed in more detail in the relevant chapters. However, some issues are addressed in this chapter to put the findings in a broader perspective. Additionally, some ethical and medical dilemmas and aspects of methodology regarding research into marijuana and MDMA use are discussed.

\section{EFFECT OF MARIJUANA AND MDMA ON DRIVING AND COGNITION}

Some factors need to be taken into account when interpreting the results of the studies described in this dissertation. The behavioural effects of marijuana and MDMA reported here may be a conservative estimate of the actual effects of the drugs in real life. When used recreationally, a range of factors, which are discussed below, may modify the effect of a drug. Additionally, pre-morbid conditions and irreversibility of cognitive decline may have contributed to the cognitive impairment and the heightened feelings of depression and anxiety observed in abstinent drug users.

\section{WITHIN SUBJECT EFFECTS IN INTOXICATED USERS: ACUTE EFFECTS}

The placebo-controlled studies presented in chapters 3-5 showed that a small dose of marijuana alone does not impair driving performance and MDMA even improved tracking and movement speed. This seems ambiguous given the observation that MDMA and marijuana cause driving impairments. However, MDMA also reduced object movement estimation. This may compromise driving performance if the impaired movement estimation leads to inadequate anticipation of other traffic. While a small dose of marijuana 
alone did not affect driving, higher doses and concurrent use of other psychoactive substances may stimulate marijuana-induced impairments of performance. Furthermore, the drug-induced impairment of driving performance may last longer than the subjective effect of the drug.

\section{Dose}

In the present within-subject studies, the acute effects of MDMA and marijuana on cognitive/driving performance were rather modest. Marijuana did not affect general driving performance and MDMA did not affect some cognitive functions (e.g. visual search, planning and semantic memory) and even improved other functions (e.g. tracking and movement time). However, the doses administered were at the lower end of those used recreationally, in order to minimize possible side effects, but they were high enough to produce psychoactive effects. Users of marijuana and MDMA often use higher doses than those used in the experiments, e.g. the mean dose of THC preferred by marijuana users is approximately $300 \mu \mathrm{g} / \mathrm{kg}, 3$ times the dose used in the present marijuana study (Drug Information and Monitoring System and Trimbos Institute 2003; Robbe 1994; Winstock et al. 2001). The mean dose of MDMA in Dutch ecstasy pills tested by the Drug Information and Monitoring System (DIMS) was $83 \mathrm{mg}$ as compared to the dose of $75 \mathrm{mg}$ that was used in the present study (Drug Information and Monitoring System and Trimbos Institute 2003; Robbe 1994; Winstock et al. 2001). Additionally, subsequent doses are often consumed, leading to higher doses and a longer action (Drug Information and Monitoring System and Trimbos Institute 2003; Robbe 1994; Winstock et al. 2001). The behavioural effects of marijuana and MDMA, including those on driving, are dose dependent (Cami et al. 2000; Ramaekers et al. 2003). Therefore, the cognitive dysfunction and driving impairment observed in the present study may become more severe when higher doses of marijuana or MDMA are used.

\section{Concurrent drug use}

When used alone, a small dose of marijuana or alcohol did not affect city-driving performance, but their combined use led to a significant decrease in visual search at intersections. Thus the behavioural effects of these two substances are additive and increase with combined use. Earlier studies reported the additive effect of marijuana and alcohol on driving impairment (Ramaekers et al. 2003; Ramaekers et al. 2000; Robbe 1998). When used in 'real-life', marijuana is frequently used with alcohol, thus increasing the user's risk of behavioural impairment (Chait and Perry 1994). MDMA also is often used together with alcohol or other drugs (Winstock et al. 2001). The effect on performance of MDMA used together with other substances has not yet been investigated, but MDMA and alcohol have an additive effect on reduced immune function (Pacifici et al. 1999). Thus it can be assumed that these two substances will have an additive effect on cognitive performance. When used 
in real-life, the observed effects of MDMA and marijuana alone are likely to be more severe when these drugs are used concurrently with other psychoactive substances.

It is important to note that although the doses of alcohol and THC used in the withinsubject study were high enough to impair city driving, these substances are not likely to be detected by the police during road-side screening because the blood alcohol concentration was well below the legal limit and drug testing is still not common. Because psychoactive substances may have unknown and unpredictable additive or synergistic effects on driving performance when used in combination, it is highly advisable to proceed with drug testing when intoxication is suspected and the driver's alcohol levels are below the legal limit.

\section{Duration of subjective versus objective drug effects}

The effects of MDMA on task performance were still detectable 5 hours after drug administration, as described in chapter 5 . Yet, the findings reported in chapter 6 , as well as previous results, show that the subjective effects of MDMA have mostly faded 4-5 hours after drug intake (Cami et al. 2000; Liechti et al. 2001; Liechti et al. 2000). So, the objective effects of MDMA may persist long after the subjective effects have subsided. The user may feel it is safe to drive or perform demanding tasks requiring complex cognitive capacities under the mistaken belief that the effect of the drug has worn off. The likelihood that drug users will drive a car in an intoxicated state is high because many of these drugs are used outside the home environment. And as a previous survey indicated, 1 out of 10 visitors of raves drive home afterwards (Spruit 1997). Others may go straight to work, where they may be working with heavy machinery. These subjectively often not perceived, but potentially dangerous, residual effects of MDMA are currently not well documented and should be given greater emphasis in information campaigns on the dangers of drug use.

It can be concluded that at least some impairment of cognitive and driving skills can be expected when marijuana and MDMA are used and that this impairment is likely to increase with the dose and with concurrent use of other psychoactive substances. The behavioural impairment may persist even after subjective drug effects have faded. Earlier findings have shown that drivers intoxicated with marijuana or MDMA put themselves, and consequently their fellow traffic participants, at an increased risk of being involved in a car crash (Albery et al. 2000; Logan and Couper 2001; Ramaekers et al. 2003).

\section{BETWEEN SUBJECT EFFECTS IN ABSTINENT USERS: LONG TERM EFFECTS}

The results of the studies described in chapters 6 and 7 raise concern about the cognitire function of abstinent users of MDMA and MDMA/marijuana. Memory and executive function were impaired in marijuana and MDMA/marijuana users and the former also exhibited poorer decision-making abilities. Marijuana users had an impaired ability to make decisions relative to MDMA/marijuana users, but only after correction for the frequency of marijuana use. Other cognitive functions and driving performance did not differ between 
marijuana and MDMA/marijuana users. Most likely, both substances have the potency to impair cognition, as suggested by Parrott et al (2003b). Feelings of depression and anxiety were increased in MDMA/marijuana users compared to marijuana users, indicating that MDMA rather than marijuana is associated with these mood changes. These mord changes may be caused by a diminished function of the serotonin system, as has been observed earlier in MDMA users (Reneman et al. 2000; Ricaurte et al. 1993). The association between anxiety and depression and deficits in the serotonin system support this finding (Olivier et al. 1999). MDMA users may put themselves at risk of developing psychiatric and neurological disorders. Indeed, psychiatric disorders have already been reported in heavy users of MDMA (Parrott et al. 2003; Schifano et al. 1998). However, other factors, such as reversibility and pre-morbid conditions, need to be taken into account when interpreting these results because these factors may have contributed to the performance impairment and changed mood in MDMA/marijuana and marijuana users.

\section{Pre-morbid conditions}

Earlier observations that the severity of the cognitive impairment and psychological problems is associated with the frequency of drug use support the notion that cognitive decline and increased feelings of depression and anxiety may be at least partly drug induced. Yet, the increased feelings of depression and anxiety, impaired cognitive function and driving impairments observed in marijuana or MDMA/marijuana users may have resulted from drug-induced or pre-existing neurological damage. Drug use and mental or neurological disorders that are associated with cognitive impairment (e.g. AttentionDeficit/Hyperactivity Disorder, depression, schizophrenia) often co-exist (Agosti et al. 2002; Swadi and Bobier 2003). Since we cannot exclude that cognitive psychopathology antedated drug use in some participants, it can not be excluded that the findings presented in chapters 6 and 7 resulted partly from pre-morbid conditions.

\section{Reversibility of impaired task performance}

The present findings indicate that the cognitive function of users of marijuana and MDMA/marijuana is diminished. However, these impairments of performance may be reversible after a period of prolonged abstinence. All subjects in the present studies were current users of MDMA and/or marijuana and had used the drug within 12 months prior to testing. Their cognitive impairment and increased feelings of depression and anxiety may diminish or disappear after a prolonged period of abstinence. Previous studies have indicated that the cognitive impairments induced by MDMA or marijuana are reversible, but findings are not conclusive on this topic, especially with regard to MDMA (Gerra et al. 2000; Harrison et al. 2002; Iversen 2003; Pope et al. 2001a; Reneman et al. 2001; Thomasius et al. 2003). Reneman et al (2001) observed reversible neural damage in MDMA users who were abstinent for more than a year, but they still had memory impairments. 
It can be concluded that users of marijuana and MDMA/marjjuana exhibit cognitive dysfunction and poorer driving performance in potentially dangerous traffic situations while MDMA/marijuana users also report increased feelings of depression and anxiety. The use of between-subject designs in abstinent users cannot exclude that the results may have been at least partly attributable to pre-morbid conditions and that the observed effects may be reversible.

\section{PROBLEMS AND DILEMMAS FOR MARIJUANA AND MDMA RESEARCH}

Besides the legal issues involved in experimental studies when administering psychoactive substances to humans, some ethical and medical dilemmas and methodological issues need to be taken into consideration. These issues are discussed below.

\section{ETHICAL AND MEDical DILEMMAS}

When administering psychoactive agents in an experimental setting, the health risk for volunteers and the scientific relevance of the potential findings need to be carefully evaluated. Usually, placebo-controlled studies are conducted in humans only if the physical and mental risks are expected to be mild and reversible and if the scientific goal is being served. Studies of prohibited drugs provide information about the drugs' desired and undesired behavioural properties that can be used to inform health workers and educators and to inform and warn -potential- users. The risks (e.g. physical, legal) for volunteers need to be evaluated carefully.

MDMA has been lethal in recreational settings and therefore MDMA researchers are confronted with a medical dilemma when administering this agent to subjects (Henry 1992 67; Mueller and Korey 1998 162; Spaans et al. 1999 122). Does scientific benefit justify exposing volunteers to risk when studying the acute effects of MDMA? In the placebocontrolled studies presented in this dissertation, a number of measures were taken to minimize the medical risks to volunteers, especially in the MDMA study. Subjects were carefully screened and excluded if they had conditions that potentially increased the health risks of MDMA use (e.g. heart disease, depression, psychotic episodes). During experimental sessions, a physician was on-call at all times. In addition, subjects were asked to return to the research facility after 7 and 11 days so that renal function could be monitored. Factors known to stimulate side effects of MDMA, i.e. strenuous physical activity, hot room temperature, concurrent alcohol and or drug use, were avoided or controlled for during the experiment.

Although the acute side effects of MDMA can be prevented or monitored, this is not possible for long-term neurotoxic effects. A placebo-controlled study by Vollenweider et al (1998) provoked dialogue about the ethics of administering a potentially neurotoxic substance to volunteers (Gijsman et al. 1999; Vollenweider et al. 1999). Vollenweider and 
colleagues were accused of putting drug-naïve subjects in danger of developing long-lasting neural damage after MDMA intake (Gijsman et al. 1999).

We avoided this potential ethical problem by excluding MDMA-naive subjects from study participation and by including recreational users of MDMA instead. All included subjects had used MDMA in the past 12 months and none of them was planning to discontinue use of MDMA in the near future. Since all subjects had used MDMA voluntarily at least 5 times in the past year, they had already been exposed repeatedly to the potential neurotoxic effects of this drug before they participated in the study. Another advantage of restricting study inclusion to repeated users of the study drugs is that the problem of potentially stimulating drug use in drug-naive subjects is avoided. A study conducted by Vollenweider et al (2001) supports the notion that it is safe to administer a single dose of MDMA to humans in a clinical setting. Vollenweider and colleagues did not observe any changes in serotonin transporter binding in their subjects 4 weeks after they were administered MDMA in a placebo-controlled experiment (Vollenweider et al. 2001). So it is unlikely that the single dose administered to recreational users in an experimental setting induced irreversible neurotoxic damage.

In summary, all possible measures were taken to minimize the physical risk to the subjects in the placebo-controlled studies presented in chapters 3 to 5 . In addition, all subjects had a history of repeated use of the study drug, thus avoiding first-time exposure to a possibly addictive and/or neurotoxic substance.

\section{METHODOLOGY}

Since many drug users are polydrug users, the problem of multiple drug use emerges when investigating the behavioural effects of a single drug in abstinent drug users (Pope et al. 2001b; Riley et al. 2001; Winstock et al. 2001). Many researchers conducting betweensubject studies have failed to address the potential confounding effect of polydrug use. Therefore drugs other than the study drug may have been responsible for the impaired performance observed in MDMA users when compared to non drug users (Krystal et al. 1992; McCann et al. 1998; Parrott et al. 1998; Reneman et al. 2000). One way to control for this is to select subjects who use only one type of drug. However, in practice these subjects are hard to find since most users of illicit drugs have used a number of different types of drugs at least once. For example, most MDMA users additionally use marijuana (Winstock et al. 2001). Alternatively, comparing users of the study drug with naive drug users and polydrug users who have no experience with the study drug can control for polydrug use. In future studies, it is advisable to use a drug-using control group in addition to a drug-naive control group. Also more attention should be paid to the history of alcohol use in subjects. In the between-subject studies, the frequency of alcohol use differed between groups, and although we could control for it statistically, it would be better if study groups had a similar history of alcohol intake. 
Between-subject designs are quicker, cheaper and easier than longitudinal studies. Yet, a conclusive causal association between a drug and behavioural impairment cannot be established with this type of study because differences in pre-morbid conditions between subjects cannot be fully excluded. To study a causal role of MDMA and/or marijuana in cognitive impairment, longitudinal studies are the best methodological approach. However, these studies are not often conducted because they require large study groups, are time consuming, are very expensive and the cohorts are often difficult to maintain. Betweensubject designs cannot replace longitudinal studies but can provide a valuable contribution to knowledge about the neurotoxic effects of a drug. Between-subject designs cannot conclusively determine whether performance impairment results solely from the use of a specific drug. Still, previous findings report that a higher frequency of marijuana and MDMA use is associated with increased cognitive impairment (Bhattachary and Powell 2001; Bolla et al. 2002; Gouzoulis-Mayfrank et al. 2000; Pope and Yurgelun-Todd 1996; Schifano et al. 1998). This dose-related association with performance impairment supports the notion that marijuana and MDMA at least contributed to the performance impairment observed in the abstinent users. In addition, comparison of users of different drugs, i.e. marijuana users and MDMA/marijuana users, makes it possible to control for factors that predispose to drug use in general. If behaviour or psychological differences are observed between groups of drug users, it may be assumed that not pre-morbid differences but rather differences in drug use are responsible for the differences observed..

Another methodological problem is the absence of guidelines to classify the degree of drug use in subjects. Criteria used by researchers to classify drug use as mild, moderate or heavy are very inconsistent. In one study, heavy marijuana use was classified as lifetime use of 5000 times and higher while in another study 'heavy users' had used the drug 50 times or more (Andreasson et al. 1987; Pope et al. 2001a). The same inconsistencies of criteria for heavy use can be found in MDMA studies (Daumann et al. 2003; Parrott et al. 2001; Parrott et al. 2000; Verkes et al. 2001). Criteria for minimal use of a study drug also differ greatly between studies assessing the behavioural effects of marijuana and MDMA (Parrott and Lasky 1998; Verkes et al. 2001). For consistency and comparability, it is advisable to create guideline for future drug studies.

\section{CONCLUSION}

Even though the effects of marijuana and MDMA on task performance may also be affected by factors not taken into account in the studies presented in this dissertation (i.e. dose effect and concurrent drug or alcohol use), it can be concluded that a single recreational dose of MDMA and low doses of marijuana in combination with alcohol can compromise the execution of complex behaviours such as driving. In abstinent users of marijuana and MDMA/marijuana, cognitive function and driving proficiency were worse 
than those of non drug users, even though the former were not under the influence of drugs at the time of testing. MDMA use was also associated with increased feelings of depression and anxiety. Findings from the present dissertation indicate that MDMA levels in body fluids can predict MDMA-induced behavioural changes, but more research is needed in this regard. In addition, future between-subject and longitudinal studies may provide evidence to further support the association between life-time use of marijuana and MDMA and long-term performance impairment in abstinent users. It can be hypothesized that marijuana or MDMA-induced effects on other complex behaviours (e.g. flying an airplane, handling heavy machinery) resemble those on driving performance.

Although studies are addressing the long-term and acute effects of marijuana and MDMA use, it is advisable to open a dialogue about ethical, medical and methodological dilemmas associated with drug research, especially in regard to potentially neurotoxic agents like MDMA. The development of clear guidelines for drug research will ultimately increase the quality, consistency and compatibility of results of future MDMA and marijuana research.

\section{REFERENCES}

Agosti V, Nunes E, Levin F (2002) Rates of psychiatric comorbidity among U.S. residents with lifetime cannabis dependence. Am J Drug Alcohol Abuse 28: 643-52

Albery IP, Strang J, Gossop M, Griffiths P (2000) Illicit drugs and driving: prevalence, beliefs and accident involvement among a cohort of current out-of-treatment drug users. Drug and Alcohol Dependence 58: 197-204

Ameri A (1999) The effects of cannabinoids on the brain. Progress in Neurobiology 58: 315-48

Andreasson S, Allebeck P, Engstrom A, Rydberg U (1987) Cannabis and schizophrenia. A longitudinal study of Swedish conscripts. Lancet 2: 1483-6

Bhattachary S, Powell JH (2001) Recreational use of 3,4-methylenedioxymethamphetamine (MDMA) or 'ecstasy': evidence for cognitive impairment. Psychological Medicine 31: 647-58.

Bolla KI, Brown K, Eldreth D, Tate K, Cadet JL (2002) Dose-related neurocognitive effects of marijuana use. Neurology 59: 1337-43

Cami J, Farre M, Mas M, Roset PN, Poudevida S, Mas A, San L, de la Torre R (2000) Human pharmacology of 3,4-methylenedioxymethamphetamine ("ecstasy"): psychomotor performance and subjective effects. Journal of Clinical Psychopharmacology 20: 455-66.

Chait LD, Perry JL (1994) Acute and residual effects of alcohol and marijuana, alone and in combination, on mood and performance. Psychopharmacology 115: 340-9

Daumann J, Fimm B, Willmes K, Thron A, Gouzoulis-Mayfrank E (2003) Cerebral activation in abstinent ecstasy (MDMA) users during a working memory task: a functional magnetic resonance imaging (fMRI) study. Brain Res Cogn Brain Res 16: 479-87

Drug Information and Monitoring System and Trimbos Institute (2003), http:// wrww.trimbos.nl/ default.asp?id $=868$

Gerra G, Zaimovic A, Ferri M, Zambelli U, Timpano M, Neri E, Marzocchi GF, Delsignore R, Brambilla $F(2000)$ Long-lasting effects of (+/-)3,4-methylenedioxymethamphetamine (ecstasy) on serotonin system function in humans. Biological Psychiatry 47: 127-36

Gijsman HJ, Verkes RJ, van Gerven JM, Cohen AF (1999) MDMA study. Neuropsychopharmacology 21: 597 
Gouzoulis-Mayfrank E, Daumann J, Tuchtenhagen F, Pelz S, Becker S, Kunert HJ, Fimm B, Sass H (2000) Impaired cognitive performance in drug free users of recreational ecstasy (MDM $A$ ). Journal of Neurology, Neurosurgery and Psychiatry 68: 719-25

Harrison GP, Jr., Gruber AJ, Hudson JI, Huestis MA, Yurgelun-Todd D (2002) Cognitive measures in long-term cannabis users. Journal of Clinical Pharmacology 42: 41S-47S

Henry JA (1992) Ecstasy and the dance of death [editorial; comment]. British Medical Journal 305: 5-6 Iversen L (2003) Cannabis and the brain. Brain 126: 1252-70

Krystal JH, Price LH, Opsahl C, Ricaurte GA, Heninger GR (1992) Chronic 3,4methylenedioxymethamphetamine (MDMA) use: effects on mood and neuropsychological function? American Journal of Drug and Alcohol Abuse 18: 331-41

Liechti ME, Gamma A, Vollenweider FX (2001) Gender differences in the subjective effects of MDMA. Psychopharmacology 154: 161-8.

Liechti ME, Saur MR, Gamma A, Hell D, Vollenweider FX (2000) Psychological and physiological effects of MDMA ("Ecstasy") after pretreatment with the 5-HT(2) antagonist ketanserin in healthy humans. Neuropsychopharmacology 23: 396-404.

Logan BK, Couper FJ (2001) 3,4-Methylenedioxymethamphetamine (MDMA, ecstasy) and driving impairment. Journal of Forensic Sciences 46: 1426-33.

McCann UD, Szabo Z, Scheffel U, Dannals RF, Ricaurte GA (1998) Positron emission tomographic evidence of toxic effect of MDMA ("Ecstasy") on brain serotonin neurons in human beings. Lancet 352: 1433-7

Mueller PD, Korey WS (1998) Death by "ecstasy": the serotonin syndrome? Annals of Emergency Medicine 32: 377-80

Olivier B, Soudijn W, van Wijngaarden I (1999) The 5-HT1A receptor and its ligands: structure and function. Progress in Drug Research 52: 103-65

Pacifici R, Zuccaro P, Farre M, Pichini S, Di Carlo S, Roset PN, Ortuno J, Segura J, de la Torre R (1999) Immunomodulating properties of MDMA alone and in combination with alcohol: a pilot study. Life Sciences 65: L309-16

Parrott AC (2001) Human psychopharmacology of Ecstasy (MDMA): a review of 15 years of empirical research. Human Psychopharmacology Clinical and Experimental 16: 557-577

Parrott AC, Buchanan T, Heffernan TM, Scholey A, Ling J, Rodgers J (2003) Parkinson's disorder, psychomotor problems and dopaminergic neurotoxicity in recreational ecstasy/MDMA users.

Psychopharmacology 167: 449-50

Parrott AC, Lasky J (1998) Ecstasy (MDMA) effects upon mood and cognition: before, during and after a Saterday night dance. Psychopharmacology 139: 261-268

Parrott AC, Lees A, Garnham NJ, Jones M, Wesnes K (1998) Cognitive performance in recreational users of MDMA of 'ecstasy': evidence for memory deficits. Journal of Psychopharmacology 12: 79-83

Parrott AC, Milani RM, Parmar R, Turner JD (2001) Recreational ecstasy/MDMA and other drug users from the UK and Italy: psychiatric symptoms and psychobiological problems. Psychopharmacology 159: 77-82.

Parrott AC, Sisk E, Turner JJ (2000) Psychobiological problems in heavy 'ecstasy' (MDMA) polydrug users. Drug and Alcohol Dependence 60: 105-10

Pope HG, Jr., Gruber AJ, Hudson JI, Huestis MA, Yurgelun-Todd D (2001a) Neuropsychological performance in long-term cannabis users. Archives of General Psychiatry 58: 909-15

Pope HG, Jr., Ionescu-Pioggia M, Pope KW (2001b) Drug use and life style among college undergraduates: a 30-year longitudinal study. American Journal of Psychiatry 158: 1519-21.

Pope HG, Jr., Yurgelun-Todd D (1996) The residual cognitive effects of heavy marijuana use in college students. Jama 275: 521-7

Ramaekers JG, Berghaus G, van Laar M, Drummer OH (2004) Dose related risk of motor vehicle crashes after cannabis use. Drug and Alcohol Dependence 73: 109-119. 
Ramaekers JG, Robbe HW, O'Hanlon JF (2000) Marijuana, alcohol and actual driving performance. Human Psychopharmacology Clinical and Experimental 15: 551-558

Reneman L, Booij J, Schmand B, van den Brink W, Gunning B (2000) Memory disturbances in "Ecstasy" users are correlated with an altered brain serotonin neurotransmission.

Psychopharmacology 148: 322-4

Reneman L, Lavalaye J, Schmand B, de Wolff FA, van den Brink W, den Heeten GJ, Booij J (2001) Cortical serotonin transporter density and verbal memory in individuals who stopped using 3,4methylenedioxymethamphetamine (MDMA or "ecstasy"): preliminary findings. Archives of General Psychiatry 58: 901-6

Ricaurte GA, Markowska AL, Wenk GL, Hatzidimitriou G, Wlos J, Olton DS (1993) 3,4Methylenedioxymethamphetamine, serotonin and memory. Journal of Pharmacology and Experimental Therapeutics 266: 1097-105

Riley SC, James C, Gregory D, Dingle H, Cadger M (2001) Patterns of recreational drug use at dance events in Edinburgh, Scotland. Addiction 96: 1035-47

Robbe H (1998) Marijuana's impairing effects on driving are moderate when taken alone but severe when combined with alcohol. Human Psychopharmacology Clinical and Experimental 13: S70-S78

Robbe HWJ (1994) Influence of Marijuana on Driving. University of Maastricht, University of Maastricht

Schifano F, Di Furia L, Forza G, Minicuci N, Bricolo R (1998) MDMA (ecstasy') consumption in the context of polydrug abuse: a report on 150 patients. Drug and Alcohol Dependence 52: 85-90

Spaans E, Beltman W, Joore JCA, Mensinga TT, de Vries I, Mostert LJ, Meulenbelt J (1999) Landelijke registratie klinische "XTC"-incidenten. Rijksinstituut voor Volksgezondheid en Milieu (RIVM),

Bilthoven, pp 52

Spruit IP (1997) XTC in Nederland. Trimbos-Instituut in opdracht van ministerie van

Volksgezondheid, Welzijn en Sport, Den Haag, pp 49

Swadi H, Bobier C (2003) Substance use disorder comorbidity among inpatient youths with psychiatric disorder. Aust N Z J Psychiatry 37: 294-8

Thomasius R, Petersen K, Buchert R, Andresen B, Zapletalova P, Wartberg L, Nebeling B, Schmoldt A (2003) Mood, cognition and scrotonin transporter availability in current and former ecstasy (MDMA) users. Psychopharmacology 167: 85-96

Verkes RJ, Gijsman HJ, Pieters MS, Schoemaker RC, de Visser S, Kuijpers M, Pennings EJ, de Bruin $D$, Van de Wijngaart G, Van Gerven JM, Cohen AF (2001) Cognitive performance and serotonergic function in users of ecstasy. Psychopharmacology 153: 196-202.

Vollenweider FX, Gamma A, Liechti M, Huber T (1999) Is a single dose of MDMA harmless? Neuropsychopharmacology 21: 598-600

Vollenweider FX, Jones RT, Baggot MJ (2001) Caveat emptor: editors beware.

Neuropsychopharmacology 24: 461-3.

Winstock AR, Griffiths P, Stewart D (2001) Drugs and the dance music scene: a survey of current drug use patterns among a sample of dance music enthusiasts in the UK. Drug and Alcohol Dependence 64: $9-17$ 



\section{SUMMARY}

Marijuana ( $\Delta^{9}$-tetrahydrocannabinol; THC) and ecstasy ( \pm 3,4-methylenedioxymethamphetamine; MDMA) are two of the most commonly used recreational drugs in today's Western world. The use of these drugs has been associated with unsafe driving and cognitive impairment in intoxicated drivers. In abstinent users of marijuana and ecstasy, cognitive decline has been observed in previous studies, especially in heavy users. The aim of the present dissertation is to investigate the effects of marijuana and MDMA on cognitive function and driving performance in recreational users of these drugs. The studies presented in this dissertation have addressed both the acute and long term effects of marijuana and/or MDMA.

Chapter 1 presents the rationale behind the studies and the general structure of the dissertation. Pharmacological mechanisms and previous findings on behavioural effects of marijuana and MDMA and are briefly presented together with previous findings that indicate unsafe driving after marijuana or MDMA intake. Additionally, the investigated domains and the followed approach to address aim of the research are outlined.

Chapter 2 provides an overview of prior findings regarding acute cognitive and behavioural effects of the mostly used illicit drugs in the Western world. Additionally, behavioural effects of commonly abused prescription drugs (e.g. tranquillizers and medicinal stimulants), as well as psychoactive compounds found in common household or industrial products (e.g. inhalants) are described. Without exception, all illicit drugs have the potential to impair cognitive and behavioural skills that allow a person to engage in normal daily activities, such as driving and working. Interaction with the environment may be compromised by a distorted perception of the world due to mind altering effects of psychoactive drugs. Sedating drugs produce central nervous system (CNS) depressant effects, leading to reduced accuracy and responsivity and overall dysfunction over a wide range of cognitive domains. Psychostimulants on the other hand can induce a state of over-activation in which premature and inaccurate responding may occur. Additionally, drugs may produce mood and attitude changes (overconfidence and aggression) and diminish a person's judgment (poor decision making and risk assessment). Interaction effects between various illicit drugs, as well as concurrent use of alcohol, can produce additive behavioural effects, which are often unpredictable.

Chapter 3 presents the effects of low doses of marijuana and alcohol, and their combination, on visual search at intersections and on general driving proficiency in a City Driving Test. Sixteen recreational users of alcohol and marijuana were treated 
with these substances alone, or combined or placebo in a cross-over design. On separate evenings, subjects received THC $100 \mu \mathrm{g} / \mathrm{kg}$, alcohol or placcho was administered. Alcohol doses administered were sufficient for achieving blood alcohol concentrations of about $0.05 \mathrm{~g} / \mathrm{dl}$. Initial drinking preceded smoking by one hour. The 45 min City Driving Test commenced 15 min after smoking and was conducted over a fixed route within the city limits of Maastricht. An eye movement recording system provided relative frequency measures of appropriate visual search at intersections. General driving quality was rated by a licensed driving instructor. After placebo subjects searched for traffic approaching from side streets on the right in $84 \%$ of all cases. Visual search frequency did not change when alcohol or marijuana were administered alone but when those substances were administered concurrently, frequency of visual search dropped to $81 \%$. Performance as rated on the Driving Proficiency Scale did not differ between treatments. It was concluded that the effects of low doses of THC $(100 \mu \mathrm{g} / \mathrm{kg})$ and alcohol (BAC $<0.05 \mathrm{~g} / \mathrm{dl})$ on driving skills as measured in the present study are minimal when taken alone, but more severe when administered concurrently.

Chapter 4 presents the influence of a single dose of MDMA $75 \mathrm{mg}$ and alcohol 0.5 $\mathrm{g} / \mathrm{kg}$ on cognitive function, psychomotor performance and driving related task performance. Twelve healthy recreational MDMA users participated in a double-blind, double-dummy, placebo-controlled three-way cross-over study. MDMA improved psychomotor performance, such as movement speed and tracking performance. Tracking performance improved in a single task, as well as under divided attention. After MDMA, the ability to predict object movement under divided attention was disturbed as compared to placebo. There was no effect of MDMA on visual search, planning or retrieval from semantic memory. It was concluded that some aspects of driving (e.g. tracking) were improved by MDMA, but that the inability to accurately predict object movement suggests impairment of particular performance skills relevant to driving, especially when the driver has to anticipate movements of other traffic, e.g. when approaching an intersection.

Chapter 5 presents the influence of MDMA on driving ability and the predictive value of MDMA levels in body fluids (blood, urine, saliva and sweat) for driver impairment. For the latter a close association between driving performance and MDMA levels in these markers is necessary. In addition, it was hypothesised that physiological activation and estimates of mood might be used for recognizing the use of MDMA in drivers. Performance on laboratory tasks associated with driving, along with biological and physiological markers of MDMA use were collected in twelve recreational MDMA users. They were treated with a single dose of MDMA $75 \mathrm{mg}$ and placebo according to a double-blind, placebo-controlled, cross-over study design. MDMA increased heart rate, blood pressure, body temperature and cortisol secretion and dilated pupil size as compared to placebo. Task performance (i.e. visuomotor tracking performance and 
movement time) and MDMA concentrations assessed in blood, urine, saliva and sweat were moderately but significantly associated. Physiological activation after MDMA usc as well as feelings of vigor, friendliness and reduced feelings of fatigue were also, significantly associated with changes in MDMA concentrations in most of the 4 body fluids. It is concluded that the detection of MDMA in blood, saliva, sweat and urine can predict changes in mental task performance, physiological variables and mood in MDMA users under the influence of MDMA.

Chapter 6 outlines the effect use of MDMA and/or marijuana may have on cognitive function, mood and decision making in abstinent recreational users of these drugs. Repeated MDMA use is reported to impair cognition and cause increased feelings of depression and anxiety. However, many relevant studies have failed to control for use of drugs other than MDMA, especially marijuana (THC). To address these confounding effects we compared mental task performance of $11 \mathrm{MDMA} / \mathrm{THC}$ users, 15 THC users and 15 non-drug users matched for age and intellect. The hypothesis was tested that reported feelings of depression and anxiety and cognitive impairment, defined as problems with memory, executive function and decision making, are more severe in MDMA/THC users than in THC users and non drug users. Results showed that the MDMA/THC users reported more feelings of depression and anxiety than THC users and non-drug users. Memory function was impaired in both groups of drug users. MDMA/THC users showed slower psychomotor speed and less mental flexibility than non-drug users. THC users exhibited less mental flexibility and performed worse on the decision making task compared to non-drug users but these functions were similar to those in MDMA/THC users.

It was concluded that MDMA use is associated with increased feelings of depression and anxiety. THC users were impaired in some cognitive abilities at least in the same degree than MDMA/THC users, suggesting that some cognitive impairment often attributed to MDMA is most likely at least partly due to concurrent THC use.

Chapter 7 reports the effect use of MDMA and marijuana may have on driving performance in abstinent users. Repeated use of the popular "party drug" MDMA is associated with neurotoxicity and cognitive impairments, even after periods of abstinence. However it is unclear whether these impairments are due to repeated use of MDMA or concurrent drugs of abuse and how these impairments interfere with key activities of daily life such as automobile driving. The current study assessed the simulated driving performance of 12 MDMA users (MDMA/THC), 15 marijuana (THC) users and 15 non-drug using age-matched controls. Results showed that the THC users' mean speed reduction in response to passing a car parked on the shoulder of the road was $7 \mathrm{mph}$ less than that of controls. Compared to non-drug using controls the MDMA/THC users were less able to mitigate the effects of an illegal intersection incursion by another vehicle and entered the collision with a higher speed 
(42 versus $26 \mathrm{mph}$ ). In real life this $16 \mathrm{mph}$ difference would increase the likelihord of injuring parties in both colliding vehicles. Processing speed, divided attention, selective attention, and sustained attention, measured off-road, did not differ between groups, suggesting that the lower speed reduction in the MDMA/THC users was more likely due to executive function impairments (incorrect situation interpretation and awareness) than to reduced processing speed. Compared to non-drug users, MDMA/THC users may be at a greater risk for driver performance errors that lead to crashes. As collision speed did not differ between MDMA/THC users and THC users, a specific role of MDMA as opposed to THC toxicity -in driving performance impairment- remains to be established.

Chapter 8 evaluates the findings of this dissertation in a broader perspective. After a brief summary of the major findings, some additional factors important for interpreting the acute and long term effects of MDMA and marijuana on cognition, driving performance and mood are described. When results of the present studies is generalized to recreational use of these two drugs, factors like doses used, concurrent drug use duration of acute effects are important to note. Additionally, some medical, ethical and methodological issues are discussed that marijuana and MDMA researchers are confronted with. Marijuana, especially when combined with alcohol, and MDMA potentially impaired cognition and driving performance in intoxicated users. In sum, abstinent recreational users of MDMA and/or marijuana exhibited impaired cognition and decision making and when confronted with a potentially dangerous traffic situation, abstinent users of MDMA/marijuana were more likely to sustain more severe injury than drug naive controls. It is concluded that use of MDMA and/or marijuana has the potency to interfere with complex performance, especially driving, in both intoxicated and abstinent recreational users of these drugs. 


\section{SAMENVATTING}

Marihuana ( $\Delta^{9}$-tetrahydrocannabinol; THC) en ecstasy ( \pm 3,4-methylenedioxymethamphetamine; MDMA) behoren in de moderne Westerse maatschappij tot de meest gebruikte recreatieve drugs. Het gebruik van marihuana and ecstasy wordt vaak in verband gebracht met verminderd cognitief functioneren en onveilig rijgedrag wanneer men onder invloed is van deze drugs (geintoxiceerd). Ook wanneer gebruikers van marihuana en ecstasy niet onder invloed zijn (abstinent), hebben onderzoekers in het verleden een cognitieve achteruitgang aangetoond, vooral bij frequent gebruik. Dit proefschrift beschrijft verschillende studies naar de effecten van marihuana en ecstasy gebruik op cognitief functioneren en rijvaardigheid. De studies richten zich zowel op de acute effecten als op de lange termijn effecten.

In boofdstuk 1 wordt de achterliggende gedachte van de studies gepresenteerd en wordt de algemene structuur van het proefschrift uiteengezet. De farmacologische werkingmechanismen en eerder gevonden effecten van marihuana en ecstasy op gedrag en rijvaardigheid worden kort beschreven. Tevens worden de onderzochte domeinen en de gebruikte methoden behandeld.

Hoofdstuk 2 geeft een overzicht van resultaten van eerdere studies naar de acute effecten op cognitie en gedrag van de meest gebruikte illegale drugs in de westerse maatschappij. Verder worden gedragseffecten besproken van medicijnen die vaak misbruikt worden voor recreatieve doeleinden en psychoactieve middelen die in huishoudelijke of industriële producten zitten (b.v. lijmen en brandstoffen).

$\mathrm{Al}$ deze middelen kunnen in potentie cognitieve-, en gedrags-capaciteiten verminderen die nodig zijn om in het dagelijkse leven te kunnen functioneren, zoals het besturen van een auto of werken. Adequate interactie met de omgeving kan in gevaar komen wanneer de buitenwereld op een vertekende manier wordt waargenomen als gevolg van gebruik van geestverruimende middelen. Kalmerende middelen hebben een sederende werking op het centrale zenuwstelsel waardoor de correctheid van handelen en cognitie afneemt. Stimulerende middelen kunnen daarentegen leiden tot overactivatie wat weer kan resulteren in voorbarige en incorrecte reacties.

Tevens kunnen drugs stemming en attitude veranderen (overmoed en agressie) en het beoordelingsvermogen negatief beinvloeden (slechte besluitvorming en inschatten van risico's). Het gebruik van meerdere drugs of combinaties van drugs met alcohol tegelijkertijd kunnen additionele en vaak onvoorspelbare gedragseffecten produceren.

Hoofdstuk 3 beschrijft de effecten van een lage dosering marihuana, al dan niet in combinatie met alcohol, op visueel scannen van verkeer op kruispunten en rijgedrag tijdens een stadsrit. Zestien recreatieve gebruikers van alcohol en marihuana kregen 
deze middelen alleen of in combinatie toegediend in een cross-over design. De hoeveelheid alcohol was voldoende om een bloed alcohol concentratic (BAC) te generen van $.05 \mathrm{~g} / \mathrm{dl}$. Het roken van de marihuana sigaret (met cen dosering THC van $100 \mu \mathrm{g} / \mathrm{kg}$ lichaamsgewicht) volgde een uur na alcohol inname. De 45 minuten lange stadsrit startte 15 minuten na het roken en vond plats op een vastgestelde route binnen de bebouwde kom van Maastricht. Een systeem dat oogbewegingen vastlegt, registreerde de frequentie van het scannen van ander verkeer.

$\mathrm{Na}$ placebo werd door de proefpersonen bij $84 \%$ van de kruispunten visueel gescand naar verkeer uit zijstraten van rechts. De mate van visueel scannen veranderde niet na alcohol of marihuana inname alleen maar wanneer deze stoffen tegelijkertijd werden toegediend daalde de frequentie naar $81 \%$. De algemene rijvaardigheid, gemeten met behulp van een ANWB rijvaardigheidslijst, bleef gelijk bij de verschillende condities. Geconcludeerd kan worden dat de negatieve effecten op rijvaardigheid minimaal zijn bij enkel toedienen van een lage dosis THC $(100 \mu \mathrm{g} / \mathrm{kg})$ of alcohol $(\mathrm{BAC}<.05 \mathrm{~g} / \mathrm{dl})$, maar toenemen wanneer deze stoffen in combinatie worden gebruikt.

In boofdstuk 4 wordt de invloed van ecstasy (met een dosering van 75 mg MDMA) en alcohol $(0.5 \mathrm{~g} / \mathrm{kg}$ lichaamsgewicht) beschreven, op cognitief functioneren, psychomotoriek en functies die gerelateerd zijn aan rijvaardigheid. Twaalf gezonde recreatieve MDMA gebruikers deden mee aan deze studie die was uitgevoerd volgens een dubbel-blind, placebo-gecontroleerd, 3-weg cross-over design.

MDMA verbeterde psychomotoriek zoals bewegingssnelheid en tracking; tracking verbeterde tijdens een enkele taak, als ook wanneer men de aandacht over tracking en een andere taak moest verdelen. Na MDMA voorspelden de proefpersonen een object beweging tijdens verdeelde aandacht slechter dan in de placebo situatie. MDMA had geen effect op risueel zoeken, planning en informatic ophalen uit semantisch geheugen. Geconcludeerd kan worden dat MDMA bepaalde aspecten van rijvaardigheid verbetert (m.n. tracking). Echter, het niet in staat zijn om adequaat beweging te voorspellen, wijst op een verslechtering van specifieke capaciteiten die relevant zijn voor rijvaardigheid, met name wanneer een chauffeur moet anticiperen op andere verkeersdeelnemers zoals b.v. tijdens het naderen van een kruising.

Hoofdstuk 5 beschrijft de invloed van ecstasy (MDMA) op rijvaardigheid en de voorspellende waarde van MDMA concentraties in lichaamsvloeistoffen (bloed, urine, speeksel en zweet) voor een verandering in rijgedrag. Voor dit laatste is een hechte associatie nodig tussen rijvaardigheid en MDMA concentraties in lichaamsvloeistof. Tevens werd de hypothese getest dat verhoogde fysiologische activiteit en stemming kunnen worden gebruikt voor het herkennen van MDMA gebruik in chauffeurs. Prestatie op laboratorium testen die gerelateerd zijn aan rijvaardigheid, aangevuld met biologische en fysiologische maatstaven van MDMA intoxicatie werden gemeten in twaalf recreatieve MDMA gebruikers. Zij werden behandeld met een dosis MDMA 75 $\mathrm{mg}$ in een studie volgens een dubbel-blind, placebo-gecontroleerd, cross-over design. 
MDMA verhoogde hartslag, bloeddruk, lichaamstemperatuur en cortisol afgifte, en verwijdde de pupilgrootte ten opzichte van placebo. Associaties tussen taak prestatie (tracking en bewegingstijd) en MDMA concentraties gemeten in bloed, urine, speeksel en zweet waren minimaal, maar significant. De meeste associaties tussen verandering in MDMA concentraties in de vier lichaamsvloeistoffen enerzijds en fysiologische activiteit, gevoelens van levenskracht, vriendelijkheid en verminderde moeheid anderzijds waren significant. Geconcludeerd kan worden dat de MDMA concentraties in bloed, speeksel, zweet en urine een voorspellende waarde hebben voor mentale taak prestatie, fysiologie en stemming van MDMA gebruikers wanneer ze onder invloed zijn van MDMA.

Hoofdstuk 6 behandelt de effecten van het gebruik van ecstasy en/of marihuana op cognitief functioneren, stemming en besluitvorming in gebruikers die niet onder invloed van drugs waren op het moment dat ze getest worden (abstinent). Herhaaldelijk gebruik van MDMA wordt in verband gebracht met verslechtering van cognitieve functies en verhoogde gevoelens van depressie en angst. Echter, veel studies hebben verzuimd te controleren voor het gebruik van andere drugs dan MDMA in hun onderzoekspopulatie, vooral marihuana gebruik. Om deze verstorende factor aan te pakken is mentale taak prestatie vergeleken van 11 MDMA/THC gebruikers, 15 THC gebruikers en 15 drugnaïeve controlepersonen die qua leeftijd en opleiding niet verschilden. De hypothese werd getoetst dat gevoelens van depressie en angst, verslechterd cognitief functioneren (geheugen, executieve functies en besluitvorming) heviger zijn in gebruikers van MDMA/THC dan in THC gebruikers of de drugnaïeve controlegroep.

Onderzoeksresultaten lieten zien dat MDMA/THC gebruikers meer gevoelens van depressie en angst rapporteerden dan de THC gebruikers en de drugnaïeve controlepersonen. Het geheugen was verslechterd in beide groepen drug gebruikers. MDMA/THC gebruikers vertoonden tevens een vertraagde psychomotore snelheid en verminderde mentaal flexibiliteit dan de drugnä̈eve controlegroep. Verminderde mentale flexibiliteit werd ook gevonden bij gebruikers van THC terwiil deze groep ook meer moeite hadden met het nemen van juiste beslissingen. Er was echter geen significant verschil in deze functies tussen THC en MDMA/THC gebruikers. De conclusie van het onderzoek luidt dat het gebruik van MDMA in verband staat met verhoogde gevoelens van depressie en angst. Bij gebruikers van THC wordt vaak een verslechtering van cognitieve vaardigheden waargenomen die op zijn minste even erg was als die in MDMA/THC gebruikers. Dit suggereert dat verslechtering van cognitieve functies die vaak aan MDMA gebruik wordt toegeschreven in MDMA/THC gebruikers, minstens voor een deel veroorzaakt wordt door hun gebruik van THC.

Hoofdstuk 7 beschrijft de effecten van het gebruik van ecstasy en marihuana op rijvaardigheid wanneer deze gebruikers niet onder invloed zijn van drugs. 
Herhaaldelijk gebruik van de populaire "feestdrug" MDMA wordt vaak in verband gebracht met neurotoxiciteit en cognitieve verslechtering, zelfs na een periode van onthouding. Het is echter niet duidelijk of deze verslechtering verootzaakt wordt door MDMA of door ander drugs die tevens gebruikt worden en hoe deze verslechtering hoofdactiviteiten in het dagelijkse leven beïnvloeden, zoals het besturen van een auto. In deze studie werd rijvaardigheid tijdens een rijsimulatie vergeleken van 12 MDMA/THC gebruikers, 15 THC gebruikers en 15 drugnaïeve controlepersonen.

De resultaten laten zien dat de THC gebruikers minder afremmen $( \pm 11 \mathrm{~km} / \mathrm{u})$ bij het passeren van een geparkeerde auto. MDMA/THC gebruikers waren minder goed in staat om de gevolgen van een botsing met een auto, die zonder voorrang de kruising opkwam, te voorkomen. MDMA/THC gebruikers reden op het moment van het ongeluk $42 \mathrm{mijl} / \mathrm{u}( \pm 67 \mathrm{~km} / \mathrm{u})$, drugnaïeve controlepersonen $\pm 42 \mathrm{~km} / \mathrm{u}$. In een werkelijke verkeerssituatie zouden deze $\pm 35 \mathrm{~km} / \mathrm{u}$ extra snelheid de kans op letsel verhoogt. Snelheid van informatieverwerking, verdeelde aandacht en volgehouden aandacht die gemeten waren m.b.v. computer taken verschilden niet tussen de verschillende groepen. Dit suggereert dat eerder verschillen in uitvoerende functies (verkeerd inschatten van de verkeerssituatie en bewustzijn) dan een afname van snelheid van informatie verwerking verantwoordelijk is voor de lagere afname in snelheid bij MDMA/THC gebruikers. MDMA/THC gebruikers kunnen een groter risico lopen dan de drugnaïeve controle groep om bestuurdersfouten te maken die kunnen leiden tot een auto-ongeluk. Er was geen significant verschil tussen beide groepen drugsgebruikers in snelheid op het moment van het ongeluk. Daarom kan niet eenduidig geconcludeerd worden dat neurotoxische effecten van MDMA (en niet die van THC) verantwoordelijk zijn voor de gevonden afname in rijvaardigheid.

In hoofdstuk 8 worden de resultaten van de studies in dit proefschrift in een breder perspectief geplaatst. Na een korte samenvatting van de meest belangrijke resultaten worden enkele factoren besproken die van belang zijn voor de interpretatie van de korte en lange termijn effecten van ecstasy (MDMA) en marihuana (THC) op cognitief functioneren, rijvaardigheid en stemming. Wanneer de resultaten van de huidige studies gegeneraliseerd worden naar de gevolgen roor de recreatieve gebruikers van deze twee drugs, zijn enkele factoren van belang zoals de gebruikte dosering, gelijktijdig gebruik van andere psychoactieve stoffen en de duur van acute effecten. Verder wordt in dit hoofdstuk aandacht besteed aan de rol van premorbide factoren op de gevonden resultaten in abstinente gebruikers en het vraagstuk ran irreversibiliteit van deze effecten kort besproken. Tot slot komen enkele medische, ethische en methodologische dilemma's en problemen waar drugsonderzoekers mee te maken krijgen aan de orde. 


\section{DANKWOORD}

Onderzoek doe je niet alleen en de afgelopen jaren hebben vele personen een bijdrage geleverd aan de totstandkoming van dit proefschrift. Ik wil dan ook iedereen bedanken die direct of zijdelings betrokken is geweest bij dit proces.

Mijn promotor Jelle Jolles, bedankt voor je vertrouwen en de kans te kunnen promoveren. Jouw macrovisie was erg verhelderend bij het schrijven van dit proefschrift. Mijn copromotor Jan Ramaekers, bedankt voor je adviezen, vertrouwen en dat je deur altijd open staat. Ik wil jou en Wim Riedel, de andere hoofdonderzoeker van mijn projecten in Maastricht, bedanken voor jullie begeleiding en kritische houding bij het opzetten van de studies en het schrijven van de manuscripten. Nienke Muntjewerff, Nele Samyn, Gert de Boeck, dank voor jullie medische en toxicologische expertise tijdens de studies. Karen Sikkema, Linda Booij, Anita van Oers, Anja de Bruijn en tevens alle proefpersonen, bedankt voor jullie hulp en tijd tijdens de data collectie.

Eef Theunissen, alweer drie jaar mijn kamergenote, bedankt voor je gezelligheid, het stoom afblazen, je motiverende woorden en niet te vergeten de heerlijke lunches. Ik vind het geweldig dat je mijn paranimf wilt zijn. Kim Kuypers en Marleen Wingen, bedankt voor jullie gezelligheid en alle woordgrappen. De overige mensen van NC en NP, in het bijzonder Jeroen Schmitt, Annemiek Vermeeren, Arjan Blokland, Sven Stapert, Daniëlle Tisserand en Brenda Jorissen bedank ik voor hun wetenschappelijke bijdrage, adviezen, discussies en collegialiteit. Annemie Jeukens, bedankt voor je ondersteuning en gezelligheid.

In the United States of America, I would like to thank all the people at the department of Neurology of the University of Iowa Hospitals and Clinics who were involved in the MDMA studies conducted in Iowa City. Special thanks to Matthew Rizzo and Antoine Bechara. Yout encouragement, trust and advice were essential for the success of the studies conducted at your department. Also thanks to Nicole Skaar, Jennifer Zanter, Cynthia Cutshall, Sarah Batchelder and Carol Devore for their help. Thank you all so much for making me feel at home in Iowa City. Your experience, knowledge and friendship has been a great inspiration to me.

De families Lamers en Buiting dank ik voor hun steun en interesse tijdens de afgelopen jaren. In het bijzonder wil ik mijn ouders bedanken voor de kans om te gaan studeren. Ma, ik ben voorlopig even uitgeleerd en kan nu eindelijk eens op zoek naar een echte baan. Mijn vader, die helaas mijn promotie niet meer kan meemaken, bedank ik voor de eigenschap te willen weten 'hoe dingen werken'. Mijn broer Jos en zus José: bedankt dat jullie me hebben aangezet te gaan studeren. José en Wim, ik heb het altijd erg gewaardeerd dat ik altijd welkom was voor kortere en langere periodes. Vooral omdat ik niet altijd de meest gemakkelijke persoon was, niet in de laatste plaats door mijn niet te stuiten eigenwijsheid. 
Zonder jullie motivatie zou ik het waarschijnlijk nooit tot een universitaire studic "geschopt" hebben. Tevens wil ik Jan, Graziňa, Peter, Marjan, Ton, Charlot, Annet en alle kids, bedanken voor hun interesse in mijn projecten. Micha, bist du der Nächste? Antoon \& Dora en Frank \& Cathy, jullie hebben steeds enorm meegeleefd met een onverminderde interesse. Speciale dank ook aan oma Buiting en oma Klompjes, waar de thee altijd klaar, en de tijd even stil staat.

Lieve Belinda, al meer dan 20 jaar hecht ik zeer veel waarde aan onze vriendschap. Toen wij vriendinnen werden, kreeg ik er een hele familie bij. Belin, Ben, Sjaak, Els en Esther, bedankt voor jullie steun door de jaren heen. Belin, ik vind het een eer dat je mijn paranimf wilt zijn.

Verder wil ik iedereen bedanken die mijn academische carrière een stuk aangenamer hebben gemaakt, in het bijzondere Belin, Ben, Harro, Racheel, Christianne, Charles Danielle, Michael, Wendy, Walther, Lieuwkje, Rob, Ellen, Christel, Pien, Ed, Jan, Luc, Sabrina en de bewoners van de "Leuvenlaan-flat". Ik dank jullie voor jullie vriendschap, de fijne gesprekken, motiverende woorden, leuke uitstapjes, etentjes en filmmarathons en reisjes door de jaren heen. Jullie hebben er op je eigen manier aan bijgedragen dat dit proefschrift er is. Sorry dat ik zo weinig tijd had de afgelopen periode.

Theo, mijn lieve echtgenoot, mijn rots in de branding en gewoon een kanjer. Je engelengeduld, je vertrouwen, steun, vriendschap en creativiteit zijn een inspiratie en een bron van rust voor me. Met jou is elke dag een feest. We kunnen eindelijk weer eens ons lijstje gaan bijwerken... 


\section{CURRICULUM VITAE}

Caroline Lamers werd geboren op 22 december 1969 in Tegelen. In 1988 behaalde zij haar VWO diploma aan het Collegium Marianum in Venlo. Ze studeerde 2 jaar Chinees en Engels in Maastricht en kwam na een omweg via Beijing en Colchester toch weer in Maastricht terecht. Hier begon ze in 1991 aan de Universiteit Maastricht met de opleiding Gezondheidswetenschappen, afstudeerrichting Geestelijke Gezondheidkunde (GGK) die ze in 1997 met succes afrondde. Inmiddels werkte ze al een aantal jaren naast haar studie GGK als onderzoeksassistente bij het Instituut voor Humane Psychofarmacologie (IHP). Hier werd haar interesse voor onderzoek gewekt. Na haar afstuderen ging ze verder met onderzoek. In 1999 ging ze in op het aanbod om als assistent in opleiding te gaan werken bij het Instituut Hersenen en Gedrag, eerst bij de vakgroep Psychiatrie en Neuropsychologie en later bij de vakgroep Neurocognitie. De afgelopen jaren heeft zij onderzoek verricht naar de acute en lange termijn effecten van marihuana (THC) en ecstasy (MDMA) op cognitieve vaardigheden en rijvaardigheid onder leiding van dr. J. Ramaekers en Prof. dr. J. Jolles. Naast onderzoek in Nederland, voerde ze ook onderzoek uit aan de University of Iowa Hospitals and Clinics van Iowa City (VS) onder leiding van Prof. dr. M. Rizzo en Prof. dr. A. Bechara. Momenteel is Caroline Lamers werkzaam als docent aan de faculteit Psychologie van de Universiteit Maastricht. 



\section{PUBLICATIONS}

Bögels SM and Lamers CTJ. (2002). The causal role of self-awareness in blushing-anxious, socially-anxious and social phobics individuals. Behaviour Research and Therapy; 40(12):1367-84.

Lamers CTJ, Bechara A, Rizzo M and Ramaekers JG. (submitted for publication). Cognitive function and mood in MDMA/THC users, THC users and non-drug using controls.

Lamers CTJ and Ramaekers JG. (2001). Visual search and urban city driving under the influence of marijuana and alcohol. Human Psychopharmacology Clinical and Experimental;16(5):393-401.

Lamers CTJ, Ramaekers JG, Muntjewerff ND, Sikkema K, Samyn N, Read NL, Brookhuis, KA. and Riedel WJ. Dissociable effects of a single dose of MDMA on psychomotor skills and attentional performance. Journal of Psychopharmacology 2003;17(4):369-377.

Lamers CTJ, Ramaekers JG, Samyn N, Schmitt JAJ and Riedel WJ. (submitted for publication). MDMA levels in four different human body fluids after a placebo-controlled single dose of MDMA predict changes in psychomotor performance, physiological activation and mood.

Lamers CTJ, Rizzo M, Bechara A and Ramaekers JG. (submitted for publication). Simulated driving and attention in repeated users of MDMA and THC as compared to THC users and non-drug using controls.

Ramaekers JG, Lamers CTJ, Verhey F, Muntjewerff ND, Mobbs E, Sanders N, Lewis, JM. and Lockton JA. A comparative study of the effects of carbamazepine and the NMDA receptor antagonist remacemide on road tracking and car-following performance in actual traffic. Psychopharmacology 2002;159(2):203-10.

Riedel WJ and Lamers CTJ. A Pilot Study of Impairment Testing of MDMA with a ComputerBased Task. Project Deliverable DR2b, Certified EU Research Project. Leeds: School of Psychology, University of Leeds; 2000. Report No.: Contract No RO-98-RS.3054.

Rizzo M, Lamers, CTJ, Andersen GJ, Ramaekers JG, Bechara A and Sauer, CG (submitted for publication). Loss of motion sensitivity for the perception of heading in abstinent ecstasy and marijuana users.

Samyn N, De Boeck G, Wood M, Lamers CTJ, De Waard D, Brookhuis KA, Verstraete, AG and Riedel, WJ. Plasma, oral fluid and sweat wipe ecstasy concentrations in controlled and real life conditions. Forensic Science International 2002;128(1-2):90-7.

Schmitt JA, Lamers CTJ, Ramaekers JG and Riedel WJ. Performance and Behavioral Effects of Illicit Drugs. In: Burns M, editor. Medical-Legal Aspects of Drugs: Lawyers and Judges Publishing Company Inc; 2003. p. 133-167.

Waard Dd, Brookhuis KA, Pernot LMC, Lamers CTJ, Booij L, Sikkema KL,Muntjewerff, ND, Vuurman, EFPM en Riedel, WJ. Een onderzoek naar de effecten van MDMA (ecstasy) op cognitieve en psychomotorische functies, rijgedrag in de simulator, en consequenties roor de verkeersveiligheid. Groningen: Rijksuniversiteit Groningen; 2000. Report No.: COV 00-06. 


\section{ABSTRACTS}

Lamers CTJ, Ramaekers JG. Marijuana and Alcohol Effects on Visual Search and Gencral Driving Proficiency. Journal of Psychopharmacology 1999; 13(3): A53.

Lamers CT], Ramaekers JG, Riedel WJ. Drugs of Abuse Effects on Attention and Driving Performance. Proceedings of the 4th Dutch Endo-Neuro Meeting Doorwerth, 2000): p. 115.

Lamers CTJ, Ramaekers JG, Riedel WJ. Acute cognitive and psychomotor effects of MDMA (ecstasy) as compared to alcohol and placebo. Proceedings of the 5th Dutch Endo-Neuro Meeting Doorwerth, 2001; p. 28.

Lamers CTJ, Ramackers JG, Riedel WJ. Acute cognitive and psychomotor effects of MDMA (ecstasy) compared to alcohol and placebo. Proceedings of the CCNP Annual Meeting, 17-20 June 2001; Banff: p. 58.

Lamers CTJ, Ramackers JG, Samyn N, Read NL, Riedel WJ. The Influence of MDMA on Cognition and Psychomotor Function, and the Importance for Driving Capacity. In: Mayhew D, Dussault C, (eds). 16th International Conference on Alcohol, Drugs and Traffic Safety: Montréal: Société de l'assurance automobile du Québec; 2002: DP602

Peters FT, Samyn N, Kraemer T, DeRijk RH, Lamers CTJ, Maurer HH. Enantioselective determination of amphetamine like designer drugs in DUID cases? A chiral look at plasma samples from a controlled study with MDMA and from clinical toxicological cases. Annual Toxicology Anals 2002; 14 (276).

Riedel WJ, Schmitt JAJ, Lamers C, Vuurman EFPM, Ramaekers JG. Assessment of Route Navigational Memory in Actual City Traffic as a Measure of Attentional Capacity under the Influence of Drugs: Rationale and Application of a New Test. European Neuropsychopharmacology 2001; 11 (3): S334.

Samyn N, De Boeck G, De Waard D, Brookhuis K, Lamers C, Riedel W. Driving under the Influence of Ecstasy: Toxicological Data in Controlled and Real Life Conditions. TIAFT 2001 . 